Fernanda Ciampaglia |

Galiano Ciampaglia. Razões de uma arquitetura 
Os arquitetos (e não apenas eles) têm o hábito de ocultar suas fontes de inspiração e até mesmo de tentar sublimá-las, como se isto fosse possível. Mas, ao fazê-lo, o processo de projetar se torna nebuloso, ao passo que, ao revelarmos o que nos moveu e estimulou em primeiro lugar, podemos nos explicar a nós mesmos e motivar nossa decisões. Hermann Hertzberger 



\section{Galiano Ciampaglia. Razões de uma arquitetura}

\section{Fernanda Ciampaglia}

Orientador: Prof. Dr. Paulo Júlio Valentino Bruna

Dissertação apresentada a Faculdade de Arquitetura e Urbanismo da Universidade de São Paulo para obtenção do título de mestre em Arquitetura e Urbanismo

Área de concentração:

História e Fundamentos da Arquitetura e do Urbanismo

São Paulo 
AUTORIZO A REPRODUÇÃO E DIVULGAÇÃO DESTE TRABALHO, POR QUALQUER MEIO CONVENCIONAL OU ELETRÔNICO, PARA FINS DE ESTUDO E PESQUISA, DESDE QUE CITADA A FONTE.

E-MAIL: fciampaglia@uol.com.br

\section{Ciampaglia, Fernanda}

C565g Galiano Ciampaglia. Razões de uma arquitetura / Fernanda Ciampaglia. --São Paulo, 2012.

206 p. : il.

Dissertação (Mestrado - Área de Concentração: História e Fundamentos da Arquitetura e do Urbanismo) - FAUUSP.

Orientador: Paulo Júlio Valentino Bruna

1.Arquitetura moderna 2.Arquitetura orgânica 3. História da arquitetura 4.Patrimônio histórico 5.Azevedo, Francisco de Paula Ramos de, 1851-1928 6.Wright, Frank Lloyd, 1867-1959 7.Ciampaglia, Galiano, 1913- I.Título 



\section{Resumo}

"Galiano Ciampaglia. Razões de uma arquitetura" - estuda um arquiteto que identifica as bases da profissão no ofício do pai, um mestre-canteiro a serviço de Ramos de Azevedo. Vinculado com seus pares, Jacob Ruchti e Miguel Forte, à historiografia da cidade através do edifício-sede IAB-SP, Galiano Ciampaglia (n.1913) é também protagonista do pioneirismo da Escola de Engenharia Mackenzie que, em 1939, forma a primeira turma de arquitetos paulistas reconhecidos pelo Ministério da Educação e da Saúde.

Desenhado a partir de fragmentos de quase um século, o caráter do estudo é em primeiro lugar de natureza histórica. O diferencial do gênero é agregar a um estudioso de Frank Lloyd Wright e à uma produção focada na casa paulista, uma personalidade e uma formação ao mesmo tempo pragmática e erudita, fundamentais à compreensão de sua obra e de sua reserva.

Palavras-chave: Arquitetura moderna; Arquitetura orgânica; Azevedo, Ramos; Ciampaglia, Galiano; História da arquitetura; Patrimônio histórico; Wright, Frank Lloyd; 



\begin{abstract}
"Galiano Ciampaglia. Reasons for an architecture" studies an architect that identifies as bases for his profession, his own father's occupation, as a master - mason that worked for Ramos de Azevedo. Together with his partners, Jacob Ruchti e Miguel Forte, Galiano Ciampaglia (born 1913) is connected to the history of the city as one of the designers of IAB-SP's main office. He is also a graduate of Mackenzie Engineering School's first class of architect's officially recognized in São Paulo by the Ministry of Education and Health.

Drawn from the scraps of nearly a century, the essence of the study is primarily historic. The differentiation in this case is to add to this Frank Lloyd Wright admirator and a residential specialist, a personality and background at the same time pragmatic and erudite, fundamental to the understanding of his work and heritage.
\end{abstract}

Key words: Modern architecture; Azevedo, Ramos; Ciampaglia, Galiano; History of Architecture; Historic heritage ; Wright, Frank Lloyd; 

SUMÁRIO

Introdução

CAPÍTULO I: A cantaria da rua Maria Teresa

Escola de Engenharia Mackenzie

Arquiteto ou engenheiro-arquiteto 35

Frank Lloyd Wright, o eixo

CAPÍTULO II: Sintonia com o movimento moderno

A experiência em madeira

Referências

Arquitetura como cidade

A Arquitécnica e o concurso IAB-SP

O professor

CAPÍTULO III: A casa paulista

São Paulo, anos 40

O mobiliário

O escritório Forte \& Ciampaglia

Bienais

Uma pista

Galiano Ciampaglia lui même

Bibliografia

Consulta a acervo público 



\section{Introdução}

Apesar de muitas vezes bem-sucedido, o gênero parece ter se desenvolvido recentemente em nossos programas de pós-graduação e coleções editorais, em detrimento de avaliações mais cuidadosas das relações entre as personalidades e suas trajetórias individuais, o campo arquitetônico e o que extrapola a disciplina.

José Tavares Correia de Lira

A história e a critica arquitetônica carecem trazer à luz certos personagens como justifica este estudo com foco em Galiano Ciampaglia.

Presença cativa no cenário dos anos 40 e 50 entre o grupo formado por Carlos Millan, Jacob Ruchti, Miguel Forte, Plinio Croce, Roberto Aflalo e Salvador Candia, acostumamo-nos ao nome de Galiano Ciampaglia compartilhando créditos. Seja em projetos residenciais, na participação de concursos como a sede paulistana do Instituto de Arquitetos do Brasil ou como par de um escritório até mesmo quando a autonomia do autor já era uma realidade.

Nesse contexto, não se distingue Galiano Ciampaglia na historiografia da arquitetura brasileira, notadamente na produção da casa paulista. Da primeira residência projetada, nos anos 40 , somente a partir de 2003, com a publicação não acadêmica do Documento Galiano Ciampaglia, alguns autores começariam a reconhecer o co-autor para então se aproximar do profissional autônomo que se seguiu.

É bem verdade que "um maior aprofundamento e difusão da crítica da arquitetura moderna brasileira através dos estudos acadêmicos, num primeiro momento privilegiaram os projetos de maior repercussão ou ainda os arquitetos dedicados de forma intensa ao ensino" ". Neste caso é provável que ao deixar a carreira de professor da Faculdade de Arquitetura Mackenzie, em meados dos anos 70, Galiano Ciampaglia só tenha feito reforçar a pouca visibilidade que a personalidade já Ihe garantia. 
Todavia, não se trata aqui de mensurar o que foi perdido com um distanciamento que tem início, em 1983, através do discurso acadêmico envolvendo a produção do escritório Forte \& Ciampaglia. Trata-se de recolocar arquiteto e obra no cenário daquele que foi o seu universo e especialidade: as residências.

O fato é que diante de uma obra compartilhada cuja agenda carece de revisão e de outra praticamente desconhecida, a metodologia de uma primeira monografia é operativa. Nesse sentido, não é intento o aprofundamento dos temas que envolvam o arquiteto que não são poucos, se considerarmos a escolha da profissão e a filosofia com que a exerceu remontarem ao ofício do pai, um mestre-canteiro a serviço do ecletismo de Ramos de Azevedo. Da mesma forma o estudo procede em relação ao ensino Beaux-Arts, a Frank Lloyd Wright, ao movimento moderno e à casa paulista.

De caráter histórico e apoiado no corpus documental que as revisões e os laços familiares envolvidos impuseram recuperar, o propósito é situar Galiano Ciampaglia em cada um desses contextos e através da sua atuação frente aos mesmos trazer novos fatos e iluminar obscuridades.

Mas há ainda uma questão. Diante de um protagonista reservado e de uma reconhecida formação erudita, o estudo recorre ao acervo remanescente e anotações do arquiteto como forma de identificar os seus interesses e suprir o discurso que Ihe falta. Todavia, fica claro não ser intento reproduzir um inventário ou, no caso de rubricas, usar a cronologia a favor ou contra o arquiteto. $O$ que se busca é sintonizar Galiano Ciampaglia com a produção destacada pelos críticos e historiadores ao longo de um percurso que se expande às novas posturas e enfrentamentos em relação à cidade e à arquitetura entendida como tal.

O estudo é organizado em três capítulos: A cantaria da Rua Maria Teresa, Sintonia com o movimento moderno e A casa paulista.

A cantaria da Rua Maria Teresa surge como uma nova referência entre as oficinas existentes na cidade e que operavam na mesma época que o Liceu de Artes e Ofícios de São Paulo, a serviço de Ramos de Azevedo. 
A convivência de Galiano Ciampaglia com o ofício do pai se apresenta como alicerce para a escolha da profissão e do entendimento da arquitetura como uma aplicação prática de um conhecimento estabelecido através de normas de compreensão da realidade. A noção da obediência ao material como condição para o domínio técnico do artesão e a identificação do trabalho com o saber-fazendo e o fazer-sabendo sugerem a preferência pela Escola de Engenharia Mackenzie, de aprendizado dinâmico voltado à prática. O momento incerto diante do quadro político dos anos $30 \mathrm{e}$ das retaliações aplicadas à escola acaba por estimular iniciativas como o encerramento do curso de engenheiro-arquiteto, em 1934, e a diplomação dos primeiros arquitetos paulistas reconhecidos pelo Ministério da Educação e da Saúde já, em 1939, antecipando um título que seria inerente à Faculdade de Arquitetura Mackenzie, em 1947.

Em reduto Beaux-Arts, o propagado hermetismo do diretor Christiano Stockler das Neves face à arquitetura moderna se contrapõe ao acervo da biblioteca da escola onde Galiano Ciampaglia tem acesso a Frank Lloyd Wright. Do texto The logic of the Plan (publicado na edição de janeiro de 1928 da revista Architectural Record) ao livro Modern Architecture. Being the Kahn lectures, o eixo em Wright se consolidaria na biblioteca formada e estudada ao longo de décadas.

O segundo capítulo, Sintonia com o movimento moderno, recupera a faceta positiva da divisão entre a tradição Beaux-arts, de Stockler das Neves, e as notícias de uma nova arquitetura que chegavam à revelia do mestre. O conflito estimula a troca de informações, a procura por referências e, até mesmo, iniciativas de ordem prática, por parte dos alunos. No caso de Galiano Ciampaglia, a opção pelos livros é nítida no seu acervo. Em síntese, ao se formar, a sua consciência sobre o movimento moderno estava associada ao panorama utilitário de Bruno Taut, dos anos 20, às teorias de Le Corbusier expostas nos Congressos Internacionais de Arquitetura Moderna, ao racionalismo italiano da revista Casabella e ao trabalho pioneiro do Museu de Arte Moderna de Nova York. Dos primeiros resultados e difusão, o interesse de Galiano Ciampaglia acompanha a mudança de paradigma do movimento moderno quando a cidade $\mathrm{e} o$ planejamento urbano assumem o centro da discussão, e se amplia 
até a sintonia das publicações com a mudança radical da atitude das pessoas em relação à arquitetura moderna.

O compromisso com a modernidade assumido por Carlos Millan, Galiano Ciampaglia, Jacob Ruchti, Miguel Forte, Plinio Croce, Roberto Aflalo e Salvador Candia é exercido através de diferentes parcerias. Manifesta-se na fundação da revista Pilotis, no final dos anos 40, editada entre outros, por Candia e Millan, na criação da loja de design Branco \& Preto, em 1952, à qual só não aderem Galiano Ciampaglia e Salvador Candia, na atuação de professores da Faculdade de Arquitetura Mackenzie, ou ainda, em uma das propostas vencedoras do concurso para a sede paulistana do Instituto de Arquitetos do Brasil, apresentada por Forte, Ruchti e Ciampaglia, em 1946. Neste caso, a importância da obra tombada pela Secretaria da Cultura do Estado de São Paulo, em 2002, estimulou o resgate do processo como um todo, da premiação ao edifício construído, inclusive da participação de alguns dos autores do projeto, na diretoria do Instituto. Mais que isso. Traz à luz outros papéis vividos por Forte, Ruchti e Ciampaglia frente às condições do mercado de construções, naquele período.

O terceiro capítulo, $A$ casa paulista, é introduzido pelo cenário da cidade de São Paulo favorável às referências norte-americanas na arquitetura doméstica.

Enquanto na São Paulo dos anos 30, o habitar moderno é adiado devido à crise de construção, na década de 40, a cidade já consolidada como a grande metrópole brasileira oferece um cenário favorável à profissão de arquiteto, principalmente para aqueles que se decidem pelo universo das residências. As urbanizações promovidas pela Companhia City, a partir de 1917, à semelhança das cidades-jardim inglesas, haviam sido bem sucedidas e se estendiam além do pioneiro Jardim América. A presença americana introduzida no primeiro pós-guerra ampliara a sua penetração através do papel fundamental do cinema e as revistas norteamericanas haviam se incumbido de fazer do american way of life o objeto de desejo dos paulistas.

Em 1942, Galiano Ciampaglia e Miguel Forte fundam o escritório Forte \& Ciampaglia. Todavia, antes da obra em si, a retomada daquela agenda, da afinidade dos arquitetos ao repertório efetivo, é 
fundamental. Redesenhada a obra a partir de dois autores, o estudo abre espaço para a carreira solo dos arquitetos identificada a partir de meados dos anos 50.

Nesse sentido, se a fase compartilhada foi pautada na política de revezamento da prancheta ao canteiro, a trajetória independente pode sugerir o pensamento de um arquiteto em relação ao outro, naquele período. É o que o estudo se propõe com foco em Galiano Ciampaglia, o autor autônomo.

Ocorre que um aspecto vinculado à sua personalidade e à reserva do seu trabalho desequilibra o resgate das duas fases. Enquanto a obra compartilhada é documentada e registrada, quase que na íntegra, o que hoje se configura como parte da produção residencial de Galiano Ciampaglia, passadas quase cinco décadas sem acesso e divulgação, é um puzzle de alguns originais, desenhos cedidos por clientes, imagens à época das obras e até mesmo correspondências que resgatam a memória de projetos não localizados. Suprida por ensaios fotográficos recentes e pela visão de arquitetos e usuários das casas projetadas, a produção doméstica é acompanhada até a conclusão da última residência a reunir condições de ser trazida ao estudo.

Recuperada a coerência de uma vida profissional e suas bases conceituais, Galiano Ciampaglia. Razões de uma arquitetura reflete sobre a necessária revisão da historiografia da arquitetura paulista e brasileira.

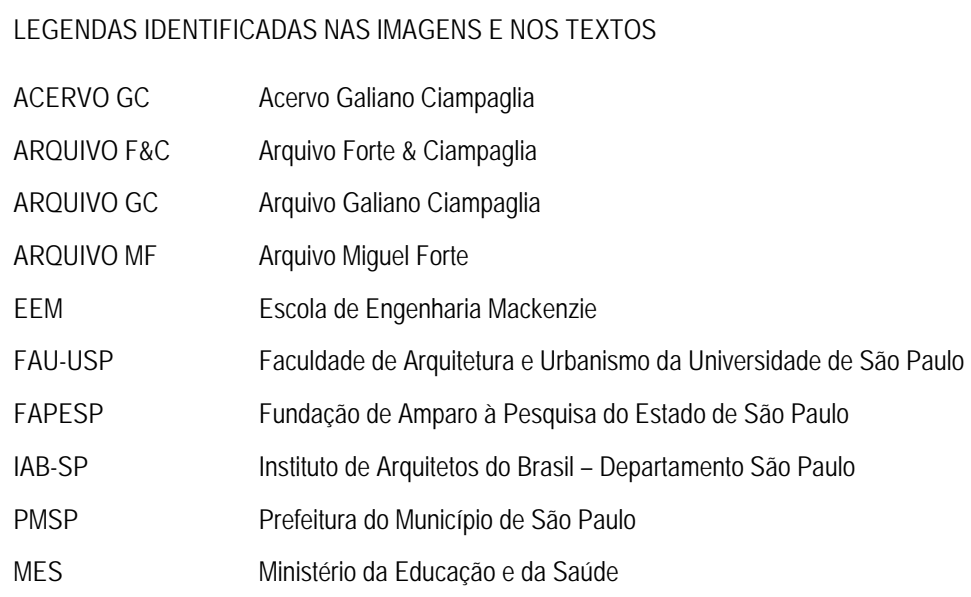

NOTA

${ }^{1}$ Texto de Lucio Gomes Machado sobre Galiano Ciampaglia 


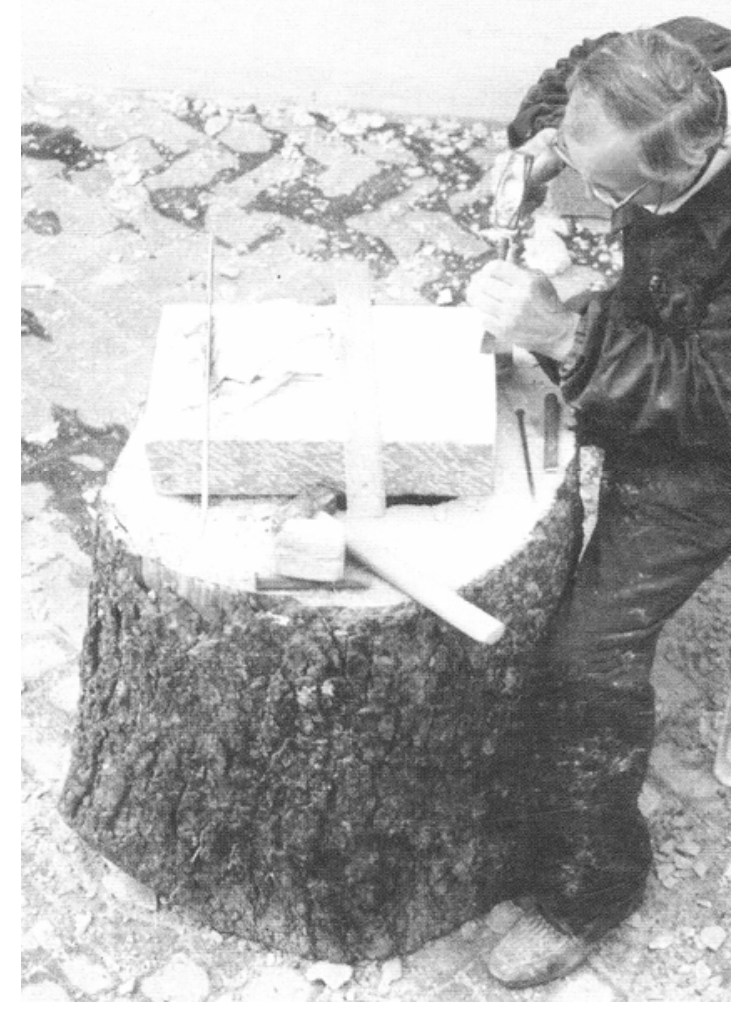

I. A cantaria da rua Maria Teresa 
Na São Paulo de 1886,

"[...] era patente a falta de gente qualificada a desenvolver em grande escala tanto projetos arquitetônicos quanto executar racionalmente obras avantajadas e de fino acabamento [...] Raros os pedreiros realmente profissionais aptos a encarar de frente as novas obras do Ecletismo cheio de exigências que os humildes trabalhadores locais não sabiam atender. A cidade em crescimento espantoso necessitava urgentemente de arquitetos, engenheiros civis, eletricistas, metalúrgicos, geólogos, mestres-de-obras qualificados, marceneiros, carpinteiros, serralheiros, estucadores, pintores, moldadores $[\ldots] "$. 1 .

Dois acontecimentos convergiram para a implantação do modelo arquitetônico capaz de apagar a monotonia da cidade de taipa: a presença de um contingente de italianos que na passagem do século atingiria a marca de $40 \%$ da população e a chegada na cidade de Francisco de Paula Ramos de Azevedo (1851-1928) "a convite do ainda barão de Parnaíba para construir o edifício do Tesouro Nacional, obra do governo central em São Paulo que, mais tarde, abrigou a Secretaria da Fazenda e o Tesouro Estadual” ${ }^{2}$.

O quadro vigente - trazido por Carlos Lemos - exigiu iniciativas do ilustre arquiteto, homem dotado de uma "incrível capacidade de trabalho, de coordenação, de mando e de orientar bons negócios" 3 . A primeira foi organizar a Casa Ernesto de Castro com toda a sorte de materiais importados dos quais dependiam as construções do Ecletismo. A segunda, se alinhar a outros pioneiros e, em 1984, fundar a Escola Politécnica com cursos de engenharia e de engenheiros-arquitetos, e onde se revelaria um fervoroso educador. E, a terceira, para a qual "deu a sua alma", foi assumir o comando do Liceu de Artes e Ofícios, em 1895, "para onde levou para lecionar nas várias oficinas os profissionais mais capacitados que encontrou, praticamente, todos italianos" 4 .

O fato é que o senso de oportunidade de Ramos de Azevedo e os italianos disponíveis na cidade desenham "a faceta importante deste quadro" 5 onde nasce a biografia de Galiano Ciampaglia. 


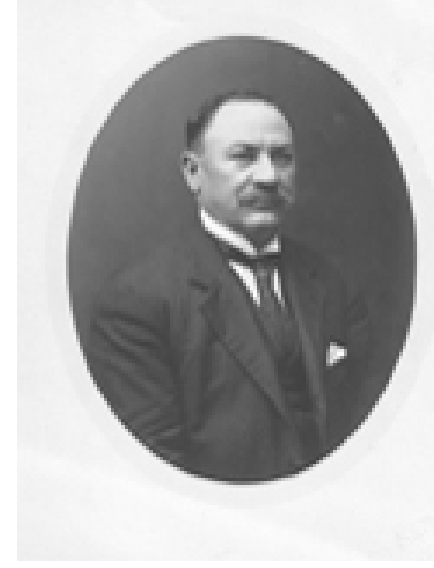

NUNZIOCIAMPAGLIA ARQUIVOGC

Galiano Ciampaglia é filho de imigrantes de Pescopennataro, cidade localizada nas colinas italianas do Alto Molise, confins com Abruzzo e reduto do artesanato em estuque e pedra. O pai, Nunzio Ciampaglia (1867-1940), um mestre-canteiro, depois de passar dois anos no Texas, Estados Unidos, chega a São Paulo onde o primeiro registro oficial é o seu casamento, em 1891. Empreendedor nato e atento às oportunidades, adquire uma jazida de granito que the permite executar o calçamento da cidade. Com os aluguéis assegurando os melhores rendimentos faz construir casas para a família e renda, na esquina das ruas Apa e São João, onde Galiano nasce em 1913. No meio tempo, aprimora o ofício no Liceu de Artes e Ofícios onde "há registros da aplicação da geometria descritiva à construção civil, à estereometria, ao corte das pedras, à alvenaria e cantaria, como também à definição dos elementos de arquitetura, arcos e abóbodas" 6.

Com o advento da Primeira Guerra Mundial e dos bloqueios navais, a falta de dinheiro gerado pelas exportações de café e a carência de material industrializado no exterior paralisam o ritmo das construções. A partir do armistício, quando é clara a retomada do setor, Nunzio Ciampaglia se prepara para atender a demanda do escritório de Ramos de Azevedo ${ }^{7}$ que organizado como a empresa capitalista moderna estava fadado a vencer todas as concorrências de projetos para o Estado e "para o capital financeiro que instala seus bancos com fartura decorativa" 8 .
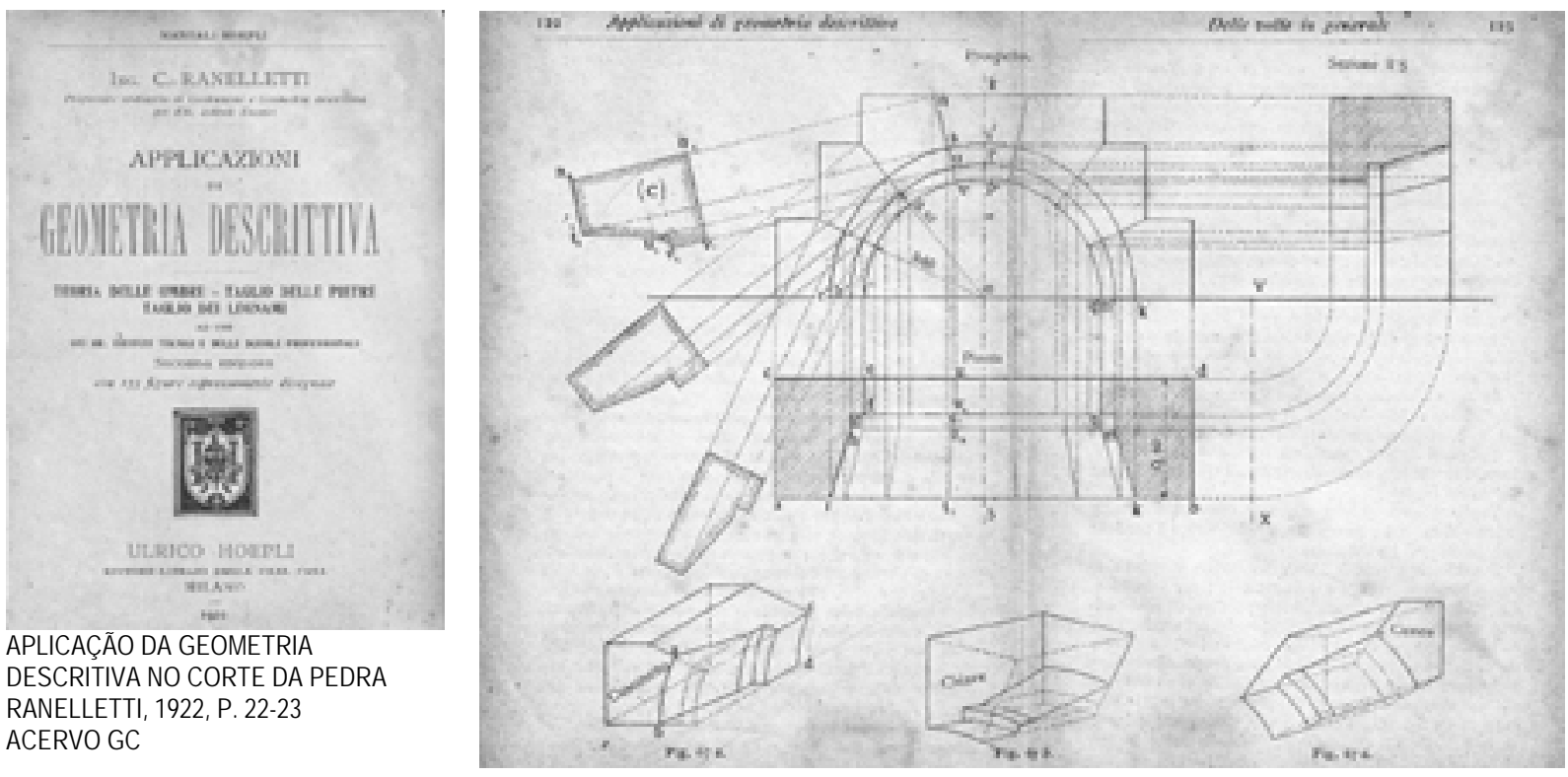
CANTARIA RUAMARIA TERESA NUNZIO CIAMPAGLIA(D) ARQUIVOGC
ANOS 30

FACULDADE DO LARGO S.FRANCISCO ICAMENTODE COLUNA PRODUZIDANA CANTARIA DA RUA MARIA TERESA ARQUIVOGC

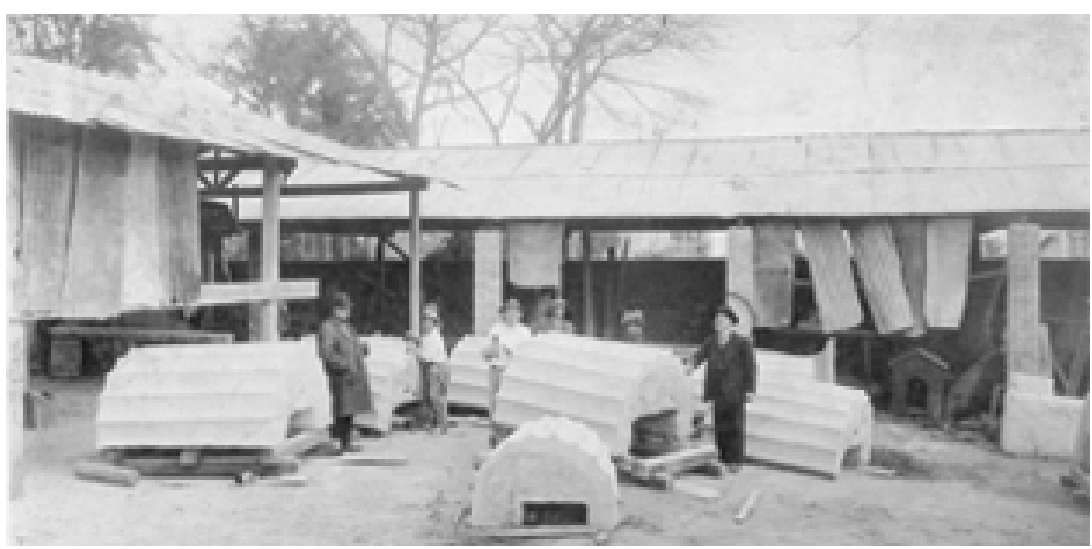

Em 1918, Nunzio Ciampaglia ativa uma propriedade adquirida na rua Maria Teresa, a 200 metros do largo do Arouche. Instala galpões, organiza um escritório, contrata artesãos e começa a executar serviços de granito para algumas obras que fariam parte do patrimônio da cidade. A produção reflete "a feição eclética da cidade de São Paulo" 9 esboçada em grande parte pelo escritório de Ramos e pelo Liceu. A entrada do Palácio da Justiça (1920-1933) ostenta quatro colunas de granito cinza de ordem dórica. No Salão dos Passos Perdidos estão perfiladas dezesseis colunas jônicas de granito vermelho. O Banco do Comércio e Indústria (anos 20) reflete a multiplicidade de elementos ornamentais. A estrutura tem caráter neoclássico com colunas duplas de ordem jônica executadas em pedra rosa. No Banco Português (1926), as colunas são de granito cinza polido. A primeira etapa do Edifício-sede Light (1929) é executada em granito cinza. Na década de 30, após a morte de Ramos, Ricardo Severo orienta a reforma da Faculdade de Direito do largo São Francisco. Do seu núcleo primitivo que remonta ao convento franciscano de taipa, permanece o pátio das arcadas ${ }^{10}$.

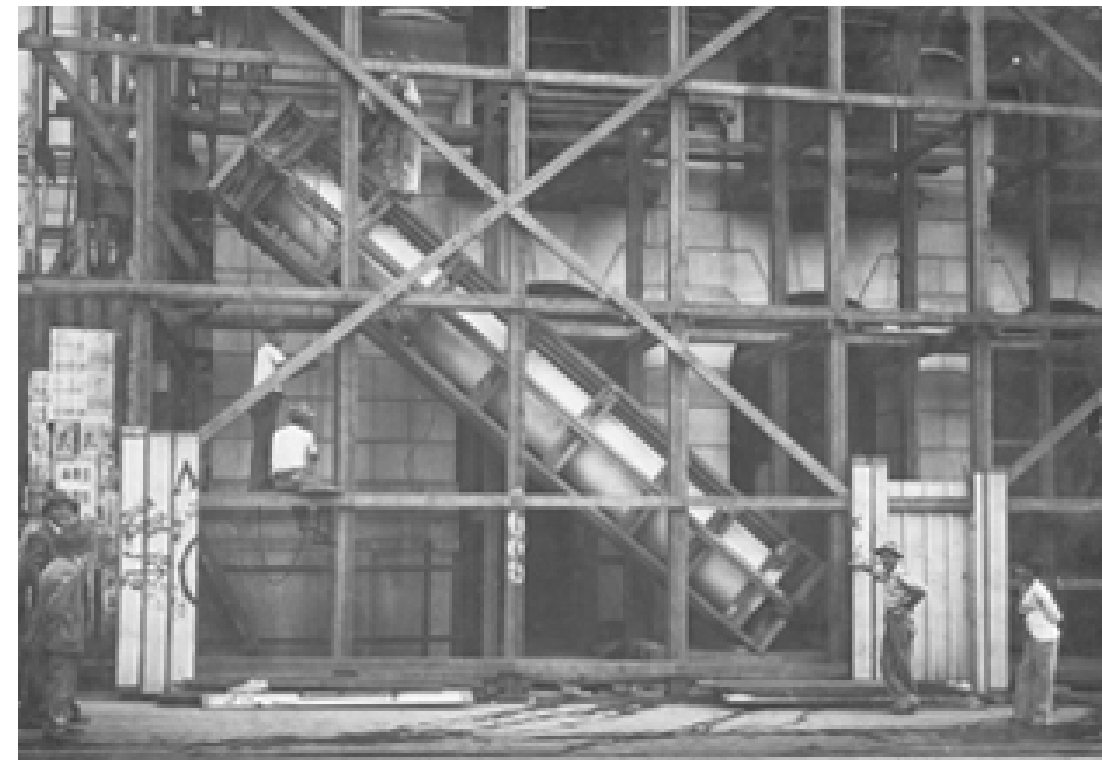


Algumas das obras executadas por Nunzio Ciampaglia constam da coletânea organizada pelo Archivio di Stato di Campobasso ${ }^{11}$ sobre os mestres regionais que desenvolveram o ofício no exterior. Todavia, a mais significativa delas foi articulada no Liceu por trinta e dois amigos, entre empreiteiros, fornecedores e mestres, em homenagem ao ilustre arquiteto, falecido em 12 de junho de 1928. Com projeto do escultor Galileu Emendabile, o monumento a Ramos de Azevedo foi inaugurado em 25 de janeiro de 1934, no Jardim da Luz. Os serviços de granito que incluem oito colunas dóricas de sustentação saíram da cantaria da Rua Maria Teresa.

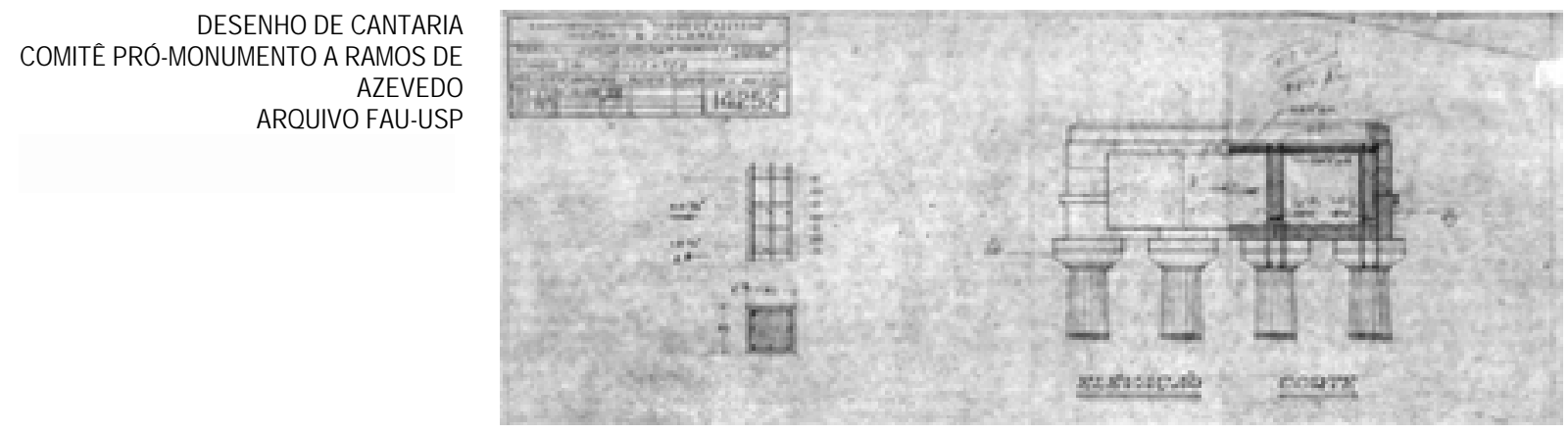

1934. COMITÊPRÓ-MONUMENTOA RAMOS DE AZEVEDO

NUNZIOCIAMPAGLIA(D)

ARQUIVOGC

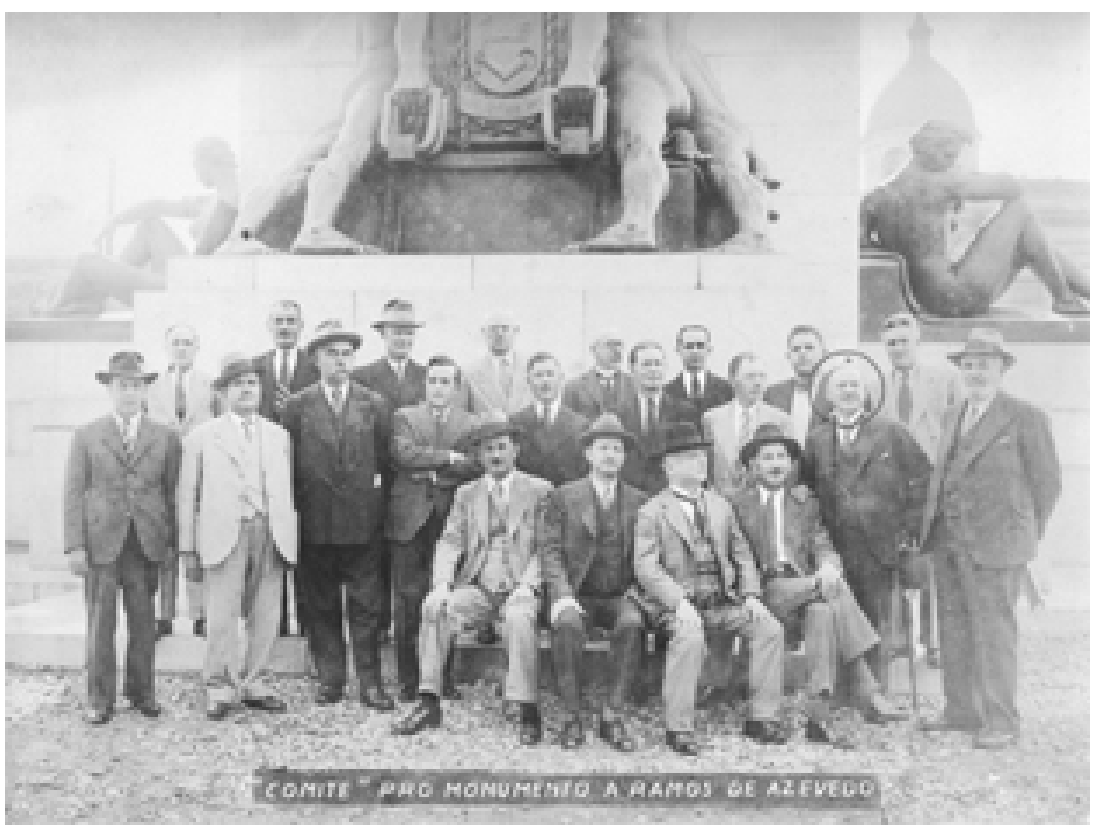


1921. ANIVERSÁRIO DE 70 ANOS DE RAMOS DEAZEVEDO (E) NUNZIO CIAMPAGLIA(D) LEMOS, 1993

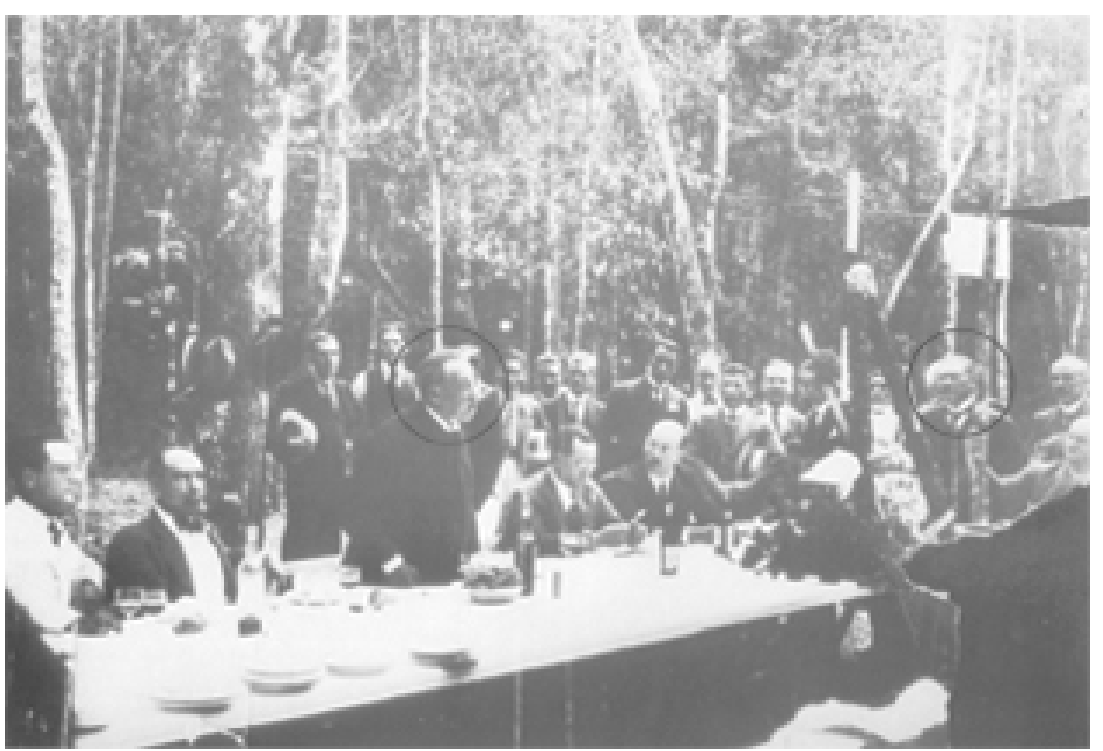

Não se conhece em pormenores a passagem de Nunzio Ciampaglia pelo Liceu. $O$ fato é que o mestre-canteiro é presença constante nas comemorações em torno do "maestro" ${ }^{12}$, como no almoço comemorativo dos 70 anos do arquiteto, em 1921, ou na churrascada no sítio de Inhaíba, em 1928. A festa recuperada por Lemos é digna de reprodução:

"Na Sorocabana, foram reservados dois vagões especiais para transportar os convidados até a pequena estação afastada alguns quilômetros do sítio. Eram mais de 150 pessoas que dali foram levadas pelos mais variados veículos puxados a cavalos e bestas, que iam e vinham com bastante rapidez. Em pouco tempo estavam todos lá na sede festiva. Houve uma churrascada memorável, em que todos beberam muito e sempre animados por uma banda de música, cujos componentes eram todos mestres e empreiteiros de Ramos [...] Ximenes e auxiliares, todos vestidos de branco, distribuíam os assados em profusão. Alegria geral. Ricardo Severo, no meio de todos, comandava os eventos dando ordens através dos sons de uma buzina de chifre, que sempre lhe ficava pendurada na cintura. $\mathrm{Na}$ hora do registro fotográfico daquele afável encontro, quase todos comportaram-se como divertidas crianças enfeitando-se com os fios prateados do líquen popularmente conhecido por "barba de velho", que se prendiam aos galhos das árvores do bosque ao lado das churrasqueiras" ${ }^{13}$. 
1928. CHURRASCOINHAÍBA RAMOS DE AVEDO ( NO ALTO) NUNZIO CIAMPAGLIA(ABAIXO) LEMOS, 1993

1928. CHURRASCO INHAÍBA RICARDO SEVEROERAMOSDE AZEVEDO (C)

NUNZIOCIAMPAGLA(D) ARQUIVOGC
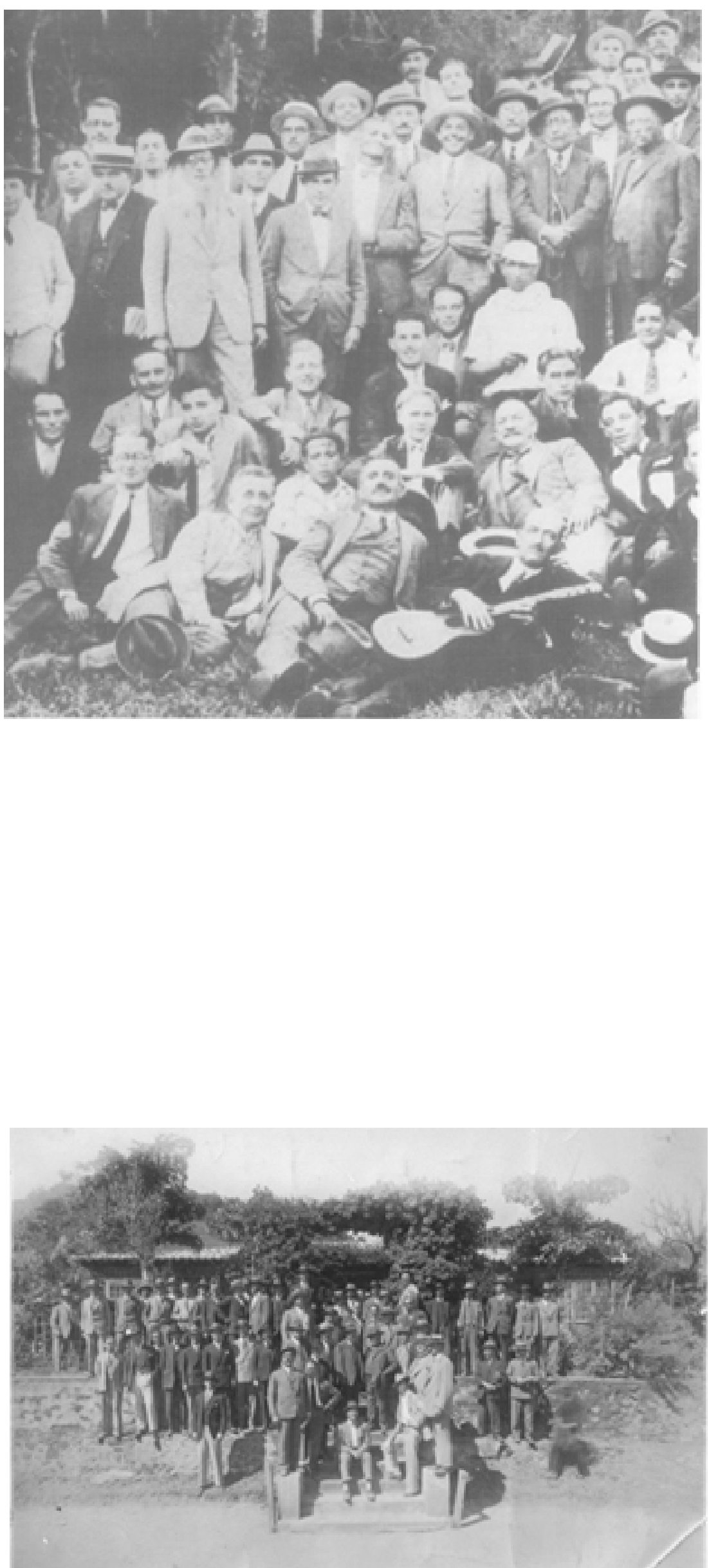


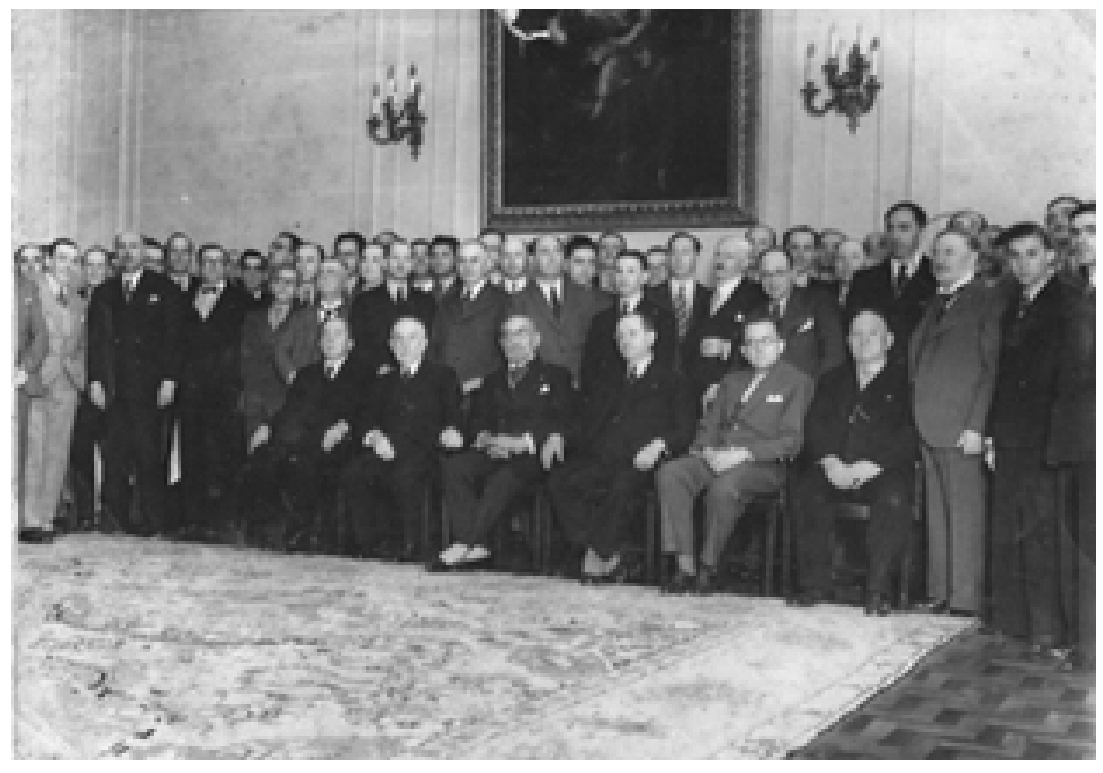

CERIMÔNIA NÃO IDENTIFICADA RICARDO SEVERO NO (C); NUNZIO CIAMPAGLIA(D) ARQUIVOGC

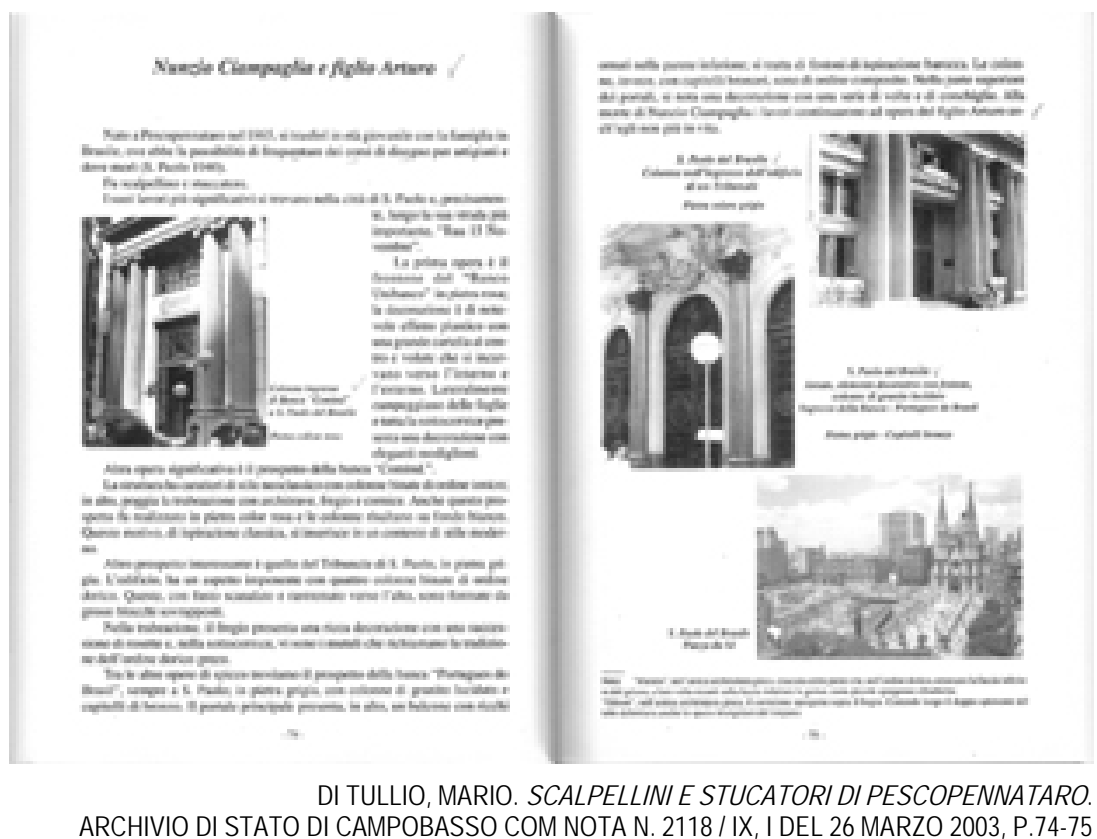


$\mathrm{Na}$ família de quatro irmãs e um primogênito educado na Itália, Galiano Ciampaglia cresceu familiarizado com o ofício do pai. Em meados de 1920, ao mudar-se com a família para a casa da Rua Maria Teresa passou a conviver diretamente com o artesanato pescolano e com a movimentação da oficina. O granito vermelho chegava de Itu, o cinza, da jazida da família e outros eram importados da Itália através do irmão que lá morava. Depois de moldadas pelas turmas do revestimento e do "ornato", as peças eram transportadas e montadas nos endereços nobres da cidade.

Entre pequenos ensaios do ofício, Galiano cultivou as raízes humanistas e os valores clássicos no Instituto Médio Dante Alighieri, onde desenvolveu o hábito da leitura e começou a ter presente a arquitetura e o urbanismo através dos livros das cidades italianas da Idade Média até a Renascença. Revelaria mais tarde que o significado da cidade chegou a deixá-lo dividido entre as duas disciplinas ${ }^{14}$.

O envolvimento de Galiano com o conceito de qualidade - "se é do Liceu, é bom porque ali está Ramos a dirigí-lo; se é de Ramos de Azevedo, é sem defeitos porque tudo é executado pelo Liceu" ${ }^{15}$-, a obediência ao material como condição para o domínio técnico do artesão e a identificação do trabalho com o saber- fazendo e o fazersabendo, seriam preponderantes na escolha da profissão e na filosofia com que a exerceu.

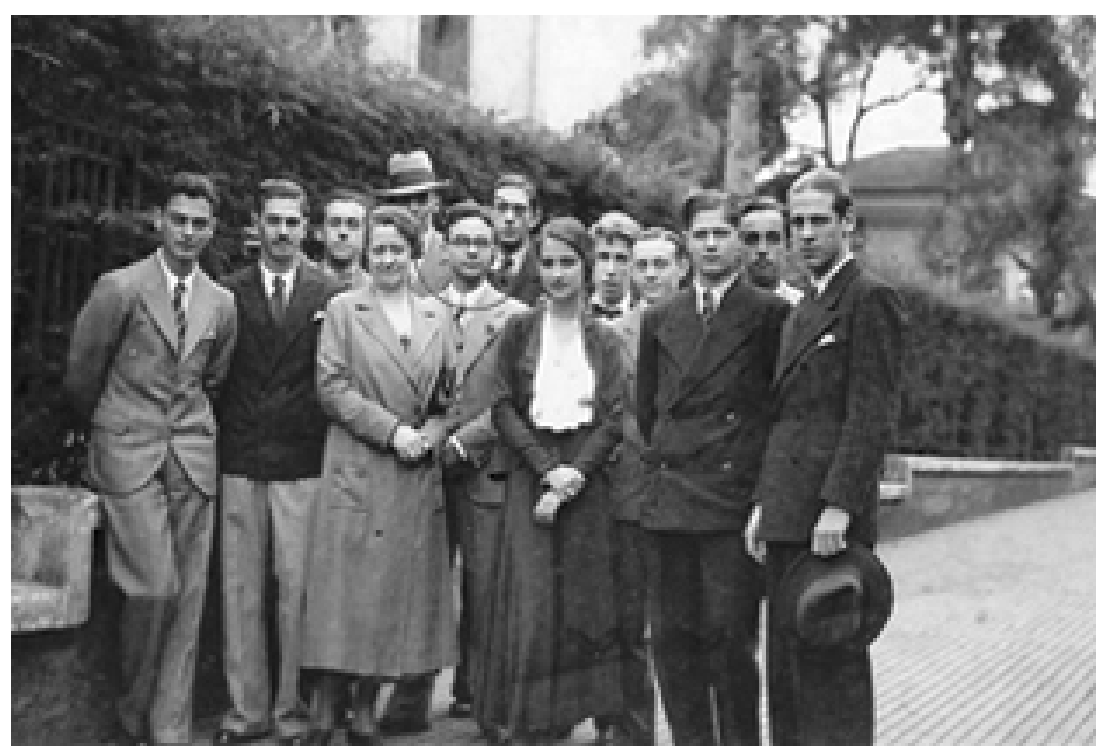




\section{A Escola de Engenharia Mackenzie College}

Marcada pela Revolução de Getúlio Vargas, a década de 30 é palco de relevantes eventos no âmbito do ensino superior e profissional. Em 1930, é criado o Ministério da Educação e Saúde Pública ${ }^{16}$, em 1931, o Conselho Nacional de Educação ${ }^{17}$ e, em 1933, são regulamentadas as profissões de engenheiro, arquiteto e agrônomo, seguidas da criação dos respectivos conselhos federais e regionais CONFEA e CREA ${ }^{18}$. A efeméride não fica sem registro pela Escola de Engenharia Mackenzie College:

"Foi afinal, tornada realidade a regulamentação das profissões de engenheiro, arquiteto e agrimensor, por várias vezes tentada sem alcançar o êxito desejado, com a installação dos conselhos federal e regionaes. Poderão agora as escolas de engenharia e architectura esclarecer, ativamente, aos seus alumnos que, a profissão por elles abraçada é respeitada e inaccessível aos que não buscaram os necessários conhecimentos nas escolas superiores, não se submettendo aos estudos exhaustivos, que bem merecem um ajusta recompensa na vida prática. Nenhum profissional poderá agora exercer a engenharia ou architectura sem possuir a carteira profissional, para o que é indispensável o registro do diploma no Ministério da Educação e Saúde Pública, de acordo com os requisitos exigidos por lei" 19

Ocorre que no clima acirrado às vésperas da Revolução Constitucionalista de 1932, uma série de retaliações indiretas aos paulistas acabava por comprometer o ensino de arquitetura a começar pelo encerramento do curso de arquitetos da Academia de Belas Artes de São Paulo, fundado em 1928. Também em 1932, havia sido decretada a cassação dos diplomas da Escola de Engenharia Mackenzie College que, até 1923, esteve vinculada a Universidade de Nova York ${ }^{20}$.

O estudo de Marcel Mendes - A Escola de Engenharia Mackenzie College e a questão do reconhecimento (1932-1938) - atribui ao episódio a transferência de alunos para o curso de engenheiroarquiteto da Escola Politécnica de São Paulo e para o curso de arquiteto da Escola Nacional de Belas Artes do Rio de Janeiro ${ }^{21}$. 
Não foi o caso de Galiano Ciampaglia que, em 1934, ingressa na Escola de Engenharia Mackenzie. O pragmatismo assimilado do ofício do pai sugere a preferência pela instituição que segue as diretrizes da Escola Nova Americana de aprendizagem dinâmica e participativa onde o aluno seria obrigado a aprender através da prática ${ }^{22}$.

O curso de engenheiro-arquiteto da escola remonta ao catálogo de 1917-19 da escola, quando era organizado de acordo com o curso de engenharia civil ${ }^{23}$. Dirigido por Christiano Stockler das Neves, formado em 1911, na Fine Arts School da Universidade da Pensylvannia, o curso estabelecia conexões entre o bom gosto da École des Beaux-Arts de Paris e a tecnologia avançada. Além disso, o diretor preconizava o projeto arquitetônico como a única atividade a que os arquitetos deveriam se dedicar ${ }^{24}$, em contraponto ao curso de orientação germânica da Escola Politécnica que "visava formar engenheiros-arquitetos preparados para projetar e construir edificações" ${ }^{25}$.

Avalia Mendes que, em 1934, a nomeação do engenheiro Dr. Álvaro Pereira de Souza Lima, para inspetor federal, "sinalizou, com boa nitidez, qual seria o caminho que o Mackenzie deveria percorrer se quisesse harmonizar-se com as diretrizes governamentais" ${ }^{26}$. Entre as primeiras medidas, a turma de Galiano Ciampaglia protagoniza a extinção do curso de engenheiro-arquiteto e a reestruturação da escola nos cursos de Engenheiros Civis, Eletricistas e Industriais, e no curso de Bellas Artes segmentado em Pintura e Escultura, e Arquitetura, a partir de então, com seis anos de duração.

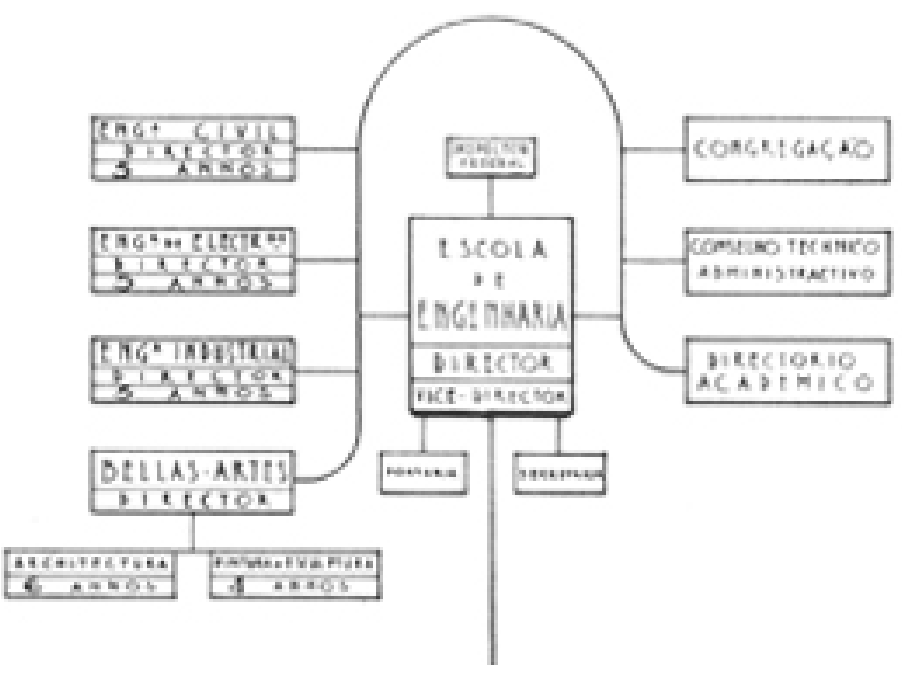




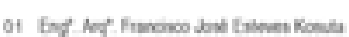

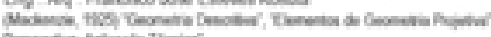

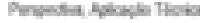

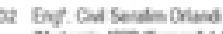

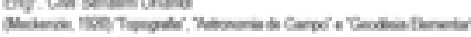

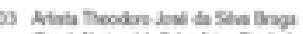

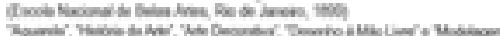

Ot

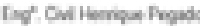
Conone hemits

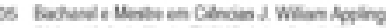

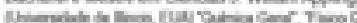

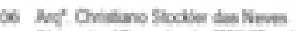

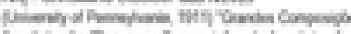

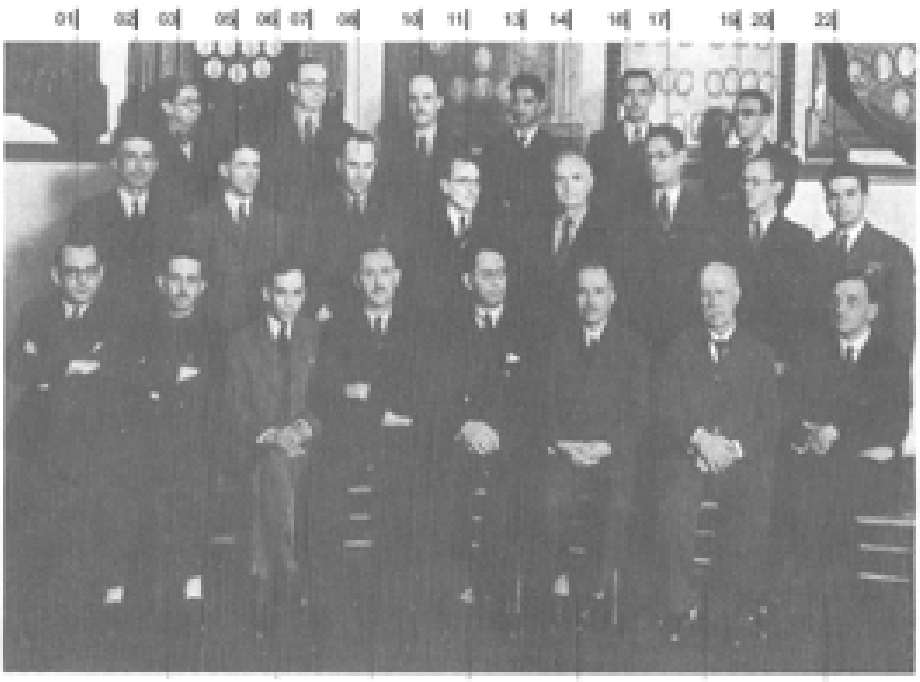

ad oc va
34|
14
21

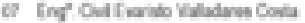

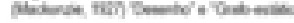

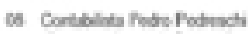

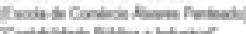

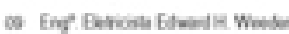

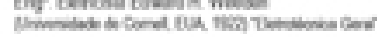

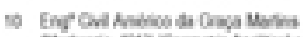

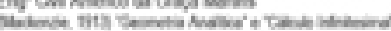

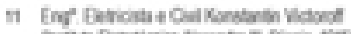

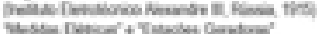

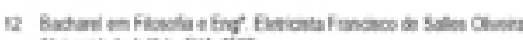

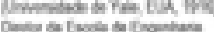

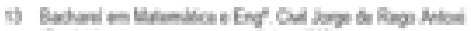

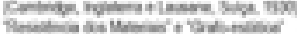

4 Eng OA Reande Vercie Omathe

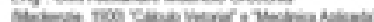

is Eng, Oul Neunden Narano Cosoo

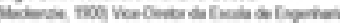

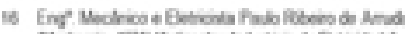

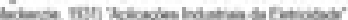

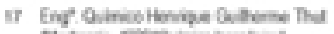

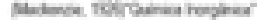

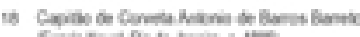

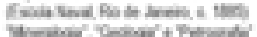

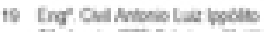

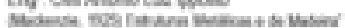

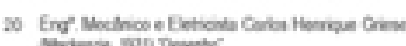

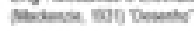

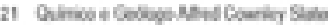

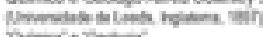

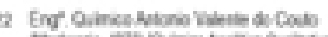

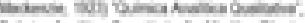


A conquista era almejada por Stockler das Neves desde o III Congresso Pan-Americano de Arquitetos (Buenos Aires, 1927) quando manifestou a sua aversão à dupla titulação: "a Architectura é, antes de tudo, uma bella arte e não um ramo da engenharia" ${ }^{27}$. No Congresso seguinte (Rio de Janeiro, 1930), Stockler das Neves apresentou a tese "Regulamentação da Profissão de Architecto", baseada no argumento de que os benefícios dessa medida se refletiriam, não só nos arquitetos, mas na estética das cidades e na comunidade.

O paradigma Beaux Arts que dominou o ensino da arquitetura até meados do século XX, no Mackenzie College era adicionado da posição de Stockler das Neves que via na arquitetura moderna um modismo passageiro. Tendo na revista Arquitetura e Construções um veículo para suas manifestações, em 1931, não perdeu a oportunidade de atacar Frank Lloyd Wright diante do apoio do mestre norte-americano aos estudantes da ENBA contra os acadêmicos que não deram espaço para Lúcio Costa resistir na direção da escola do Rio de Janeiro: "Lloyd Wright com suas curiosas teorias sobre arquitetura não é levado a sério nos Estados Unidos e tampouco na Europa [...] é um excêntrico. Quer fazer arte pessoal. Fracassará como todos os que fizeram tais tentativas" 28 .

Sobre a organização do currículo, nas aulas de "Arquitetura Analítica", ministradas nos dois primeiros anos, os alunos se limitavam a copiar e aquarelar fragmentos de modelos renascentistas e barrocos com direito a menções honrosas e publicações na Revista de Engenharia Mackenzie. Enquanto para Lúcio Costa, a composição arquitetônica é "a finalidade mesma da profissão do arquiteto e para onde convergem e onde se corporificam todas as demais disciplinas do curso" ${ }^{29}$, propondo o seu recuo como base do ensino, Stockler das Neves introduzia as disciplinas de "Pequenas Composições" e "Grandes Composições", somente a partir do terceiro e do quarto ano letivo. Das disciplinas e mestres, recentemente Galiano recordou-se das aulas de modelagem, de perspectiva e de serviços de madeira, no caso, as "mais interessantes" ${ }^{30}$. 


\section{E.E.M.}

BELLAS ARTES-ARCHITECTURA 1934-1939

\section{Disciplinas}

1. ANO (1934)

Goometria Analtica

Calloulo Infinitesima:

Geometria Descritiva

Topografia

História da Arte

Arquitetura Anaitica

Desenho à mbo-livre

Modologem

Oficina de Ferro e Madeira

2. ANO (1935)

Perspectiva

Sombras

Resistencia dos materiais.

Grafo-Estatica

Historia da Arie

Arquiteturn Anolitica

Desenho à mio-livre

Modolagem

3. ANO (1936)

História da Arte

Arte Decorativa

Hidraulica Teórica

Estruturas Metilicas e de Madeira

Materiais de Construça

Estereotomia

Pecuenas Composicbes

$4^{5}$ ANO (1937)

Higiene

Historia da Arte

Arte Decorativa

Estabilidade-Alvenaria

Sistomas e. Detalhes de Construpbes

Teoria e Filosofla da Arquitetura

Grandes Composipses

5. ANO (1938)

Teoria e Filosofia da Arquitetura

Grandes Composicbes

Direito administrativo

Economia Politica

Prática Profissional

Legislaça

Contabilidade

6. ANO (1939)

Utbarismo

Grandes Composicobes

Pratica Profissional

Fisica Aplicada

Sistemas e Detalhes de Construgbes.

\section{HISTÓRICO ESCOLAR GC}

ARQUIVOEEM

ATELIEREEM

E/D: SOPHIEELMA CAPPS; MANOEI SOUTELLE GALIANO CIAMPAGLIA; IGOR SRESNEVSKY; JACOB RUCHT; MIGUE FORTE(NOALTO)
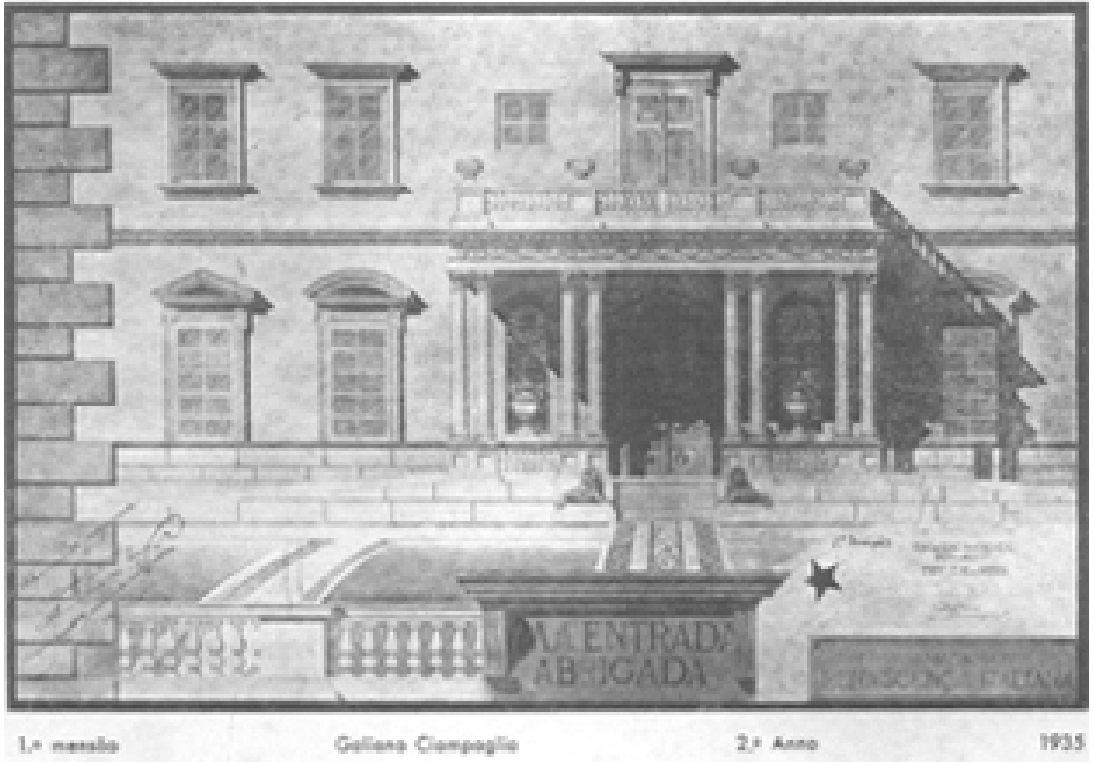

2. Anso

inss

TRABALHODE GALANO CIAMPAG IA REVSTA DE ENGENHARIA MACKENVIE N.64. ANNO XXI, MAIO, 1935, P. 23

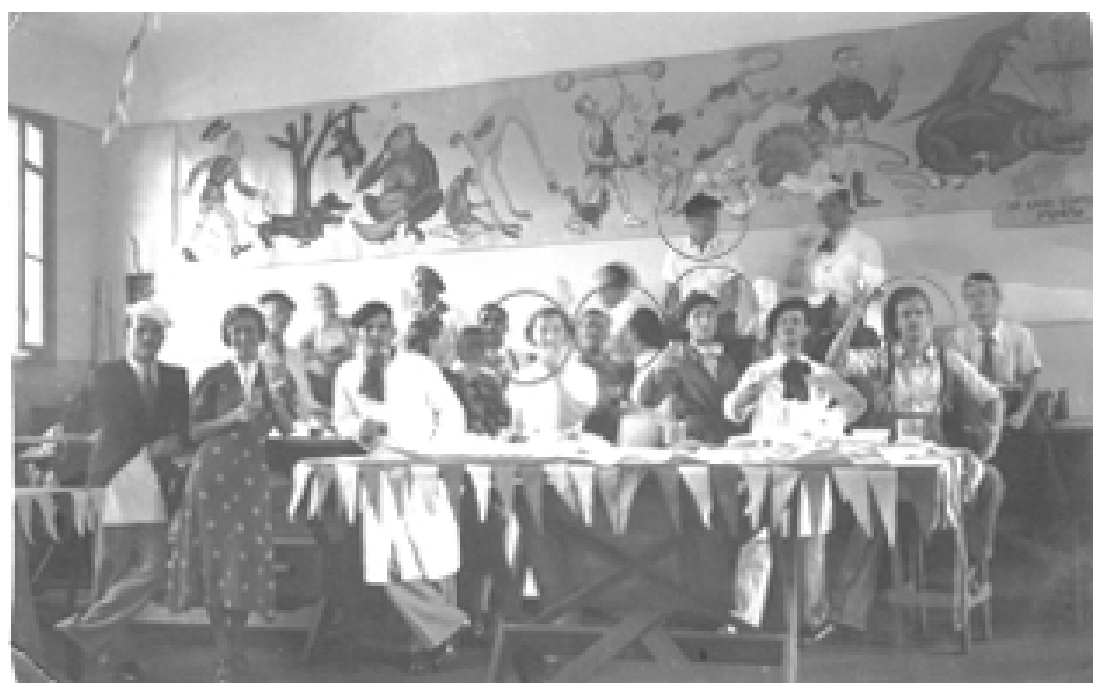


Até assumir a diretoria da Faculdade de Arquitetura Mackenzie, em 1947, o mestre Beaux-Arts esteve atento ao aprimoramento do curso. É o que sugerem iniciativas como, em 1920, a inclusão de "Architectura Moderna", no conteúdo da disciplina "História da Architectura", em 1923, a introdução da disciplina "Urbanismo", e ainda, em 1931, a criação do curso de engenheiro-arquiteto compartilhado com o de engenheiro nos dois primeiros anos.

À parte o seu propagado hermetismo frente à arquitetura moderna, em 2007, Marcel Mendes identificou entre os documentos da Escola de Engenharia Mackenzie o convite feito a Stockler das Neves para que fizesse parte na organização da Faculdade de Arquitetura da Universidade de São Paulo, fundada em 1948. A notícia foi trazida pelo próprio Christiano, no banquete realizado em 29 de outubro de 1947, quando assumiu a direção da recém-fundada Faculdade de Arquitetura Mackenzie:

"Queremos vos dar uma notícia muito agradável, estamos certos. É o honroso convite que nos fez o Magnífico Reitor da Universidade de São Paulo, o ilustre Prof. Lineu Prestes, para tomarmos parte na organização da Faculdade de Arquitetura dessa universidade, conjuntamente com os ilustres Professores Anhaia Mello e Henrique Jorge Guedes, todos nossos bons amigos. Será mais uma escola de arquitetura que terá nossa São Paulo, o que bem demonstra o reconhecimento de nossos dirigentes em relação ao papel importante que representa a arte milenar na civilização dos povos. Esse gesto elegante e nobre do Magnífico Reitor para com um antigo professor do Mackenzie veiu estreitar, ainda mais, as nossas cordiais relações com os estabelecimentos oficiais de ensino cujos chefes bem compreendem os serviços que vem prestando o Mackenzie a São Paulo e ao Brasil" ${ }^{31}$.

Nesse sentido merece reflexão a rígida orientação do curso direcionada para a arquitetura clássica referenciada à Beaux Arts de Paris.

A primeira questão está no acervo da biblioteca da escola. Em contraponto às muitas declarações de ex-alunos sobre a inexistência de revistas de Arquitetura Moderna na biblioteca, "não tinha L'Architecture d'aujourd'hui, Arts \& Architecture, Casabella, não tinha Domus" 32 , segundo depoimento de Salvador Candia, formado em 1948 , 
"[...] o Mackenzie tinha coisas preciosas. Digo tinha - vejam o tempo do verbo - tinha o recorde desde 1898, quer dizer no Mackenzie estava documentada toda a arquitetura moderna desde a Escola de Chicago, enfim tudo o que aconteceu. Alguém, nesse intervalo, por falta de espaço, mandou jogar fora todas as revistas. Isso é a burrice em nível universitário" ${ }^{33}$.

De fato, como declarou recentemente, foi na biblioteca da escola, em 1936, onde Galiano teve o seu primeiro contato com Frank Lloyd Wright através do texto "The logic of the plan" (da série "In the cause of Architecture", publicada pela Architectural Record), seguido da edição da Architectural Forum (1938) dedicada à obra do mestre de Taliesin ${ }^{34}$.

Essa abertura pode ser vista como um avanço, por exemplo, em relação ao acervo da ENBA, dos anos 1930, sobre o qual o próprio Wright faria referência na edição de 1943 de An Autobiography: "os professores da escola me boicotaram, banindo meus livros e as publicações da arquitetura moderna da biblioteca da instituição" ${ }^{35}$.

Um levantamento recente nas "mapotecas antigas" do Mackenzie ${ }^{36}$, relativo ao período cursado por Galiano Ciampaglia (1934-1939), revela vestígios das revistas Arts \& Architecture, Architectural Record e The Architectural Forum, além das italianas Casabella e Domus. No caso de Casabella, a seção "Architettura Mondiale" reproduzia projetos destacados em revistas norte-americanas, francesas, alemãs, russas e japonesas. Na Domus, cuja edição mais antiga remonta a 1931, a seção "Indicazioni Letterarie" era uma fonte preciosa de publicações recentes.

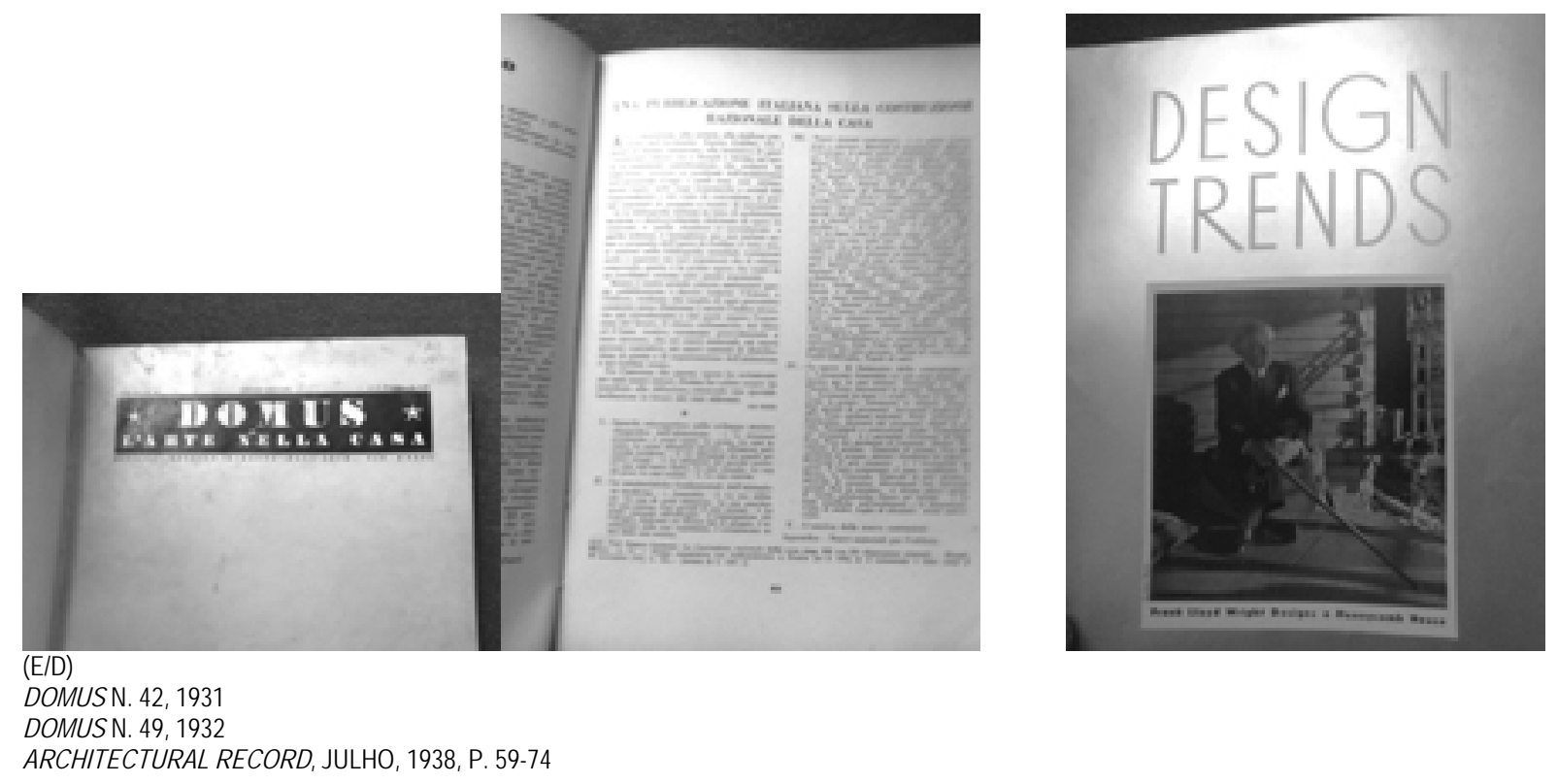


Outra questão refere-se à aceitação de propostas com tendências modernizantes desenvolvidas por alguns alunos, na disciplina "Grandes Composições". É o caso do "Sanatório para tuberculosos" apresentado por Galiano Ciampaglia, em 1938. Avaliado com grau "plenamente", sugere uma fluidez orgânica que nada tem a ver com a tradição acadêmica pautada pela simétrica. No trabalho, é nítida a influência da edição da Architectural Forum, dedicada a Wright, e disponível na biblioteca da escola.

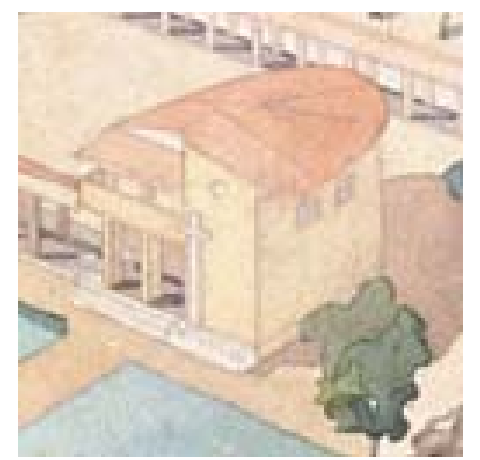

DETALHEDACAPELA GALIANO CIAMPAGLIA

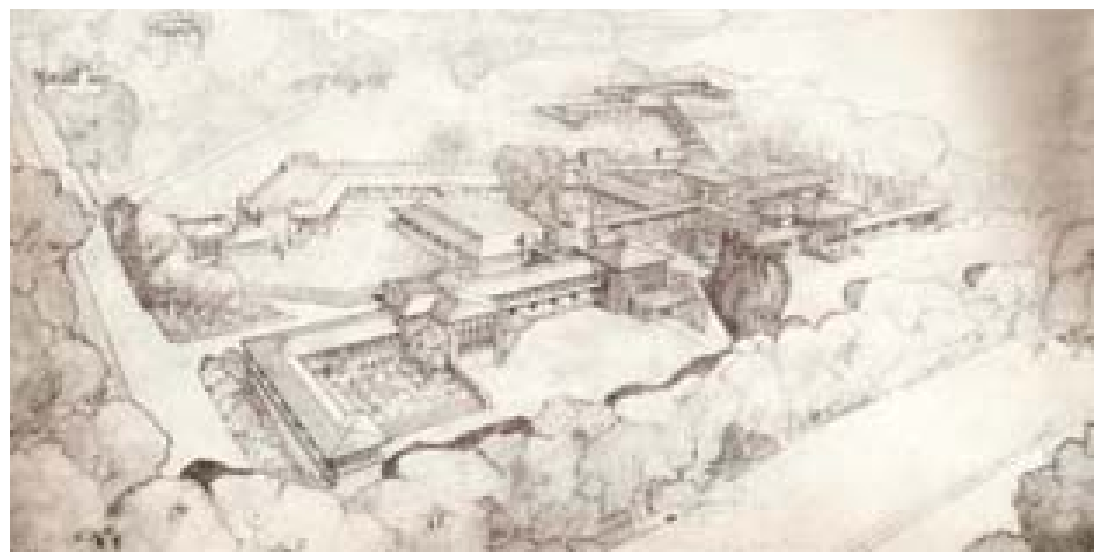

ACIMA

TALIESIN. FRANK LOYDWRIGHT THEARCHITECTURAL FORUM, 1938, P. 21 / ACERVO GC

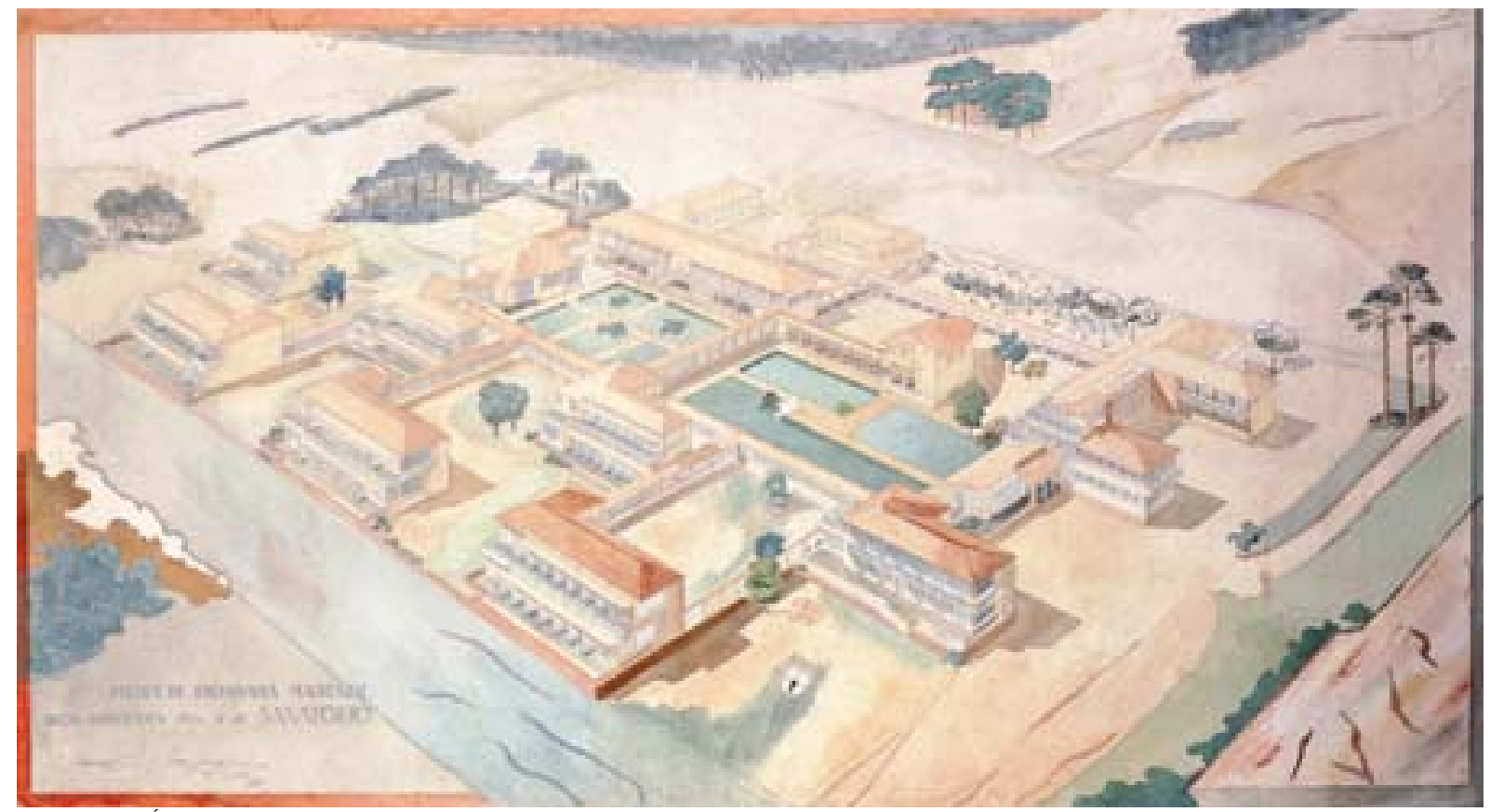




\section{* Arquiteto ou engenheiro-arquiteto}

Como trazido por Ficher, na virada dos anos 30, o arquiteto ainda não era visto com bons olhos e suas atribuições confundidas com as do engenheiro:

"[...] embora arquitetos e engenheiros pudessem ocupar, e muitas vezes ocupassem, o mesmo espaço econômico no negócio da construção, ainda no final da década de 1930 e até mesmo durante a década de 1940, o título em si de "arquiteto" preservava uma conotação pejorativa, designando mais um mestre free-lance ou o construtor prático do que o portador de um diploma do curso superior" ${ }^{37}$.

De fato, ainda em 1981, Artigas falaria de como "nos temos confundido com os engenheiros, tanto quanto estes com os construtores" ${ }^{38}$.

No caso de São Paulo, o tema ganha relevo no estudo Ensino e profissão. O curso de engenheiro-arquiteto da Escola Politécnica que aborda as décadas que antecederam a criação das escolas especializadas de arquitetura desligadas dos cursos de engenharia. Dirigido aos "engenheiros-arquitetos" da Poli, questões como leigo ou profissional, engenheiro ou arquiteto, projeto ou construção, percorrem quatro décadas de debates, decretos e leis, sem excluir o personagem central do curso de engenheiro-arquiteto do Mackenzie College, Christiano Stockler das Neves. Em comum, as duas escolas têm como marco o ano de 1947 que define o ensino autônomo de arquitetura, no Mackenzie.

A partir do evento, a historiografia convencionou biografar como "engenheiros-arquitetos", os alunos formados pelos cursos de arquitetura vinculados às escolas de engenharia, e como "arquitetos", aqueles formados pelas faculdades de arquitetura. Sob esse enfoque, Ficher recua ao Decreto Federal n. 23.275, de 7 de julho de 1947, que dá reconhecimento à Faculdade de Arquitetura Mackenzie instalada em 12 de agosto sob a direção de Stockler das Neves e que viria a "diplomar sua primeira turma, composta por dois arquitetos, ainda em 1947" 39 . 
Sem entrar no mérito de como ou quando os papéis de engenheiros e arquitetos chegariam a ganhar nitidez no chamado "negócio da construção", o fato é que na Escola de Engenharia Mackenzie os primeiros diplomas de "arquiteto", reconhecidos pelo Ministério da Educação e da Saúde, remontam a 1939.

Com o encerramento do curso de engenheiro-arquiteto, em 1934, seguido, em 1938, da restituição do reconhecimento dos diplomas pelo Governo Federal ${ }^{40}$, o ANUÁRIO EEM 1939 faz referência à primeira "Colação de Gráu dos Engenheiros e Arquitetos" ${ }^{41}$. Segundo a Ata da 98o reunião da Congregação da Escola de Engenharia Mackenzie, realizada aos vinte e seis de dezembro de 1939, às 21 horas, no Teatro Municipal da cidade de São Paulo, e, mais precisamente, nas palavras do Diretor da Escola, Professor Henrique Pegado:

"cumprindo dispositivo regulamentar, acha-se reunida a Congregação da Escola de Engenharia Mackenzie, a fim de conferir os gráus de 'Engenheiro' e 'Arquiteto' aos alunos que terminaram o curso este ano, após haverem cumprido todas as suas obrigações acadêmicas" ${ }^{42}$.

$\mathrm{Na}$ oportunidade, diplomas de "arquiteto" foram então conferidos a Galiano Ciampaglia (n.579), Igor Sresnewsky (n.580), Manoel Amadeu G. de Soutello (n. 581), Miguel Forte (n. 582) e Sophie Elma Muller Capps (n. 583) ${ }^{43}$.

Protegida por uma zona de conforto de décadas, a historiografia sequer prestou atenção ao fato trazido a público por Galiano Ciampaglia, em 2002, por ocasião da cerimônia de tombamento do edifício-sede IAB-SP ${ }^{44}$. Em 2010, o artigo "A primeira turma de arquitetos mackenzistas" ${ }^{45}$, fundamentado por um dos diplomas reconhecidos pelo MES, em 1940, esbarrou na questão que já havia sido levantada por Mendes, em 2007:

"Com as mudanças introduzidas, passaram os futuros graduados a receber diploma de "arquiteto"? A resposta é positiva, mas isso não se verificou prontamente, pois as turmas em andamento, que cursaram apenas cinco anos, mantiveram o título anterior [...] Os anuários da época (entre 19341960) alternam menções ao título de Engenheiro-arquiteto e Arquiteto, revelando certa insegurança na melhor adequação, circunstância essa que se apresenta como nota negativa" ${ }^{46}$. 
Reexaminados, os arquivos e anuários confirmaram o cumprimento de seis anos apenas para as turmas que ingressaram na escola a partir de 1934 e cujas colações de grau fazem distinção entre "arquitetos" e "engenheiros". É bem verdade que diante da paulatina adequação a que esteve sujeito o curriculum, o diploma de "arquiteto" ou de "engenheiro-arquiteto" não é relevante na qualidade do profissional formado no período de transição da Escola de Engenharia Mackenzie para a Faculdade de Arquitetura Mackenzie. A relevância está na própria historiografia da arquitetura paulista que passaria a creditar à Escola de Engenharia Mackenzie esse pioneirismo, já em 1939. Na Escola Politécnica, o curso de "engenheiro-arquiteto" foi mantido até $1954{ }^{47}$.

\begin{tabular}{|c|c|c|c|c|c|c|c|}
\hline \multirow{3}{*}{$\begin{array}{l}\text { COLAÇĀO DE GRÁU } \\
\text { Formados Conclusào }\end{array}$} & \multicolumn{6}{|c|}{ Engenheirandos (architectos) } & \multirow{3}{*}{\begin{tabular}{|c|} 
Arquitetos \\
$26 / 12 / 39$ \\
1939 \\
\end{tabular}} \\
\hline & \multirow[b]{2}{*}{1933} & \multirow{2}{*}{$22 / 07 / 35$} & \multirow[b]{2}{*}{1935} & \multirow[b]{2}{*}{1936} & \multirow{2}{*}{$\begin{array}{c}27 / 11 / 37 \\
1937^{*}\end{array}$} & \multirow[b]{2}{*}{1938} & \\
\hline & & & & & & & \\
\hline Galiano Ciampaglia (5) & \multirow{3}{*}{$4^{\circ}$ ano } & \multirow{9}{*}{$\begin{array}{l}1^{6} \text { ano } \\
5^{*} \text { ano } \\
1^{\circ} \text { ano } \\
2^{\circ} \text { ano } \\
3^{\circ} \text { ano } \\
2^{\circ} \text { ano } \\
1^{\circ} \text { ano } \\
1^{\circ} \text { ano } \\
5^{\circ} \text { ano }\end{array}$} & \multirow[t]{2}{*}{$2^{4}$ ano } & \multirow[t]{2}{*}{$3^{3}$ ano } & \multirow[t]{2}{*}{$4^{\circ}$ ano } & \multirow[t]{2}{*}{$5^{\circ}$ ano } & \multirow[t]{2}{*}{$6^{\circ}$ ano } \\
\hline Francisco J.D. Caiuby (1) & & & & & & & \\
\hline Igor Sresnewsky (5) & & & \multirow{7}{*}{$\begin{array}{l}2^{\circ} \text { ano } \\
2^{*} \text { ano } \\
4^{*} \text { ano } \\
3^{*} \text { ano } \\
2^{*} \text { ano } \\
2^{*} \text { ano }\end{array}$} & \multirow{7}{*}{$\begin{array}{l}3^{\circ} \text { ano } \\
3^{\circ} \text { ano } \\
5^{\circ} \text { ano } \\
4^{*} \text { ano } \\
3^{*} \text { ano } \\
3^{*} \text { ano }\end{array}$} & \multirow{7}{*}{$\begin{array}{l}4^{\circ} \text { ano } \\
4^{\circ} \text { ano } \\
5^{\circ} \text { ano } \\
5^{\circ} \text { ano } \\
4^{\circ} \text { ano } \\
4^{\circ} \text { ano }\end{array}$} & \multirow{2}{*}{$\left|\begin{array}{l}5^{\circ} \text { ano } \\
5^{\circ} \text { ano }\end{array}\right|$} & \multirow{2}{*}{$\begin{array}{l}6^{\circ} \text { ano } \\
6^{\circ} \text { ano }\end{array}$} \\
\hline Manoel Amadeu G. de Soutello (4) & \multirow{6}{*}{$\begin{array}{l}1^{\circ} \text { ano } \\
2^{\circ} \text { ano } \\
1^{\circ} \text { ano }\end{array}$} & & & & & & \\
\hline Manoel Carlos G. de Soutello (2) & & & & & & \multirow{5}{*}{$\begin{array}{l}5^{\circ} \text { ano } \\
5^{\circ} \text { ano }\end{array}$} & \multirow{5}{*}{$\begin{array}{l}6^{\circ} \text { ano } \\
6^{\circ} \text { ano }\end{array}$} \\
\hline Mauricio F, dos Santos Cruz (3) & & & & & & & \\
\hline Miguel Forte (5) & & & & & & & \\
\hline Sophie Elma M. Capps (5) & & & & & & & \\
\hline Walter Saraiva Kneese (1) & & & & & & & \\
\hline \multicolumn{8}{|c|}{ 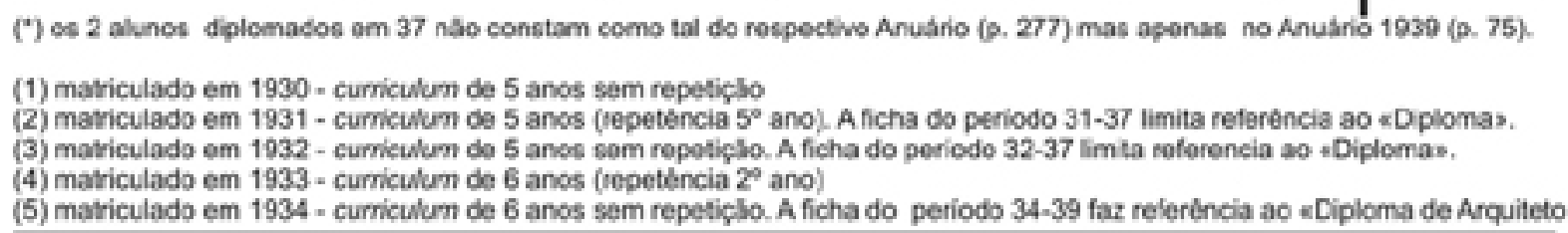 } \\
\hline
\end{tabular}




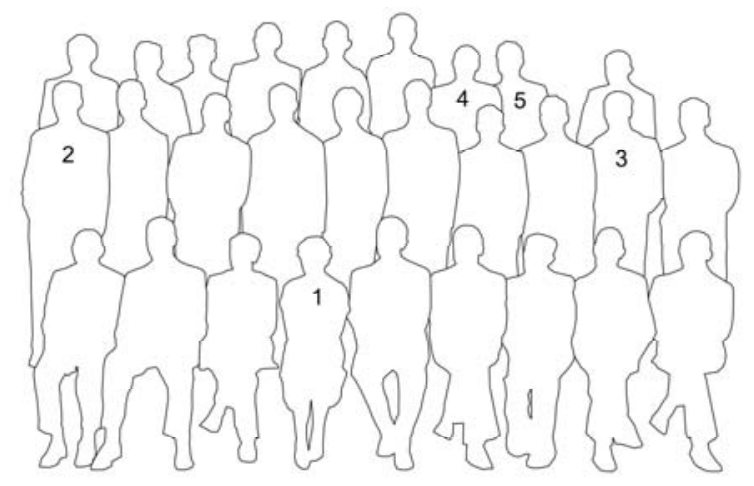

1938. ESCOLADEENGENHARIAMACKENZIE

DESPEDIDA DA TURMA DE 1934. ENTRE OS ALUNOS, CONSTAM OS CINCO ARQUITETOS QUE SE FORMARIAM EM 1939:

(1) SOPHIE E. CAPPS LADEADA PELOS PROFESSORES ANTONIO LUIZ IPPÓLITOE ELEXANDRE MAURICIO ORECCHIA

(2) IGOR SRESNEWSKY

(3) MIGUEL FORTE

(4) MANOEL AMADEU G. DE SOUTELO

5) GALIANO CIAMPAGLIA

ARQUIVOGC

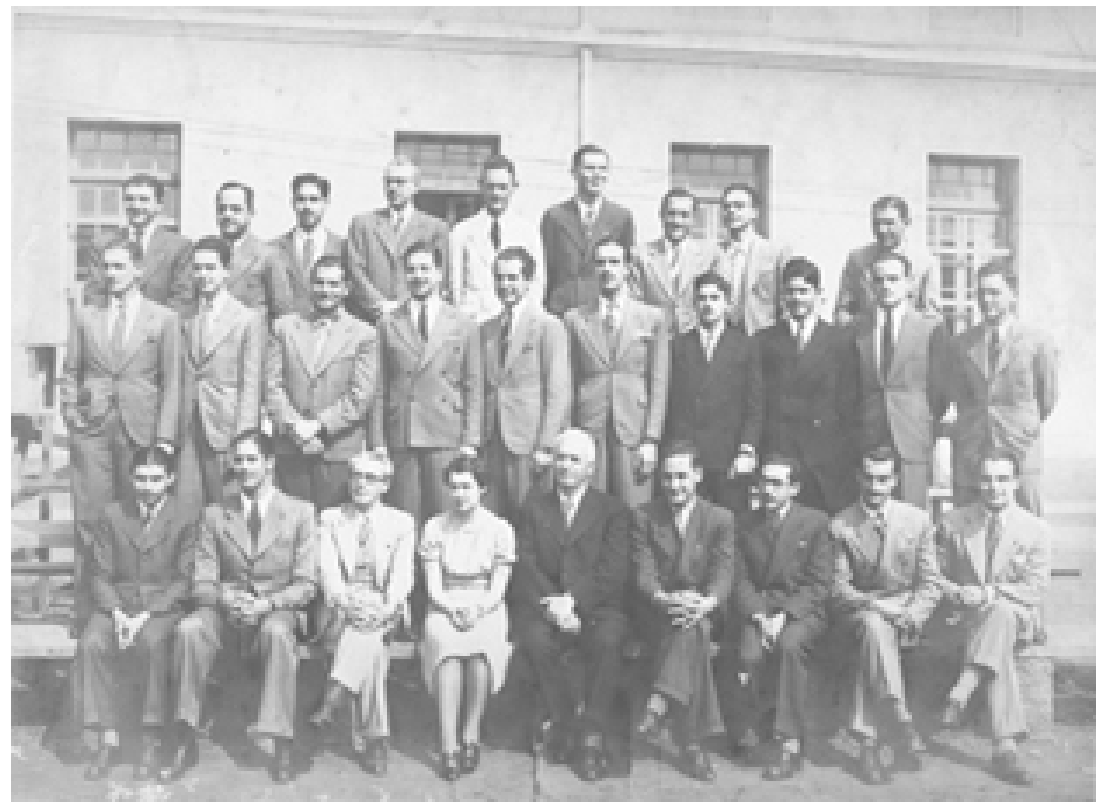


A

ESCOLA DE ENGENHARIA MACKENZIE

SAO PAVLO - BRASIL.

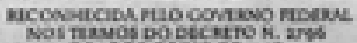

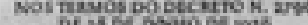

rosests

DIPLOMA

N.579

ATESTA

GALIANO CIAMPAGLIA

NVNZ1O CAMEAGLA

, w Mate os nis

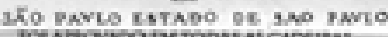

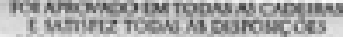

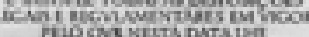

CONFERE

ocalo de

ARQVITETO

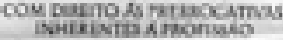

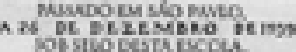

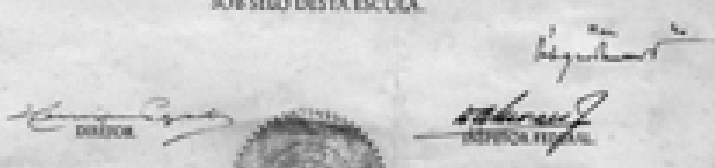

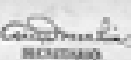

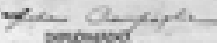
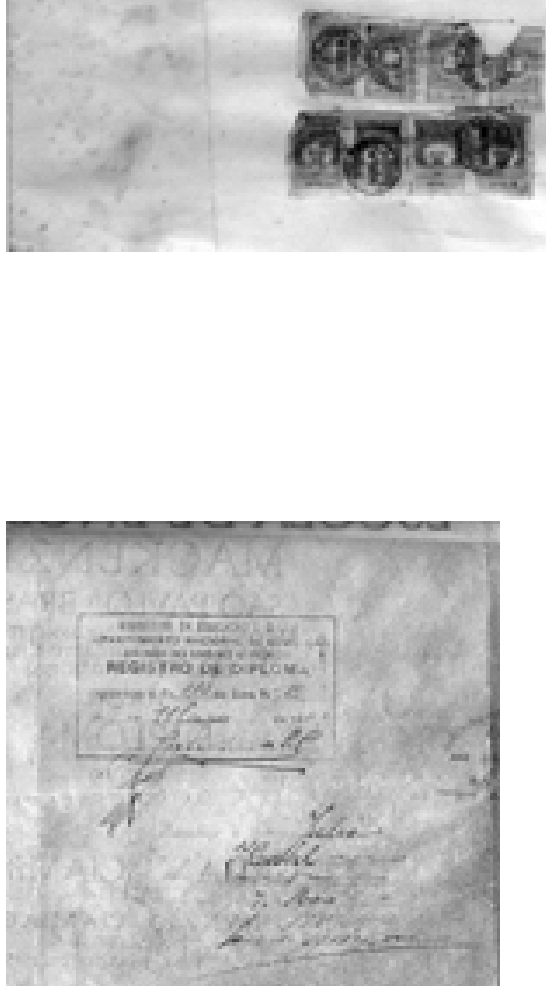

DIPLOMAN. 579 (1939) E REGISTRO MES (1940)

ARQUIVOGC 


\section{Frank Lloyd Wright, o eixo}

A arquitetura nova não nasceu ao mesmo tempo que o cubismo; e quem quiser estudar os seus efeitos figurativos segundo a visão desta escola encontrar-se-ia com o problema de poder justificar tão só a Le Corbusier e alguns dos seus imitadores [...] A arquitetura nova nasceu verdadeiramente na esteira do impressionismo: refiro-me a Frank Lloyd Wright [...] As obras de Wright, a casa Willits de 1901, a casa Barton de 1904, ou a casa Coonley de 1908 são simples volumes não divididos por paredes interiores: todo o apartamento é dum só ambiente, quase sem divisões. O exterior desenvolvese em linhas horizontais, com terraços salientes, telhados pouco inclinados quase planos. As janelas encontram-se nos andares superiores apresentando-se como faixas contínuas na parte alta dos muros. $\mathrm{O}$ jogo das massas acusa a influência da arquitetura do Extremo Oriente.... O cubismo está longe, não só porque estamos em 1901 ou em 1904, mas também porque para definir os elementos figurativos desta construção, devemos referir-nos à visão impressionista, ou mesmo à visão de Cézanne. Wright, pelo sentido íntimo da sua obra e pela ressonância do estilo que influenciou não só os arquitetos americanos, mas os europeus, desde Berlage a Dudok, de Loos a Hoffmann e trave sde Tony Garnier, o próprio Le Corbusier, pode ser considerado o Cézanne da arquitetura nova. Será preciso sublinhar a concordância do plein-air dos impressionistas com o amor pela natureza de Wright que é no campo que realiza as suas obras primas? Vale a pena insistir na influência da arquitetura japonesa em Wright ou do "japonesismo" de um que outro impressionista em Wright? [...] Uma vivenda de Wright, quando estou dentro, faz-me pensar sempre em Elsie, a protagonista duma novela de Sherwood Anderson, The New Englander: 'Elsie corre na vastidão dos campos, cheia dum único desejo. Queria evadir-se da sua vida para entrar nessa vida nova e mais doce que ela pressentia nascer em algum ângulo dos campos'. Eu sei porque a obra de Wright desperta estes pensamentos: o próprio Wright o diz quando, escrevendo sobre arquitetura, faz um apelo à liberdade do espírito humano. Edoardo Persico

O texto de Edoardo Persico, extraído da conferência Profezia in Architettura, pronunciada em 1935, sugere uma resposta às discussões que cercaram a presença do arquiteto norte-americano na exposição The International Style, realizada no MoMA, em 1932: se convidado ou, pelo contrário, ser considerado tão só o "pioneiro" romântico. Afinal, a mostra organizada por Philip Johnson e HenryRussel Hitchcock pretendia "estabelecer um cânon de uma determinada arquitetura cúbica, lisa, de fachadas brancas ou revestida de metal e vidro, e de propostas funcionais e simples" ${ }^{48}$. 
Por fim, como convidado, Frank Lloyd Wright apresenta projetos de uma fase caracterizada por uma redução lingüística. Para Zevi, a maquete House on the Mesa, apresentada na mostra, "prova que ele já está para além do racionalismo" ${ }^{49}$.

No estudo da biografia de Galiano Ciampaglia, dedicar um dos eixos a Frank Lloyd Wright não é um gesto gratuito. Os primeiros sinais recuam ao reduto Beaux-Arts quando "foi salvo" pela edição da Architectural Forum, de 1938 - dedicada ao arquiteto norte-americano - e se deixou envolver pela "casa do homem", às vésperas de se formar. À parte o discurso inflamado, a afinidade de Galiano Ciampaglia com $\mathrm{o}$ arquiteto norte-americano ficaria registrada na "notável biblioteca" ${ }^{50}$ que acumula publicações do mestre, ou sobre ele, até $1995{ }^{51}$, permeadas por edições especiais de periódicos ${ }^{52}$, ensaios ${ }^{53}$ e teses acadêmicas, e que não passaria despercebida de Adriana Irigoyen, em 2004, durante uma entrevista.

No panorama da arquitetura, a Frank Lloyd Wright são atribuídas diferentes posições: radical individualista, distante, determinante para o nascimento do movimento moderno, ou ainda, precursor das "Gerações" ${ }^{54}$ que o legitimaram. Zevi enuncia que, de 1910 até finais dos anos setenta, "assistimos a redescobertas periódicas de Wright intercaladas por períodos de silêncio". A "primeira", talvez "a mais clamorosa" ${ }^{55}$, é a exposição de suas obras em Berlim e a publicação da luxuosa edição Wasmuth (1910-11). Relata Donald W. Hoppen que, chegando em Berlim, Wright foi recebido por jovens arquitetos. Ludwig Mies van der Rohe declarou: "Ele era a personificação de tido - que estávamos buscando, a verdadeira origem da nova arquitetura" ${ }^{56}$.

1932. MOMA HOUSE ONTHEMESA FRANK LLOYDWRIGH THEARCHITECTURAL FORUM, 1938, P. ACERVOGC

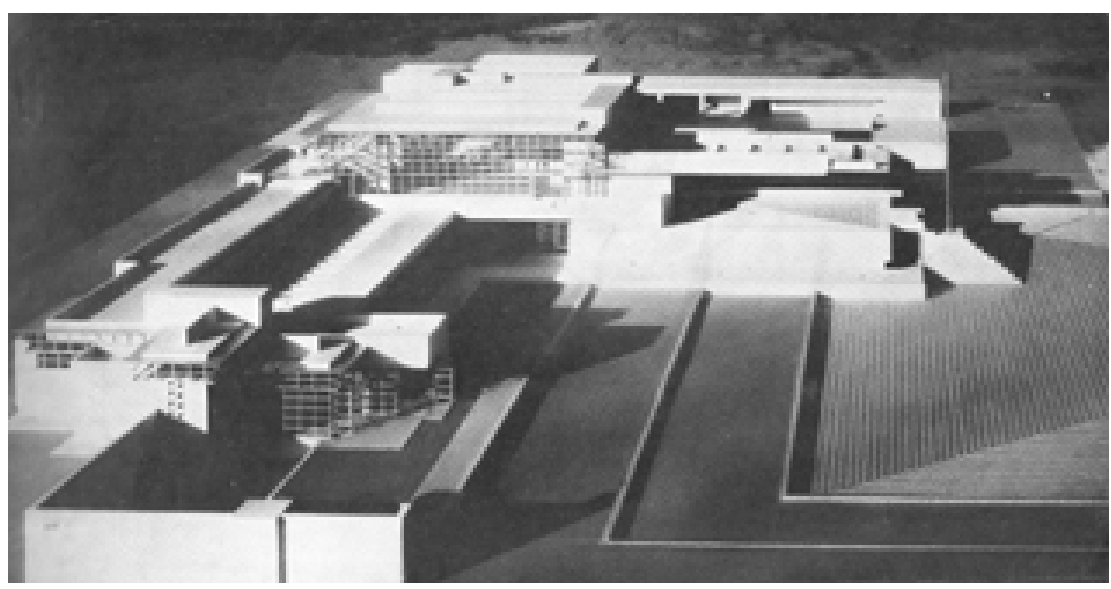




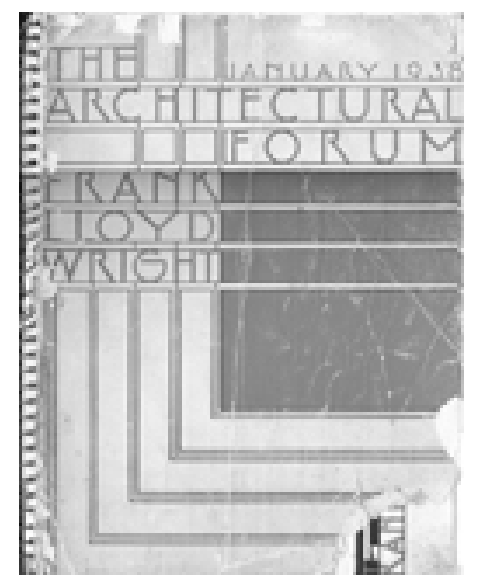

THEARCHITECTURAL FORUM,1938 ACERVOGC
PRINCETON MONOGRAPHS IN ART AND ARCHAEDLOGY

MODERN ARCHITECTURE BEING THE KAHN LECTURES FOR 1930 BY FRANK LLOYD WRIGHT

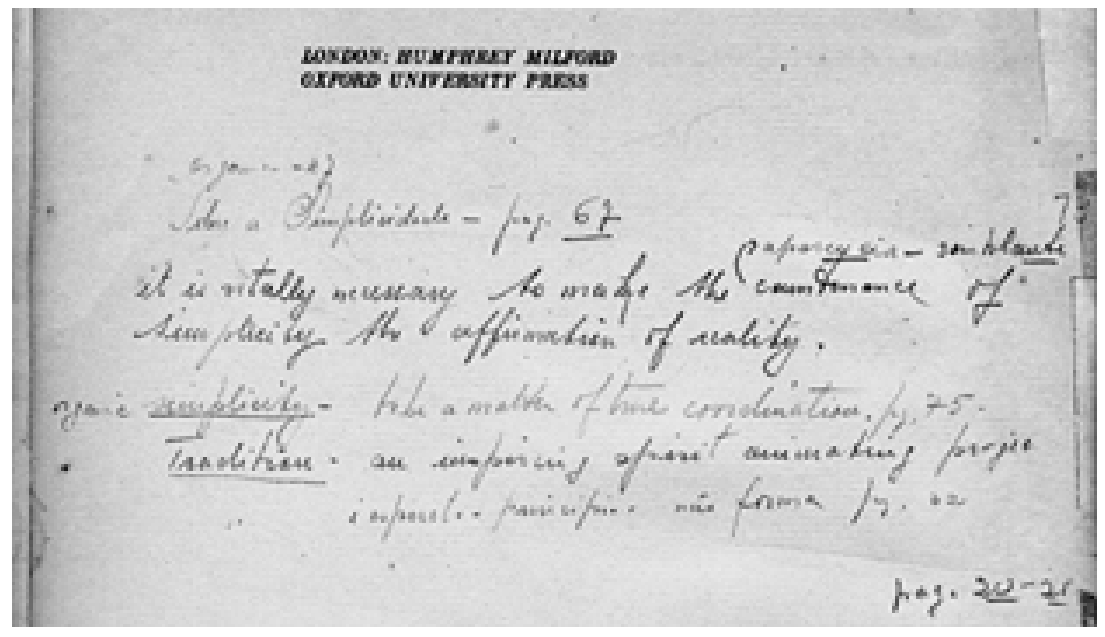

ACIMA: WRIGHT, 1931 ACERVOGC

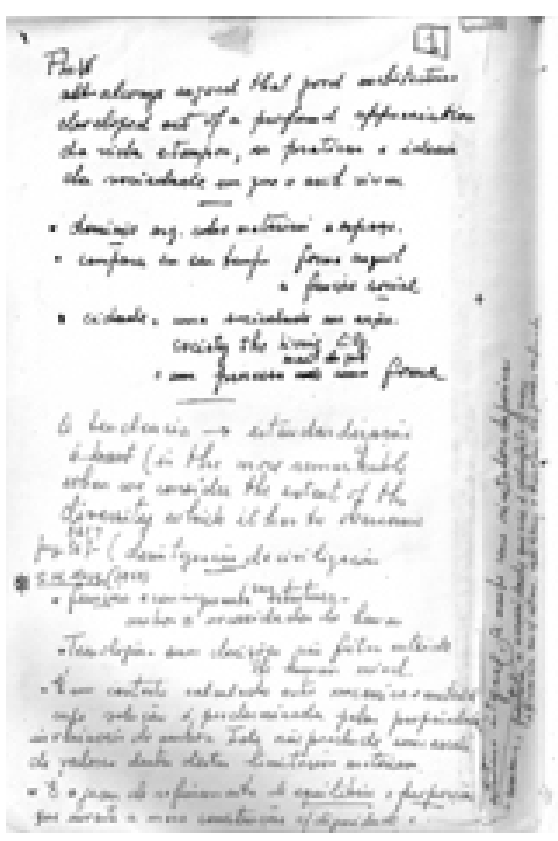




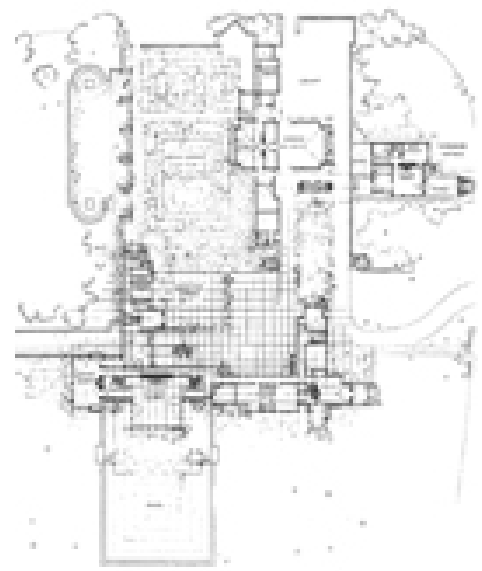

CASA COONLEY. 1908 RRANKLOYDWRIGHT WRIGHT, 1975, P. 157 ACERVOGC

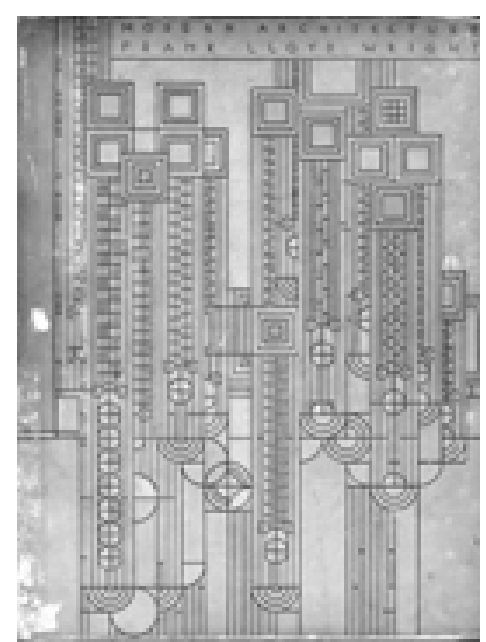

WRIGHT, 1931 ACERVOGC
O ritmo do acervo de Galiano Ciampaglia é sugerido por rubricas. No contexto das anotações, na própria obra ou fora dela, além da cronologia não ser representativa, um caderno reflete a complexidade que é estudar Wright, como reconhecem os seus críticos:

"é difícil encontrar no apaixonado discurso de Wright definições claras, que tenham valor fora do contexto e do tom, e não necessitem de justificativa. Para se fazer justiça, seria necessário percorrer toda a obra de Frank Lloyd Wright, escritor, e excluir o núcleo da sua concepção sobre a vida e a arquitetura, que é na totalidade expressa mais por alusão que por uma clara que é na totalidade expressa mais por alusão que por uma clara exposição. Wright não é um teórico" 57 .

Depois de ouvir falar de Wright na casa de Jacob Ruchti, o primeiro texto do mestre foi lido na biblioteca da escola. Em contraponto à orientação acadêmica, no texto The logic of the plan, a planta surge como "a alma poética de uma construção" e como o julgamento se um arquiteto é mestre ou não. Para Wright, a concepção de uma boa planta deve considerar o método construtivo, a escala, a articulação, a expressão e os materiais. Imagens da casa Coonley sustentam que um plano é orgânico quando o desenvolvimento em todas as direções é inerente, inevitável:

"O edifício não é mais um bloco de materiais de construção para ser tratado artificialmente no exterior como uma escultura. $O$ ambiente interno, o espaço no qual se vive é de fato o edifício [...] o ambiente que deve ser expresso no exterior [...] é o pensamento avançado de uma nova era na arquitetura. Procura uma sua expressão externa para formar uma arquitetura integral" 58 .

Na edição de janeiro da Architectural Forum (1938), questões como o terreno, a sensação de abrigo, a natureza dos materiais, a importância do espaço e da proporção (como um instinto), e o mobiliário integrado, se apresentam como constantes do universo wrightiano. Imagens do Taliesin, da Fallingwater e de unidades Usonian reforçam a "vitalidade da assimetria" diante da qual Frank Lloyd Wright ainda oscilava, na virada do século $19{ }^{59}$.

O primeiro livro do acervo, Modern Architecture. Being the Kahn Lectures, reúne a série de conferências pronunciadas em Princeton, em 1930. Em Machinery, Materials and Men, Wright fala da trindade que constitui o coração da arquitetura enquanto arte - a natureza dos materiais, a terceira dimensão e o ornamento integral. ${ }^{60}$. 


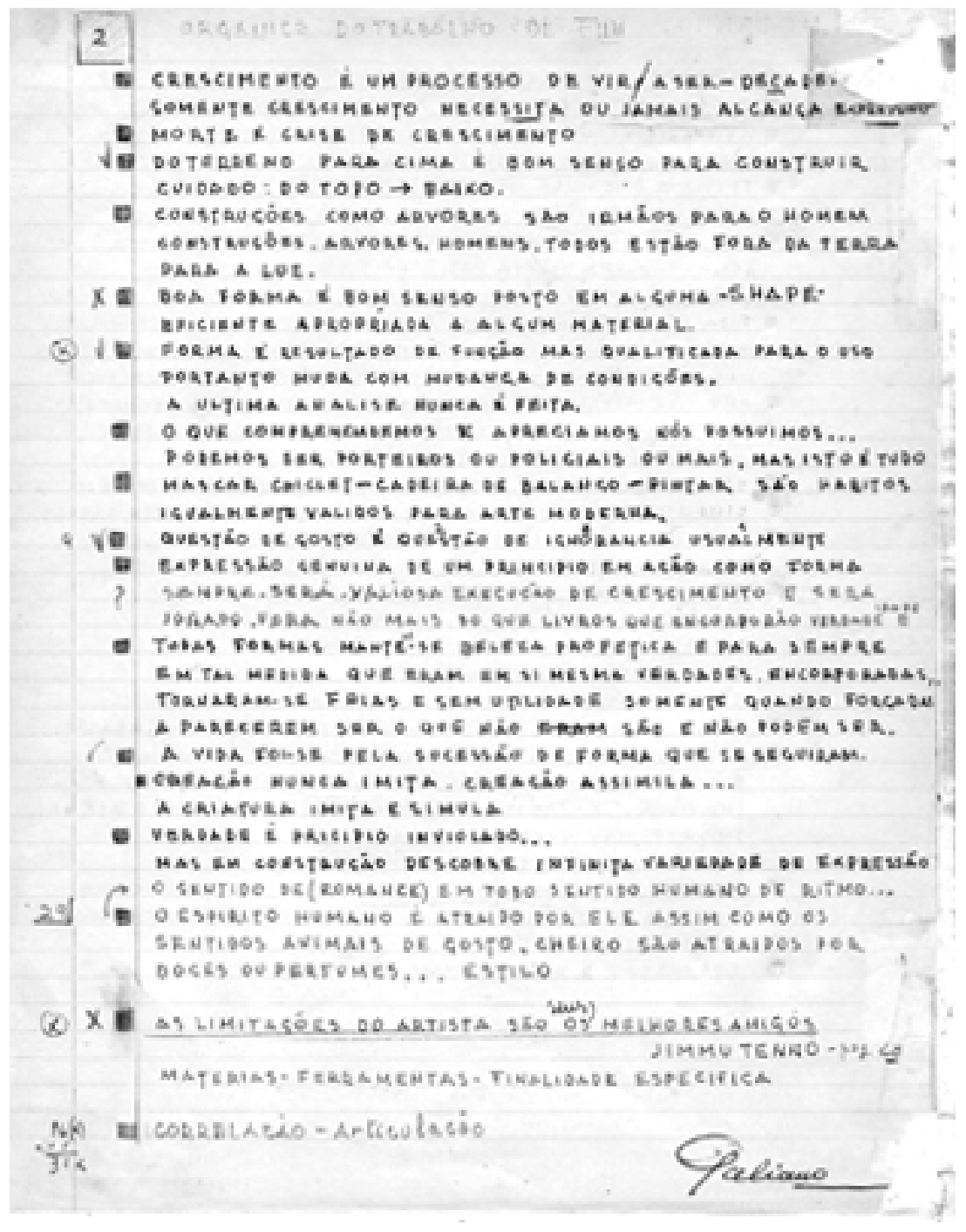

Na conferência Style in Industry, em contraponto ao estilo Beaux-arts, o mestre adota a arte e a cultura japonesa como referência para a eliminação do supérfluo. Na conferência The Carboard House ${ }^{61}$, como antagonista de Le Corbusier, Wright ataca a "machine d'habiter" e, a partir da "casa do homem", formula a base de uma residência moderna em nove pontos:

1. Reduzir ao mínimo as paredes divisórias criando um ambiente circunscrito e articulado de maneira que o ar, a luz e o visual, permeiem o conjunto com um sentido de unidade.

2. Harmonizar o edifício com o ambiente exterior ampliando e acentuando os planos paralelos ao terreno.

3. Eliminar a concepção de ambientes e da casa como "caixas" [...] Dar a casa proporções mais livremente humanas [...] 
4. Levar o "porão insalubre" até a superfície [...] de modo que as fundações apareçam como uma base plana sobre a qual se ergue a construção.

5. Dar a todas as aberturas internas e externas proporções lógicas e humanas $[\ldots]$

6. Usar sempre que possível um único material próprio da natureza, tornado o edifício mais expressivo na sua função.

7. Integrar todas as instalações ao edifício

8. Incorporar o mobiliário como arquitetura orgânica

9. Eliminar o decorador, todas as curvas e a opulência

Recém-saído de um ensino antagônico à formação teórica, Galiano Ciampaglia se defronta com a dificuldade para entender os quarenta conceitos da arquitetura moderna e sente o impacto do conhecimento que envolvia a formação de um arquiteto ${ }^{62}$, sobretudo aquela que identificou em Wright, também reverenciada por seus críticos:

"Entre os pontos críticos determinados pela herética figura wrightiana, revestem em particular relevo [...] a excepcionalidade da formação não só fora do âmbito dos profissionais americanos, mas igualmente longe dos parâmetros típicos da tradição ocidental, oscilante entre o espaço e o tempo, classicismo monumental e romantismo pitoresco" ${ }^{63}$.

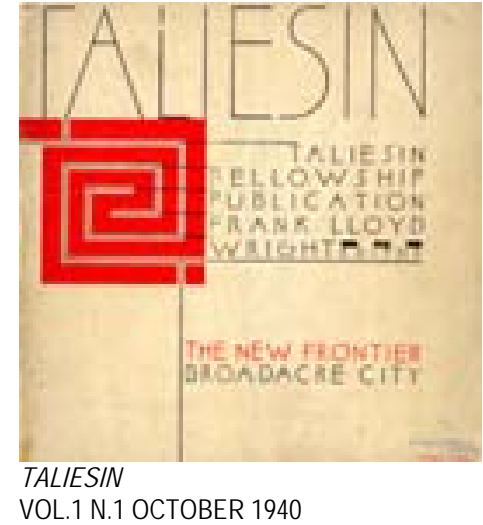

A rotina de correspondências com a escola de Taliesin tem início com a edição do magazine Taliesin ${ }^{64}$, dedicada a Broadacre City. Além de uma conversa com Mies van der Rohe, o verso do periódico relaciona os livros escritos por Frank Lloyd Wright, no período de 1897-1939. A edição de $1941^{65}$ aborda a metodologia de trabalho e de ensino da escola. O mestre incorpora à educação dos aprendizes, música, artesanato e filosofia. Estimula o exercício na perspectiva, no desenho abstrato dos motivos vegetais, nos estudos e, em particular, na natureza dos materiais. Através do método Learning by doing, os aprendizes são preparados para projetar, detalhar e fazer maquetes.

Em 1945, por $\$ 5,00$, Galiano Ciampaglia torna-se assinante do magazine Taliesin. O contato que o mantém a par das atividades da escola, se estende a The Frank Lloyd Wright Foundation, até anos 50 , incluindo convites para eventos em torno do arquiteto norteamericano. 

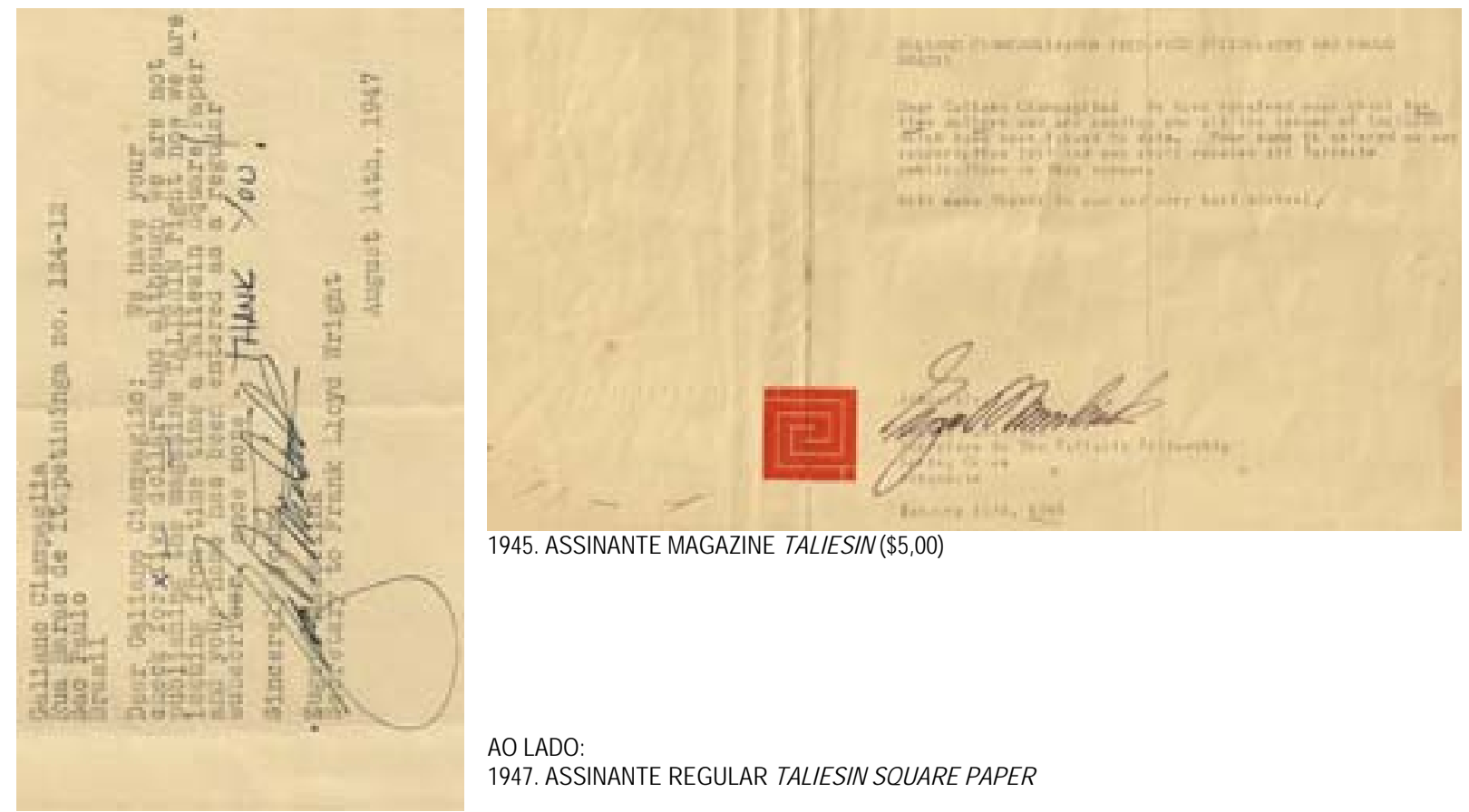

1945. ASSINANTE MAGAZINE TALIESIN $(\$ 5,00)$

AOLADO:

1947. ASSINANTE REGULAR TALIESIN SQUARE PAPER
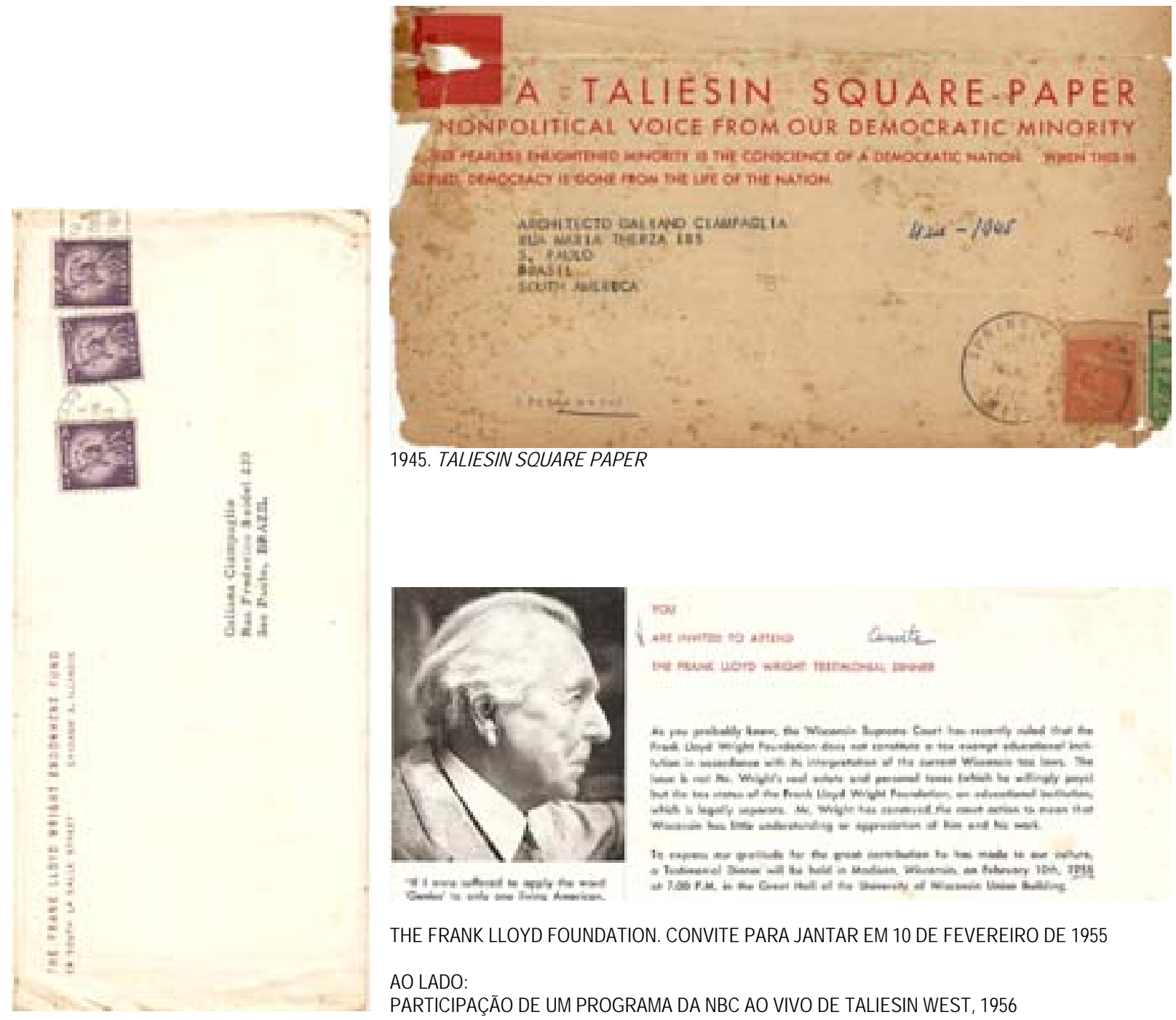

1945. TALIESIN SQUARE PAPER

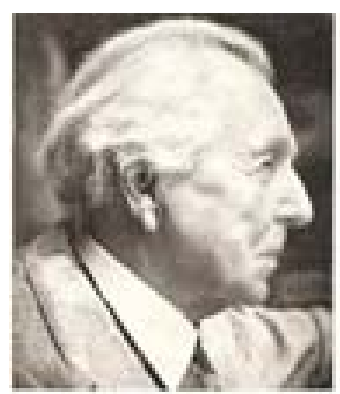

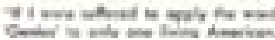

row

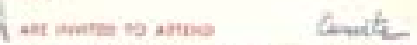

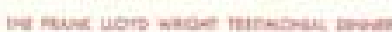

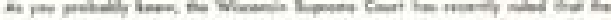

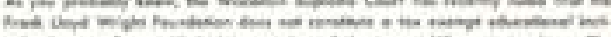
cos Mas

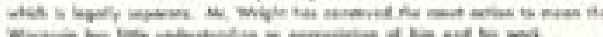

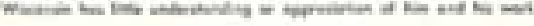

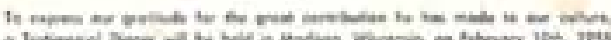

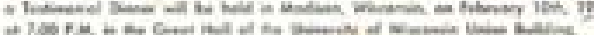

THEFRANK U OYD FOUNDATION COMMTE PARA JANTAREM 10 DE FEVEREIRO DE 1955

AOLADO:

PARTICIPAÇÃO DE UM PROGRAMA DA NBC AO VIVO DE TALIESIN WEST, 1956 


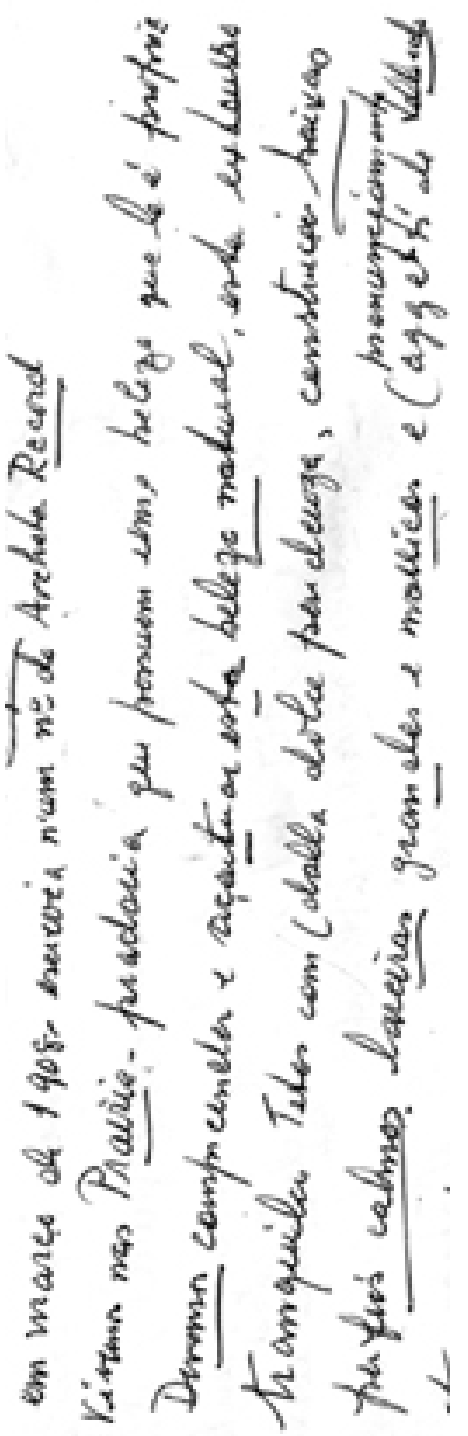

Em 1941 e 1942, a publicação de dois livros culmina com a "quarta" descoberta de Frank Lloyd Wright. É quando Galiano Ciampaglia tem acesso ao universo teórico do mestre através de Frank Lloyd Wright on Architecture: selected wrightings $1894-1940{ }^{66}$. Na coletânea de Frederick Gutheim, o ensaio "1908: In the Cause of Architecture, I", destaca as características para uma arquitetura orgânica:

1. simplicidade

2. tantos estilos de arquitetura quantos estilos de pessoas: [...] "o nosso ideal é a democracia: a mais vasta expressão do individual em um todo harmonioso"

3. o edifício concebido como fato orgânico, como a natureza

4. cores que se harmonizam com as formas naturais: [...] "andem nos bosques e nos campos para encontrar os vossos esquemas de cores"

5. mostrar os materiais pelo que são

6. a casa tem caráter, de tal modo que mostre a sua função distante de toda a moda efêmera ${ }^{67}$

A filosofia Prairie é destacada:

"Devemos compreender e acentuar esta beleza natural, esta extensão tranqüila. Telhados com "una dolce pendenza", construções baixas, perfis calmos, lareiras grandes e maciças, terraços baixos [...] Amava a pradaria, a grande simplicidade" 68 .

In the nature of materials: the buildings of FLLW: $1887-1941^{69}$, de Henry Russel-Hitchcock, é o texto pioneiro para a difusão internacional da obra do arquiteto norte-americano, baseado na retrospectiva The Work of Frank Lloyd Wright organizada pelo Museu de Arte Moderna de Nova York, em 1940. Foi a oportunidade de Hitchcock rever a posição de "romântico" que havia reservado ao arquiteto a Wright, na mostra International Style, em 1932.

Em 1943, Galiano Ciampaglia adquire a reedição de $A n$ Autobiography ${ }^{70}$ que adiciona aos livros Family, Fellowship, Work e Freedom, o livro Form. Neste, Wright detalha o conceito de habitar Usonian. Focado na economia e na simplicidade, o arquiteto propõe a casa térrea, elimina o telhado e o revestimento ou pintura dos materiais. Além do mobiliário, incorpora a iluminação ao edifício. Introduz o carpot em substituição à garagem fechada, o workplace entendido como a integração da cozinha ao ambiente de refeições e ao estar, e a liberação do fundo do lote para os jardins ${ }^{71}$. 
No pós-guerra, Bruno Zevi cria na Itália a APAO (Associação para uma Arquitetura Orgânica) e associa o momento à "quinta" descoberta de Wright.

Em 1945, é publicada a edição italiana Frank Lloyd L. Wright. Architettura Organica ${ }^{72}$ que reproduz a série de conferências pronunciadas em Londres, em 1939. Em uma das palestras, Wright remonta ao livro The Book of Tea e ao princípio da arquitetura orgânica: "foi Lao-Tse, cinco séculos antes de Cristo, o primeiro a declarar, pelo que me consta, que a realidade de uma construção não consiste nas quatro paredes e no teto, mas no espaço que deles resulta e no qual se vive" ${ }^{73}$ :

"Os taoistas acreditavam que a comédia da vida poderia ser infinitamente mais interessante se cada um olhasse o senso da unidade. Segundo eles, dar a devida proporção às coisas e se colocar no lugar dos outros sem perder o seu, este é o segredo do sucesso no drama da vida. Para jogar bem nosso jogo, é necessário que conheçamos todas as peças; a concepção da totalidade não deve jamais se perder naquela da individualidade. E Laotsé o demonstra através da sua metáfora favorita do vazio. É no vazio, pretende ele, que reside o que é verdadeiramente essencial. Se encontrará, por exemplo, a realidade de uma sala no espaço livre formado pelo teto e pelas paredes, não no próprio teto e nas paredes" 74.
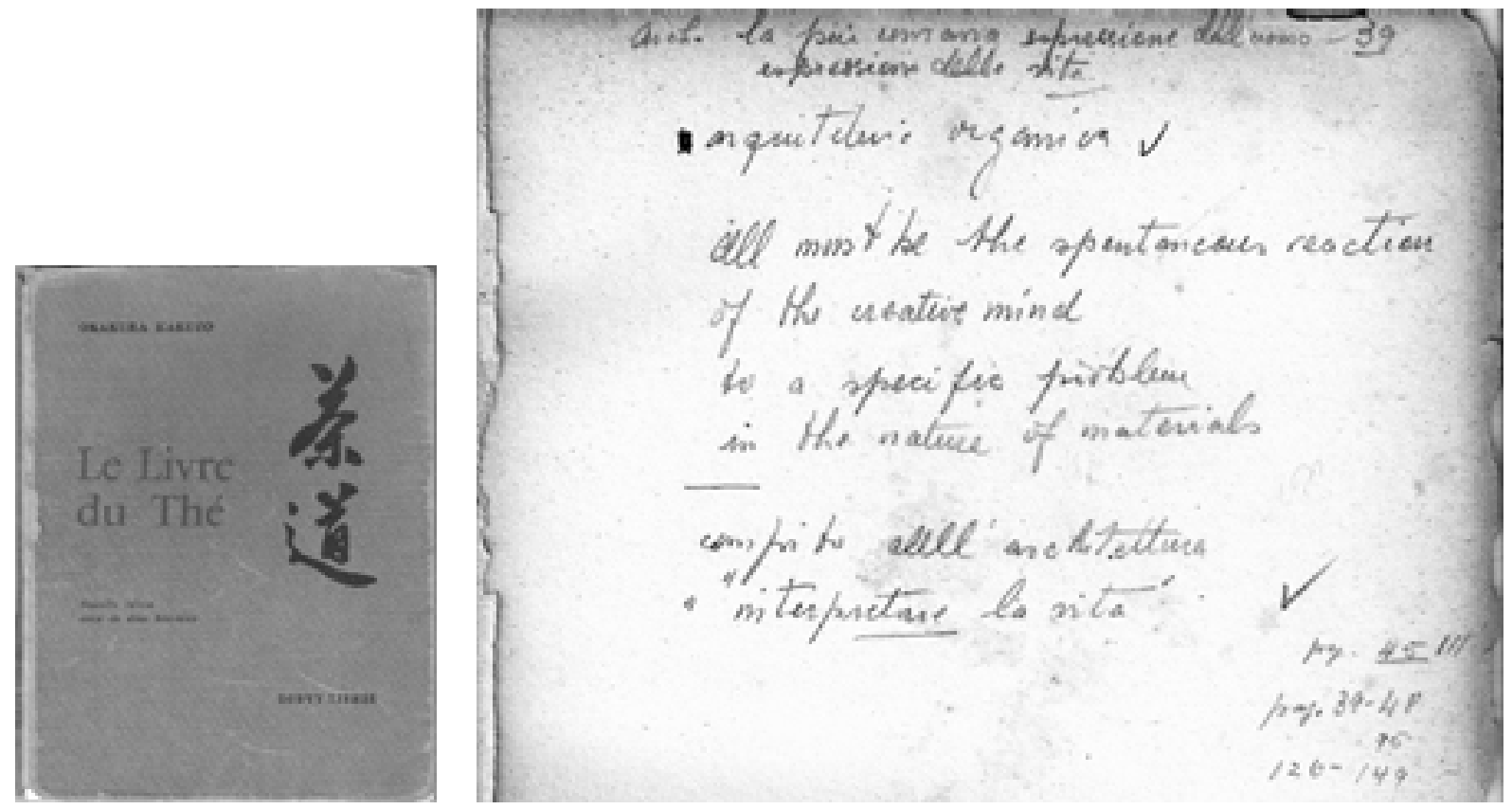
Architecture and Modern Life ${ }^{75}$, escrita por Frank Lloyd Wright e o sociólogo Baker Brownell, em 1937, é recuperada em 1946. Segundo Lewis Munford, a obra discute as idéias fundamentais de Wright, seus motivos e propósitos ${ }^{76}$. São estabelecidos os cinco pontos da integração arquitetura - vida moderna ${ }^{77}$ :

1. a arquitetura aparecerá como economia [...] Nada está presente que não Ihe contribua.

2. a arquitetura tem a honestidade. Tijolo é tijolo, parece e serve como ele é.

3. a arquitetura é funcional. Suas partes são reveladas e expressas.

4. a arquitetura é orgânica. Forma e função são uma só [...] Tem, por certo, individualidade.

5. a arquitetura tem alguma beleza inerente à sua estrutura e a magia da expressão [...] Ela tem um significado, e esse significado tem o semblante da verdade.

A edição de janeiro de The Architectural Forum, de 1948, cuja essência é dirigida às unidades Usonian, marca os dez anos da primeira publicação do periódico, dedicada ao arquiteto norteamericano.

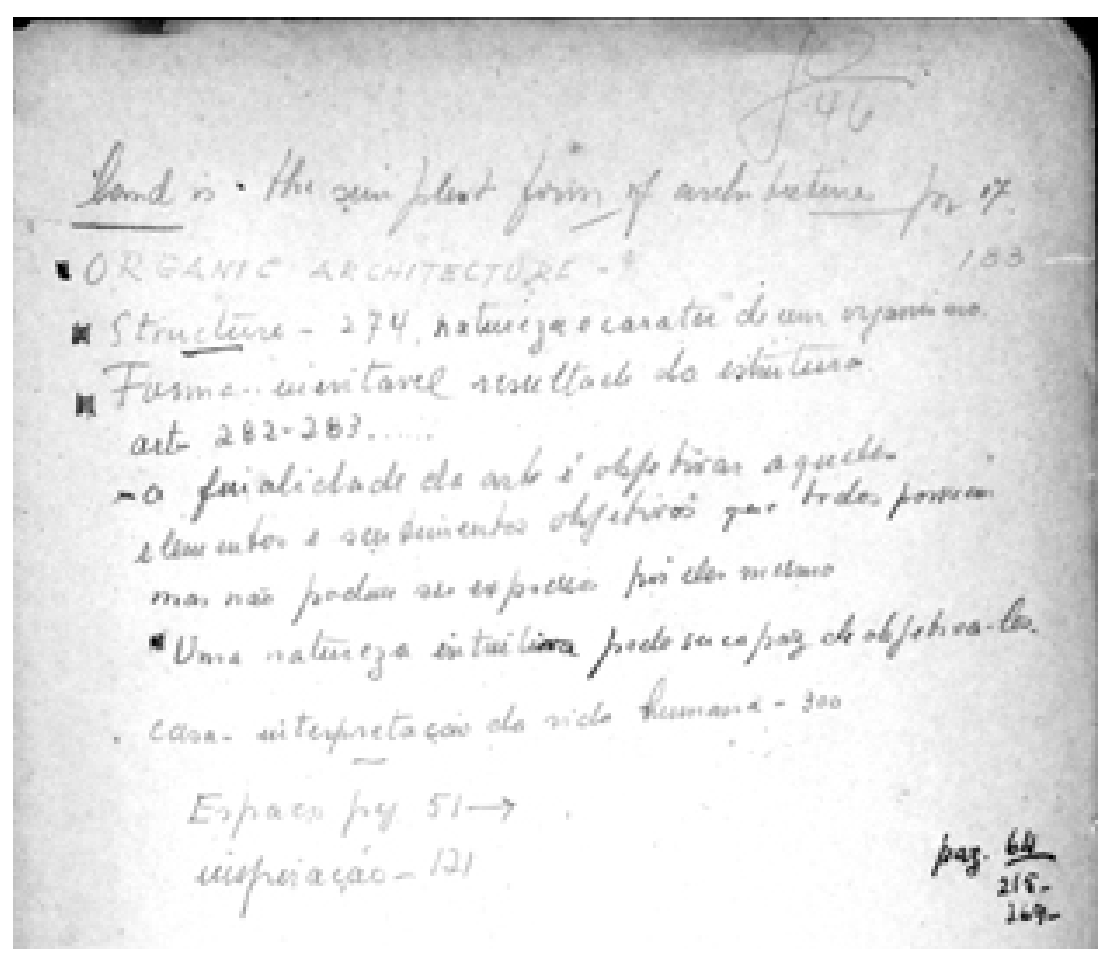


Genius and Mobocracy ${ }^{78}$, rubricada em 1950, é referência teórica para a análise da casa e da vida suburbanas nos Estados Unidos ${ }^{79}$.

Como parte dos momentos relevantes da cultura wrightiana, na Itália, em 1951, Frank Lloyd Wright recebe o diploma honoris causa do Instituto universitário de arquitetura, em Veneza. Em Florença, onde é nomeado cidadão honorário, é realizada uma exposição de suas obras, no palácio Strozzi. A mostra é registrada na revista Casabella.

Os "nove pontos necessários" à redefinição da linguagem orgânica publicados em L' avenir de l'architecture (1966) ${ }^{80}$ estão preservados na edição de Architecture de Lumière que reproduz a célebre entrevista de Wright, concedida a Hugh Downs (NBC), em 1953:

1. Natureza [...] Princípio inerente.

2. Orgânico [...] Intrínseco

3. A forma segue a função é insignificante [...] "Forma e função são uma" é significante.

4. A arquitetura orgânica vê a realidade como o romance intrínseco da criação humana.

5. A tradição deve ter muitas tradições assim como a verdade deve ter muitas verdades.

6. Ornamento é para a arquitetura o que a florescência de uma árvore é para a sua estrutura. Da coisa, não na coisa.

7. O espírito cresce de dentro para cima e para fora.

8. A terceira dimensão não é densidade, mas profundidade.

9. Espaço é o contínuo transformar-se ${ }^{81}$.

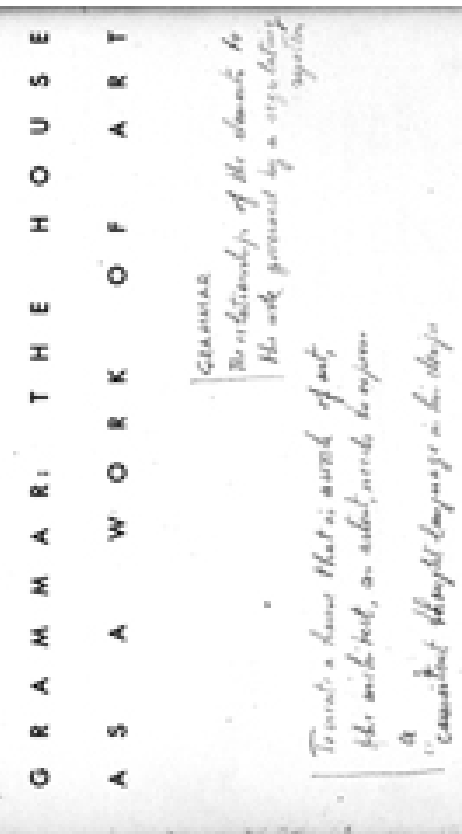

Em 1954, é publicada The Natural House ${ }^{82}$. Wright aborda desde a economia e o bem estar do indivíduo até o processo construtivo das unidades Usonian. A obra retoma o universo orgânico da plasticidade, do ornamento integrado e da natureza dos materiais como filosofia da simplicidade. Sobre esta, Wright esclarece o conceito-chave da simplicidade na arquitetura orgânica:

"Uma das características essenciais da arquitetura orgânica é a simplicidade natural [...] Simplicidade é uma expressão direta, clara desta qualidade essencial da coisa que está na natureza, da coisa em si. O padrão inato ou orgânico da forma de qualquer coisa é esta forma que é, portanto, verdadeiramente simples [...]" ${ }^{83}$. 


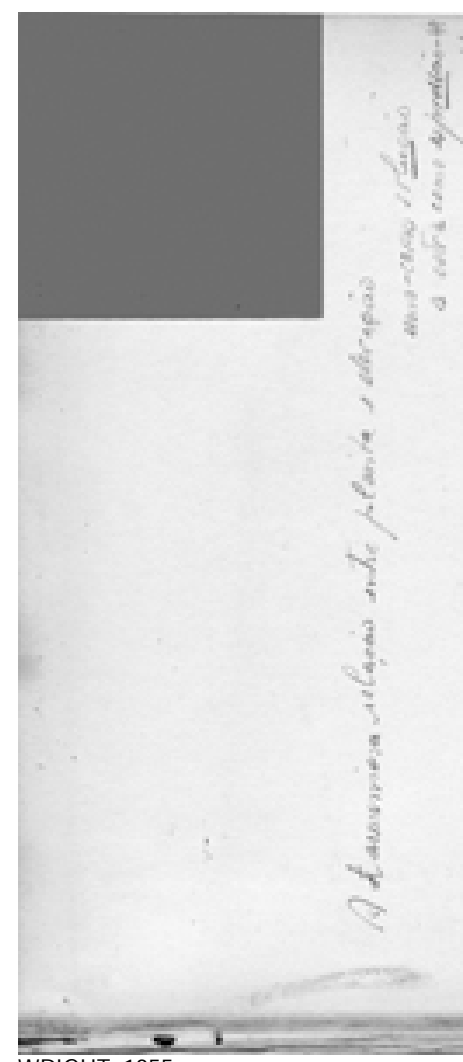

WRIGHT, 1955 ANOTACÔESGC ACERVOGC
An American Architecture (1955) ${ }^{84}$, retoma conceitos orgânicos como a importância do espaço interno, a terceira dimensão, a continuidade, o ornamento orgânico integral, a padronização, a relação unidade-todo. Detalha "a destruição da caixa". Wright estabelece "uma relação harmoniosa entre planta e elevação dos edifícios, considerando uma como a solução e a outra como a expressão que cada problema representa no todo que é um projeto" 85 .

The Story of the Tower (1956) ${ }^{86}$, enfoca o conceito do arranha-céu orgânico de Wright. A respeito da abordagem altamente tectônica de Wright, Frampton considera que "orgânico" passou a significar o uso de balanços em concreto como se tratasse da forma natural, de algo semelhante a uma árvore ${ }^{87}$.

A Testament (1957) ${ }^{88}$ é organizado em dois livros: Autobiographical e The New Architecture. Para Wright "a beleza é sempre conseqüência de uma plenitude natural: expressão intrínseca. Excesso nunca deve ser confundido com exuberância" ${ }^{89}$.

Em 1958, é publicada The Living City. Frampton analisa que na obra, Wright retoma a busca cultural contínua que marcou sua carreira - o uso da máquina sem deixar-se brutalizar ${ }^{90}$ :

"A arquitetura orgânica tem demonstrado que uma rigorosa estandardização mecânica não deve necessariamente ser um impedimento a uma liberdade de expressão pessoal [...] se nós entendemos por "expressão pessoal”, o fruto de uma personalidade autêntica e não um estilo estéril - ou clichê [...] usar a máquina sim, mas apenas nos limites e propósitos humanos [...] esta é a arquitetura orgânica e esta é Broadacre City" ${ }^{91}$.

Em 1959, a morte de Wright provoca uma série de publicações sobre o arquiteto. A Associação dos Arquitetos Americanos (AIA), de Michigan, publica um boletim com as realizações locais. De Olgiwanna Lloyd Wright, são publicados Our House ${ }^{92}$, The Shinning Brown ${ }^{93}$ e Frank Lloyd Wright: his life, his work, his word ${ }^{94}$. Em 1960 é publicado, Writings and buildings ${ }^{95}$, a importante coletânea de Edgar Kaufmann. Architecture. Man in Possession of his earth ${ }^{96}$, é biografado por Iwanna Lloyd Wright. Os anos sessenta são marcados por ensaios sobre Wright na revista L'architettura. Cronache e storia, dirigida por Bruno Zevi. Surgem também os primeiros estudos sobre o arquiteto norte-americano. 
Em 1966 é publicado Frank Lloyd Wright: a study in architectural content ${ }^{97}$. Na obra, Norris Kelly Smith se compromete a interpretar a arquitetura de Wright a partir de dois ideais opostos: nas residências, ele buscou expressar o eterno anseio do homem pela liberdade e harmonia individual com a natureza, enquanto que nos edifícios públicos, ele buscou expressar o desejo do homem para a coletividade da sociedade organizada.

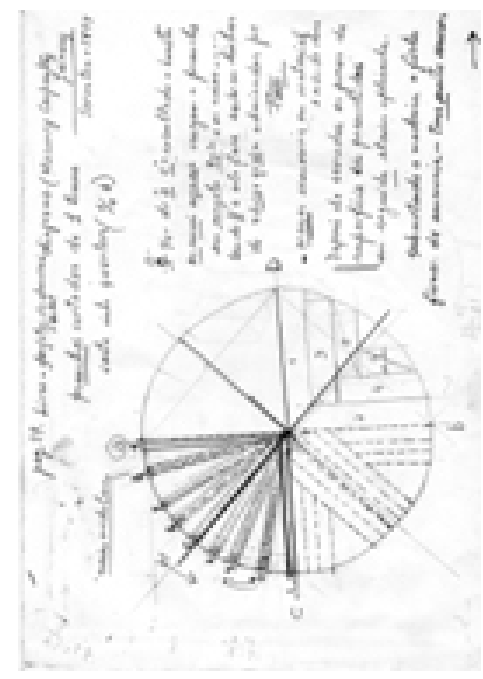

ANOTAÇÕES (HANKS, 1979) ACERVOGC
Em 1974, é publicado Le matrici di una architettura orgânica ${ }^{98}$, de Fabrizio Brunetti. $\mathrm{O}$ autor intenta preencher uma lacuna acerca dos motivos da formação da linguagem arquitetônica wrightiana. Em 1975, In the cause of Architecture ${ }^{99}$, retoma os artigos de Frank Lloyd Wright, publicados na revista Architectural Record, entre 1908 e 1928. Em 1976, é publicado o estudo Frank Lloyd Wright's Usonian Houses. The case for Organic Architecture ${ }^{100}$, de John Sergeant. $O$ autor discute a concepção inovadora do projeto das casas e da sua construção, até a implantação das mesmas em Broadacre City. Em 1978, é publicado o estudo Pensiero Organico e Architettura Wrightiana ${ }^{101}$, de Edward Frank, autor que desde 1969 se dedica a exaustivas pesquisas sobre Wright, publicadas na revista L'architettura. Cronache e storia. Em 1979, The Decorative Designs of Frank Lloyd Wright ${ }^{102}$, de David A. Hanks, é voltado à coesão de detalhes que Wright imprimia aos elementos de seus projetos como um todo: mobiliário, cortinas, tapetes, vitrais, luminárias, vasos, etc. Segue-se, Apprendice to Genius. Years with Frank Lloyd Wright ${ }^{103}$, de Edgar Taffel.

Em 1983, é publicado Man about town. Frank Lloyd Wright in New York City ${ }^{104}$, de Herbert Muschamp. O autor tenta explicar a forma particular de expressão alcançada por Wright nos edifícios, desenhos e escritos provenientes de sua ligação com Nova York. Dos anos 80 e 90. identificam-se: Writings on Wright ${ }^{105} \mathrm{e}$ In the realm of ideas ${ }^{106}$; His Living Voice ${ }^{107}$; Frank Lloyd Wright ${ }^{108}$ (Benedikt Taschen). O acervo acumula publicações sobre interiores, detalhes e design: Frank Lloyd Wright: Interiors and furniture ${ }^{109}$; Details of Frank Lloyd Wright ${ }^{110}$; Frank Lloyd Wright Design ${ }^{111}$. Sobre desenhos, o acervo preserva: Taliesin Drawings ${ }^{112}$; Drawings for a living architecture ${ }^{113}$; Drawings and Plans of Frank Lloyd Wright. The early period (18931909) ${ }^{114}$. 
Como um estudioso, Galiano Ciampaglia esteve atento às vertentes da formação de Frank Lloyd Wright, como Louis Sullivan ${ }^{115}$, o teórico John Ruskin ${ }^{116}$ e a arquitetura gótica, reconhecida por Wright, "[...] a mais verdadeira arquitetura orgânica - onde forma, estrutura e ornamento integral são uma só" ${ }^{117}$. A partir dos anos 40 , o acervo reflete $o$ interesse pela arte e a cultura japonesa ${ }^{118}$.
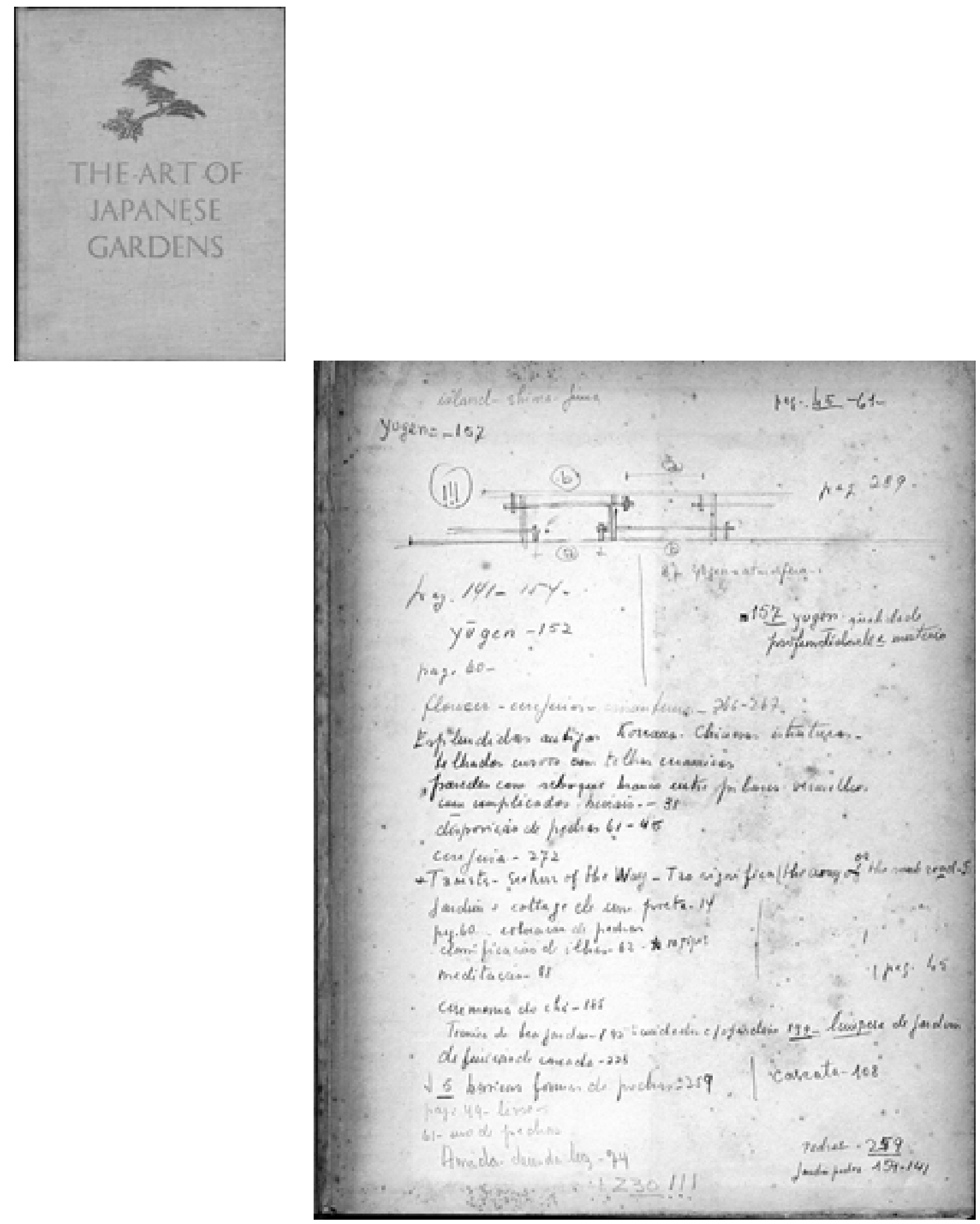
${ }^{1}$ LEMOS, 1993, p. 43

2 Op. Cit. p. 21

${ }^{3}$ Op. Cit. p.43

${ }^{4}$ Op. Cit. p. 52

${ }^{5}$ LEMOS, 1994, p. 93

${ }^{6}$ BELLUZZO, 1988, p. 127

${ }^{7}$ Desde 1886, com escritório pessoal, em 1907, Ramos estrutura o "Escritório Técnico F.P. Ramos de Azevedo" em sociedade com Ricardo Severo. O engenheiro nascido em Lisboa é autor da conferência "A Arte Tradicional no Brasil", proferida em 1914, na Escola Politécnica, que preconizava a manifestação de nacionalidade a partir da valorização da arte tradicional e culminaria no movimento conhecido como "neocolonial". O tema é tratado em SEGAWA (2002, p. 35-39)

${ }^{8}$ BELLUZZO, Op. Cit. p. 116

${ }^{9}$ A relação intrínseca do escritório de Ramos com o Liceu é tratada por Ana Maria de Moraes Belluzzo no estudo Artesanato, arte e indústria. Fau-usp, 1988.

${ }^{10}$ BELLUZZO, Op. Cit. p. 236

11 DI TULLIO, Mario. Scalpellini e Stucatori di Pescopenataro. Archivio di Stato di Campobasso con nota n. 2118/IX, 1 del marzo 2003, p. 74-75

${ }^{12}$ LEMOS, 1993, p. 53

${ }^{13}$ Op. Cit. p. 109

${ }^{14}$ Entrevista de Galiano Ciampaglia ao IAB-SP, em 2003 (ANEXO 1 deste)

${ }^{15}$ LEMOS, Op. Cit. p. 50

${ }^{16}$ Decreto Federal n. 19.402 de 14 de novembro de 1930

${ }^{17}$ Decreto Federal n. 19.850 de 11 de abril de 1931

${ }^{18}$ Decreto n. 23.569, de 11 de dezembro de 1933

${ }^{19}$ ANUARIO EEM 1934, p. 104

20 Pela Lei n. 4.659-A/23 de 19 de janeiro de 1923, promulgada pelo Congresso Nacional, a escola é equiparada às Instituições Federais.

${ }^{21}$ MENDES, 1999, p. 91

${ }^{22}$ CAMARGO, 2000, p. 73

${ }^{23}$ STOCKLER e BREIA, 2005, p. 152

${ }^{24}$ FICHER, 2005, p. 242

${ }^{25}$ Op. Cit. p. 6-7

${ }^{26}$ Op. Cit. p. 138

${ }^{27}$ STOCKLER e BREIA, Op. Cit. p. 121

${ }^{28}$ DAS NEVES, 1931 , p. 3-5

${ }^{29}$ COSTA, 2007 in "Considerações sobre o ensino da arquitetura" (1945), p. 112-116

${ }^{30}$ Entrevista de Galiano Ciampaglia ao IAB-SP, em 2003 (ANEXO 1 deste)

31 CORRESPONDÊNCIA, ano 1947, v. 13-16, p. 190. Documento de Arquivo EEM trazido à luz pelo Professor Marcel Mendes em 2007 por ocasião de um ensaio ainda não publicado e disponibilizado à autora.

32 Depoimento de Jorge Wilheim a MATERA (2005, p. 25)

33 in Arquitetura e Desenvolvimento 1979, p. 27-29.

${ }^{34}$ IRIGOYEN, 2005, p. 101-102

${ }^{35}$ WRIGHT, 1943, p. 516

${ }^{36}$ Realizado pela autora em 2009

${ }^{37}$ FICHER, Op. Cit. p. 240 e 243

${ }^{38}$ ARTIGAS, 1999, p. 45 
${ }^{39}$ FICHER, Op. Cit. p. 253

${ }^{40}$ Decreto n. 2.796, de 28 de junho de 1938,

${ }^{41}$ De acordo com o ANUÁRIO EEM 1938 (p. 81), a diretoria da Escola de Engenharia Mackenzie estuda os dizeres e formato "para fixar definitivamente o tipo de diploma a ser conferido aos engenheiros e arquitetos". Depois de seguidas referências à "Colação de Grau dos Engenheirandos", nos anuários anteriores, o ANUÁRIO EEM 1939 se refere à "Colação de Gráu dos Engenheiros e Arquitetos" (p. 53)

${ }^{42}$ ANUÁRIO EEM 1939, p. 53

${ }^{43}$ De acordo com o Registro de Diplomas - arquivo EEM

${ }^{44}$ Boletim IAB, n. 26, entrevista

45 CIAMPAGLIA, Fernanda. A primeira turma de arquitetos mackenzistas. www.vitruvius.com.br/revistas/read/drops/10.01/3422>

${ }^{46}$ MENDES, Marcel. O curso de engenheiros-arquitetos do Mackenzie e a figura de seu criador, Christiano Stockler das Neves (1917-1947), XXXX, p. 20-21 / não publicado.

${ }^{47}$ FICHER, Op. Cit. p. 17

${ }^{48}$ MONTANER, 2001, p. 13

${ }^{49}$ ZEVI, 1985, p. 143

${ }^{50}$ IRIGOYEN, 2005, p. 102

${ }^{51}$ COSTANTINO, Maria. Frank Lloyd Wright Design. London: Bison Books, 1995

52 The Architectural Forum, January 1938, January 1948 e January 1951, Jahre Lebendige Architektur, 1952, Forma e Colore. n. 65. Sadea Editori, 1965, Global Architecture. A.D.A. Edita, Tokyo Co. Ltd., 1973 e Global Interior. A.D.A. Edita Tokyo Co. Ltd., Japan, 1977

${ }^{53}$ Entre estes, destacam-se aqueles publicados nos anos 50, na House Beautiful, e nos anos 60, na revista romana L'Architettura. Cronache e storia de Bruno Zevi.

${ }^{54}$ Segundo Montaner, as "Gerações" do movimento moderno são quatro. Wright, com Bruno Taut e outros, as precedem (2001, p. 36).

${ }^{55}$ ZEVI, Op. Cit. p. 11.

${ }^{56}$ HOPPEN, 1993, p. 37

${ }^{57}$ ZEVI, 1945, p. 100 (tradução da autora)

${ }^{58} \mathrm{O}$ texto disponível na biblioteca da escola foi publicado na edição de janeiro de 1928 da revista Architectural Record que, em 1927, retoma os ensaios de Wright já divulgados em 1908 e 1914 sob o título "In the cause of Architecture". As citações foram extraídas da publicação In the cause of architecture. Gutheim-Architectural Record, USA, 1973, p. 153-156

59 Frampton analisa que "na virada do século 19, Wright ainda oscilava entre a autoridade da ordem clássica e a vitalidade da assimetria" (2001, p. 61)

60 ZEVI, 1985, p. 17

${ }^{61}$ WRIGHT, 1931, p.65-80

${ }^{62}$ Entrevista de Galiano Ciampaglia, IAB-SP, 2003 (ANEXO)

${ }^{63}$ ZEVI, OP. Cit. p. 9

${ }^{64}$ Taliesin Fellowship, vol 1. n. 1, October 1940 (Editor Frank Lloyd Wright)

${ }^{65}$ Taliesin Fellowship, vol 1. n. 2, February 1941 (Editor Frank Lloyd Wright).

${ }^{66}$ WRIGHT, Frank Lloyd Wright. Frank Lloyd Wright on Architecture: Selected Writings, 1894-1940. Edited by Frederick Gutheim. New York: Duell, Sloan and Pearce, 1941 (rubricado em 41)

${ }^{67}$ Op. Cit. p. 33-34

${ }^{68}$ Ibidem. O texto é reproduzido de anotações do arquiteto, inclusive o itálico 
69 HITCHCOCK, Henry-Russel. In the nature of materials. New York: Duel, Sloan and Pearce, 1942 (rub 1942)

${ }^{70}$ WRIGHT, Frank Lloyd. An Autobiography. New York: Duell, Sloan and Pearce, 1943 (rub 43)

${ }^{71}$ Op. Cit. p. $489-493$

72 WRIGHT, Frank Lloyd. Architettura organica. Muggiani Tipografo- Editore Milano, 1945

${ }^{73}$ Op. Cit. p. 27

${ }^{74}$ KAKUZO, 1969 p. $52-53$

${ }^{75}$ BROWNELL, Baker e WRIGHT, Frank Lloyd. Architecture and Modern Life. Harper \& Brothers Publishers, New York and London, 1938 - 3a edição (rub 46).

${ }^{76}$ MUNFORD, 1938, p. 551

${ }^{77}$ BROWNELL, Baker e WRIGHT, Frank Lloyd, Op. Cit. p. 14-5

${ }^{78}$ WRIGHT. Genius and Mobocracy. New York: Duell, Sloan and Pearce, 1949

${ }^{79}$ IRIGOYEN, Op.Cit. p. 22

${ }^{80}$ WRIGHT, Frank Lloyd. L'avenir de l'architecture. Horizon Press, New York, 1966

81 LES 9 MOTS NÉCESSAIRES "Definitions de F.L.W", IN: Architecture de Lumière, n. $11 \mathrm{~s} /$ data, p. 12.

${ }^{82}$ WRIGHT, Frank Lloyd. The natural House. New York: Horizon Press, 1954

${ }^{83}$ Op. Cit. p. 187

${ }^{84}$ WRIGHT, Frank Lloyd. An American architecture. New York: Horizon Press, 1955

${ }^{85} \mathrm{Op}$. Cit. Folha de rosto. Os grifos são do arquiteto

${ }^{86}$ WRIGHT, Frank Lloyd. The Story of the Tower. New York: Horizon Press, 1956

${ }^{87}$ FRAMPTON, 2000, p. 227

${ }^{88}$ WRIGHT, Frank Lloyd. A Testament. New York: Horizon Press, 1957

89 Op. Cit. p. 16

${ }^{90}$ FRAMPTON, 2000, p. 230

${ }^{91}$ WRIGHT, 1958, p.86-7 (Itálico de Galiano Ciampaglia)

${ }^{92}$ WRIGHT, Olgiwanna Lloyd. Our House. Horizon Press, N.Y, 1959

${ }^{93}$ WRIGHT, Olgivanna Lloyd.The Shinning Brown, 1960

${ }^{94}$ WRIGHT, Olgiwanna Lloyd. Frank Lloyd Wright, his life, his work, his words. Horizon Press, 1966

${ }^{95}$ WRIGHT, Frank Lloyd. Frank Lloyd Wright: Writings and buildings (organizado por Edgar Kaufmann e Ben Raeburn) Nova York: Horizon Press, 1960

${ }^{96}$ WRIGHT, Frank Lloyd. Architecture. Man in Possession of his earth. Doubleday \& Company, Inc., Garden City, New York, 1962

${ }^{97}$ SMITH, Norris Kelly. FLW, a study in architectural content. Prentice-Hall, Inc, New York, 1966

${ }^{98}$ BRUNETTI, Fabrizio. Le matrici di uma architettura organica. Teorema Edizioni. Firenze, 1974

${ }^{99}$ WRIGHT, Frank Lloyd. In the cause of architecture. Architectural Record Books, 1975 100 SERGEANT, John. Frank Lloyd Wright 's Usonian Houses. The case for Organic Architecture. Whitney Library of Design, New York, 1976

101 FRANK, Edward. Pensiero Organico e Architettura Wrightiana. Dedalo Libri, Bari, 1978

102 HANKS, David A. The Decorative Designs of FLLW. E.P. Dutton, N.Y., 1979

${ }^{103}$ TAFEL, Edgar. Apprendice to Genius. Years with Frank Lloyd Wright. McGraw Hill Book Company, 1979 
${ }^{104}$ MUSCHAMP, Herbert. Man about town. Frank Lloyd Wright in New York City. The MIT Press, Massachusetts Institute of Technology , Cambridge, Massachusetts, 1983 105 BROOKS, Harold Allen. Writings on Wright: Selected Comment on Frank Lloyd Wright. London: The MIT Press, 1985.

${ }^{106}$ PFEIFFER, B. Brooks and NORDLAND, G. Frank Lloyd Wright. In the realm of ideas. Southern Illinois University Press, 1988

107 PFEIFFER, B. Brooks. Frank Lloyd Wright. His living Voice. The Press at California State University, Fresno, 1987

${ }^{108}$ PFEIFFER, Bruce Brooks. Frank Lloyd Wright. Benedikt Taschen Verlag GmbH, 1993 ${ }^{109}$ HEINZ, Thomas A. FLLW- Interiors and furniture. Academy Editions - Ernst \& Sohn, 1994

110 WRIGHT, Frank Lloyd. Details of Frank Lloyd Wright. Thames and Hudson Ltd, London, 1994

${ }^{111}$ COSTANTINO, Maria. Frank Lloyd Wright Design. London: Bison Books, 1995

112 WRIGHT, Frank Lloyd. Taliesin Drawings. Wittenborn, Schultz, Inc, 1952

${ }^{113}$ WRIGHT, Frank Lloyd. Drawings for a living architecture. The Bear Foundation inc. and Edgar J. Kauffmann C. Foundation by Horizon Press New York, 1959

114 WRIGHT, Frank Lloyd. Drawings and Plans of FLW / The early period (1893-1909). Dover Publications, Inc, New York, 1983

115 Sobre Sullivan, o acervo preserva: Frank Lloyd Wright on Louis Sullivan, in Architectural Forum, August, 1949, p. 94-97; DUNCAN, Hugh Dalziel. Attualità di Louis Sullivan. In: Casabella, N. 204, febraio-marzo 1954 p. 7-31; EATON, Leonard K. Louis Sullivan an Hendrik Berlage. In: Progressive Architecture, November 1956, p. 138-141, 202-204-210-216-220-222-226-230-234; Drawings by Louis Sullivan. In: Architectural Record March 1966 p. 147-154

${ }^{116}$ Sobre Ruskin, o acervo preserva: RUSKIN, John. The Venice Stones, 18...; La Biblia d'Amiens. Milano: Valentino Bompiani \$ Co., 1946. Sobre William Morris, fundador do movimento Arts and Crafts, sob inspiração de Ruskin, Ciampaglia conserva: DE CARLO, Giancarlo. William Morris. Buenos Aires: Ediciones Infinito, 1955; MORRIS, William. Architettura e Socialismo. Editore Laterza, Bari, 1963.

117 HOPPEN, 1993, p. 37-8

${ }^{118} \mathrm{KUCH}$, Loraine E.The Art of Japanese Gardens. New York: The John day Company, 1940 (rub 1940); seguiram-se: ISHIMOTO, Tatsuo.The art of driftwood and dried arrangements. 1951; HARADA, Jiro. The Lesson of Japonese Architecture. London: The Studio Limited, 1954; SEIKE, Kiyosi. The art of Japanese Joinery. Weatherhill/ Tankosha. N.Y.-Tokyo, 1986 


\section{Sintonia com o movimento moderno}

De um lado do abismo, encontramos o sistema decrépito do pensamento europeu - um ecletismo sem fundamento, que dispõe sempre de milhares de receitas artística - pronto a buscar a verdade em qualquer lugar, desde que seja no passado. Do outro lado abre-se uma nova via, que ainda é preciso desbravar, terras desconhecidas que é preciso colonizar. A concepção de mundo do arquiteto contemporâneo forja-se no contato com sua época para que elaborem os novos métodos do pensamento arquitetônico. M. la. Guinzburg 


\section{A experiência em madeira}

A divisão entre a tradição Beaux-Arts e as notícias de uma nova arquitetura teve a sua faceta positiva que foi estimular a troca de informações e a procura por referências entre os contemporâneos de Galiano Ciampaglia. Igor Sresnewsky revela o seu interesse pela acústica, especialidade na qual se destacaria ao longo da vida profissional; Miguel Forte estagia por dois anos, no escritório de Rino Levi; Jacob Ruchti associa a experiência com o pai, um arquiteto suíço, à vanguarda artística de São Paulo, como no 2 o Salão de Maio, realizado em 1938, quando apresenta uma escultura de cimento ${ }^{1}$; Galiano Ciampaglia confirma a afinidade com os livros, compartilhada por Ruchti.

Em contraponto à mídia impressa paulista que somente em 1938 lança a revista Acrópole, as bibliotecas e livrarias da cidade eram fartas em publicações sobre a atividade dos mestres europeus.

Na Europa, no campo das revistas, a tradicional Architectural Review circulava com uma nova abordagem - em 1926, fundavam-se Die form, órgão da Deutscher Werkbund e Das Neue Frankfurt; em 1928, as italianas Casabella e Domus; em 1930, L'Architecture d' aujourd'hui. Nos EUA, iniciativas de editores de revistas foram fundamentais, com em 1927, quando a Architectural Record retoma a publicação de ensaios de Frank Lloyd Wright já divulgados, em 1908 e 1914, sob o título "In the cause of architecture".

O próprio Mackenzie disponibilizava aos alunos periódicos norteamericanos, além de Casabella, dirigida por Giuseppe Pagano, e de Domus, dirigida por Gió Ponti. O periódico mais antigo do acervo de Galiano Ciampaglia remonta à edição de 1936 de Casabella. A revista seria acompanhada pelo arquiteto, até os anos 70 .

Através da iniciativa conjunta de Jacob Ruchti e Igor Sresnewsky, em 1937, a Revista de Engenharia Mackenzie publica, sob o título "Architectura Funcional", um resumo do ensaio New bulding art in California, escrito por Richard Neutra, em 1935, para a revista California Arts \& Architecture. No texto, Neutra propunha uma arquitetura voltada às necessidades psicológicas e práticas do usuário. 
"Casabellan nel 1936, proseguendo il" programma di studio e di propaganda dell' architettura moderna iniziato otto anni fa, volgerà particolarmente la sua attenzione ai più urgenti problemi edilizi del Paese, e darà ampi resoconti dell' attività mondiale nel campo delle realizzazioni tecniche e sociali. "Casabella" intende, così, di confermare la sua utilità come "strumento di lavoro" e sostituire vantaggiosamente con un attentissimo servizio di informazione le riviste straniere d'architettura.

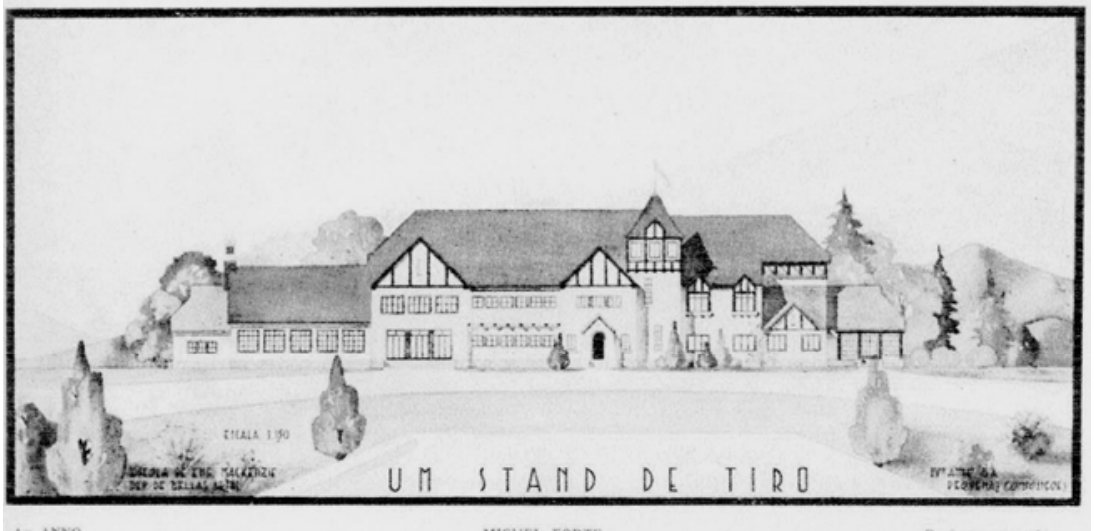

\section{ARCHITECTURA FUNCIONAL}

NOALTO: CASABELLA, 1936

ABAIXO: ARCHITECTURAFUNCIONAL

REVISTA DE ENGENHARIA MACKENZIE N. 67 OUT 1937 P. $132-3$

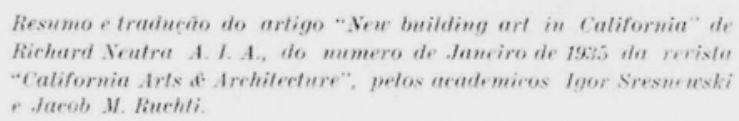

Resumo e traducto do artigo "Sex building art in Culiformin" de Richard Seutra A. I. A. do mumero de Janeiro de 1505 da revista "Califormin Arts of Archilecture", petos academinos lyor Sresmuski e. Jacob M. Buchli

Parece-nos que o termo "Architectura Moderna". tem tido innumeras significaçỏes. Pessoas nảo prepaparadas para julgar. interpretam de uma maneira embaraçosa e complicada. Naturalmente estando táo proximo de nosso tempo, é-nos difficil entender a soa silhueta e sua tendencia basica.

Do Japão á Belgica, da Australia á Scandinavia. percebemos um movimento forte e extenso que pro. cura relacionar a architectura contemporanea com as nossas necessidades espirituaes e praticas, e de entrelaçar corretamente a technica construtiva contemporanea com novos materiaes e methodos.

Felizmente, existe, entre a mocidade actual uma conviçảo de que nós conseruiremos novamente schar prazer $\mathrm{em}$ projectar e habitar novas edificaçōes. Exse prazer era bem conhecido em outras epocas quando pessoas se esforcavam para resolver os problemas de edificaçòes, sem dar valor á copia de exemplos extranhos do passado. Apezar de serem somente a expres. sảo das aspiraçóes. possibilidades e necessidades de sua epoca e de seu logar. Quando esmagados e torturados para serem adaptados á circunstancias bem differentes, tornam-se formas incoherentes e vãs.

A architectura moderna tem sido dada a denominaçăo de "funcional". Qual teria sido a razấo?

A igreja campestre Ukraniana, construida de madeira ou a aldeia chineza, demonstram bem claramente como se torna constructiva e organicamente bella, uma 
No mesmo ano, Galiano Ciampaglia realiza a sua primeira experiência que, apesar das muitas intervenções, ainda resiste no litoral paulista. Trata-se da casa em madeira projetada em uma aldeia de pescadores acessada pelo rio Itanhaém. $\mathrm{Na}$ volumetria "inesperada" 2 para a época, identificam-se alguns pontos voltados à otimização funcional:

- utilização do material - no caso, a madeira - subordinado à utilidade proposta, disponibilidade, adequação ao local e ao transporte

- $\quad$ modulação ajustada aos elementos industrializados disponíveis

- conforto ambiental proposto através de divisórias à meia altura e aberturas defasadas ${ }^{3}$

- integração estar-cozinha proposta pela divisória funcional que sintetiza as funções de aparador, guarda louças e guarda utensílios.

- forma decorrente da associação funcionalidade/estética

Ainda que sob o enfoque do "viver moderno" o ponto negativo resida no fato de o projeto em madeira não incorporar o banheiro, durante o 6o Fórum de Pesquisa FAU-Mackenzie, seção Arquitetura Moderna e Cidade, a casa mereceu comentários recorrentes a uma "intenção" de casa mínima ${ }^{4}$ e ao tradicional ballon frame ${ }^{5}$ - sistema construtivo de elementos estandardizados e de fácil transporte ${ }^{6}$. 

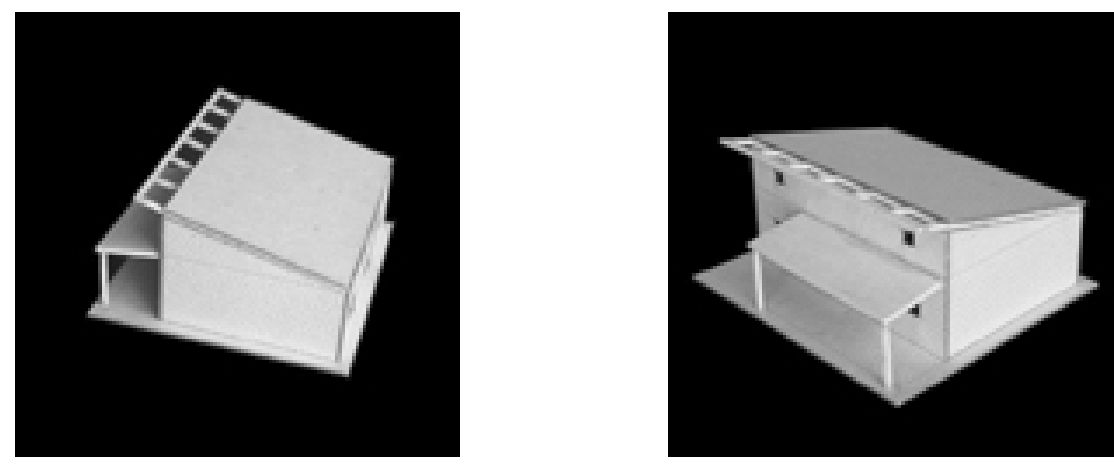

1937

CASINHA DA PRAIA DOS PESCADORES GALIANO CIAMPAGLIA

ACIMA: MAQUETE

AO LADO DE CIMA PARA BAIXO:

IMAGEMDA OBRA, 1938-39

PROJETO, 1937
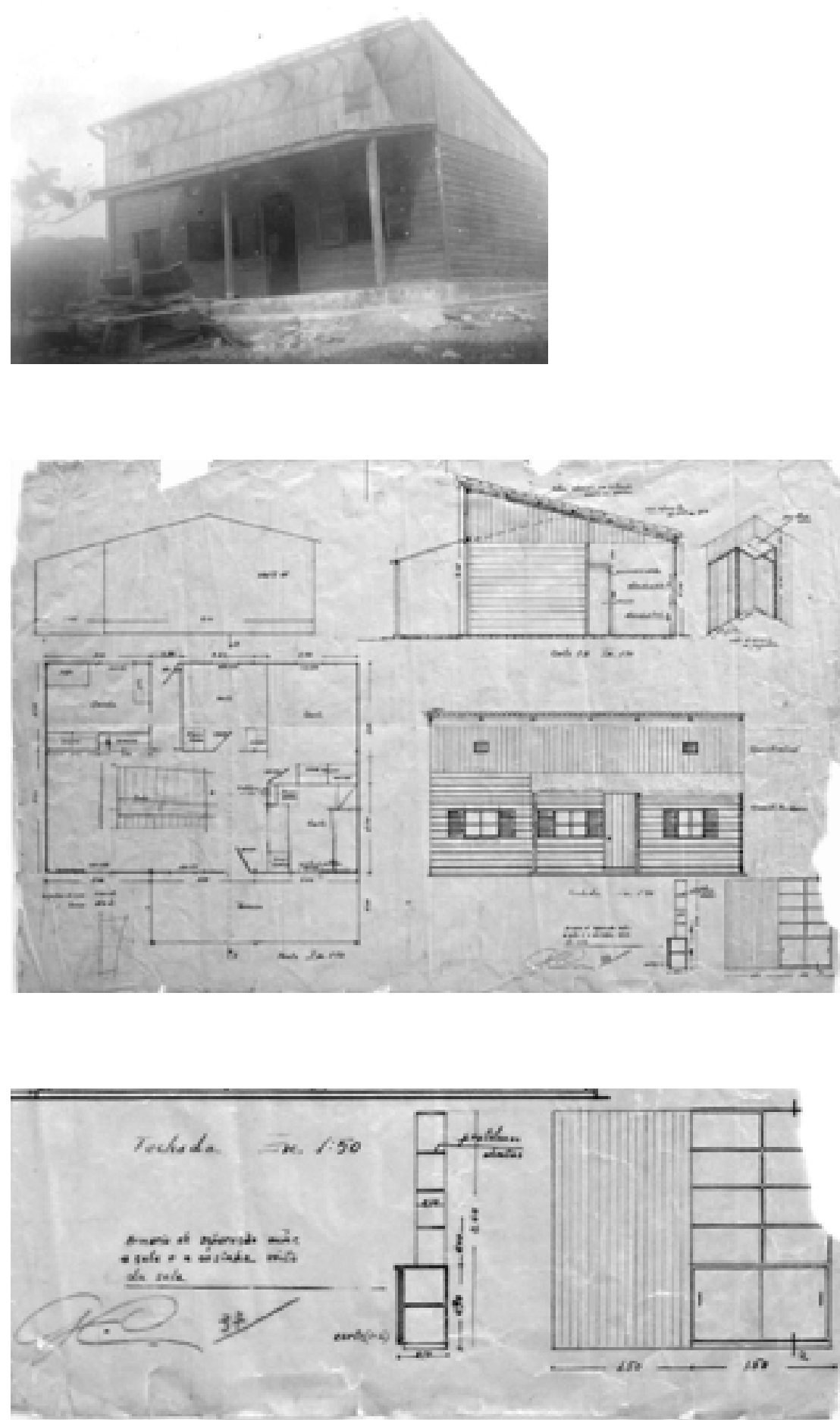

DETALHEDA DIMSÓRIAFUNCIONAL ARQUIVOGC 


\section{Referências}

É possível identificar ao longo da história da arquitetura a recorrência de certas problemáticas que demandam soluções tanto conceituais como físicas. As questões físicas, resolvidas à luz da tectônica, se expandiram para as questões conceituais ou intelectuais, problematizadas pela filosofia. Entre os assuntos teóricos permanentes estão os de origens e limites da arquitetura, de sua relação com a história e os problemas relativos ao seu significado e expressão cultural. Kate Nesbitt

A formação erudita de Galiano Ciampaglia, identificada por Eduardo de Almeida $^{7}$ e Lucio Gomes Machado ${ }^{8}$, muito tem a ver com a personalidade introspectiva e o prazer pela leitura cultivado na escola italiana. Recua aos anos 30 o seu interesse pela história, pela arte e pela filosofia, através de autores como Adolfo Morales de Los Rios ${ }^{9}$, Arnold Hauser ${ }^{10}$, Arnold J. Toynbee ${ }^{11}$, Baker Brownell ${ }^{12}$, Benedetto Croce ${ }^{13}$ Edmund Husserl ${ }^{14}$, Elie Faure ${ }^{15}$, Enzo Paci ${ }^{16}$, Erich Kahler $^{17}$, Ernst Cassirer ${ }^{18}$, Ernst H. Gombrich ${ }^{19}$, Erwin Panofsky ${ }^{20}$, Geoffrey Scott ${ }^{21}$, Gino Severini ${ }^{22}$, Guido de Ruggiero ${ }^{23}$, Herbet Read ${ }^{24}$, Jacobo Burckardt ${ }^{25}$, Johan Huizinga ${ }^{26}$, John Summerson ${ }^{27}$, John F.A. Taylor ${ }^{28}$, José Mariano Filho ${ }^{29}$, Martin Heidegger ${ }^{30}$, Paul $\mathrm{Klee}^{31}$, Rudolf Steiner ${ }^{32}$, Susanne K. Langer ${ }^{33}$, além das revistas do Serviço de Patrimônio Histórico e Artístico Nacional (SPHAN) ${ }^{34}$ cujo setor técnico era dirigido por Lúcio Costa, desde 1937.

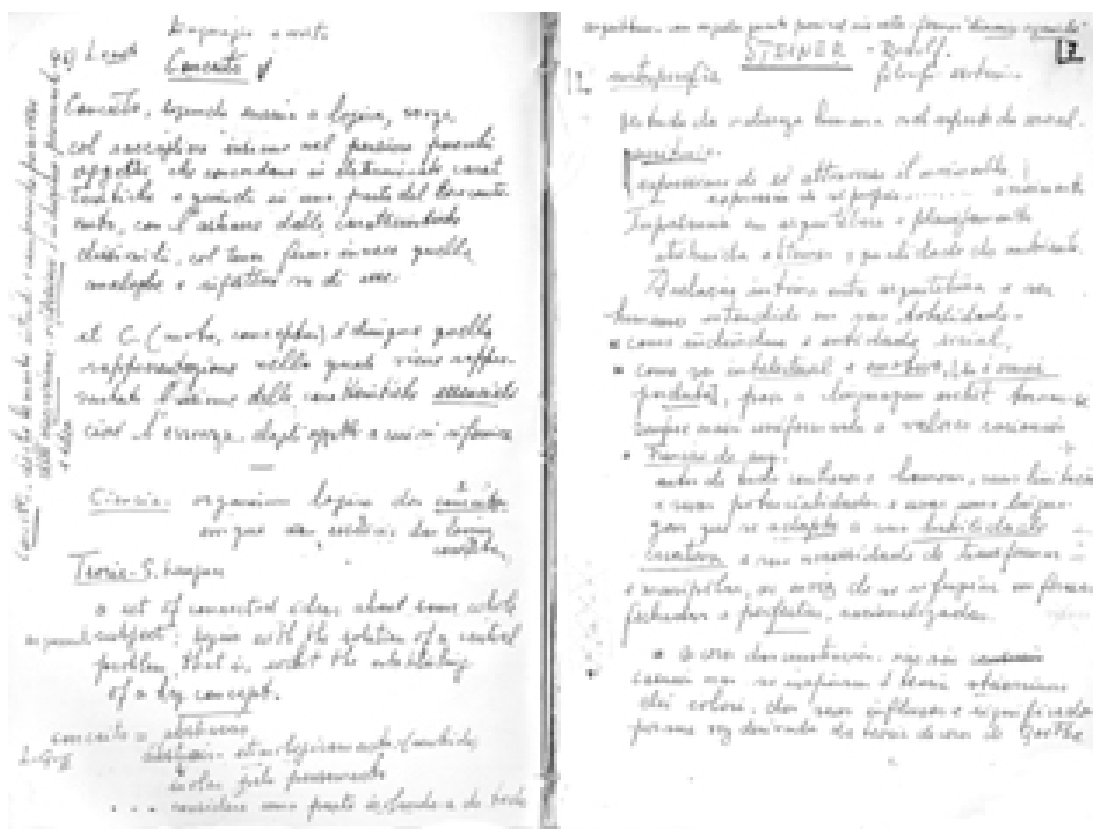


Em relação à produção dos mestres e temas relativos ao movimento moderno, ao se formar, além de Wright, a consciência de Galiano Ciampaglia estava associada ao panorama utilitário dos anos 20 , às teorias funcionalistas de Le Corbusier, ao racionalismo italiano defendido pelos editores de Casabella e ao trabalho pioneiro do MoMA voltado à divulgação dos mestres em arquitetura e design.

Em Vers une architecture ${ }^{35}$, Le Corbusier argumenta em favor de volumes simples, superfícies definidas mediante as linhas diretrizes dos volumes e a planta como princípio gerador. Sugere uma arquitetura submetida ao controle dos traçados geométricos reguladores e ao reconhecimento dos elementos da nova arquitetura nos produtos industriais - naves, aeroplanos e automóveis.

A Ville Pilotis é idealizada a partir do germe da maison Dom-Ino, uma analogia com uma peça de design apresentada no Salon d'Automne de Paris, em 1922. Aperfeiçoadas, como Ville Contemporaine e Maison Citrohan, são construídas e decoradas para o pavilhão L'Esprit Nouveau da Exposição Internacional Arts Decoratifs de Paris e publicadas no livro L'Urbanisme ${ }^{36}$.

A edição La Ville Radiuese ${ }^{37}$ é apresentada em oito partes. A segunda, "As técnicas modernas", aborda o Congrès de La Sarraz, realizado em 1928, que daria origem aos Congressos Internacionais de Arquitetura Moderna, CIAM, idealizados em defesa dos primeiros passos em direção à racionalização da indústria da construção. A 4a parte é dedicada à Ville Radiuese, apresentada no CIAM II, realizado em 1930, em Bruxelas. Frampton analisa a mudança de conceito da Immeuble-Ville, com amplo terraço ajardinado e espaço vital de altura dupla, para a unidade Ville Radiueuse (VR), um apartamento flexível de pavimento único, como a supressão qualitativa em favor da quantitativa da produção em série.

Um panorama mais amplo dos primeiros resultados formulados nos anos 20, é apresentado na obra de Bruno Taut, Die Neue Baukunst in Europa und Amerika ${ }^{38}$, quando o autor define alguns pontos da arquitetura moderna:

1. a primeira exigência em todo o edifício é o alcance da melhor utilidade possível 
2. os materiais empregados e o sistema de construção devem estar completamente subordinados a essa exigência primária

3. a beleza consiste no relacionamento direto entre edifício e finalidade, nas oportunas características dos materiais e na

4. elegância do sistema de construção

5. a estética da nova arquitetura não reconhece qualquer separação entre fachadas e plantas, entre ruas e pátios, entre a parte da frente e a de trás. Nenhum detalhe vale por si mesmo, mas é parte necessária do conjunto. Aquilo que funciona bem, também se apresenta bem.

6. até mesmo a casa em seu conjunto [...] perde o isolamento e a separação [...] a casa vive no relacionamento com os edifícios que a circundam. A casa é o produto de uma disposição coletiva e social ${ }^{39}$.

A publicação é uma mostra da atmosfera européia de vanguarda representada por De Stijl (J.J.P. Oud), Mies van der Rohe, Otto Wagner, Adolf Loos e outros. Taut põe o leitor em contato com a exposição de caráter experimental organizada, em Stuttgart, em 1927. Através do Bairro Weissenhof Siedlung, os melhores arquitetos da Europa são chamados para construir as casas: Mies van der Rohe propõe casas enfileiradas com estrutura de aço; Walter Gropius, casas isoladas pré-fabricadas e moduladas a partir de revestimento Eternit; Le Corbusier, casas de concreto e ferro com a aplicação de seus cinco pontos fundamentais: pilotis, tetos-jardim, planta livre, fenêtre en longuer e fachada livre.

Entre a produção doméstica, Mies van der Rohe apresenta uma casa de campo de tijolos aparentes. Projetos de Rudolph Schindler e Richard Neutra, nos Estados Unidos, sugerem o afluxo cultural dos europeus.

O trabalho pioneiro do Museu de Arte Moderna de Nova York MoMA - voltado à divulgação da casa moderna, recua à década de 30, através de iniciativas como a exposição itinerante com obras de Wright (1931) e The International Style, em 1932. Em 1939, o catálogo Art in our time ${ }^{40}$, reproduz a exposição organizada por ocasião de 10 을 aniversário do museu e inauguração do novo prédio. A mostra caracterizada pela pluralidade, destaca entre outros, projetos de Walter Gropius, Marcel Breuer e Richard Neutra, realizados nos Estados Unidos, que confirmam o intercâmbio cultural enunciado na obra de Bruno Taut. 


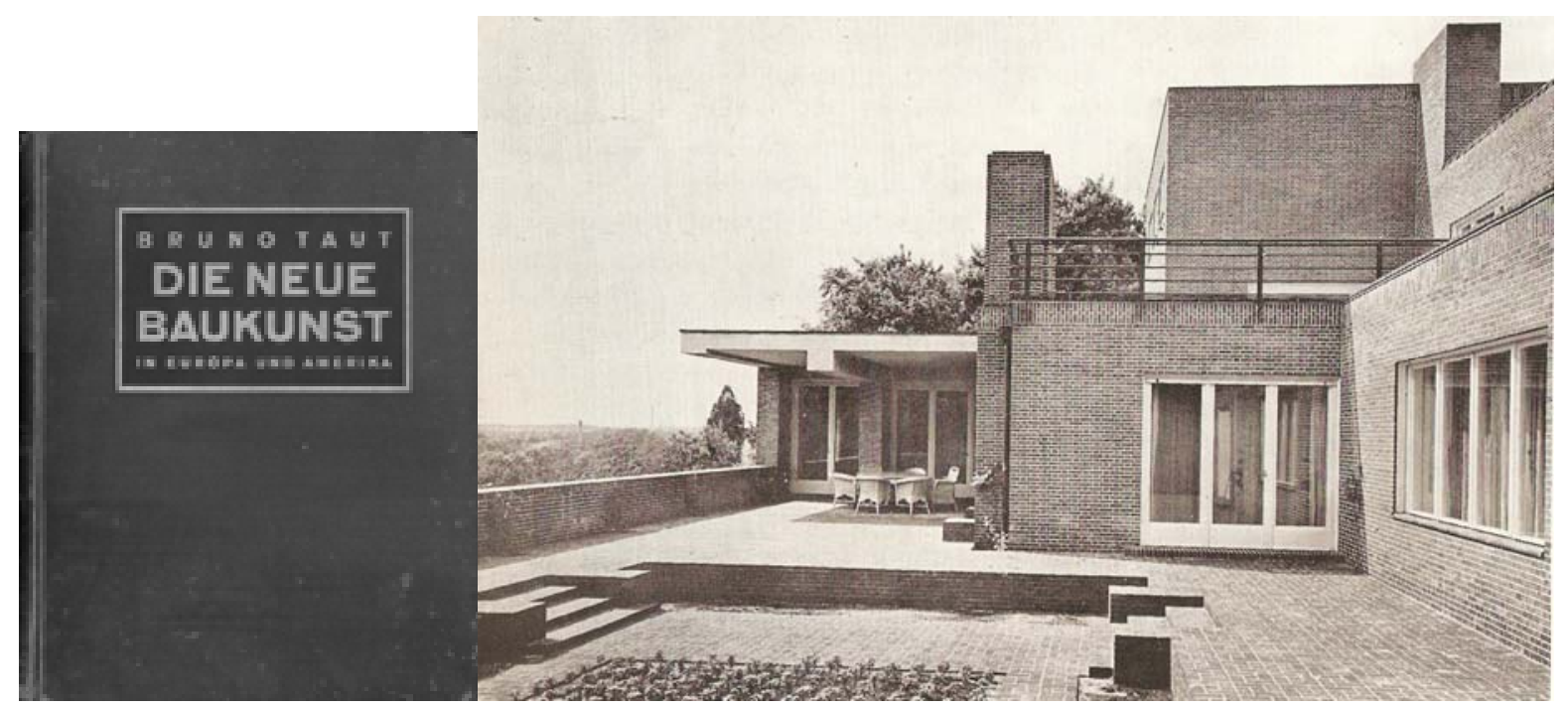

CASADE CAMPO, 1923

MIES VANDERROHE

TAUT, 1929, P. 171

ACERVOGC

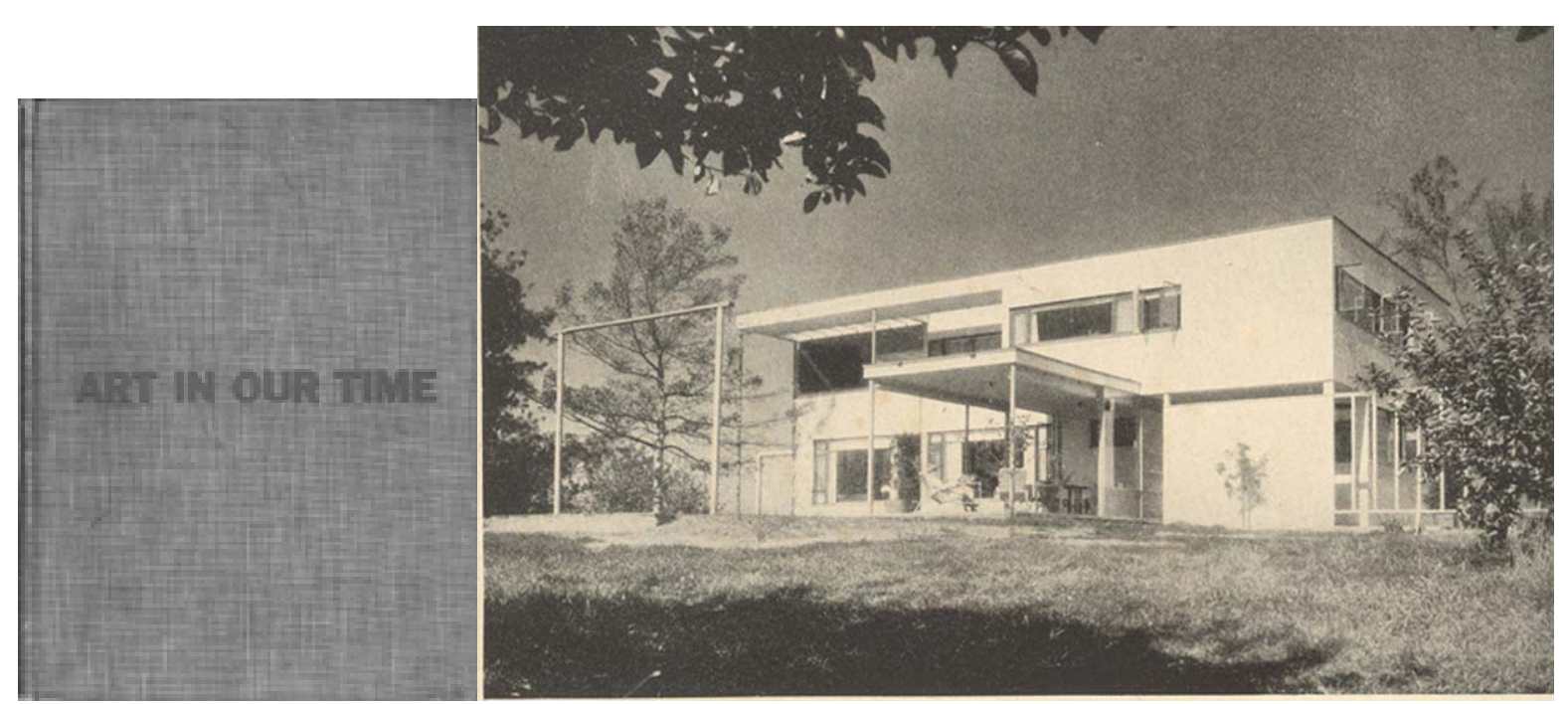

GROPIUS HOUSE, MASS, 1938

W. GROPIUS EM. BREUER,

1939, ART IN OUR TIME, P. 300

MOMA

ACERVOGC

Manuais técnicos voltados à racionalização da casa são publicados pela Hoepli de Milão. A 3a edição de Costruzione razionale della casa ${ }^{41}$, de Enrico Griffini, é clara quanto ao papel assumido pela casa moderna no contexto da nova arquitetura: "o problema da casa moderna, que na $1 \underline{a}$ edição (1931) desta obra surgia com alguma incerteza de contornos, própria das coisas que estão por florescer, aparece hoje claramente definido". Entre as múltiplas propostas, o autor apresenta a St.Mark's Tower projetada por Wright, em 1929. 
ST. MARK'S TOWER

FRANKLLOYDWRIGHT, 1929 GRIFFINI, 1939, FIG. 109E110 ACERVOGC
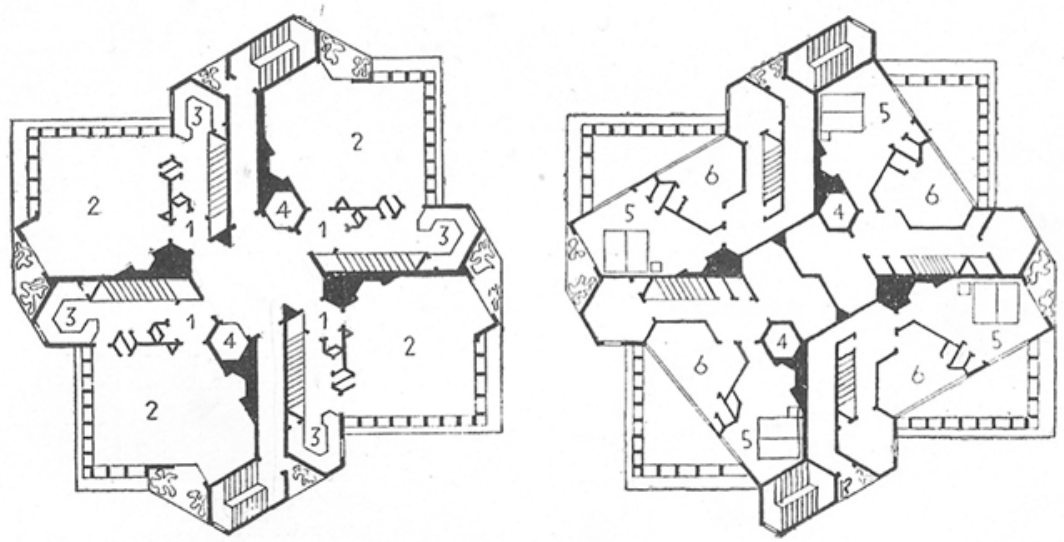

Em 1940, é publicada a antologia The New Architecture $^{42}$, de Alfred Roth. De caráter documental, a obra apresenta um panorama da situação do movimento moderno às vésperas da Segunda Guerra. Benevolo avalia que bastante interessantes são as considerações sobre a tradição e sobre a história, onde a polêmica racionalista parece estar realmente superada ${ }^{43}$. $O$ sinuoso teto de madeira da sala de conferências da Biblioteca de Viipuri, proposto por Alvar Aalto, já anunciava uma nova idéia de espaço. Em The Humanization of Architecture ${ }^{44}$, Alvar Aalto argumenta que "o funcionalismo técnico não é capaz de criar uma arquitetura definitiva". Entre outros, os ensaios Architettura e arte concreta ${ }^{45}$ e Alcune recenti opere di Alvar Aalto ${ }^{46}$, publicados pela Domus e pela Casabella, sob a direção de Ernesto Nathan Rogers, estão preservados no acervo de Galiano Ciampaglia.

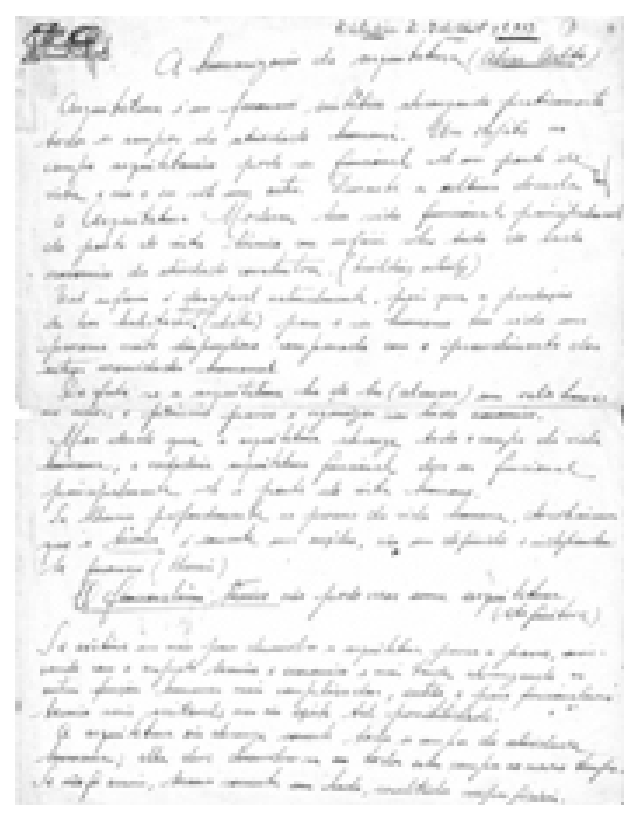


A primeira biografia de Mies van der Rohe ${ }^{47}$, o exemplo mais claro do racionalismo, é publicada pelo MoMA, em 1946, e reproduz a mostra organizada por Philip Johnson. A obra reúne os escritos e a produção do arquiteto que, em 1938, se estabelece em Chicago, convidado para dirigir a escola de arquitetura do Armour Institute of Technology.

Sobre críticos, o acervo de Galiano Ciampaglia recua ao manual de Walter Curt Behrendt, Modern Building. Its nature, Problems, and forms ${ }^{48}$. A obra que tem origem numa série de conferências sobre 0 significado do movimento moderno, pronunciadas nos EUA, entre 1934-35, é avaliada por Lewis Munford como uma "excelente interpretação crítica, sem rival em matéria de clareza, profundidade e brevidade" ${ }^{49}$. Behrendt analisa a obra de Wright "como a primeira criação no campo da arquitetura que pode considerar-se uma contribuição independente do espírito norte-americano à cultura européia" ${ }^{50}$.

Space, time and architecture ${ }^{51}$, de Sigfried Giedion, é "dirigida àqueles que se assustam com o estado presente da nossa cultura $e$ estão ansiosos para encontrar uma saída para este aparente caos de tendências contraditórias" ${ }^{52}$. A obra é complementada, em 1948, por Mechanization takes command ${ }^{53}$.

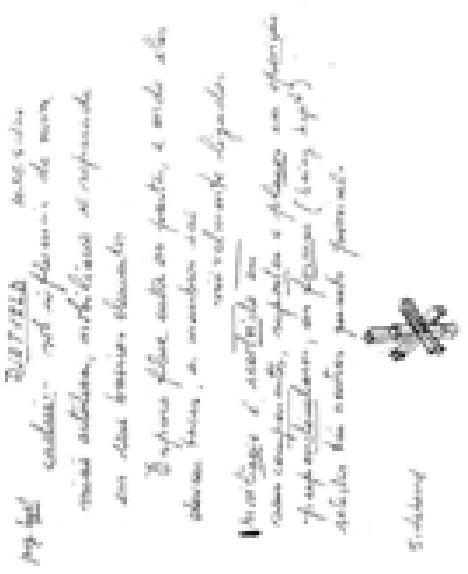

ACIMA: ANOTAÇÕES (GIEDION, 1948) AOLADO: ANOTAÇÕES (BEHRENDT, 1937) ACERVOGC

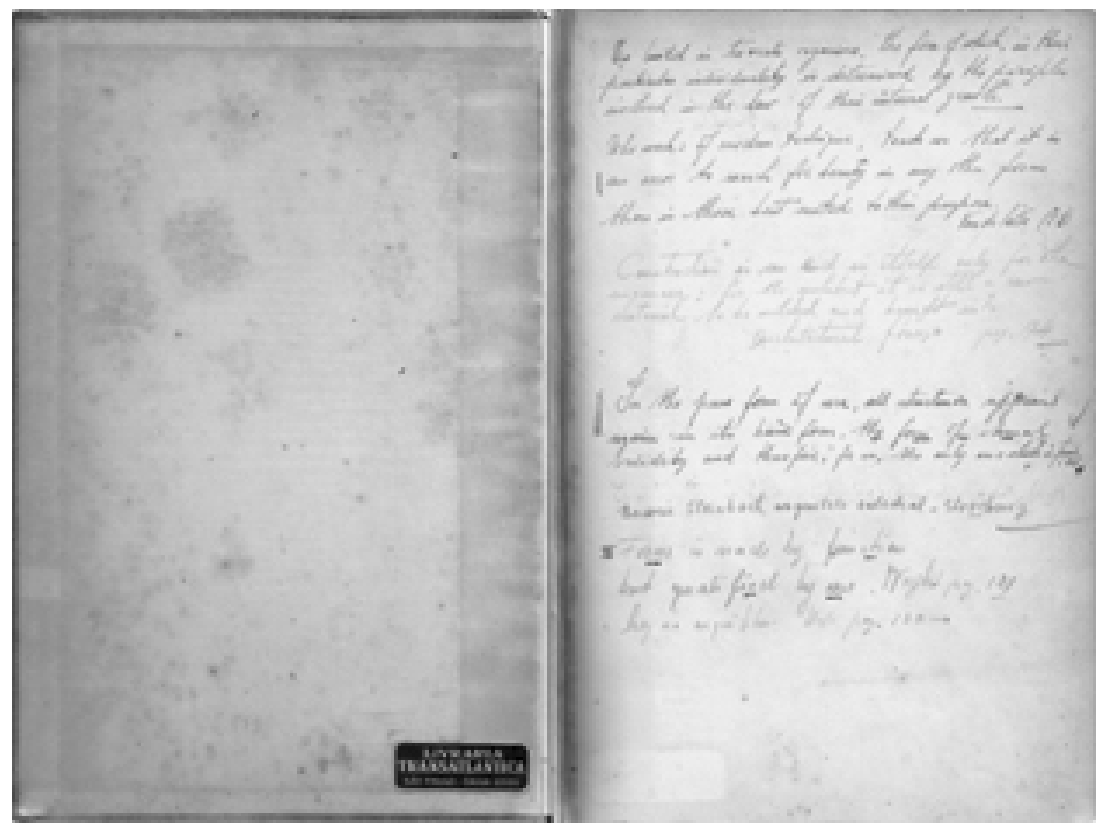


No pós-guerra, Bruno Zevi cria na Itália, a APAO (Associação para uma Arquitetura Orgânica). O crítico encabeça uma corrente definida como pós-racionalista e propõe "uma via organicista como alternativa que outorgue um papel preponderante aos dois mestres do Movimento Moderno que mais haviam explorado os campos não estritamente racionais e funcionalistas da arquitetura" ${ }^{54}$ : Wright e Aalto.

Em Verso un' architettura orgânica ${ }^{55}$, Zevi formula um contraponto entre as duas correntes:

Arquitetura orgânica / Arquitetura inorgânica

1. "Arte formativa" / "Arte decorativa"

2. Produto de sensações intuitivas/Produto do pensamento

3. Trabalho de imaginação intuitiva / Trabalho de imaginação construtiva

4. Arquitetura em contato com a natureza / Arquitetura em desdém com a natureza

5. Arquitetura da procura pelo particular / Arquitetura da procura pelo universal

6. Arquitetura prazerosa pela multiplicidade / Arquitetura que aspira pela regra, pelo sistema e pela lei

7. Realismo / idealismo

8. Naturalismo / Estilismo

9. Forma irregulares (medievais) / Formas regulares (clássico)

10. A estrutura concebida como um organismo vivo/ A estrutura concebida como um mecanismo

11. Arquitetura de formas dinâmicas / Arquitetura de formas estáticas

12. Formas independentes da geometria elementar / Formas baseadas na geometria e na estereometria

13. Produto de bom senso e de beleza razoável / Procura por proporções perfeitas, da seção áurea e de beleza absoluta

14. Anti-composição / Composição

15. Produto da realidade / Produto da educação ${ }^{56}$

De Bruno Zevi, identificam-se no acervo, Saper Vedere l'Architettura ${ }^{57}$ e Architectura in nuce ${ }^{58}$. Os ensaios sobre Wright, publicados nos anos 60, na revista L' Architettura. Cronache e Storia, dirigida por Zevi, estão preservados por Galiano Ciampaglia. 
Outra referência da cultura arquitetônica italiana são os escritos de Ernesto Nathan Rogers. A observação dos italianos pela revalorização da arquitetura espontânea ${ }^{59}$ já havia sido sugerida por Rogers como diretor da revista Domus (1946-47), no editorial "a casa do homem" ${ }^{60}$. Como diretor de Casabella-Continuitá (1953-1964), é interessante se ter presente a reprodução do mesmo editorial, em 1953, e a coerência e solidez de suas propostas que insistem constantemente em uma mesma visão da arquitetura e da cidade ${ }^{61}$.

Nos anos sessenta, os questionamentos à ortodoxia do movimento moderno culminam com a publicação de Progetto e Destino, L'architettura della cittá, II territorio della architettura e Intenzioni in Architettura. Kate Nesbitt avalia que a partir do livro Complexity and contradition in architecture os estudos se expandem a paradigmas externos à arquitetura, como a semiótica e o estruturalismo, a fenomenologia e as teorias da comunicação, em sintonia com a mudança radical da atitude das pessoas em relação à arquitetura moderna ${ }^{62}$. A partir desse momento, o acervo de Galiano Ciampaglia reúne, entre outros, autores como Aldo Rossi ${ }^{63}$, Carpenter e Mc Luhan ${ }^{64}$, Cesare Brandi ${ }^{65}$, Charles Jencks ${ }^{66}$, Christian Norberg-Schulz ${ }^{67}$, Edward T. Hall ${ }^{68}$, Gaston Bachelard ${ }^{69}$, Geoffrey Broadbent $^{70}$, Giovanni Klaus Konig ${ }^{71}$, Giulio Carlo Argan $^{72}$, Jean Baudrillard ${ }^{73}$, Lévi-Strauss ${ }^{74}$, Pierre T. De Chardin ${ }^{75}$, Robert Venturi ${ }^{76}$, Stephen Ullmann ${ }^{77}$ e Vittorio Gregotti ${ }^{78}$.

Segundo relatou a Adriana Irigoyen, em 1959, Galiano Ciampaglia assistiu à palestra de Richard Neutra, realizada na Fau-usp. 


\section{* Arquitetura como cidade}

A cidade não é apenas um traçado regular dentro de um espaço, uma distribuição ordenada de funções públicas ou privadas, um conjunto de edifícios representativos e utilitários. Como a arquitetura dá corpo e estrutura à cidade, e com ela forma um só corpo, tudo o que não funciona na cidade reflete os defeitos da sua cultura arquitetônica ou a sua incapacidade de preencher suas funções institucionais. Giulio Carlo Argan

O acervo de Galiano Ciampaglia também deixa à mostra um interesse despertado na escola elementar, através das cidades da Itália, da Idade Média até a Renascença ${ }^{79}$. Recua aos fundamentos religiosos da cidade de Fustel de Coulanges ${ }^{80}$ e se estende até quando a cidade e o planejamento urbano assumem o centro da discussão e a habitabilidade passa a ser afrontada não só por arquitetos e urbanistas, mas também por sociólogos, historiadores, economistas e geógrafos ${ }^{81}$.

Broadacre City, a visão urbanística de Wright, é conhecida através da edição de 1940, do magazine Taliesin. A escala é o homem e a técnica moderna é colocada ao seu serviço: "[...] para cada indivíduo ser o mínimo democrático nesta nação, queremos que a máquina seja socialmente útil" ${ }^{82}$. Parece fazer sentido Galiano Ciampaglia ter "encostado" o livro L'Urbanisme ${ }^{83}$. Antagônica a Wright, a visão de cidade finita de Le Corbusier defende a estandardização, a produção em massa, a máquina.

City Planning. Housing ${ }^{84}$, de Werner Heggeman, aborda os aspectos históricos, sociológicos, políticos e econômicos, relativos ao planejamento, através das teorias de John Ruskin, Camillo Sitte, Raymond Unwin, Patrick Geddes, Lewis Munford e do filósofo Oswald Splenger, entre outros. O volume III apresenta um panorama da produção internacional dos anos 1922-1937, através de realizações de Hans Meyer, Bruno Taut, Ernst May, J.J.P.Oud, H. P. Berlage, Clarence Stein e Eliel Saarinen.

The Culture of the cities é a primeira obra de Lewis Munford a integrar o acervo de Galiano Ciampaglia. Como historiador das cidades e da arquitetura o autor seria acompanhado pelo arquiteto, até os anos sessenta ${ }^{85}$. 


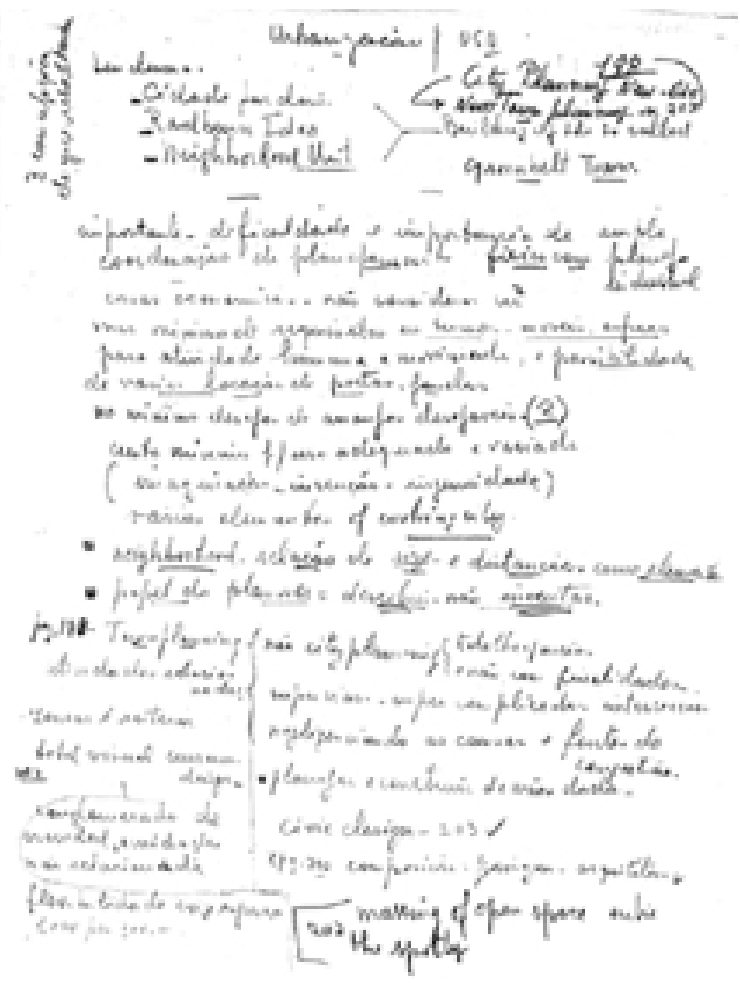

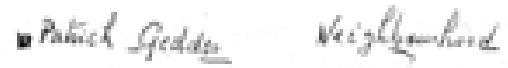

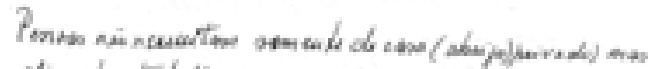

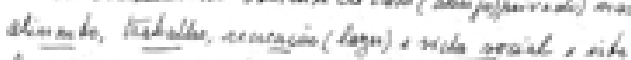

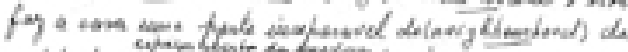

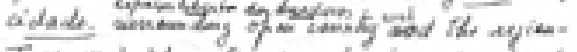

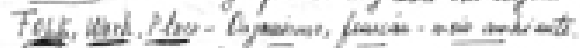

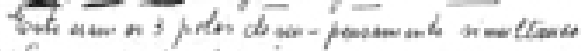

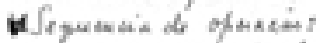

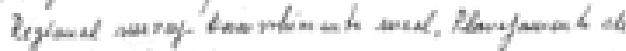
uidete. Cog doripe.

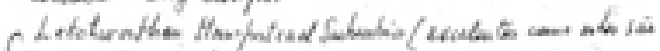

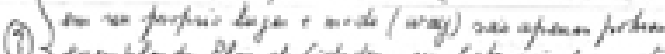

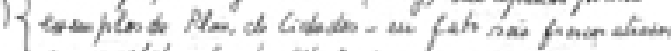

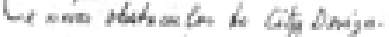

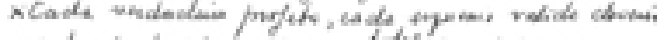

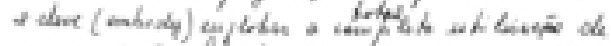

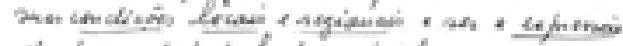

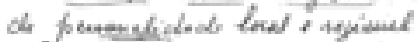
Canak. Liae.

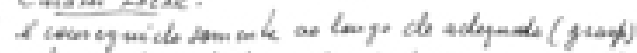

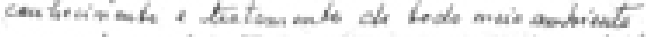

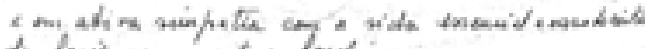

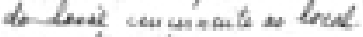

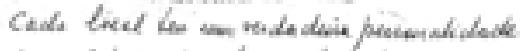

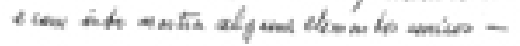


No prefácio de The Culture of the cities, a mais extensa e influente de suas obras, Munford deixa claro o seu reconhecimento ao mestre Patrick Geddes, criador da cidade regional como uma das respostas à cidade vitoriana.

Em 1942, Can our cities survive? ${ }^{86}$, de Josep Luis Sert, apresenta os temas "Cidade Funcional" e "Habitação e Lazer" ${ }^{87}$, apresentados nos Congressos Internacionais de Arquitetura Moderna, CIAM, em 1933 e 1937, com um panorama das condições de vida das cidades até então.

Em 1946, Galiano Ciampaglia rubrica The Architetonic city in the Americas ${ }^{88}$, de Hugo Leipziger.

Em 1952, The Heart of the City ${ }^{89}$, editado por E. N. Rogers, J. L. Sert e J. Tyrwhitt, retoma o CIAM VIII (1951). Frampton avalia que o tema escolhido para o congresso recua a um manifesto escrito por Giedion, Sert e Léger, em 1943:

"As pessoas querem que os edifícios que representam sua vida social e comunitária possam dar-lhes uma satisfação funcional maior. Querem satisfazer sua aspiração à monumentalidade, à alegria, ao orgulho e à comoção" ${ }^{90}$.

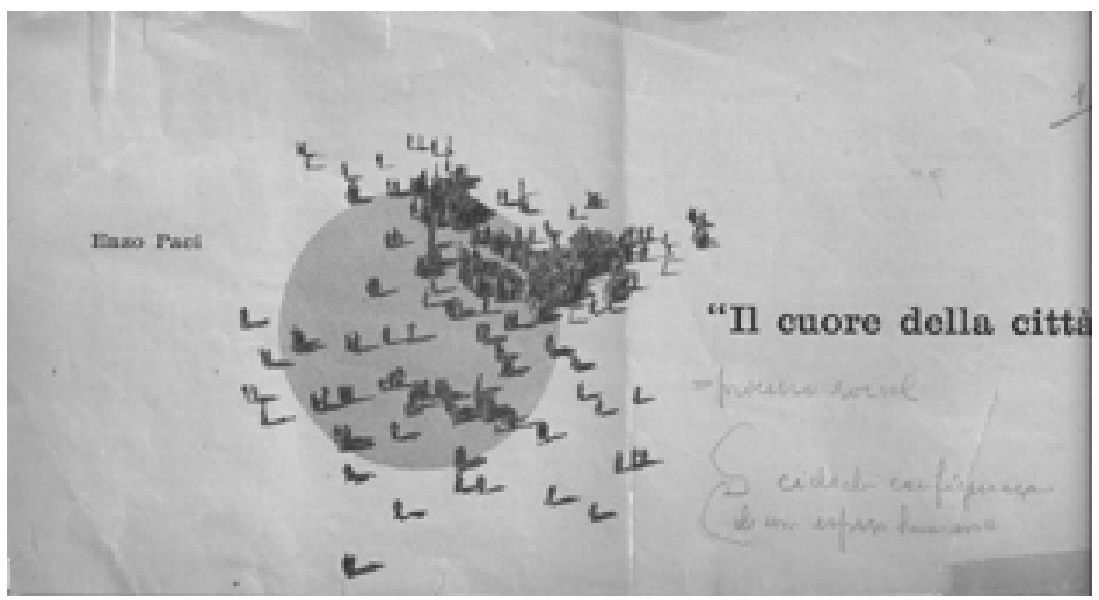

Cities in evolution ${ }^{91}$, de Patrick Geddes, publicada originalmente em 1915, é rubricada em 1952. Na mesma década é publicado L'Ambiente in espanzioni de Erwin A. Gutkind ${ }^{92}$. Benévolo avalia que através de Geddes, Munford e Gutkind "nasce uma corrente de pensamento que conserva uma repugnância ruskiana pela cidade grande e prediz o fim das metrópoles [...]" ${ }^{93}$. 


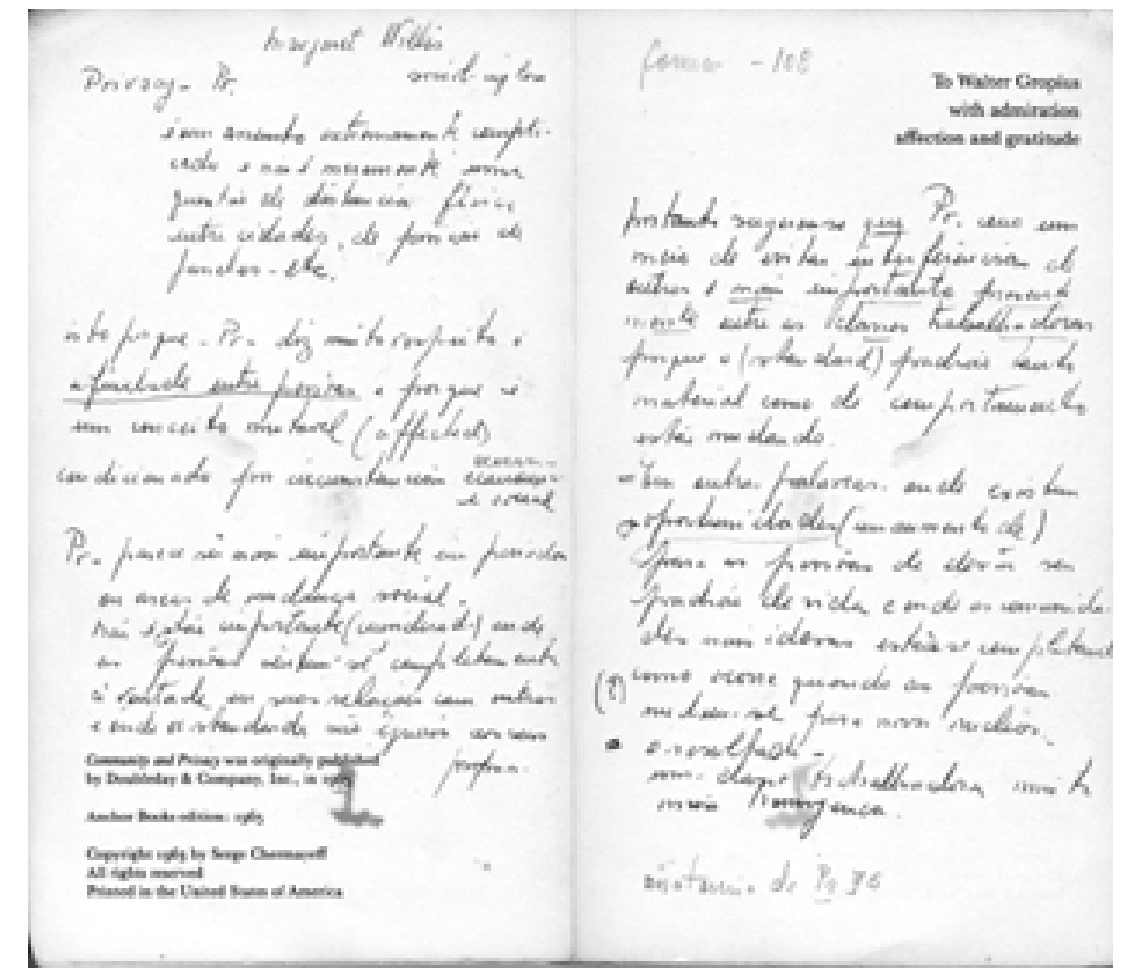

ANOTAÇÕES (CHERMAYEFF,S. E ALEXANDER, C. 1963)

ACERVOGC

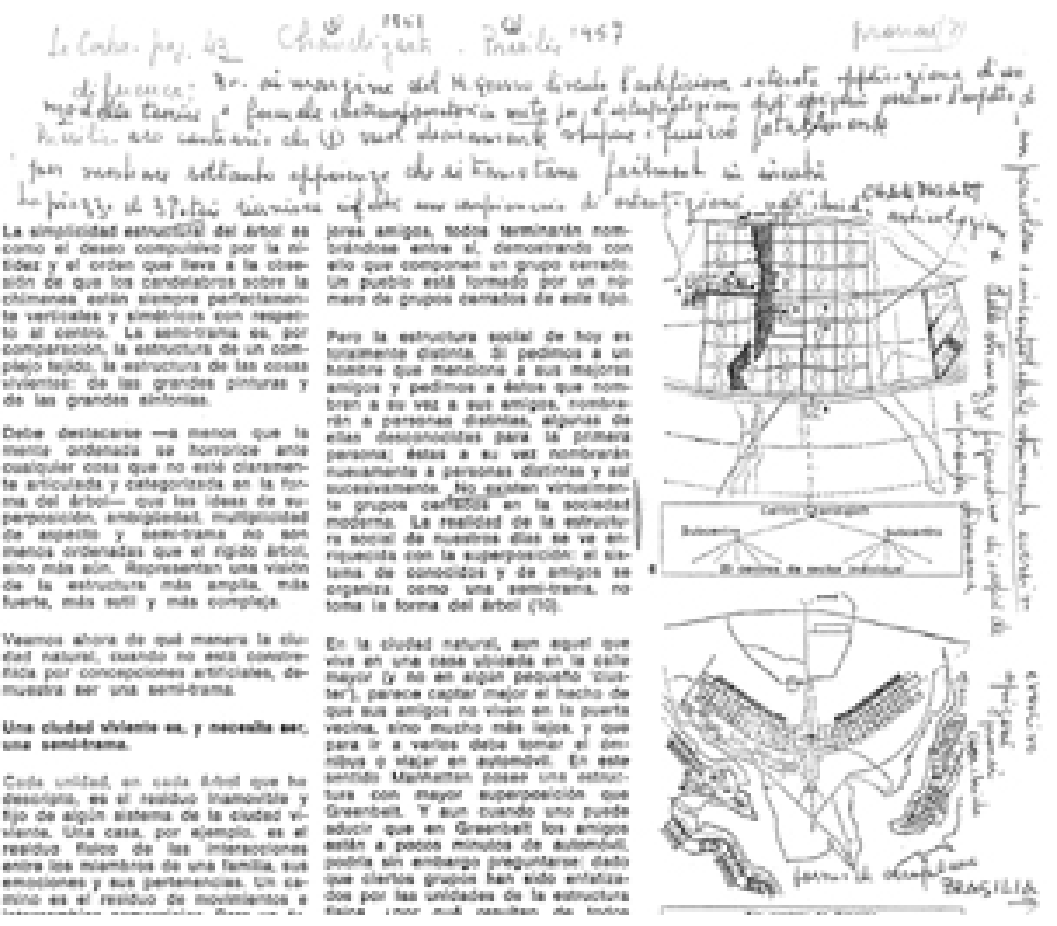


The art of building cities ${ }^{94}$, recua a proposta de Camillo Sitte de 1889. Ebenezer Howard, criador da cidade-jardim, a primeira das respostas à cidade vitoriana, recebe introdução em Green-Belt Cities de Frederic Osborn ${ }^{95}$ e é retomado em L'idea della cittá giardino ${ }^{96}$. De Clarence Stein, autor das Greenbelt derivadas do modelo howardiano da cidade-jardim ${ }^{97}$, o acervo preserva Towards new towns for América ${ }^{98}$.

Em 1950, La Cittá ${ }^{99}$ do sociólogo Max Weber retoma uma parte fundamental de Wirtschaft und Gesellschaft (Economia e Sociedade), publicada em 1922. Segue-se La cittá e il suolo urbano ${ }^{100}$ de Hans Bernoulli.

Em 1953, é rubricada Town and Country Planning text book ${ }^{101}$, uma coletânea editada pela APRR ${ }^{102} \mathrm{com}$ introdução de Sir William Holford ${ }^{103}$. Seguem-se Town Design ${ }^{104}$ de Frederick Gibberd e, em 1955 , The anatomy of the village ${ }^{105}$ de Thomas Sharp, publicada em 1946.

Nos anos 60, o acervo recupera a obra de Marcel Poete, Introdution a I'urbanisme ${ }^{106}$. Nesse ponto, o acervo incorpora publicações sobre a cidade e a sua relação com a antropologia, a sociologia, a geografia, a ecologia, a habitabilidade e o modo de vida ${ }^{107}$.

Em 1963 é publicado Community and Privacy ${ }^{108}$ de Serge Chermayeff e Christopher Alexander. Segundo Frampton, a obra apresenta pela primeira vez a altura e a densidade baixas como uma estratégia reformista da expansão urbana neocapitalista ${ }^{109}$.

Estão preservados os ensaios da série Architecture as Total Community: the challenge ahead, escritos por Albert Meyer, com consultoria de Clarence Stein, publicados pela Architectural Record, em 1964, e a edição da Architectural Record com ensaio de Edmund N. Bacon, The city as an act of will ${ }^{110}$. Architectural Record, January 1967, p. $113-128$

Em 1968, Christopher Alexander publica dois ensaios: La ciudad como mecanismo de sósten para los contatos humanos e La ciudad no es um árbol ${ }^{111}$. Em 1972, é publicado La forma dell' ambiente collettivo ${ }^{112}$, de Serge Chermayeff e Alexander Tzonis 


\begin{tabular}{|c|c|}
\hline 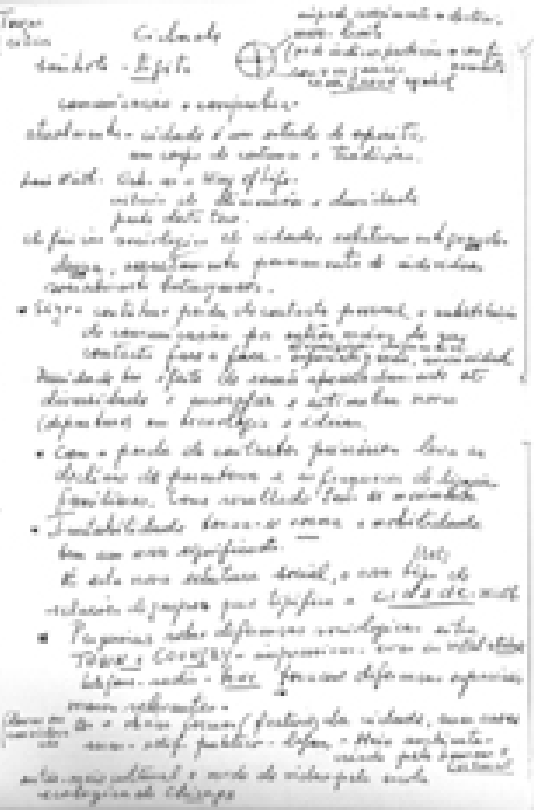 & 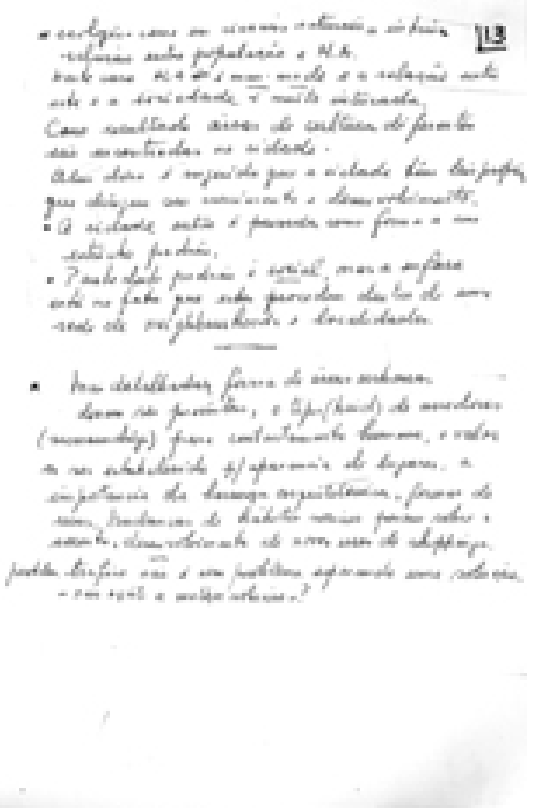 \\
\hline
\end{tabular}

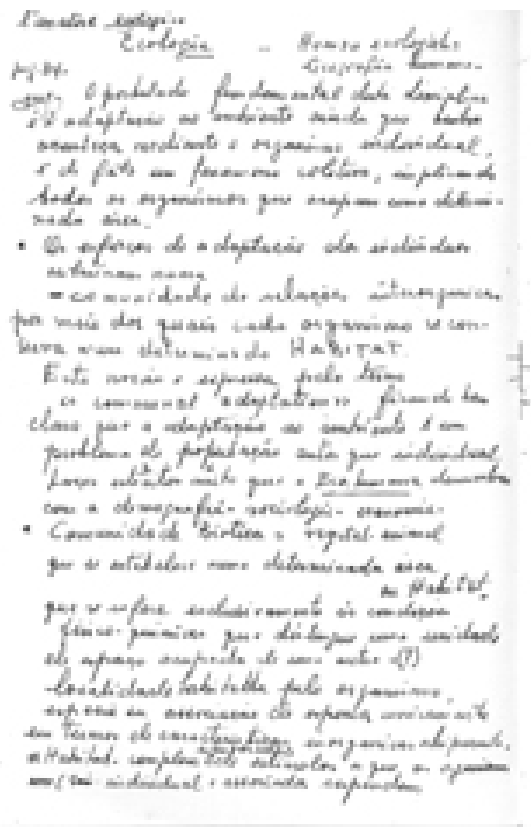

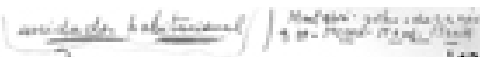

Petefouserses fifumpere

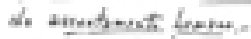

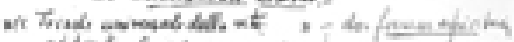

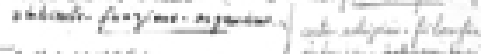

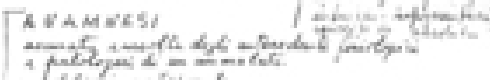

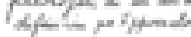

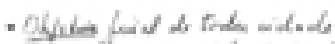

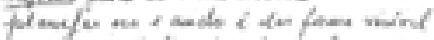

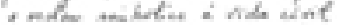

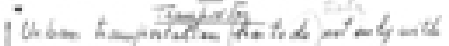

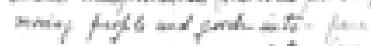

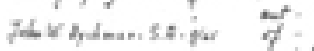

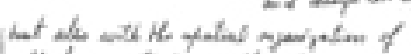

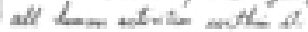

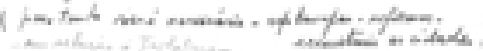

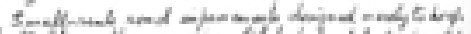

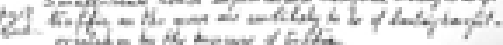

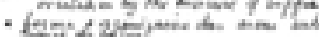

\%

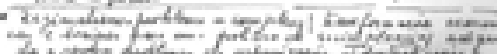


Em 1966, é publicada a obra de Aldo Rossi, L'Architettura della cittá ${ }^{113}$. Segundo Montaner, Rossi "constrói o sábio tecido do livro a partir de diferentes pontos de vista com os quais pode contemplar a cidade: desde a antropologia, a psicologia, a geografia, a arte, a novela, a economia, a política" ${ }^{114}$. E prossegue: "é a distância que separa o texto de Rossi do texto de Ludwig Hilberseimer" de 1927. De fato, em Un' idea di piano ${ }^{115}$, publicado pelo caderno Polis ${ }^{116}$, em 1967, o mestre de urbanismo da Bauhaus di Dessau refere-se aos primeiros estudos urbanísticos focados nos fatores técnicos da cidade: "tratava-se de uma concepção do tipo mecanicista que ignorava as exigências e as necessidades do homem" ${ }^{117}$. Também em 1967 é publicado L'urbanistica e l'avvenire della città ${ }^{118}$, de Giuseppe Samoná, diretor do Instituto Universitário di Arquitetura di Venezia - IAUV. L'image de la cite ${ }^{119}$ de Kevin Lynch, é adquirida em $1969^{120}$. Segundo Nesbitt, Lynch analisa como as pessoas se orientam no ambiente. Ele insiste na necessidade de uma ordem visual no entorno humano capaz de ser guardada na memória, como caminhos, limites, nódulos, bairros e pontos de referência na paisagem ${ }^{121}$.

Ainda sobre os Cuadernos Summa-Nueva Vision, em 1968 é publicado o ensaio La ciudad viviente ${ }^{122}$ dos membros do grupo Archigram: Warren Chalk, Peter Cook, Dennis Crompton, Ben Fether, David Greene, Ron Herron, Peter Taylor e Michael Webb.

Georges Candilis, um dos jovens arquitetos presentes no CIAM IX, a desafiar as quatro categorias funcionalistas da carta de Atenas (moradia, trabalho, lazer e transporte), reclamando que fosse introduzido o conceito de "identidade" e investigado de acordo com os princípios estruturais do crescimento urbano ${ }^{123}$, publica com Josic e Woods, Reflexiones sobre planeamiento y diseño urbano ${ }^{124}$. Em 1969, Henri Lefebvre [1901-1991] publica O direto à cidade ${ }^{125}$ que discute a habitabilidade da cidade moderna ${ }^{126}$. De Theo Crosby, são II senso della città e How to play the environment game ${ }^{127}$, publicadas respectivamente em 1971 e 1973. O que não encerra este percurso considerando-se correlações de obras de 1946 com ensaios publicados em $1978{ }^{128}$. 


\section{Vínculos}

Os anos 30 e 40 representam o momento de significativas mudanças em todas as órbitas, englobando o projeto moderno, que caminha do modernismo para a maturidade, vale dizer modernidade. Seu alvo principal é tornar-se cultura urbana, chegando ao transeunte através de uma convivência cotidiana, que denominamos cotidianização do moderno.

Maria Cecília França Lourenço

Na literatura acadêmica, não faltam referências ao compromisso com a modernidade assumido pelo grupo de Carlos Millan, Galiano Ciampaglia, Jacob Ruchti, Miguel Forte, Plinio Croce, Roberto Aflalo e Salvador Candia ${ }^{129}$, todos formados no Mackenzie, a partir da virada dos 30. Manifestado através de diferentes parcerias, esse comprometimento se revelou em uma das propostas vencedoras do concurso para o edifício-sede IAB-SP, apresentada por Forte, Ruchti e Ciampaglia, em 1946, na fundação da revista Pilotis, no final dos anos 40, editada por Candia, e Millan - além de Jorge Wilheim, Paola Tagliacozzo, Roberto Carvalho Franco e Sidney da Fonseca -, na fundação da loja de design Branco \& Preto, em 1952, à qual só não aderiram Galiano Ciampaglia e Salvador Candia, ou ainda, nos anos 60, como professores da Faculdade de Arquitetura Mackenzie.

No caso de Galiano Ciampaglia, é a sua biografia dos anos 30, 40 e 50 , que o vincula às noções de significativas mudanças.

A começar pelo pioneirismo da Escola de Engenharia Mackenzie que, em 1939, diploma a primeira turma de arquitetos paulistas reconhecidos pelo Ministério da Educação e da Saúde.

Em 1940, Galiano Ciampaglia participa das reuniões do Edifício Esther onde os arquitetos articulavam a criação do departamento paulista do Instituto de Arquitetos do Brasil. No mesmo ano é contratado pelo Escritório Technico Francisco Matarazzo Neto onde trabalha Lucjan Korngold que, em 1946, projetaria o cartão postal da cidade, o edifício $\mathrm{CBI}$, no vale do Anhangabaú, uma referência para as edificações comerciais projetadas a partir de então. 
Em 1942, Galiano Ciampaglia funda com Miguel Forte o escritório Forte \& Ciampaglia focado na casa moderna paulista.

Em 1943, Galiano Ciampaglia acompanha a criação do Departamento Paulista do Instituto de Arquitetos do Brasil.

Em 1944, Galiano Ciampaglia funda com Jacob Ruchti, Miguel Forte e o engenheiro Nagib Lotaif, a Arquitécnica.

Em 1946, Galiano Ciampaglia, Jacob Ruchti e Miguel Forte vencem com outras duas equipes o concurso para a sede paulistana do Instituto de Arquitetos do Brasil.

Em 1947, dois projetos de Galiano Ciampaglia, Jacob Ruchti e Miguel Forte são publicados nas revistas Architectural Record e Architectural Forum. No mesmo ano, é fundada a Faculdade de Arquitetura Mackenzie e inaugurado o Museu de Arte de São Paulo MASP.

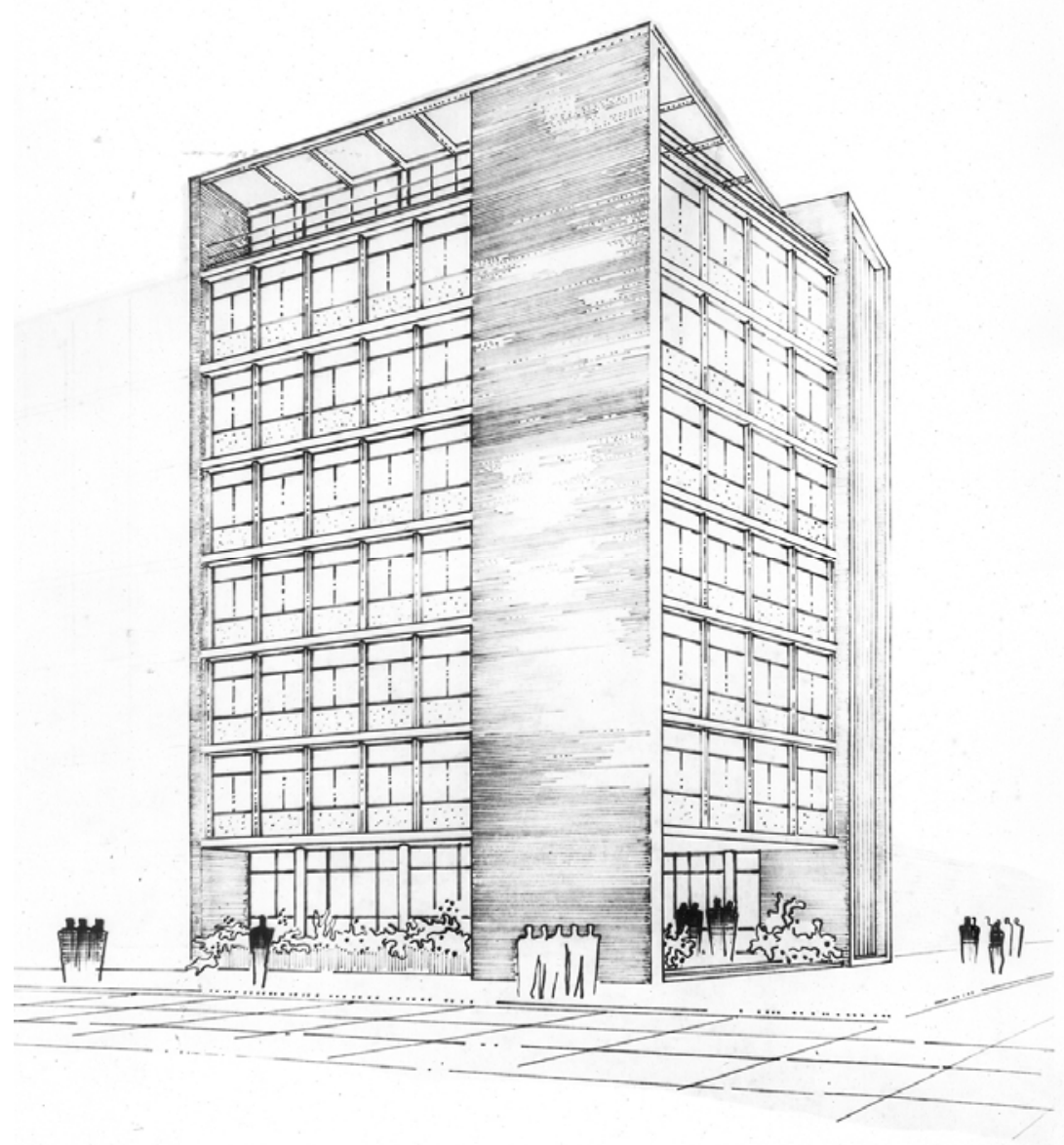


Em 1948, é criada a Faculdade de Arquitetura e Urbanismo da Universidade de São Paulo e o Museu de Arte Moderna. A Assembléia de fundadores, presidida por Matarazzo, é assinada em 3 de junho por intelectuais, pelo crítico Sergio Milliet, e por alguns arquitetos, entre eles, Eduardo Kneese de Mello, Galiano Ciampaglia, Jacob Ruchti, Luiz Saia, Miguel Forte, Rino Levi, Roberto Cerqueira César, Salvador Candia e Vilanova Artigas.

Em 1950 é inaugurada a sede paulistana do Instituto de Arquitetos do Brasil, projetada por Abelardo de Souza, Galiano Ciampaglia, Helio Duarte, Jacob Ruchti, Miguel Forte, Rino Levi, Roberto Cerqueira César e Zenon Lotufo.

Em 1950, um convênio entre o MoMA e o MAM sinaliza a criação da I Bienal do Museu de Arte Moderna. A mostra aberta em 20 de outubro de 1951 é vista como "o ápice de um percurso" 130 para a institucionalização do moderno como um todo.

Em 1953-54, na mostra conhecida como a Bienal do IV Centenário da cidade de São Paulo, Galiano Ciampaglia e Miguel Forte expõem uma residência projetada nos anos 40 .

Em 1954, Galiano Ciampaglia integra a diretoria do IAB-SP como vice-presidente da chapa de Rino Levi.

Em 1956, a residência Luis Forte, projetada por Galiano Ciampaglia e Miguel Forte, integra a antologia de Henrique Mindlin, Modern Architecture in Brazil, prefaciada por Giedion e publicada na Holanda.

Em 1957, Galiano Ciampaglia e Miguel Forte expõem três residências na IV Bienal do Museu de Arte Moderna de São Paulo.

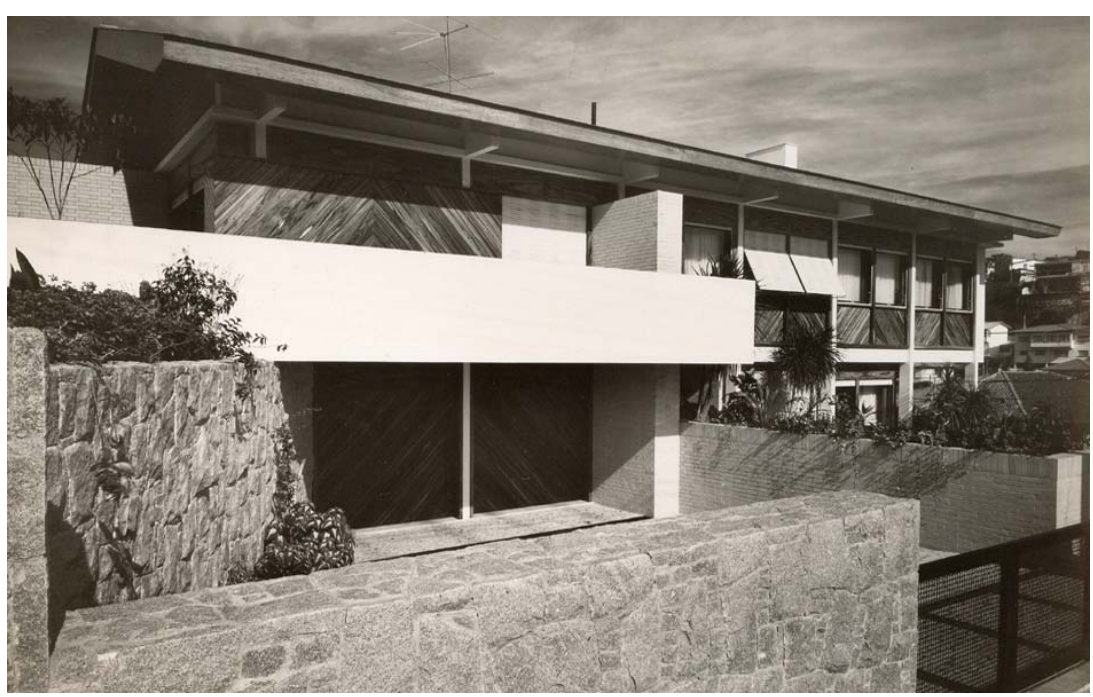




\section{* A Arquitécnica e o concurso IAB-SP}

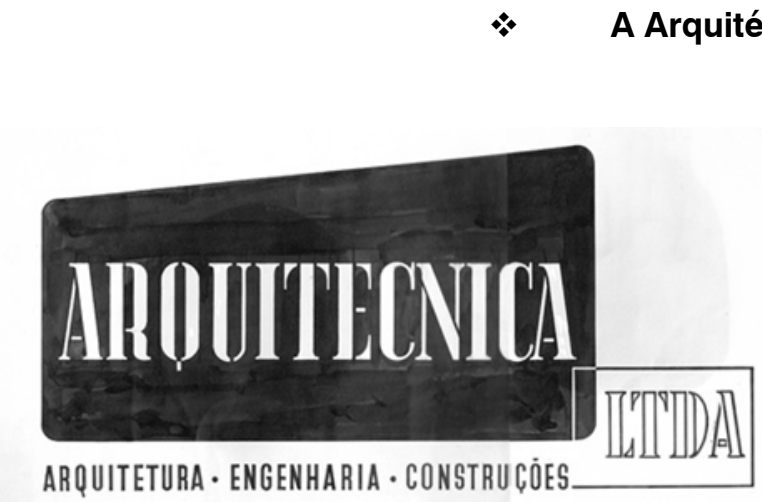

PLACADE OBRA

LOGOJACOBRUCHT

ARQUIVOGC

É fato que o concurso para o edifício-sede IAB-SP representa um marco de projeção na trajetória de Galiano Ciampaglia e, também na de Jacob Ruchti e Miguel Forte, integrantes da equipe mais jovem dentre as premiadas. $\mathrm{O}$ que se desconhece é $\mathrm{o}$ fato de o evento estar vinculado a outros papéis assumidos pelos arquitetos, quando à frente da Arquitécnica, sociedade instalada no escritório que acolheu a primeira reunião das equipes vencedoras, em 26 de outubro de 1946.

Em 1944, o entusiasmo de Galiano Ciampaglia e de Miguel Forte, por Frank Lloyd Wright, era também compartilhado por Jacob Ruchti que, em 1941, havia relacionado os conceitos espaciais do mestre norte-americano com a arte abstrata ${ }^{131}$. Diante do boom imobiliário daqueles anos e do cliente cioso do projeto e da construção pelo mesmo profissional - como declarou Forte a Ficher ${ }^{132}$-, os três arquitetos associam-se ao colega de estudos, engenheiro Nagib Lotaif, dispostos a atender as circunstâncias de mercado.

Além de um edifício residencial que agrega propósitos mais amplos, como o de incorporação, o grupo assumiu a construção de edificações projetadas por Galiano Ciampaglia e Miguel Forte, como a fábrica de guarda-chuvas S/A Domingos Forte, cuja qualidade do projeto resultou na inclusão do escritório Forte \& Ciampaglia, na Lista de Ouro da Prefeitura do Município de São Paulo. A respeito de projetos compartilhados, também por Jacob Ruchti, sabe-se de um edifício no Guarujá (não construído) e um conjunto de pequenas residências construídas no Brooklin. Sem originais ou endereços que conduzissem aos processos municipais, apenas uma delas consta da edição de novembro de 1947, da Architectural Forum, dedicada à produção brasileira. 
Ausente nas biografias de Miguel Forte e mais recentemente, na de Jacob Ruchti ${ }^{133}$, a Arquitécnica está inserida no período de relevantes eventos na trajetória dos arquitetos, como o próprio concurso do edifício-sede IAB-SP e a viagem de seis meses que Forte e Ruchti empreendem aos Estados Unidos, entre março e agosto de 1947. No caso desta, a recente premiação do concurso para a sede paulistana do IAB compartilhada com duas equipes de destacados profissionais e o sucesso de comercialização de um empreendimento residencial, motivaram os viajantes a adicionar ao roteiro cultural, a divulgação dos trabalhos realizados pelo grupo e o interesse por futuras importações e representações uma vez que a sociedade estava habilitada para transações comerciais.

Em cumplicidade com Galiano Ciampaglia à frente dos trabalhos em São Paulo ${ }^{134}$, inclusive o projeto em desenvolvimento no escritório de Rino Levi ${ }^{135}$, o manuscrito de Miguel Forte, publicado em 2001, refaz o percurso desses interesses, como a apresentação de projetos do grupo ao diretor do MoMA, Philip Johnson, e ao editor-chefe da Architectural Record, Mr. Kenneth Stowel, ou ainda, os contatos mantidos com firmas de cimento e de móveis, além de uma suposta conquista da representação da loja América House.

Sem viabilizar as metas pretendidas, além da divulgação de dois projetos nas revistas Architectural Record e Architectural Forum, o grupo foi desfeito em dezembro de 1947, concentrando-se Galiano Ciampaglia e Miguel Forte, nos projetos de residências.

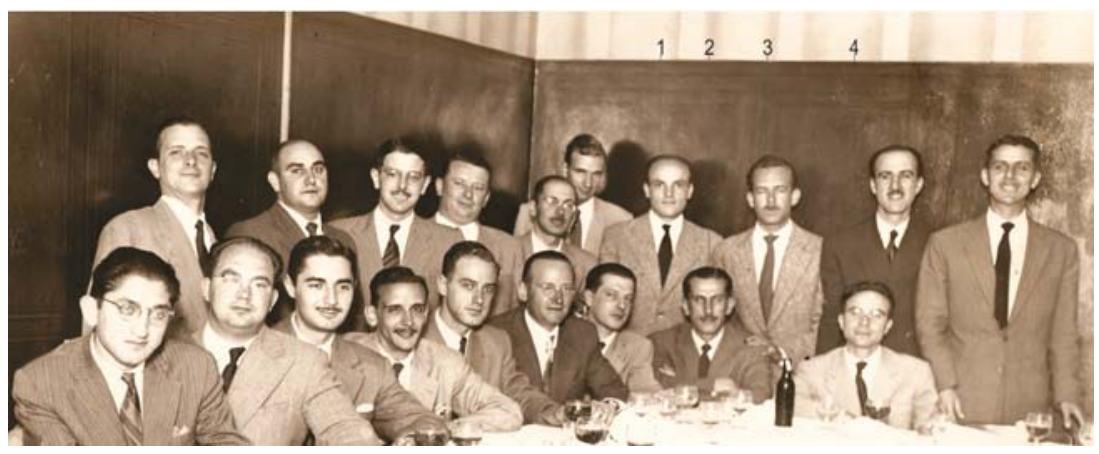



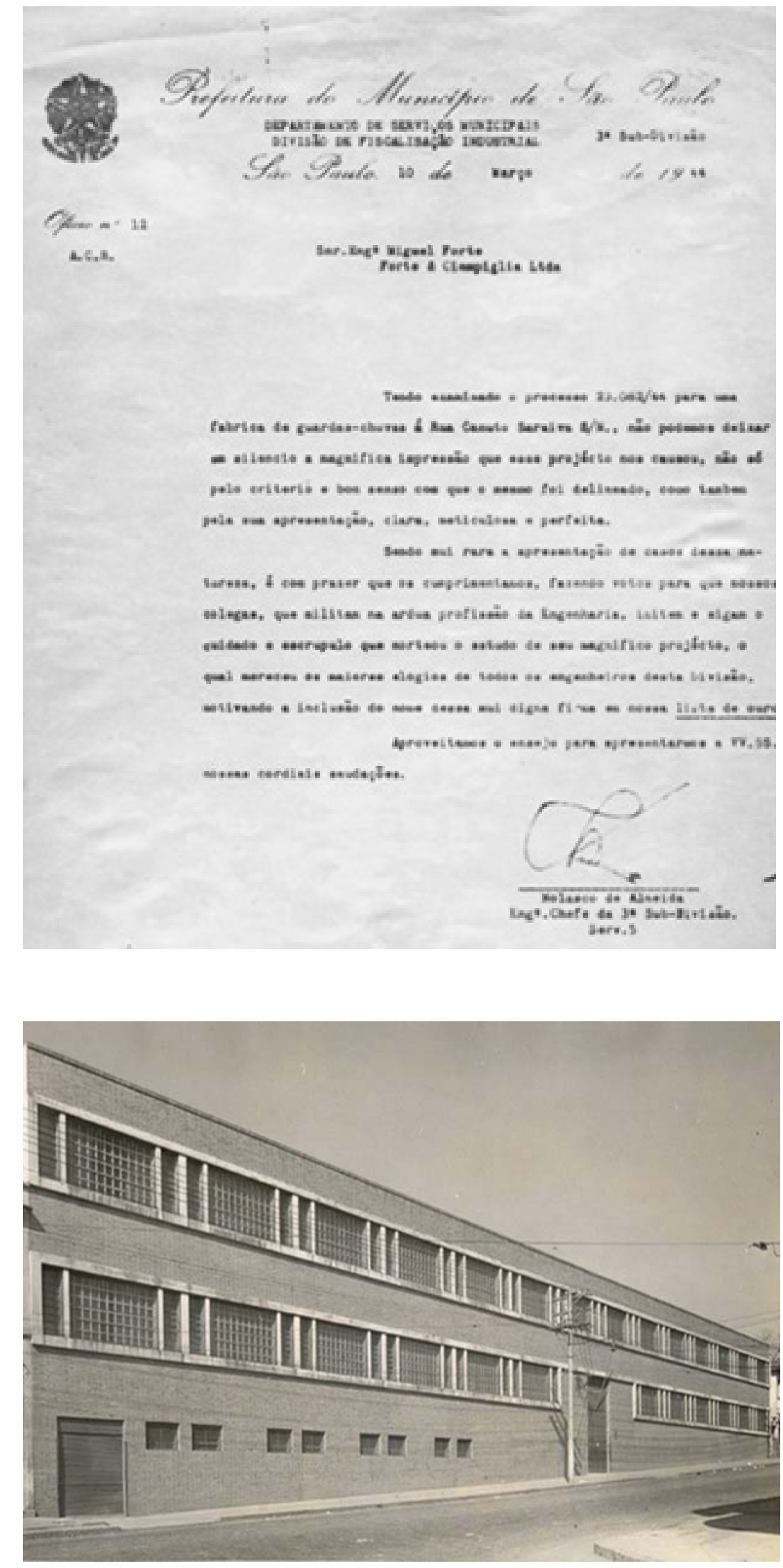

OFICIO PMSP N. 12 DE 10/03/1944

1944. S/ADOMINGOS FORTE

GALIANO CIAMPAGLIAE MIGUEL FORTE

CONSTRUÇÃO: ARQUITÉCNICA

ARQUIVOF\&C 
PROJETOFORTE, RUCHTI ECIAMPAGLIA
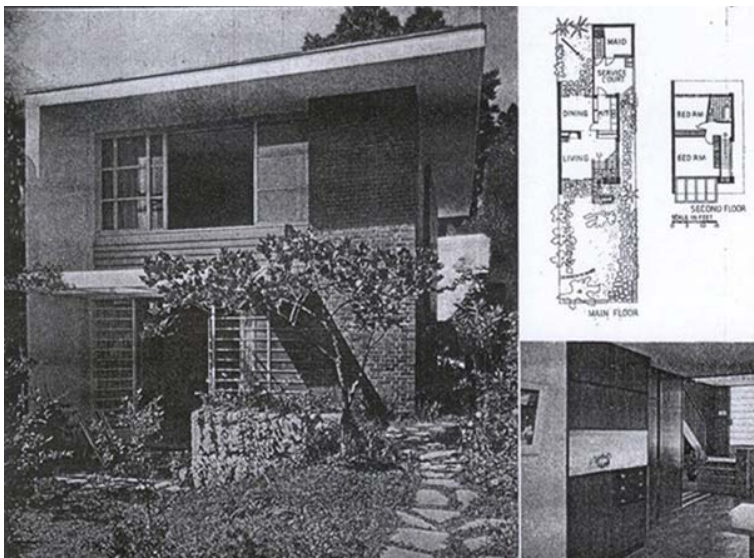

HOUSE FOR NARROW LOT

FORTE, RUCHTI, CIAMPAGLIA, Architect

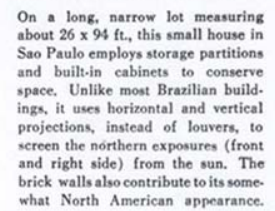

CONSTRUÇAÕ: ARQUITÉCNICA

THEARCHITECTURAL FORUM, 1947, 97

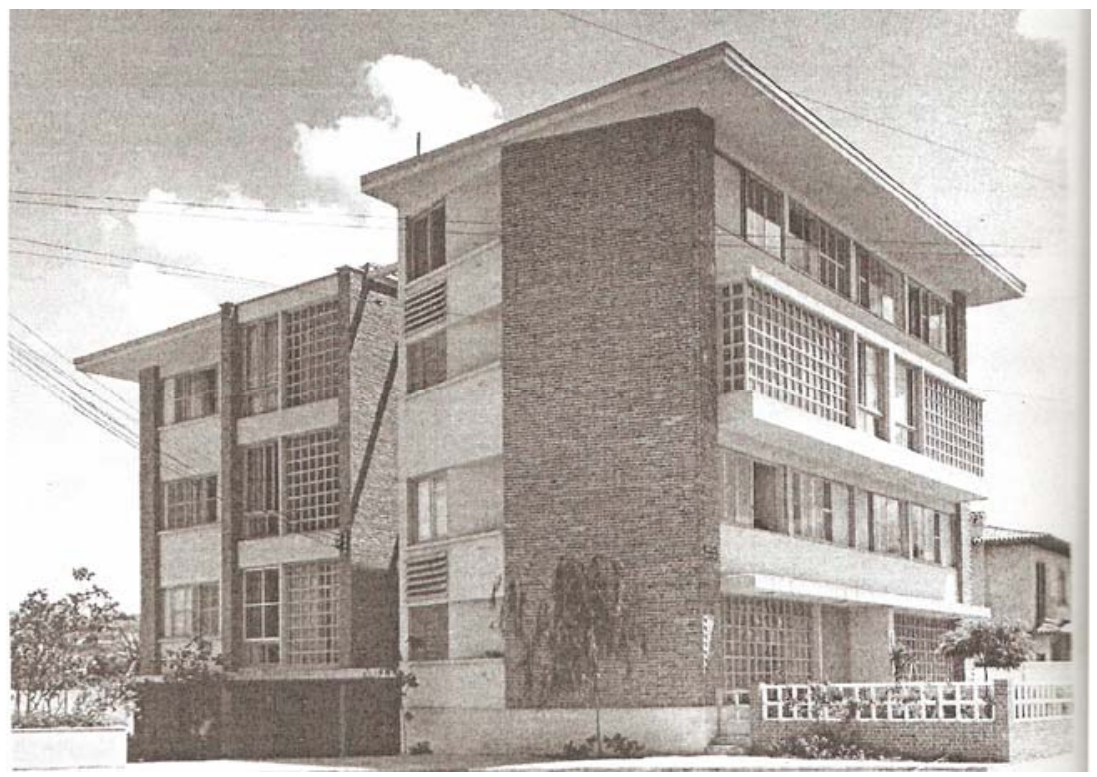

Os abatxo assinados, Jacob wauricie Buchti, biguel Forte, Galiano (iampaglia e Nagib Iotaif, querendo construir um predio de apartiméntos de tres andares, em terreno des sus propriedade sito à Av.Rebouçãs esd.da Rua Henrique Schaumann, vem respellosamente requerer a V. Excia.que se digne mandar aprovan is plantas e memoriaes anexos.

Comur cam mais que os autores do projèto são os arquitètos diplomados:Miguel Forte e Galiano Ciampaglia com escritorio' à Rua Xavier de loledo no 140,100 and. sala 3 , telefone $4-8885$, e que o engenheiro responsavel pela construção è Nagib Lotaif, engenheiro diplomado, com escritorio à Rua Dr.Falcão Filho 56,129and. sala 1222, telefone 2-6961.

$$
\begin{gathered}
6-4415 \quad 4-888 \mathrm{j} \\
\text { Nestes utermos } \\
\text { P.D. }
\end{gathered}
$$

São Paulo, 7 de julho de 1944 .

\section{DE CIMAPARABAIXO:}

1944. EDIFICIO HENRIQUE SCHAUMANN

ACAYABA, 1994, P. 33

\section{REQUERIMENTO DE ALVARÁ DE CONSTRUCÃO}

PROPRIETÁRIOS: JACOB M. RUCHT, MIGUEL FORTE, GALIANO CIAMPAGLIAENAGIB LOTAIF

AUTORES DOPROJETO: MIGUEL FORTEE GALIANO CIAMPAGLA

ARQUIVO PMSP 
Sobre o edifício residencial localizado na esquina da Rua Henrique Schaumann com Avenida Brasil, o estudo resgata o projeto e informações adicionais. Projetada em 1944 e demolida posteriormente para reurbanização da área, a obra antecipa alguns conceitos que seriam aplicados na proposta apresentada no concurso do edifício-sede IAB-SP. Alternando ortogonalidade e traçados angulares, o edifício de três andares tem nas empenas o elemento definidor de verticalidade. A doutrina funcionalista é expressa na fachada de dois blocos independentes de apartamentos em nível e unidades duplex. A angulação de 15 o é determinante no polígono de seis faces e recurso de articulação funcional interna. Em ambos os blocos, saliências são uma constante. Um elemento pouco usual à época, em edifícios, é a lareira proposta como elemento de ambientação nas unidades de um só pavimento. Nas empenas internas identifica-se um mosaico desenhado por Ruchti.

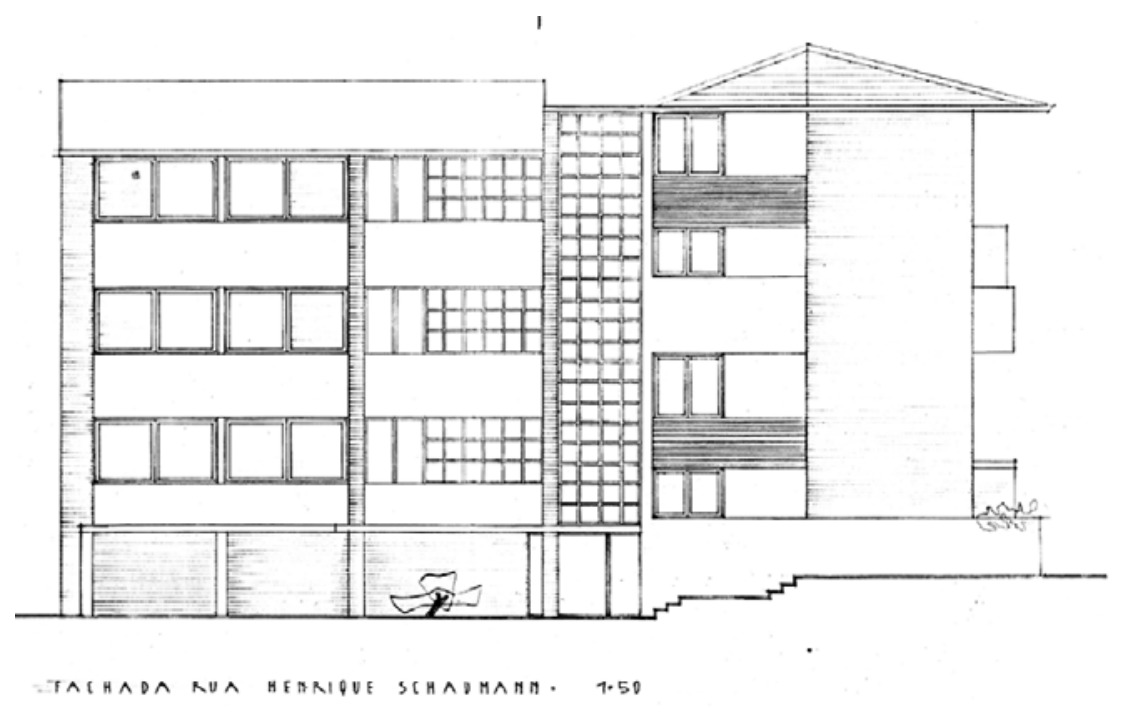

1944. EDIFÍCIO HENRIQUE SCHAUMANN

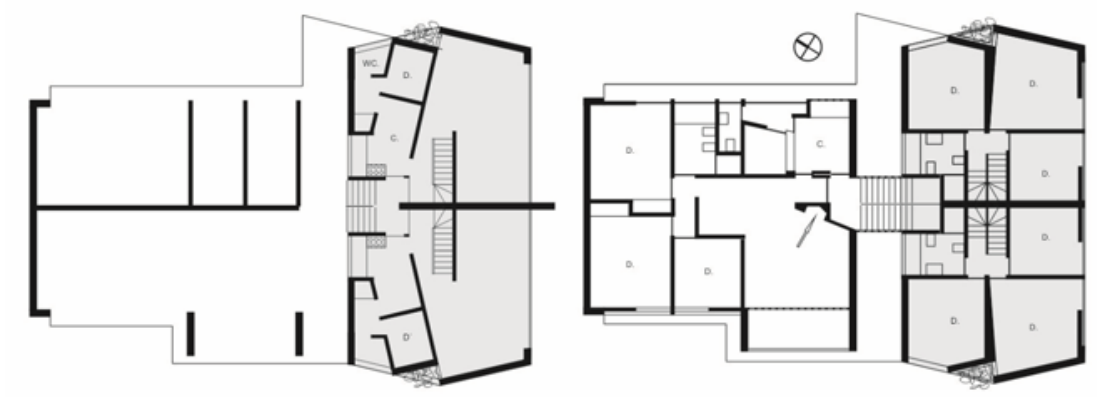

ARQUIVOFAU-USP

AOLADO:

PAVIMENTOS ALTERNADOS

REDESENHO

FONTE: ARQUIVO PMSP 
O Instituto de Arquitetos do Brasil, fundado para fomentar a discussão da arquitetura e divulgar a profissão do arquiteto na sociedade brasileira, somente a partir de 1931 se posicionaria na defesa da renovação arquitetônica em sintonia com as mudanças empreendidas por Lucio Costa na sua breve passagem como diretor da Escola Nacional de Belas Artes do Rio de Janeiro.

Os esforços de Eduardo Kneese de Mello para a criação do Departamento Paulista do Instituto dos Arquitetos são concretizados em 1943. Em 1945, após o 1o Congresso Brasileiro de Arquitetos sediado na cidade, o movimento para a construção de uma sede própria ganha importância. Adquirido o terreno com a venda do point que havia se transformado o subsolo do Edifício Esther, decidiu-se que para o projeto seria realizado um concurso entre os associados, sem prêmios aos vencedores e tampouco honorários para o desenvolvimento do projeto final. Uma diretoria provisória era então representada por Eduardo Kneese de Mello (presidente), Aldo Ferreira (Vice-Presidente), Vilanova Artigas (10 Secretário), Hélio Duarte ( 2 o secretário) e Oswaldo Corrêa Gonçalves (tesoureiro). No mesmo ano é lançado o Condomínio I.A.B. cotizado, entre outros, por Eduardo Kneese de Mello, Galiano Ciampaglia, Jacob Ruchti, Leo Ribeiro de Moraes, Miguel Forte, Rino Levi e Vilanova Artigas.

O edifício construído integra antologias da literatura, como Modern Architecture in Brazil ${ }^{136}$, Roteiro da Arquitetura Contemporânea de São Paulo ${ }^{137}$ e Arquitetura Moderna Paulistana ${ }^{138}$, nas quais é unânime a referência à inter-relação espacial expressa externamente, à estrutura independente, ao enquadramento da volumetria e ao compartilhamento das equipes premiadas.

Em 2002, durante a gestão de Gilberto Belleza, o edifício foi tombado pela Secretaria da Cultura do Estado de São Paulo por sintetizar "o que havia de mais progressista no repertório da arquitetura moderna brasileira de então" ${ }^{139}$.

Fez sentido, em 1975, o olhar crítico de Salvador Candia atribuir ao "confuso" edifício, a presença de Mies, de Wright e de Le Corbusier, segundo ele, uma constatação reconhecida por Rino Levi durante as obras do edifício: "é, mas isso aí é um projeto feito por seis, sete, oito pessoas" ${ }^{140}$. 
Não por acaso esta teria sido a intenção do júri ao premiar três equipes de diferentes ideários e estabelecer um intercâmbio mais estreito da produção paulista com as experiências cariocas em um momento em que "a centralidade do Rio se impunha" ${ }^{141}$.

É o que sugerem o concurso para a nova sede do Ministério da Educação e Saúde e o concurso realizado pela Usina Esther, na capital paulista, ambos vencidos por profissionais cariocas. No caso do MES, a premiação descartada pelo ministro Gustavo Capanema acabou por revelar o grupo de Afonso Eduardo Reidy, Carlos Leão, Ernani Vasconcelos, Jorge Moreira e Oscar Niemeyer, dirigido por Lucio Costa, que aplicou pela primeira vez elementos corbusianos como pilotis, planta livre, toit-jardin, brise-soleil e pan-verre. Da mesma forma, o concurso para o Edifício Esther (1936), vencido por Álvaro Vital Brazil e Adhemar Marinho, ambos participantes do manifesto pró Lucio Costa na ENBA, em 1931, resultou na aplicação dos dogmas corbusianos. Neste caso, trata-se do primeiro exemplar realmente moderno inaugurado na cidade de São Paulo, em 1938. Ressalva-se que no mês da premiação do concurso IAB-SP (outubro de 1946), Eduardo Kneese de Mello transmite em um artigo da revista Acrópole o entusiasmo dos paulistas com a arquitetura carioca: "é luz, é verdade, é distribuição racional, é segurança, é conforto, é regionalismo" ${ }^{142}$. Dois anos depois, Oswaldo Corrêa Gonçalves não pouparia elogios a Lucio Costa e Oscar Niemeyer na mesma revista ${ }^{143}$.

E) LUCIOCOSTAEOMES RIO DE JANEIRO, 1987 SEGAWA, 2002, P. 93

(D) ÁLVARO VITAL BRAZLL EOEDIFÍCIOESTHER SÃOPAULO,1985 OP.CIT. P. 86
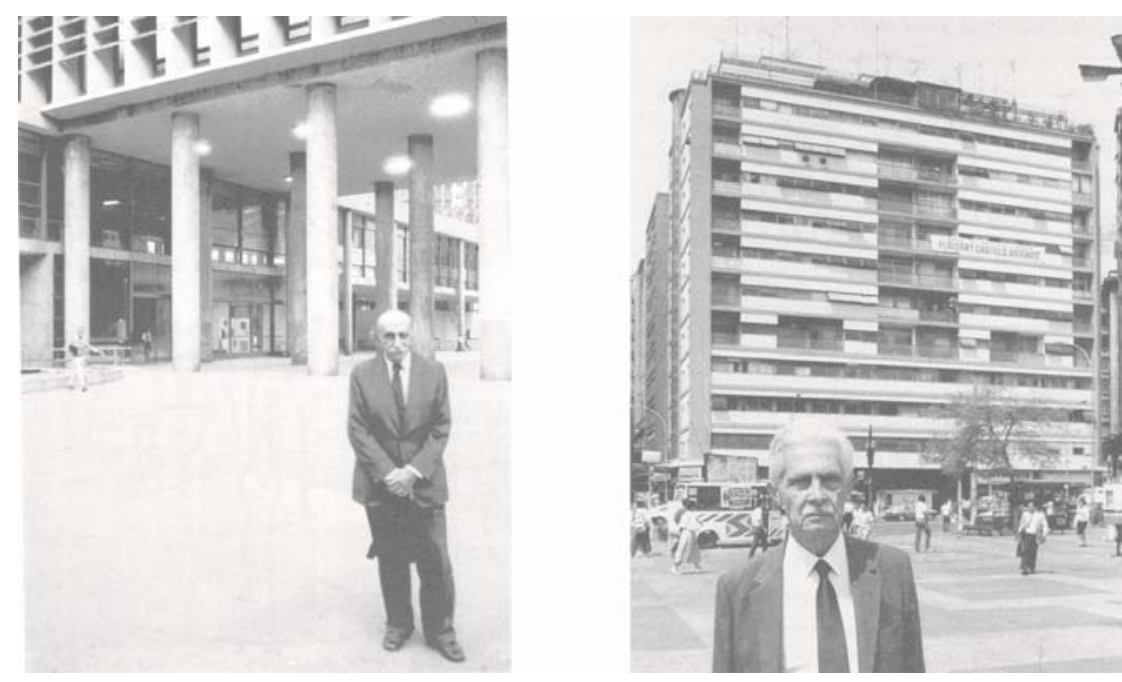
Em relação ao júri do concurso para a sede paulistana do $I A B$, à exceção de Gregori Warchavchik, formado pelo Regio Istituto Superiore di Belli Arti de Roma, e de Firmino Saldanha, formado pela Escola Politécnica (RJ), Fernando Saturnino de Brito, Helio Laje Uchôa Cavalcanti e Oscar Niemeyer são diplomados pela ENBA-RJ sob a influência de Lucio Costa quando diretor da escola. Por sua vez, Niemeyer, à época do concurso, já havia sido reconhecido internacionalmente para o movimento moderno brasileiro: em 1939, ao projetar com Costa e Paul Lester Wiener, o Pavilhão Brasileiro da Exposição Mundial de Nova York, considerado o ponto alto da exposição com o merecido destaque da revista The Architectural Forum, e, em 1942, com o Cassino da Pampulha, onde "reinterpretou a concepção corbusiana de uma promenade architecturale em uma composição espacial de extraordinário equilíbrio e vivacidade" ${ }^{144}$.

$\mathrm{Na}$ ausência de um edital, as peças gráficas de duas das propostas vencedoras, hoje arquivadas na Fau-usp ${ }^{145}$ - a terceira proposta premiada nunca foi localizada -, sugerem 0 anonimato dos participantes, apresentação em folha única, ausência de texto explicativo e um programa de necessidades composto por Loja, Sala de exposições, Auditório, Restaurante, Escritórios, Sede IAB e apartamento para zelador.

Nos concursos, como observa Fialho, cliente e arquiteto não são colocados frente a frente assumindo o autor do projeto o papel de protagonista e seu próprio crítico, sendo "notório durante o processo de desenvolvimento do projeto vencedor de um concurso, suas qualidades serem desvirtuadas, sendo importante o conhecimento do mesmo em sua forma original" ${ }^{146}$. No caso do edifício-sede $\mathrm{IAB} / \mathrm{SP}$, a dimensão desse componente torna-se um desafio frente à Ata de premiação:

"A comissão encarregada de julgar o concurso [...] examinou os treze trabalhos apresentados e resolveu por unanimidade recomendar para o estudo e elaboração do projeto definitivo os arquitetos Rino Levi, Roberto Cerqueira César, Miguel Forte, Jacob Ruchti, Galiano Ciampaglia, Zenon Lotufo, Abelardo de Souza e Helio Duarte, autores das três soluções que maior soma de qualidades reuniram. Assim decidindo, pensa a comissão ter encontrado a forma de julgamento que melhor corresponde às finalidades $e$ condições do concurso aberto. Pela distribuição, localização e articulação dos elementos constitutivos da planta, os anteprojetos dos arquitetos Rino Levi, Roberto Cerqueira César, Miguel Forte, Jacob Ruchti e Galiano 
Ciampaglia, atendem melhor as necessidades do programa. Por outro lado, o projeto dos arquitetos Zenon Lotufo, Abelardo de Souza e Helio Duarte, sem resolver estas questões com a mesma clareza, apresenta, entretanto, plasticamente, mais qualidades. A indicação dos arquitetos mencionados para em conjunto estudarem o projeto definitivo, conduzirá fatalmente a uma solução melhor, solução em que todos os problemas fiquem plenamente resolvidos dentro do espírito que orienta a arquitetura contemporânea" ${ }^{147}$.

Helio Duarte e Abelardo de Souza, formam-se na ENBA (RJ), em 1930 e 1931, com a ressalva de Abelardo de Souza ter vivenciado a passagem de Lucio Costa como diretor da escola. Instalados em São Paulo, no início da década de 40, entre 46 e 48 desenvolvem projetos com Zenon Lotufo, formado pela Escola Politécnica de São Paulo, em 1936. Como referência das realizações consideradas "exemplares da estética carioca" ${ }^{148}$, o estudo recua à proposta vencedora do concurso para sede baiana da Associação Brasileira de Imprensa (A.B.I.), apresentada pelo grupo e caracterizada pelos elementos corbusianos, como a estrutura sobre pilotis, o toit jardin, o pano vertical de brise-soleil na fachada oeste, as plantas livres e o fechamento sinuoso independente da estrutura. A partir do perfil do júri, parece coerente o argumento sobre a enigmática proposta da equipe carioca, ser aquela que, sem resolver as questões de funcionalidade com a clareza das demais, "apresenta, entretanto, plasticamente, mais qualidades".
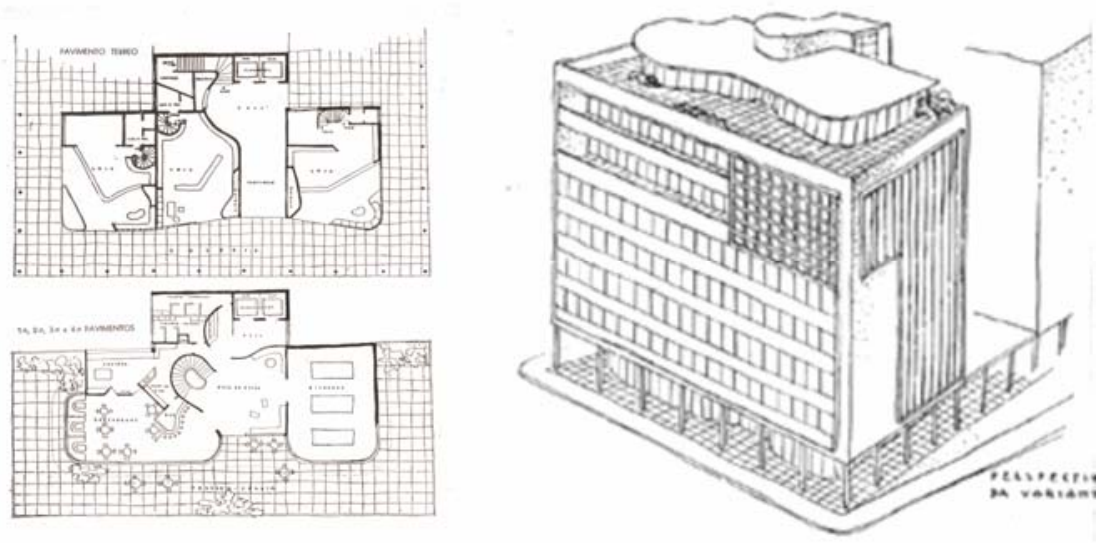
Rino Levi, formado em 1926 pela Escola Superior de Arquitetura de Roma, em 1945, associa-se a Roberto Cerqueira César, formado na Escola Politécnica de São Paulo, em 1940. Rino Levi, que "na escola romana convive com Adalberto Libera que se tornaria um dos protagonistas do racionalismo italiano em Roma" ${ }^{149}$, desenvolveu uma obra considerada "um modelo de continuidade" ${ }^{150}$. No caso da proposta premiada, a ortogonalidade da volumetria é definida por uma caixa de vidro justaposta à estrutura: no pavimento térreo, internamente, nos demais, externamente. A funcionalidade é expressa pela diferenciação de uso dos pavimentos e do escalonamento adequado às posturas municipais. Circulações verticais em diferentes pontos e escritórios concentrados nos últimos andares garantem 0 caráter independente das áreas abertas ao público e da sede do IAB, proposta em andar duplo intermediado por mezanino. Articulações e poucos traçados sinuosos são internos ao perímetro do edifício.
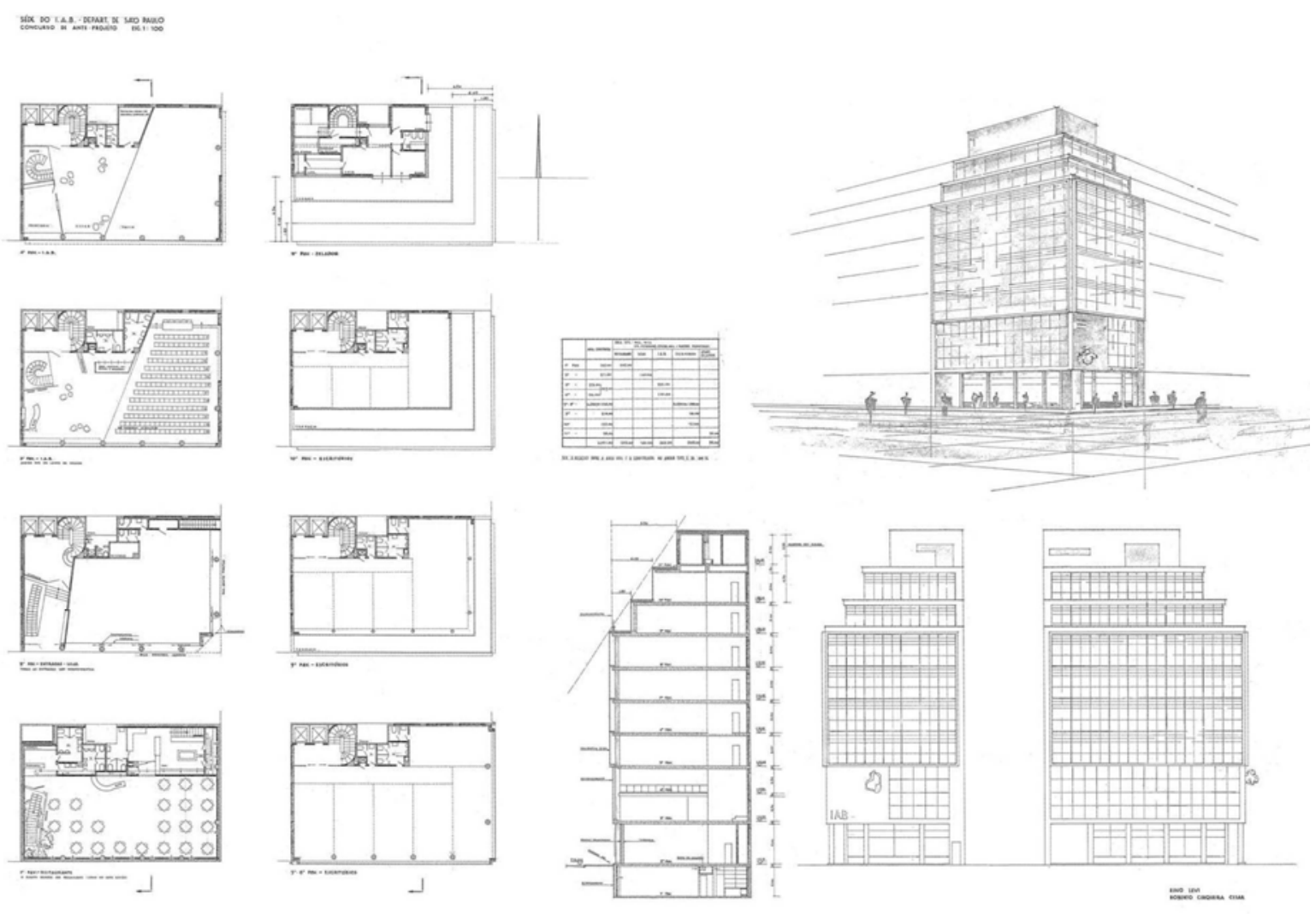

1946. PROPOSTA CONCURSO IAB-SP RINOLEV EROBERTOC. CÉSAR ARQUIVOFAU-USP 
A proposta apresentada por Forte, Ruchti e Ciampaglia, remete a alguns conceitos aplicados no edifício residencial, projetado em 1944. O edifício é caracterizado pelo enquadramento da volumetria agora garantido pela empena de tijolos como elemento definidor da verticalidade e pela área não computável de pérgolas e terraços nos andares superiores. É mantida a alternância de ortogonalidade com traçados angulares de $15^{\circ}$ e a lareira como proposta de ambientação na sede do Instituto. O acesso principal é proposto pela Rua Bento Freitas. A estrutura é interna ao perímetro e defasada dos caixilhos. Apenas no térreo e no $7^{\circ}$ andar é intermediada por painéis de vidro. A concentração dos acessos, circulação e serviços, se por um lado garante um melhor controle e racionalidade de instalações, compromete a independência de cada setor, sobretudo aquele reservado aos escritórios comprimidos entre as atividades da sede propostas em diferentes níveis.

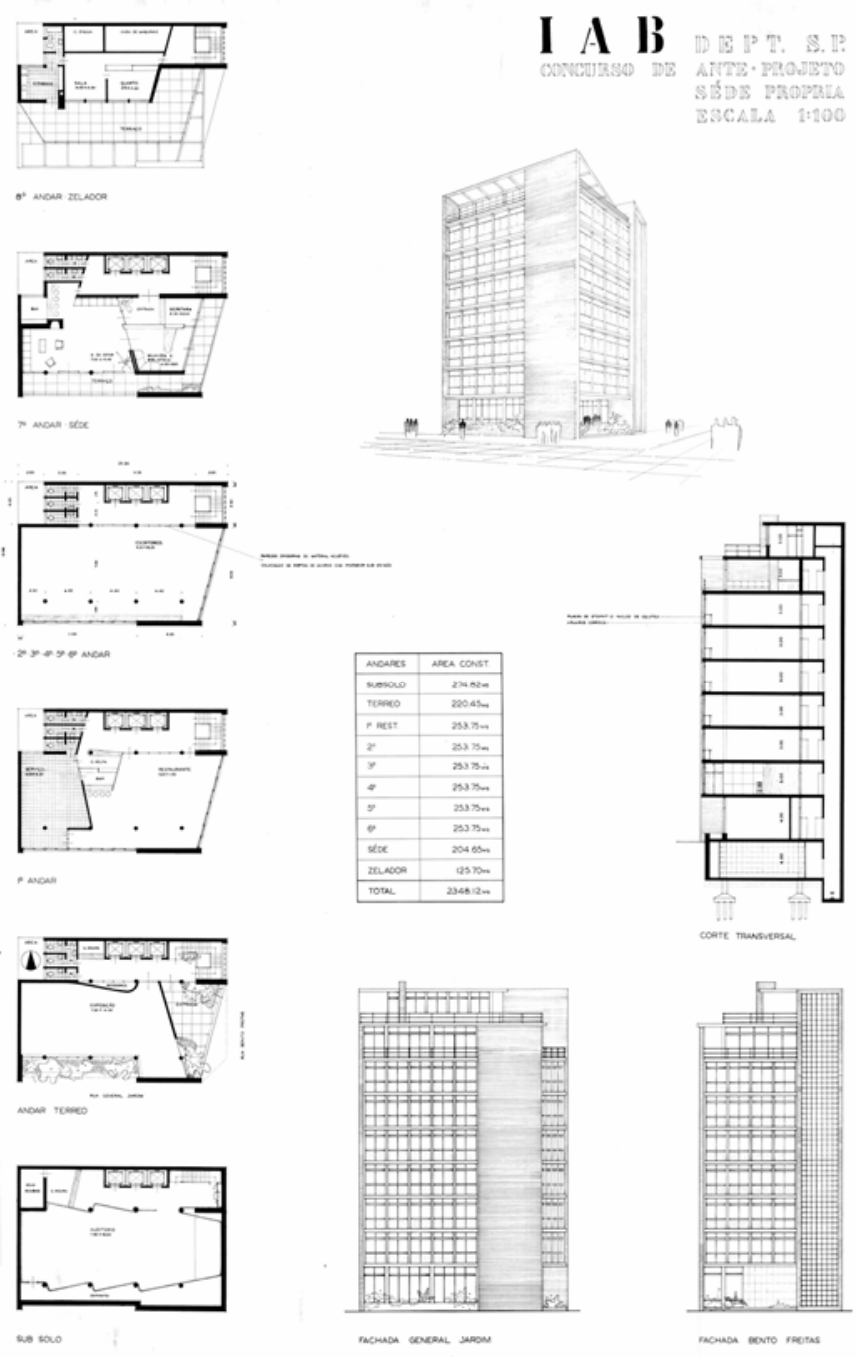


De acordo com Ata arquivada no Departamento Paulista do Instituto dos Arquitetos, a primeira reunião das equipes vencedoras é realizada no escritório da Arquitécnica, na presença de representantes das três equipes premiadas:

"Os abaixo assinados, arquitetos designados pelo Júri do concurso de anteprojeto para a elaboração do projeto definitivo da Sede do IAB- Depto. de S. Paulo, reunidos no dia 26 de outubro do corrente no escritório de "Arquitécnica Ltda", à rua Barão de Itapetininga, № 124-12으 andar, debateram o programa e demais detalhes inerentes e necessários à organização do novo projeto. Em conseqüência foram discutidas e aprovadas como sugestões à diretoria, as seguintes 5 teses:

1a tese: considerar como um todo indivisível as atividades cultural e social do I.A.B.

2a tese: considerar como desinteressadas, de qualquer caráter comercial, as iniciativas culturais do I.A.B.

3a tese: considerar como desnecessário no programa 0 apartamento do zelador.

4a tese: possibilitar aos andares destinados à venda, a divisão em grupos de 2 ou mais condomínios, cada um composto de sanitário, saleta e sala, num mínimo de 3 peças, como quer a lei.

5a tese: não considerar a idéia do restaurante público como ponto absolutamente essencial, tendo em vista que para facilidade dos sócios sua transferência para o bar do I.A.B., em caráter reduzido, seria mais proveitosa.

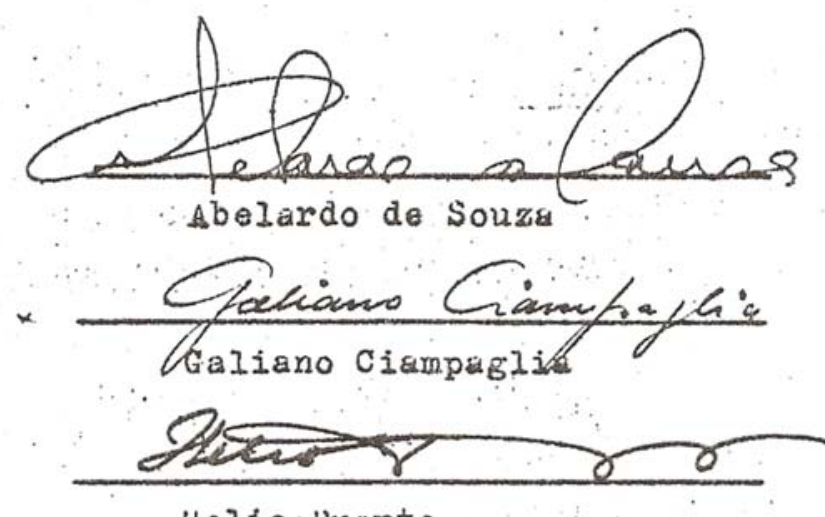

Hel10 Duarte
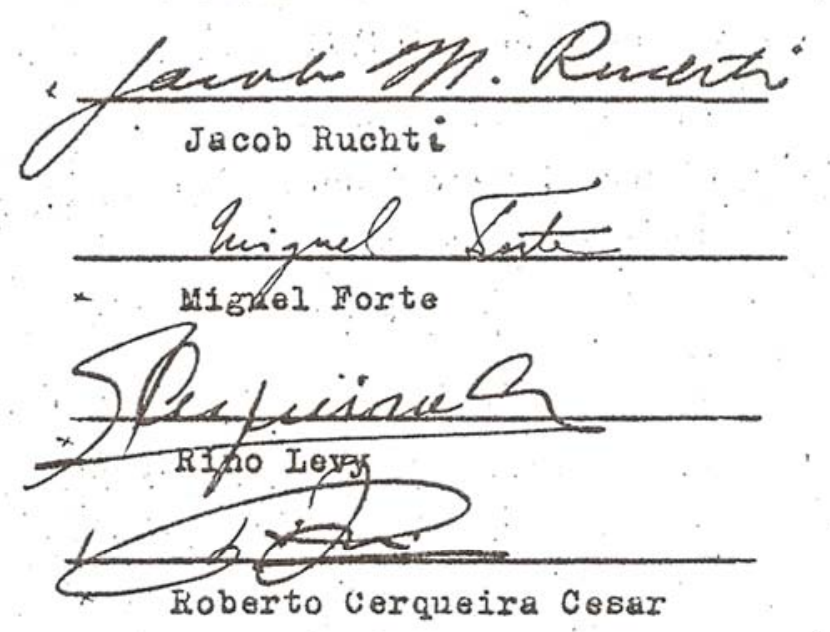

Zenon Iotueo 
Em 28 de dezembro de 1946, um novo projeto é protocolado na Prefeitura Municipal de São Paulo. No requerimento é clara a intenção de manter o enquadramento da volumetria sugerido pela proposta de Forte, Ruchti e Ciampaglia, como também o papel de Rino Levi como centralizador do processo:

[...] Outrossim, para melhor arranjo estético das fachadas e de acordo com entendimento com os engenheiros da divisão de urbanismo, pede a V. Exa. A concessão para manter no último andar o recuo exigido para o penúltimo, desistindo em compensação, de mais um andar recuado, ao qual teria direito, de acordo com o gabarito assinalado nos cortes. O arquiteto Rino Levi, autor do projeto e construtor responsável, fica autorizado a tratar do referido processo ${ }^{151}$.

1946. (E) PROPOSTA TERREO FORTE, RUCHTI E CIAMPAGLIA

(D) PROPOSTA SEDE IAB LEM E CERQUEIRA CÉSAR ARQUIVOFAUUUSP

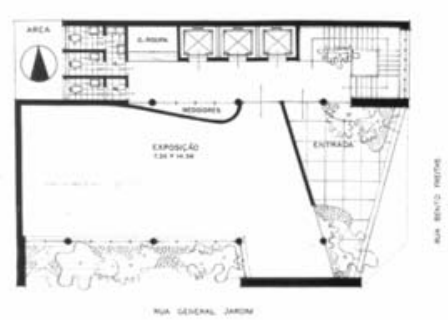

1946.

TÉRREO, SEDE IAB, ESCRITORIOS TIPO1E2 REDESENHO FONTE: PMSP N. 0.1010.417/46
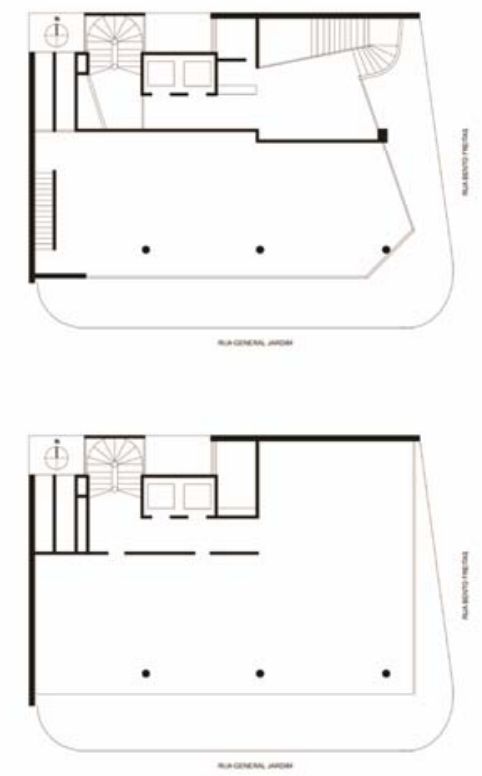

1947. PROJETOEXCUTIVO

(E) TÉRREO

(D) ESCRITÓRIOS TIPO 2 ARQUIVOFAU-USP
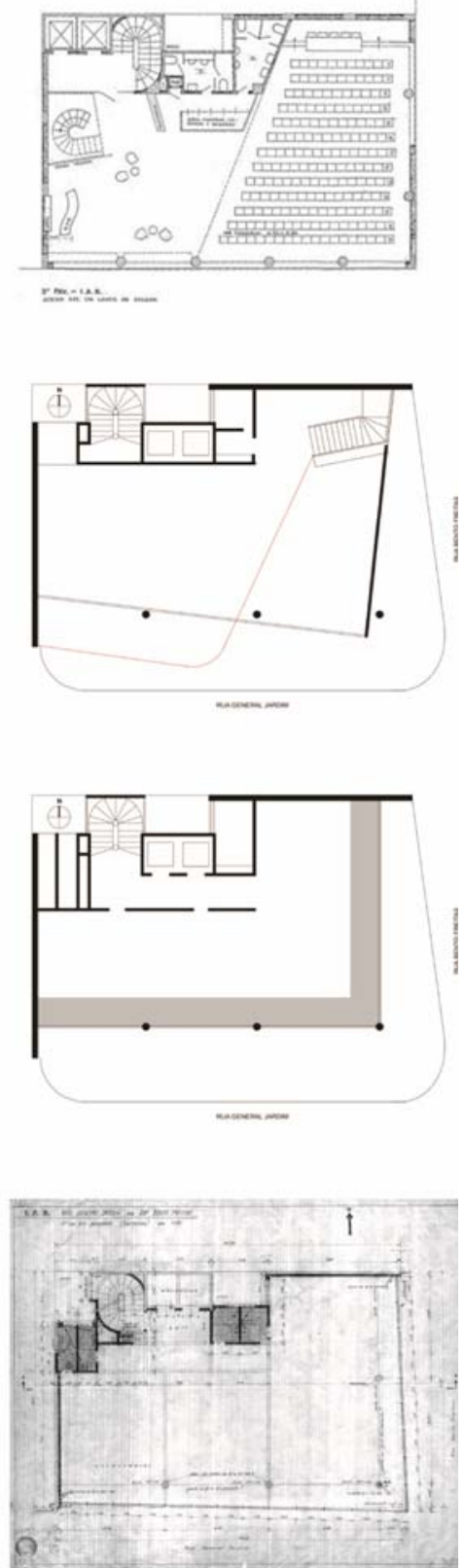

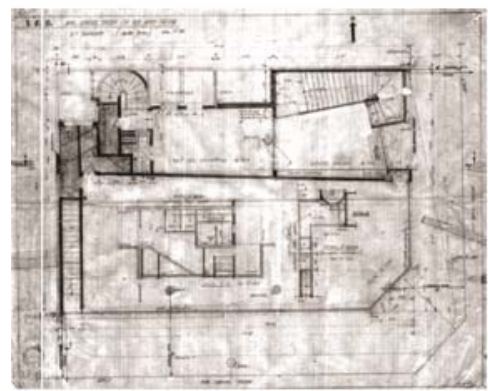


A análise das plantas anexas ao processo municipal, em confronto com as duas propostas disponíveis, sugere o que o novo projeto descarta, assume ou inova frente às mesmas. Da proposta de Levi e Cerqueira César, são mantidas a distribuição funcional, a sede em andar duplo intermediado por mezanino com auditório incorporado e a caixa de vidro para os escritórios. Da proposta de Forte, Ruchti e Ciampaglia, identificam-se o enquadramento da volumetria garantido por recuos nos dois últimos pavimentos, o acesso pela rua Bento Freitas e o desenho articulado do térreo.

É nítida uma nova intenção plástica para o andar duplo da sede IAB caracterizada por elementos compositivos sinuosos que rompem o enquadramento do edifício e pelo percurso de vedações por entre a estrutura agora em completa evidência.

Em 25 de março de 1947 o projeto é aprovado na PMSP com ressalvas quanto ao recuo dos dois últimos andares. Comparado com o projeto executivo, identificam-se ajustes no posicionamento dos elevadores, no traçado definitivo do térreo e no enquadramento da volumetria garantido por terraços nos dois últimos pavimentos.

As obras do edifício-sede IAB-SP foram concluídas em duas etapas: a primeira em 1949, sob a presidência de Kneese de Mello, e a segunda, em 1950, sob a presidência de Oswaldo Arthur Bratke. De 1946, quando as primeiras decisões foram tomadas, a 1949 quando o projeto executivo foi desenvolvido no escritório Rino Levi, entre os autores do projeto, Hélio Duarte e Abelardo de Souza participaram da diretoria IAB-SP, respectivamente como secretário (43 a 48) e eo vice-presidente (47 a 49). Entre os demais autores, participaram de diretorias da instituição: Roberto Cerqueira César, como vicepresidente (50 a 51), Rino Levi, como presidente (54 a 55) e Galiano Ciampaglia, como vice-presidente, em 54.

Para José Tavares Correia de Lira, a sede paulistana do IAB, projetada por um time também composto por arquitetos formados no Rio, está entre as obras paulistanas onde é possível reconhecer um intercâmbio mais estreito da produção local com as experiências cariocas ${ }^{152}$. É mais uma visão a sugerir uma reflexão sobre o recente afastamento da equipe carioca do projeto que deu origem ao edifício construído ${ }^{153}$. 


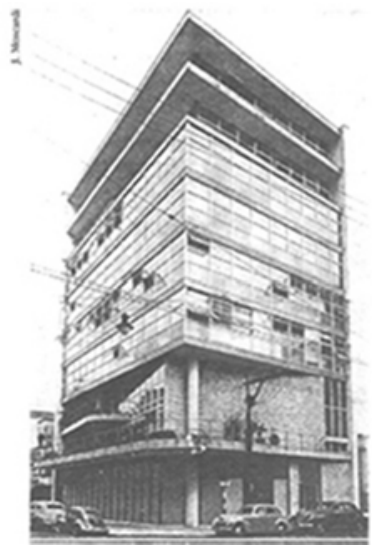

ACIMA

IAB-SP, 1950

ABELARDO DE SOUZA (1901-1981) GALIANO CIAMPAGLIA(N.1913) HÉLIO DUARTE (1906-1989) JACOB RUCHTI (1917-1974) MIGUEL FORTE (1915-2002) RINOLEV (1901-1965) ROBERTO CERQUEIRA CÉSAR $(1917-2003)$

ZENON LOTUFO(1911-1985
Em 2002, sob a presidência de Gilberto Belleza, Galiano Ciampaglia representa os colegas Abelardo de Souza, Hélio Duarte, Jacob Ruchti, Miguel Forte, Rino Levi, Roberto Cerqueira César e Zenon Lotufo, na cerimônia de tombamento do edifício-sede IAB-SP ${ }^{154}$.

Fizeram parte da mesa: Gilberto Belleza (Presidente IAB/SP), Jorge Wilheim (Secretário Municipal de Planejamento), Paulo Teixeira (Secretário Municipal da Habitação), Alonso (CREA/SP), Rosa Kliass (ABAP), Miguel Pereira (Vice-Presidente U.I.A.), Kleber Costa ( $p /$ Prefeito de Osasco), Haroldo Pinheiro (Presidente IAB/nacional), José Roberto Melhem (Condephaat) e Gianfranco Vanucchi (ASBEA)

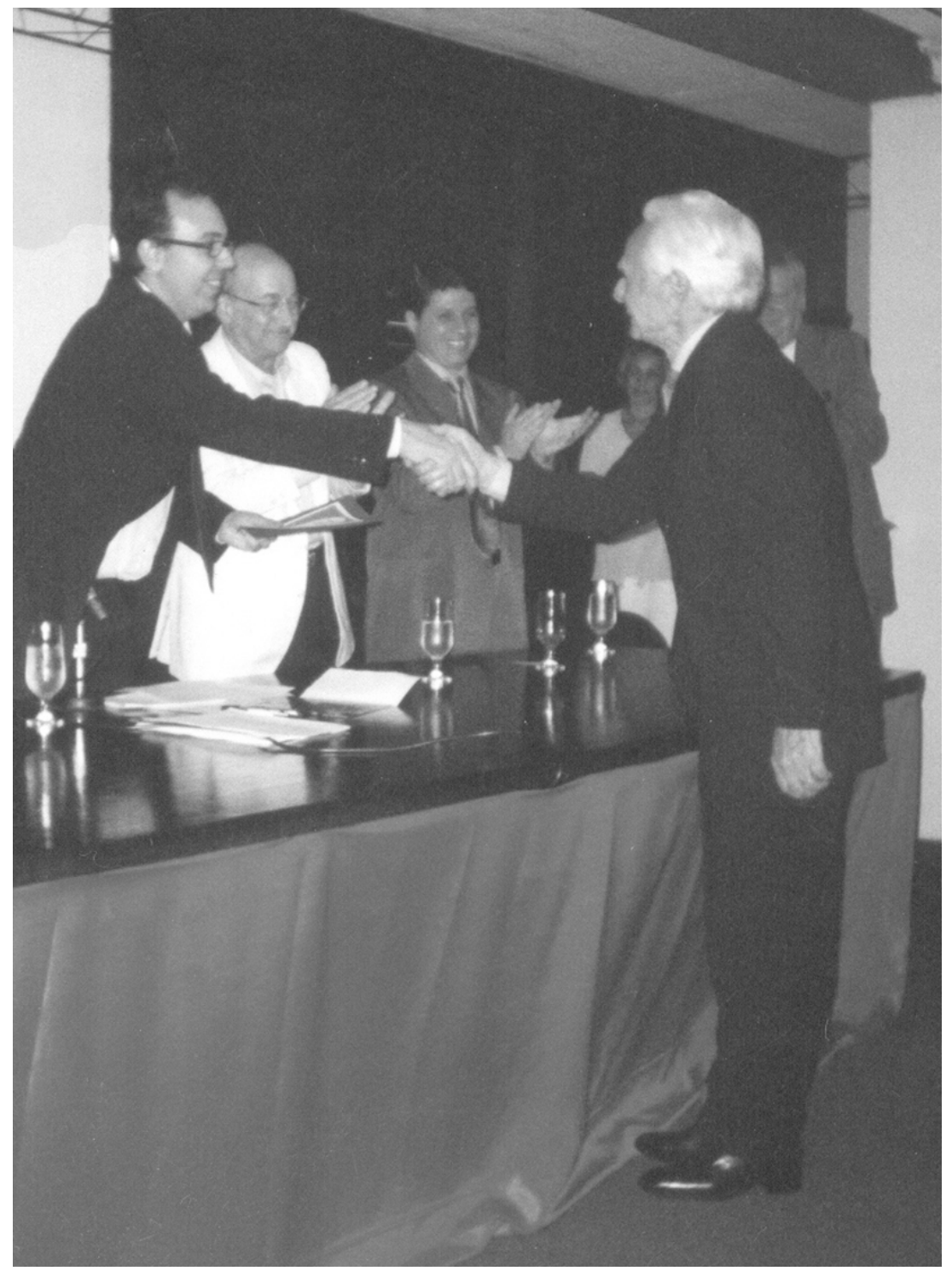

CERIMÔNIA DE TOMABAMENTO DO EDIFICIO-SEDE IAB-SP, 2002 GALANO CIAMPAGLIARECEBE OS CUMPRIMENTOS DE GILBERTOBELLZA ARQUIVOIAB-SP 


\section{* O professor}

Em 1964, logo depois da revolução, o ensino melhorou substancialmente. Nessa época lecionavam no Mackenzie, Telesforo Cristofani, Galiano Ciampaglia e Miguel Forte. Havia dois professores para cada classe. Meu companheiro era o Marcelo Fragelli. Nós tínhamos mais ou menos a mesma linha de trabalho, até participamos juntos de um concurso.

Rodolpho Ortenblad Filho

Em 1965, atuando como arquiteto autônomo desde 1958, Galiano Ciampaglia retorna ao Mackenzie como Professor da Faculdade de Arquitetura, no momento em que estavam sendo preenchidas vagas de docentes afastados por razões ideológicas, entre eles Alfredo Paesani, Fabio Penteado e Eduardo Corona ${ }^{155}$.

Indicado por Salvador Candia que entre 1964 e 1969 assumiria a direção da escola, Galiano ingressa no Mackenzie quando acabava de ser implantado o "Atelier Vertical", uma das propostas de Carlos Millan e Eduardo Corona de realizar mudanças no conteúdo didático. Mal sucedida, foi encerrada em 1965.

Nas aulas de projetos, compartilhadas por arquitetos identificados pela linha de trabalho, Galiano Ciampaglia atuou com David Ottoni e posteriormente, com Miguel Forte. Jun Okamoto recordou "aquela geração de professores que ensinavam aos alunos o valor do lápis como extensão da mente, atendendo a rapidez sucessiva da criação do pensamento" ${ }^{156}$.

Ruth Coslowsky, aluna de Galiano e de Miguel, em 1971, participou das visitas monitoradas por Forte às casas projetadas por ambos, nos anos 40 e 50. Anos mais tarde, a prática de Forte se estenderia às casas projetadas por Galiano, nos anos $60^{157}$.

O período como professor, coincide com a expansão do acervo de Galiano e anotações agora identificadas no caderno "Acadêmico". Ente elas, temas como o papel do arquiteto, o ensino de arquitetura, casa e cidade. Ex-aluno, Carlos Brandão Teixeira, recorda-se do professor e da aplicação prática da sua erudição como ferramenta de ensino.

Em 1972, o envolvimento com três importantes residências sugere o desligamento de Galiano Ciampaglia da escola. 


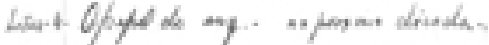

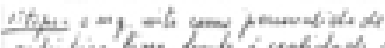

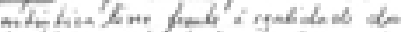

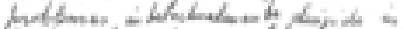

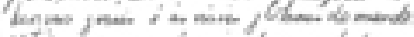

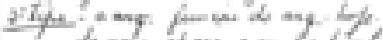

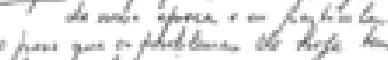

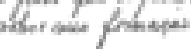

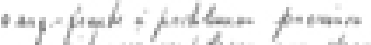

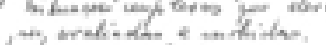

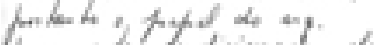

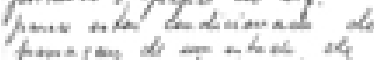

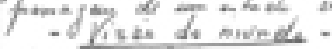
$\sin \frac{1}{2 n} \sin _{\alpha} \alpha$

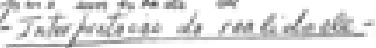

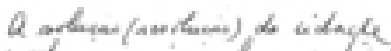

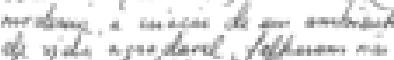

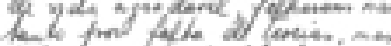
pele tome neopesidade

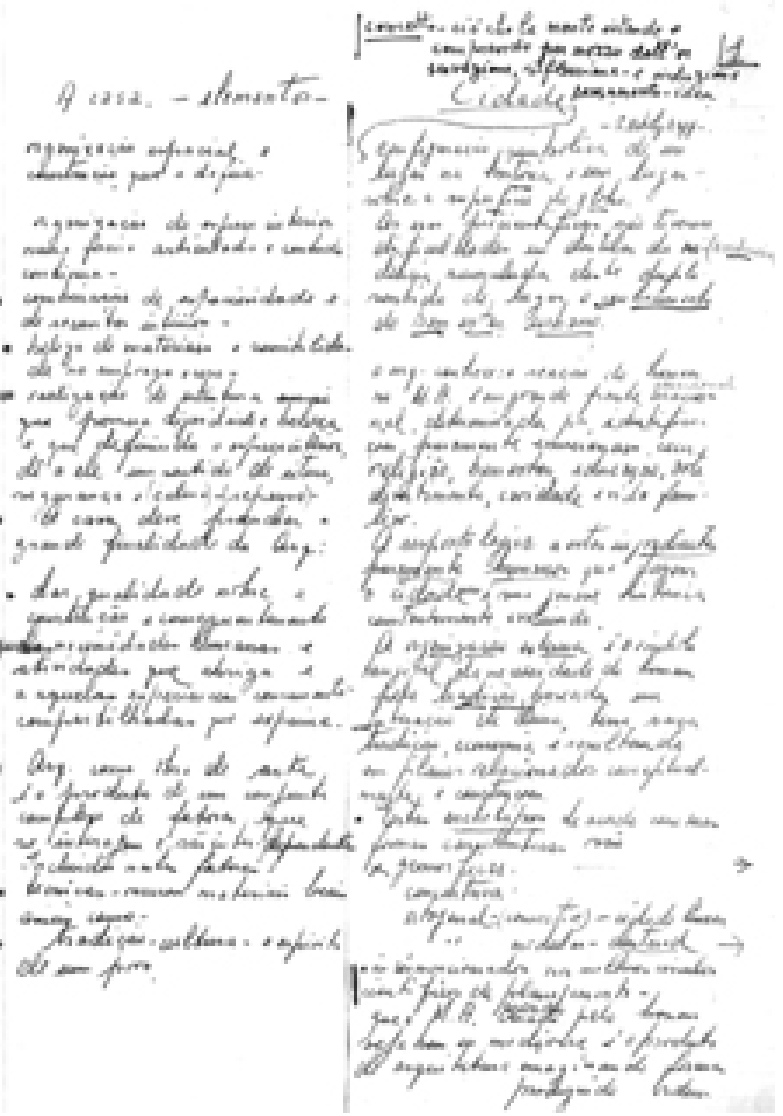

Arretithe.

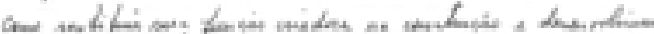

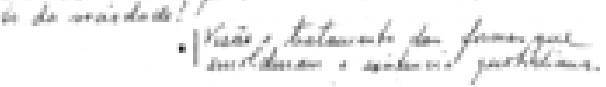

$a^{2}+42-2+2=-7$

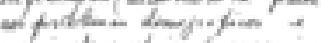

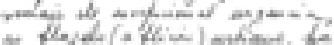

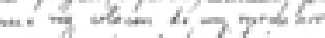

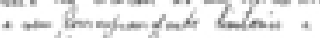

mation of a.t

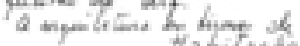

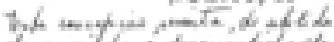

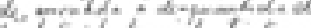

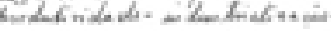

$4.24 \alpha$ a

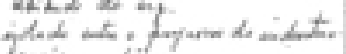

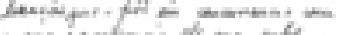

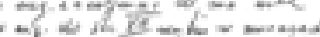

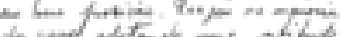

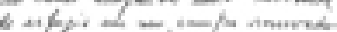

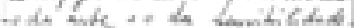

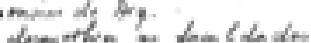
nitan as 22

$2^{2} y+2=-42^{2}+4 x^{2} y$

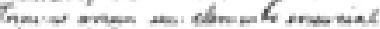
Lamida use

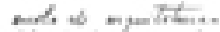

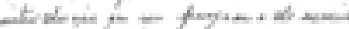

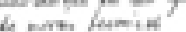

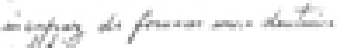

conter

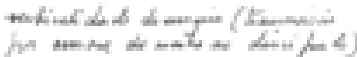

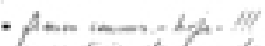

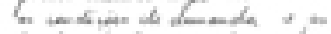

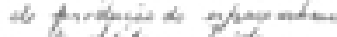

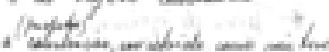

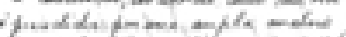

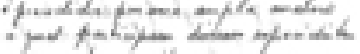

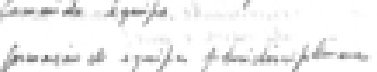


${ }^{1}$ ACAYABA, 1994, p. 32

${ }^{2}$ Avaliação de Carlos Lemos à autora em 9 de novembro de 2010

${ }^{3}$ Carlos Lemos considerou "tímidas" as entradas de ar. No caso, ressalva-se que o projeto foi elaborado durante o quarto ano letivo e a disciplina "Física Aplicada" só seria ministrada no sexto ano do curso.

${ }^{4}$ Comentário da Prof. Dra. Ruth Verde Zein

${ }^{5}$ Avaliação da Prof. Dra. Mônica Junqueira Camargo

${ }^{6}$ ZEVI, 1945, p. 82

${ }^{7}$ Entrevista de Eduardo de Almeida à autora em 13/03/2009

${ }^{8}$ GOMES MACHADO In Documento Galiano Ciampaglia, AU-114, set. 2003, p. 57

9 MORALES de LOS RIOS, Adolfo. Grandjean de Montigny e a evolução da arte brasileira. Empresa A Noite, Rio de Janeiro, 1941

10 HAUSER, Arnold. Storia sociale dell' arte/ I. preistoria Antichitá Medioevo. Milano: Giulio Einaudi Editore, 1955; Storia sociale dell' arte/ 2. Rinascimento Manierismo Barocco. Milano: Giulio Einaudi Editore, 1955; Storia sociale dell' arte/ 3. Rinascimento Manierismo Barocco. Milano: Giulio Einaudi Editore, 1956; Storia sociale dell' arte/ 4. Arte Moderna e contemporânea. Milano: Giulio Einaudi Editore, 1956

11 TOYNBEE, Arnold J. A study of History. Oxford University Press. New York, London, 1947 (rub. 1948)

12 BROWNELL, Baker. The Human Community. New York. Harper \& Brothers Publishers, 1950

${ }^{13}$ CROCE, Benedetto. Breviario de Estética. Lisboa: Livraria clássica Editora, 1914

14 HUSSERL, Edmund. La crise de l'humanité européene et la philosophie. Republications Paulet. (extrait de la Revue de Metaphysique et de Morale), Avril, 1968

${ }^{15}$ FAURE, Elie. History Art / Ancient Art. Garden City Publishing Co. Inc, 1937

${ }^{16}$ PACl, Enzo. Studi di Filosofia antica e moderna. G.B. Paravai \& C, 1949

${ }^{17}$ KAHLER, Erich. Man the measure. A new approach to history. New York: Pantheon Books, Inc., 1943

${ }^{18}$ CASSIRER, Ernst, Filosofia delle forme simboliche. Vol. 1. II Linguagio. La nuova Itália, Editrice, Firenze, 1967; Filosofia delle forme simboliche. Vol. 2. II pensiero mítico. La nuova Itália, Editrice, Firenze, 1966; Filosofia delle forme simboliche. Vol. 3 (tomo 1). Fenomenologia della conoscenza. La nuova Itália, Editrice, Firenze, 1967; Filosofia delle forme simboliche. Vol. 3 (tomo 2). Fenomenologia della conoscenza. La nuova Itália, Editrice, Firenze, 1966; Linguaggio e mito. Milano: II Saggiatore di Alberto Mondadori Editore, 1968; Antropologia Filosófica. São Paulo: Editora mestre Jou, 1972 ${ }^{19}$ GOMBRICH, Ernst H. L'Art et son histoire 1 e 2. Paris: Le Livre de Poche, 1967

${ }^{20}$ PANOFSKY, Erwin. I/ significato nelle arte visive. Giulio Einaudi Editore, 1962

${ }^{21}$ SCOTT, Geoffrey. L'architettura dell'umanesimo (1939)

${ }^{22}$ SEVERINI, Gino. Raggionamenti sulle arte figurative. Milano: Ulrico Hoepli, 1936

${ }^{23}$ DE RUGGIERO, Guido. Sommario di storia della Filosofia. Gius. Laterza \& Figli. Bari, 1948

${ }^{24}$ READ, Herbert. As origens da forma na arte. Zahar Editores, Rio de Janeiro, 1967

${ }^{25}$ BURCKARDT, Jacobo. The Civilization of the renaissance Italy. New York: Oxford University Press. Segundo Munford, "um ensaio clássico de história cultural; foi, na origem, uma ousada e apreciável síntese histórica; veio produzir um entendimento novo" (1952, p. 483). Burckardt é autor de Refexiones sobre la historia del mondo. Libreria y Editorial "El Ateneo", 1944

${ }^{26}$ HUIZINGA, John. Homo Ludens. Milano: Einaudi Editore, 1949 
${ }^{27}$ SUMMERSON, John. II linguaggio classico dell'architettura. Torino: Giulio Einaudi editore s.p.a., 1970; II linguaggio classico dell'architettura. Torino: Giulio Einaudi editore s.p.a., 1970

${ }^{28}$ TAYLOR, John F.A. Design and expression in visual arts. Dover Publications, New York, 1964

${ }^{29}$ MARIANO $F^{\circ}$, José. Estudos da Arte Brasileira, Rio de Janeiro, 1942; Acerca dos copiadores do Nordeste Brasileiro. Rio de Janeiro, 1942

${ }^{30}$ HEIDEGGER, Martin. Essais et conferences. Gallimard, 1954; Sobre o problema do ser - O caminho do campo. Livraria Duas Cidades, 1969. Segundo Norbeg-Schulz, "Heidegger não deixou nenhum texto sobre arquitetura e, no entanto, a arquitetura tem um papel muito importante em sua filosofia. Seu conceito de ser-no-mundo supõe um ambiente produzido pela mão do homem, e quando ele discute o problema do "habitar poeticamente", refere-se explicitamente à arte de construir" (in NESBITT, p. 462)

${ }^{31}$ KLEE, Paul. Theorie del'art moderne. Editions Gonthier.Paris, 1969

32 Sobre Steiner estão preservados ensaios publicados nas revistas Casabella / Architettura Steineriana / JARNA e DORNACH) e AJ. The Architect's Journal, 1980 (Steiner School in Sussex)

${ }^{33}$ LANGER, Susanne K. Sentimento e forma. Giacomo Feltrinelli Editore. Milano, 1965; Filosofia em nova chave. São Paulo; Editora Perspectiva, 1971

${ }^{34}$ SPHAN. Revista do Serviço do Patrimônio Histórico e Artístico Nacional. Rio de Janeiro MÊS. N3, 1939 ao N7, 1943

${ }^{35}$ Le CORBUSIER. Vers une architecture. Collection L' Esprit Nouveau- 3a edição, 1928

${ }^{36}$ Le CORBUSIER. L'urbanisme. Colletion de L'esprit Nouveau. Paris: Les Editions G. Crès \& Cie, 1924;

37 Le CORBUSIER. La Ville Radiuese. Coll. De L' Equipement de la civilization machiniste. Paris. L'Architecture d'Aujourd'hui, 1935

${ }^{38}$ TAUT, Bruno. Die Neue Baukunst in Europa und Amerika. Stuttgart: Julius Hoffmann, 1929

${ }^{39}$ BENEVOLO, 2006, pag. 466 e 470

${ }^{40}$ Art in our Time. Museum of Modern Art of New York, 1939.

${ }^{41}$ GRIFFINI, Enrico A. Costruzione razionale della casa. Milano: Ulrico Hoepli, 1939

${ }^{42}$ ROTH, Alfred. The New Architecture. Zurich: Verlag Dr. H. Girsberger, 1940

${ }^{43}$ BENEVOLO, 2006, p. 594

${ }^{44}$ AALTO, Alvar. The Humanization of Architectura. In The Architectural Forum, dez 1940

${ }^{45}$ AALTO, Alvar. Architettura e arte concreta. In: Domus n. 223/224/225/ 1947/ p. 3-15.

${ }^{46}$ Alcune recenti opere di Alvar Aalto. In Casabella, n. 200, p. 5-17, 1953; Ensaios do arquiteto ou sobre ele, ainda estão preservados por Ciampaglia: University building by a master hand. In: Architectural Record, april, 1965, 169-176; MOSSO, Leonardo. Alvar Aalto. Internazionalismo e tradizione. In Casabella 415-416/ 1976, p. 28-39

${ }^{47}$ VAN DER ROHE, Mies. Mies Van der Rohe. New York: The Modern Museum of Art, 1947.

${ }^{48}$ BEHRENDT, W.C. Modern Building. Its nature, Problems, and forms. New York: Harcourt, Brace and Company, 1937

${ }^{49}$ MUNFORD, 1938, p. 511

${ }^{50}$ BEHRENDT, Op. Cit, p. 138

${ }^{51}$ GIEDION, Siegfried. Space, time and architecture. London: Humphrey Milford, 1941

${ }^{52}$ GIEDION, Op.Cit. p. V. 
53 GIEDION, Siegfried. Mechanization takes command. London: Oxford University Press, 1948

${ }^{54}$ MONTANER, 2001, p. 95

${ }^{55}$ ZEVI, Bruno. Verso un' architettura organica. Torino: Giulio Einaudi Editore, 1945

${ }^{56}$ Op.Cit. p. 66

${ }^{57}$ ZEVI, Bruno. Sapere Vedere l' architettura. Torino: Giulio Einaudi Editore, 1948

${ }^{58}$ ZEVI, Bruno. Architectura in nuce. Aguilar S.A. Ediciones Madri, 1969

${ }^{59}$ MONTANER, Op.Cit. p. 84

${ }^{60}$ Op.Cit. p. 99

${ }^{61}$ Op.Cit. p. 97

${ }^{62}$ NESBITT, 2006, p. 11

${ }^{63}$ ROSSI, Aldo. L'architettura della cittá . Marsilio Editori. Padova, 1966

${ }^{64}$ CARPENTER, Edmund e McLUHAN, Marshall. Revolução na comunicação. Rio de Janeiro: Zahar Editores, 1968

${ }^{65}$ BRANDI, Cesare. Struttura e architettura, Giulio Einaudi Editore, s.p.a. Torino, 1967

${ }^{66}$ JENCKS, Charles. Architecture 2000. Books That Matter, New York, 1973

${ }^{67}$ NORBERG-SCHULZ, Christian. Intenzioni in Architettura. Paperbacks Lerici. Milano, 1967; Existence, Space \& Architecture. Praeger Publishers, New York, 1971; Meaning in western architecture. Studio Vista, New York, 1975

${ }^{68}$ HALL, Edward T. La dimensione nascosta. Valentino Bompiani Milano, 1968

69 BACHELARD, Gaston. La poetique de l'espace. Presses Universitaires de France, Paris, 1970

${ }^{70}$ BROADBENT, Geoffrey. Design in Architecture. John Wiley \& Sons, London, 1973

${ }^{71}$ KONIG, Giovanni Klaus. Architettura e Comunicazione. Libreria Editoriale Fiorentina, 1970

${ }^{72}$ ARGAN, Giulio Carlo. Progetto e destino. Casa Editrice II saggiatore,1965

${ }^{73}$ BAUDRILLARD, Jean Baudrillard. Le systeme des objets. NRF, Editions Gallimard, 1968

${ }^{74}$ LÉVI_STRAUSS e...O método estruturalista. Rio de Janeiro: Zahar Editores, 1967

${ }^{75}$ DE CHARDIN, Pierre Teilhard. O fenômeno humano. São Paulo: Editora Herder, 1966

76 VENTURI, Robert. Complexity and contradition in architecture. The Museum of Modern Art, New York, 1966

77 ULLMANN, Stephen. Semântica. Fundação Calouste Gulbenkian, 1964

${ }^{78}$ GREGOTTI, Vittorio. II territorio della architettura. Feltrinelli, 1966. Do autor identificase GREGOTTI,V.,ROSSI, A, TAFURI, M e .....Teoria della Progetazione Architettonica. Venezia: Dedalo Libri, 1968

${ }^{79}$ Entrevista de Galiano Ciampaglia ao IAB-SP, em 2003 (ANEXO 1 deste)

${ }^{80}$ DE COULANGES, Fustel. A cidade antiga Vol. 1- Estudos sobre o culto....Grécia e Roma. Lisboa: A.M. Teixeira \& C. Filhos, Ltda, 1957; Vol. 2-Estudos sobre o culto....Grécia e Roma. Lisboa: A.M. Teixeira \& C. Filhos, Ltda, 1958

${ }^{81}$ MONTANER, Op.Cit. p. 82

82 WRIGHT, An Autobiography, 1943, p. 328

${ }^{83}$ Le CORBUSIER. L'urbanisme. Colletion de L'esprit Nouveau. Paris: Les Editions G. Crès \& Cie, 1924

${ }^{84}$ HEGEMANN, Werner. City Planning housing- First volume of text: Historical and Sociological. Architectural Book Publishing Co. Inc, New York, 1936; City Planning housing- Second volume of text: Political Economy and Civic Art. Architectural Book Publishing Co., Inc, New York, 1937; City Planning housing- Volume III: A Grafic Review of civic art 1922-1937. Architectural Book Publishing Co., Inc, 1938 
85 MUNFORD, Lewis. The culture of the cities. New York: Harcourt, Brace and Company, 1938; The condition of man. New York: Harcourt, Brace and Company,1944; A conduta da vida. Editora Itatiaia Limitada. Belo Horizonte, 1959 The City in History. New York: Harcourt, Brace \& World, Inc, 1966; La carretera y la ciudad. Emece Editores, S.A. Buenos Aires, 1966; A new Regional Plan to arrest megalopolis. In: Architectural Record, March 1965, p. 147-154

${ }^{86}$ SERT, J. L. and Ciam. Can our cities survive? London: The Harvard University Press, 1942. Sobre o tema, Casabella publica o ensaio "Il cuore della cittá" do filósofo Enzo Paci.

${ }^{87}$ O CIAM IV (1933) deu origem à Carta de Atenas, publicada dez anos depois, e que sintetiza as propostas para as condições apresentadas agrupadas em cinco categorias principais: moradia, lazer, trabalho, transporte e edifícios históricos (Frampton, Op.Cit. p. 328). O CIAM V (1937) prosseguiu com o tema "cidade funcional".

88 LEIPZIGER, Hugo.The Architetonic City in Americas. The University of Texas Publication, no 4407, 1944

${ }^{89}$ The Heart of the City. London: Lund Humphries, 1952

${ }^{90}$ FRAMPTON, Op.Cit. p. 329

${ }^{91}$ GEDDES, Patrick. Cities in evolution. London: Williams \& Norgate Ltd, 1949

92 GUTKIND, E. A. L'Ambiente in Espanzioni. Edizioni di Comunitá, Milano, 1955

Community and environment. A discourse on social ecology. London: Watts and Co., 1953

${ }^{93}$ BENEVOLO, Op.Cit. p. 360

94 SITTE, Camillo. The art of Building cities. Reinhold Publishing Corporation, New York, 1944

${ }^{95}$ OSBORN, F .Green-Belt Cities. London: Faber and Faber Limited. O autor dedica a primeira parte do livro à proposta de Howard.

${ }^{96}$ HOWARD, Ebenezer e GIORDANI, Pier Luigi. L'idea della cittá giardino. Edizioni Calderini Bologan, 1962

${ }^{97}$ BENEVOLO, Op.Cit. p. 632

${ }^{98}$ STEIN, Clarence. Towards new towns for America. The University Press of Liverpool, 1951

99 WEBER, Max. La cittá. Valentino Bompiani, Milano, 1950

100 BERNOULLI, Hans. La cittá e il suolo urbano. Antonio Vallardi Editore, 1951

${ }^{101}$ APRR. Town and Country Planning text book. The Architectural Press: London 1950

${ }^{102}$ Association for Planning and Regional Reconstruction

${ }^{103}$ Holford foi membro da Comissão Julgadora do plano Piloto da Nova Capital Federal do Brasil (HALL, 2005, p. 255).

104 GIBBERD, Frederick. Town Design. Reinhard Publishing Corporation, New York, 1953

105 SHARP, Thomas. The anatomy of the village. Penguin Books, Harmondsworth, Middlesex, 1946

${ }^{106}$ PÖETE, Marcel. Introdution a l'urbanisme. Editions Anthropos Paris, 1967. A primeira edição é de 1929.

${ }^{107}$ ARVILL, Robert. Man and environment. Penguin Books, 1967; BAHRDT, Hans Paul. Lineamenti di sociologia della città. Marsílio Editori , 1966; __ECKARDT, Wolf von. A place to live. Dell Publishing Co. Inc., 1967; ETTINGER, J.Van. Towards a habitable world. Elsevier Publishing Company, 1960 GEORGE, Pierre. Sociologia e Geografia. Editora Forense, Rio de Janeiro - São Paulo, 1969; GIANNOTTI, 
Gianni. L'Analisi ecologica. Panorama della letteratura. Editorwe Boringhieri s.p.a. Torino, 1966; ___LEDRUT, Raymond. Sociologie urbaine. Paris: Presses Universitaires de France, 1968; __ SMAILES, Arhur E. The geography of towns. W.G. East, University Library of Geography, London, 1968; __ WEBBER-DYCKMAN-FOLEYGUTTENBERG-WEATON-WURSTER. Indagini sulla struttura urbana. II Saggiatore, 1968 (rub. 1968); __ WIRTH, Louis. El urbanismo como modo de vida. Ediciones 3 Buenos Aires, 1962

108 CHERMAYEFF, Serge and ALEXANDER, Christopher. Community and privacy. Anchor Books Doubleday \& Company, Inc. Garden City, New York, 1963

${ }^{109}$ FRAMPTON, Op.Cit. p, 415

${ }^{110}$ BACON, Edmund N. The city as an act of will. Architectural Record, January 1967, p. 113-128

${ }^{111}$ ALEXANDER, Christopher. Nuevas ideas sobre diseño urbano. Cuadernos summanueva vision. N. 9. Ediciones Nueva Vision SAIC, Bs. As, setiembre 1968 , p. 3- e 20

112 CHERMAYEFF,S., TZONIS,A. La forma dell'ambiente collettivo. Milano: II Saggiatore di Alberto Mondadori Editore, 1972

${ }^{113}$ ROSSI, Aldo. L'architettura della cittá. Marsilio Editori. Padova, 1966

114 MONTANER,Op.Cit. p. 139

115 HILBERSEIMER, Ludwig. Un' idea di piano. Polis n. 2: quaderni di architettura e urbanística diretti da Aldo Rossi, Marsílio Editori, 1967. Prefácio de Giorgio Grassi

${ }^{116}$ Quaderni di Architettura e Urbanística diretti da Aldo Rossi.

117 Op. Cit. p. 25

${ }^{118}$ SAMONÀ, Giuseppe. L'urbanistica e l'avvenire della città. Editori Laterza. Bari, 1967.

119 LYNCH, Kevin. L'image de la cite. Dunod Paris, 1969. A primeira edição, The Image of the City é de 1960.

${ }^{120}$ MONTANER, Op.Cit. p. 142-3

${ }^{121}$ NESBITT, Op.Cit. p. 65

${ }^{122}$ CHALK,W. e outros. La ciudad viviente. In: La ciudad viviente. Cuadernos SummaNueva Vision, Año 1, no 10, Ediciones Nueva Vision SAIC, Bs. As, 1968, p. 18-21

${ }^{123}$ MONTANER, Op.Cit. p. 30

${ }^{124}$ CANDILIS, G. JOSIC, A. WOODS, S. Reflexiones sobre planeamiento y diseño urbano. In: La ciudad viviente. Cuadernos Summa-Nueva Vision, Año 1, no 10, Ediciones Nueva Vision SAIC, Bs. As, 1968, p. 3-17.

${ }^{125}$ LEFEBVRE, Henri. O direto à cidade. Editora Documentos Ltda. São Paulo, 1969

${ }^{126}$ MONTANER, Op.Cit. p. 82

${ }^{127}$ CROSBY, Theo. II senso della città. Studio Vista, Londra Ltd.,1971; How to play the environment game. Arts Council of Great Britain and Penguin Books Ltd, 1973

${ }^{128}$ A autora refere-se a The Anatomy of the Village (1946) e correspondência com o ensaio The Village publicado em The Architects Journal de janeiro de 1978.

${ }^{129}$ Biografias acadêmicas sobre o grupo Branco \& Preto. ACAYABA, Marlene Milan. Branco e Preto: uma história de Design Brasileiro nos anos 50. São Paulo: Instituto Lina Bo e Pietro Maria Bardi, 1994; FAGGIN, Carlos Augusto Mattei. Carlos Millan: Itinerário profissional de um arquiteto paulista. FAU-USP: Tese de doutorado, 1992; FERRONI, Eduardo Rocha. Aproximações sobre a obra de Salvador Candia. FAUUSP: Dissertação de mestrado, 2008; __ MATERA, Sergio. Carlos Millan, um estudo sobre a produção em arquitetura. FAU-USP: Dissertação de mestrado, 2005; RUCHTI, Valéria. Jacob Ruchti: a modernidade e a arquitetura paulista (1940-1970). São Paulo: FAUUSP: dissertação de mestrado, 2011.

${ }^{130}$ LOURENÇO, 1995, p. 219 
${ }^{131}$ RUCHTI, Construtivismo, In revista Clima, 1941

132 "Os arquitetos queriam só projetar, mas tinham que construir, pois o cliente não queria pagar dois profissionais: o do projeto e o da obra" (FICHER, 2005, p. 246).

${ }^{133}$ RUCHTI, 2011

${ }^{134}$ No Diário de um jovem arquiteto: minha viagem aos Estados Unidos, 1947, Forte faz referências às notícias relatadas em cartas, por Laura Forte.

${ }^{135} \mathrm{~A}$ autora refere-se ao projeto executivo do edifício IAB-SP

${ }^{136}$ MINDLIN, 1956

${ }^{137}$ CORONA E LEMOS, 1963

${ }^{138}$ XAVIER, LEMOS e CORONA, 1983

139 resolução emitida em 17 de janeiro de 2002. Na ocasião, uma placa com o nome dos oito autores.

foi adicionada ao edifício.

${ }^{140}$ Depoimentos de Arquitetos Paulistas. 1979, p28.

${ }^{141}$ LIRA, 2008, p. 378

142 Eduardo Kneese de Mello. Porque a arquitetura contemporânea. Acrópole, n. 197, São Paulo, out. 1946.

${ }^{143}$ Oswaldo Corrêa Gonçalves. O arquiteto Oscar Niemeyer. Acrópole, n. 123, São Paulo, fev. 1948.

${ }^{144}$ FRAMPTON, Op.Cit. p. 311

${ }^{145}$ Rino Levi e Roberto C. César e Forte, Ruchti e Ciampaglia.

${ }^{146}$ FIALHO, 2007 p. 21-22

${ }^{147}$ Fonte IAB-SP

${ }^{148}$ FICHER, 2005, p. 291

${ }^{149}$ ANELLI, 2001

${ }^{150}$ BRUAND, 2002, p. 273

${ }^{151}$ De acordo com o processo municipal n. 0.101.417/46

152 LIRA, 2008, p. 381

${ }^{153}$ Uma das referências consta do prefácio do manuscrito de Miguel Forte, Diário de um jovem arquiteto. Minha viagem aos Estados Unidos em 1947, p. 17

154 Resolução emitida em 17 de janeiro de 2002. Na ocasião, uma placa com o nome dos oito autores foi adicionada ao edifício.

${ }^{155}$ SOCKLER e BREIA, 2005, p. 268

${ }^{156}$ Entrevista de Jun Okamoto à autora em 06/02/2009

${ }^{157}$ Entrevista de Mara Beneduce à autora em 26/05/2010 e correspondência de Erasmo C. Schutzer à autora em 06/01/2010 
III. A casa paulista

II vero compito dell'architetto é interpretare la vitta perché per la vitta son fatte le case; per vivere e viverci serenamente. Frank Lloyd Wright

(Architettura Organica) 
São Paulo, anos 40

Formado, Galiano Ciampaglia ingressa no Escritório Technico Francisco Matarazzo Neto onde Lucjan Korngold acabava de ser contratado. Lucjan Korngold, que chega ao país trazendo no currículo um diploma de honra da Trienal de Milão, em 1946, projetaria o cartão postal da cidade, o Edifício CBI, a então maior estrutura em concreto armado do país que se tornaria referência para os edifícios de escritórios projetados posteriormente. Da experiência profissional, Galiano Ciampaglia recorda-se da "casa do Pacaembu", numa referência à Residência Pikielny, um dos primeiros projetos brasileiros de Lucjan Korngold. No estudo Lucjan Korngold: a trajetória de um arquiteto imigrante, Anat Falbel avalia a obra como uma referência a elementos compositivos que lembram as fachadas das antigas residências polonesas, "numa chave moderna" ${ }^{1}$.

Superada a crise da construção dos anos 30 , a cidade de São Paulo oferecia um panorama promissor para um restrito número de arquitetos, inclusive para aqueles como Galiano Ciampaglia que relacionavam a cidade com as casas que conhecia de Frank Lloyd Wright ${ }^{2}$. As urbanizações introduzidas pela Companhia City à semelhança das cidades-jardins inglesas se estendiam além do pioneiro Jardim América, para o Pacaembu e Alto da Lapa seguidas do Jardim Europa, Jardim Paulistano, Cidade Jardim, Jardim Guedala, Morumbi e Alto de Pinheiros. De legislação rigorosa, exigiam recuos mínimos, a definição dos limites do lote com cercas vivas e vetavam a construção de muros altos.

LUCJAN KORNGOLD

FALBEL, 2003, P. 52

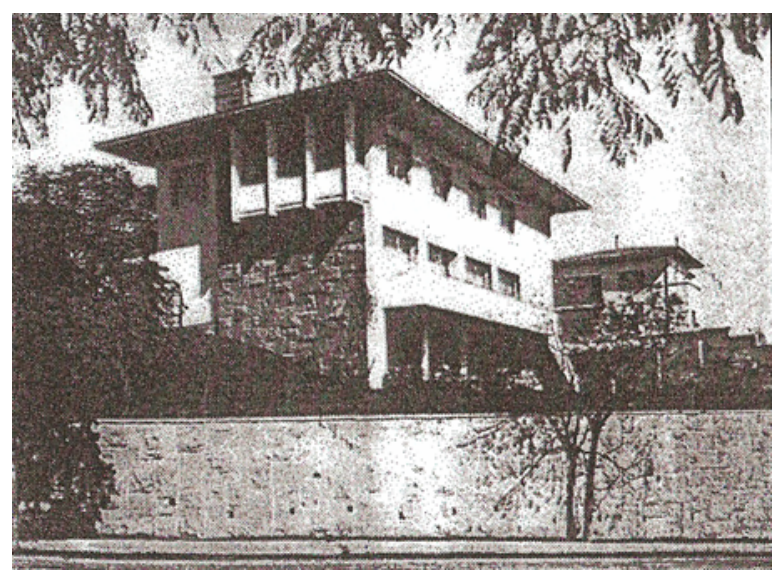


1941. VADUTODOCHÁ 
A "cruzada neocolonial" ${ }^{3}$ de Ricardo Severo, nascida em 1914, na conferência "A Arte Tradicional no Brasil", ganha adeptos no primeiro pós-guerra como "neocolonial simplificado", termo adotado por Carlos Lemos para traduzir a escassez de material do período. A casa paulista de cobertura de telhas, grandes beirais e o predomínio de cheios sobre os vazios é reorganizada com o surgimento do hall de distribuição e a definição das áreas de estar, dormir e serviço. Com o conflito mundial, a presença dos Estados Unidos ofusca o privilegiado posto ocupado pela França, país onde as elites brasileiras se espelhavam. Através do papel fundamental do cinema, os meios de comunicação de massa aceleram a penetração americana. A partir de 1925, os eletrodomésticos chegam ao país e a classe média assume um "morar a francesa" com roupagem americana no vocabulário. A partir daí, as revistas norte-americanas se incumbiriam de fazer do american way of life o "objeto de desejo" dos paulistas.

Em 2005, no estudo Da Califórnia a São Paulo: referências norteamericanas na casa moderna paulista 1945-1960, onde Galiano Ciampaglia figura entre os vinte e três protagonistas, Irigoyen argumenta:

"Sem dúvida, boa parte das conquistas mais significativas no campo da moradia individual do pós-guerra teve lugar nos Estados Unidos. Se isso se deve, em parte, à contribuição de Neutra, Schindler, Gropius, Breuer e Mies, não se pode tampouco subestimar o valor de uma consolidada tradição local, estimulada e reinterpretada por Frank Lloyd Wright. É o encontro entre o racionalismo europeu e o pragmatismo americano" ${ }^{4}$.

Em Die Neue Baukunst in Europa und Amerika ${ }^{5}$, esse intercâmbio era nítido através da influência de Rudolph Schindler dos anos passados no Taliesin (1917 -1923) ${ }^{6}$, caminho seguido por Richard Neutra que, em 1924, já frequentava a sala de desenho da escola de Frank Lloyd Wright.
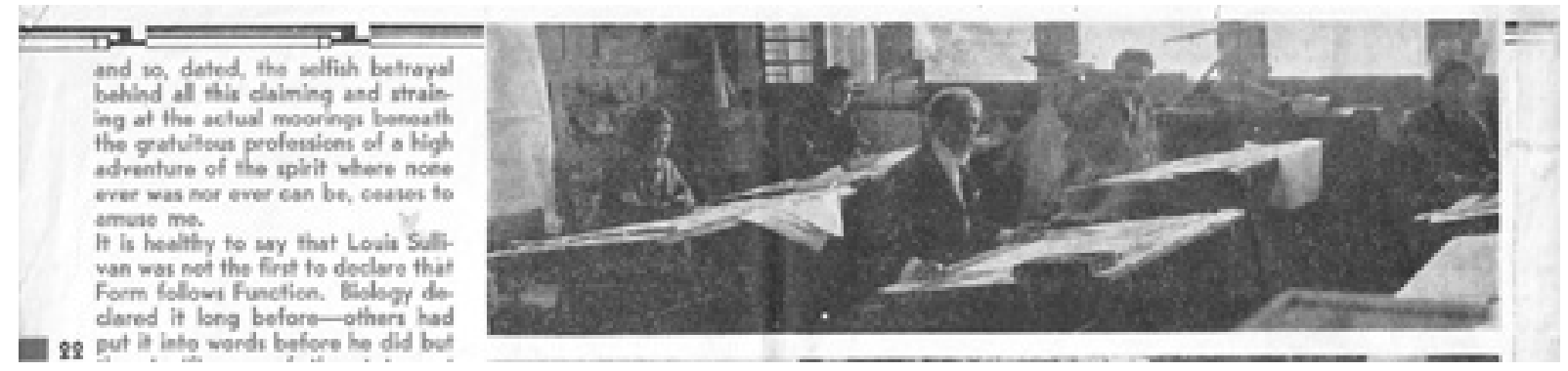
RESIDÊNCIAEMLOSANGEIES RUDOLPHSCHINDLER TAUT, 1929, P. 178 ACERVOGC

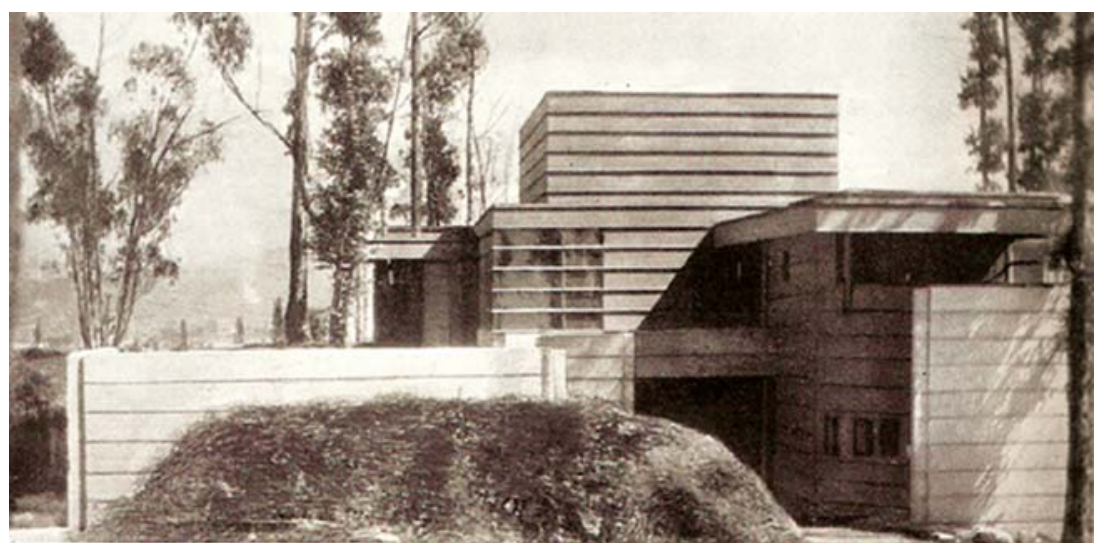

Passada uma década da publicação de Taut, o catálogo Art in our time, publicado pelo Museu de Arte Moderna de Nova York, confirma a produção dos mestres europeus, nos Estados Unidos:

"Em Houses and Housing, o bom design moderno é o tema escolhido pelo Departamento de Arquitetura e o Art Industrial para a exposição que foi preparada em colaboração com a States Housing Authority. Para a maioria dos visitantes, o projeto da casa, privada, apartamento ou conjunto habitacional em larga escala, é o mais pessoal e vital de todos os problemas de arquitetura. Especialmente neste momento, a questão de um bom design é urgentemente importante diante da imensa soma de $\$ 800,000,000$ recentemente reservada pelo governo para a construção de projetos de baixo custo em todo o país. Este dinheiro é para ser gasto pelos municípios, em muitos dos quais falta formação e experiência para lidar com um problema tão difícil tanto arquitetônica como economicamente. O museu tem o privilégio de ajudar a despertar o interesse público e cultivar o gosto pelo que pode ser descrito como uma emergência nacional da arquitetura" 7 .

Experiências de pré-fabricação e estandardização colocam, lado a lado, a Jacobs House (1937), a experiência Usonian de Frank Lloyd Wright, ao custo de $\$ 5,500$, e a Superplywood Model House (1936), a casa de férias construída por Richard Neutra, na Califórnia, por $\$ 8,000$. Também em madeira, propunha poder ser transportada e reerguida em novas fundações. Walter Gropius e Marcel Breuer, reunidos na Graduate School of Design da Universidade de Harvard, a partir de 1938, expõem a casa de Walter Gropius, em Massachussets, projetada pelos arquitetos enquanto associados, entre 1938 e 1941. 
JACOBS HOUSE, 1937 RANKLLYDWRIGHT 1939, ART IN OUR TIME, P. 303 ACERVOGC

SUPERPLYWOOD MODEI HOUSE, 1936 RICHARD NEUTRA 1939, ART IN OUR TIME, p. 303 ACERVOGC
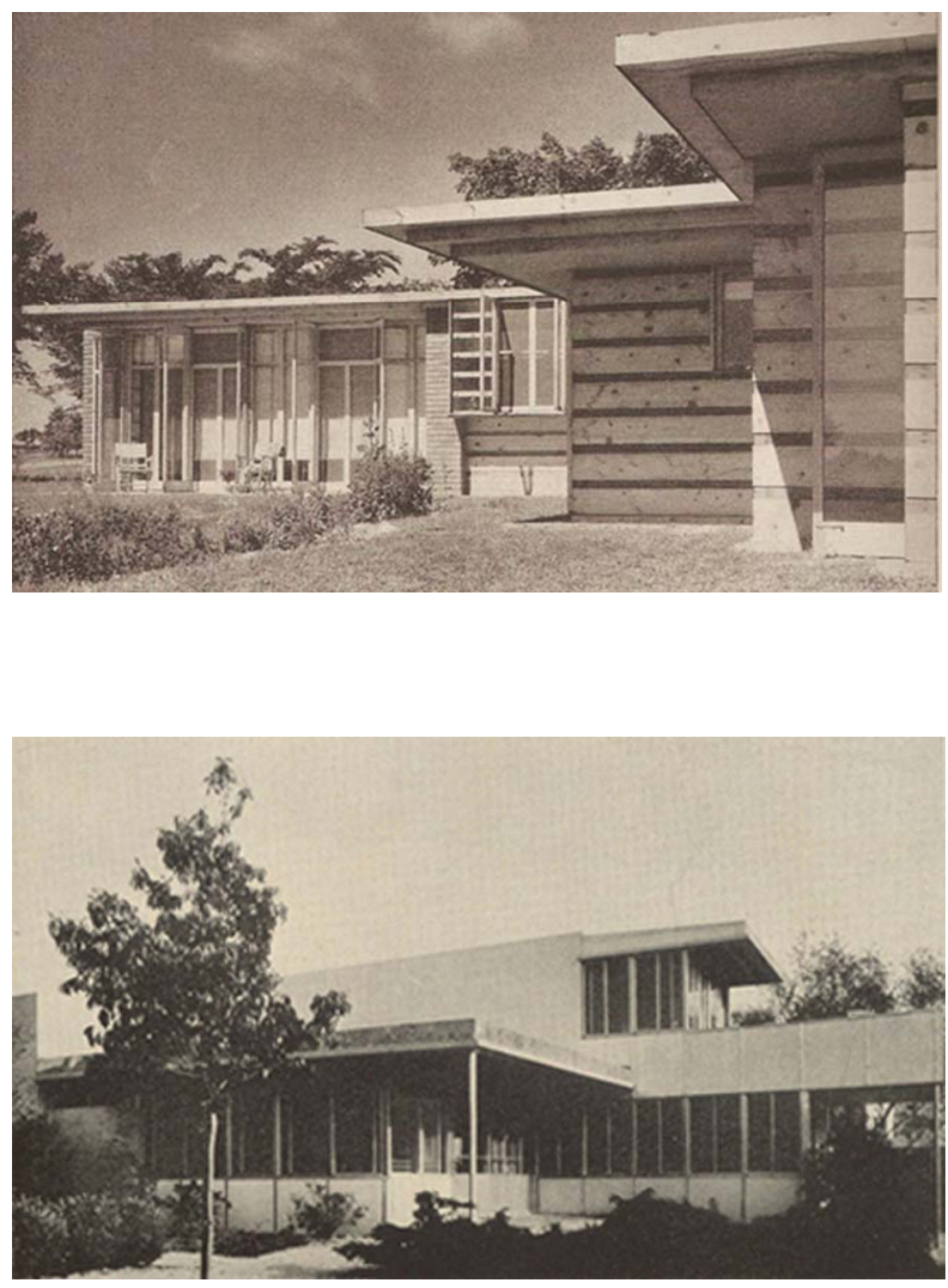

No caso de Frank Lloyd Wright, a unidade Usonian apresentada, introduz um novo conceito de habitar. Diante da recessão americana, dos anos 30, e do perfil da família Jacobs - um jornalista, sua mulher e uma filha pequena - o arquiteto propõe simplificações em relação ao modelo Prairie característico de residências de grande porte destinadas à classe média alta. Para usufruir das vantagens da época, a casa térrea é concebida como um sanduíche de painéis de madeira, os telhados dão lugar às lajes planas e o conceito de unidade se expande até a iluminação. Frank Lloyd Wright libera o fundo do lote para os jardins, introduz o carpot - uma laje que demarca o local do automóvel - e o workplace como integração da cozinha ao ambiente de refeições e ao estar ${ }^{8}$. A evolução da arquitetura doméstica de Frank Lloyd Wright, do sistema construtivo 
ao estilo de vida, é detalhada por Ana Tagliari no livro Frank Iloyd Wright. Princípio, espaço e forma na arquitetura residencial, quando a autora confronta as características das fases Prairie, Textile Blocks e Usonian.

A arquitetura norte-americana introduzia valores "modernos" e o rompimento da tradição na sociedade paulistana não era tarefa fácil, como Carlos Lemos escreveria, em 1972:

"A novidade da casa modernista de Warchavchik não passara de um episódio isolado, o que faz, até certo ponto, inadequado o título de pioneiro àquele arquiteto. $\mathrm{O}$ pioneirismo pressupõe uma seqüência, um desenvolvimento, uma sucessão de ações influenciadoras, enfim, uma concatenação em cuja extremidade se acha a matriz, o início do raciocínio, o elemento catalisador de uma série de reações em cadeia. Não foi o caso do sempre lembrado arquiteto russo. Como também não foi o caso das invenções de Flávio de Carvalho na Alameda Lorena. Na verdade, esses dois arquitetos somente chocaram a sociedade com suas manifestações "futuristas", como lembranças da Semana de 22, cujas sementes não germinaram, como era natural, em solo tão preconceituoso" 9 .

No contexto preconceituoso da sociedade paulistana, a arquitetura residencial de Frank Lloyd Wright parecia não implicar em "rompimento brusco com a tradição" ${ }^{10}$, consciência que, segundo Lemos, os arquitetos dispunham. O próprio Vilanova Artigas, em 1943, projeta a casa Rio Branco Paranhos, uma releitura das Prairie Houses.

Transportados para os loteamentos City, a aceitação do modelo Prarie insinuava-se como o mais provável para a cidade de São Paulo. A quebra de paradigmas domésticos como a introdução do carpot e do workspace e, sobretudo, a eliminação das edículas no fundo do lote, encontrariam resistência na sociedade paulistana. A arquitetura moderna ganharia espaço através das plantas voltadas à funcionalidade. 


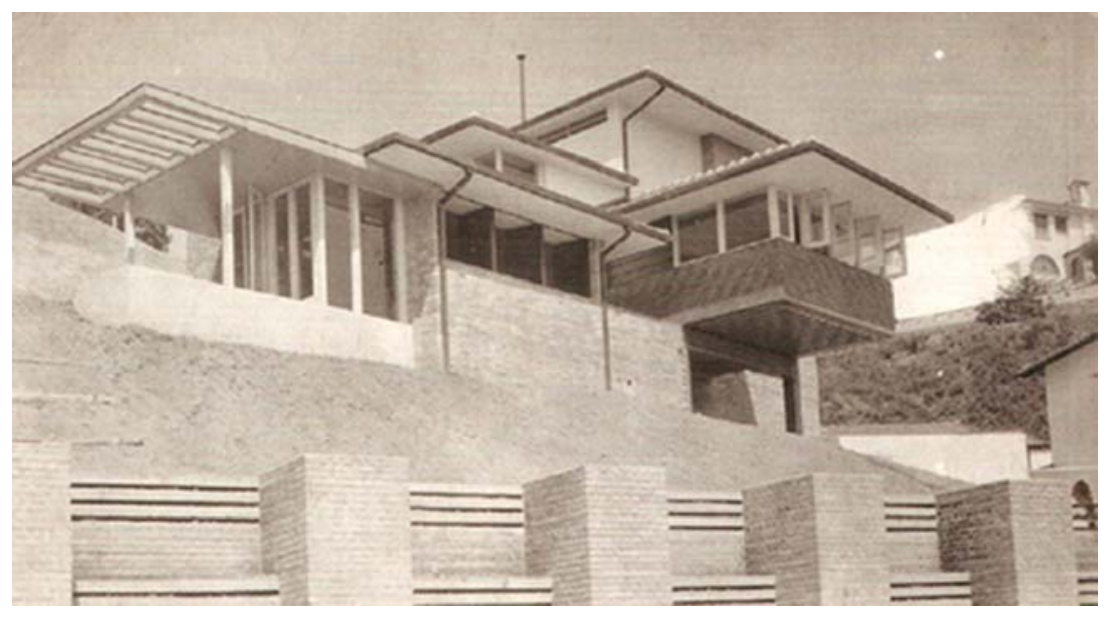

CASA RIO BRANCO PARANHOS, 1943

VLANOVAARTIGAS

IRIGOYEN, 2002

ROBIE HOUSE, 1906

RRANKLOYDWRIGHT

WRIGHT, 1931, P. 64

ACERVOGC

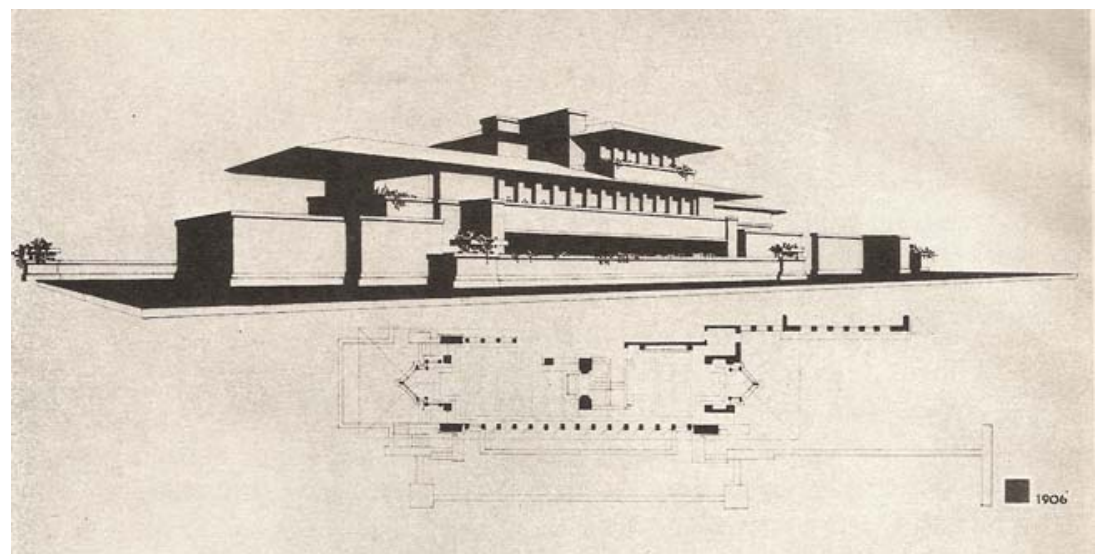




\section{O mobiliário}

Como referência do "espírito verdadeiramente moderno", em 1939, Lucio Costa escreve o ensaio Notas sobre a evolução do mobiliário luso-brasileiro, quando argumenta sobre algumas características do novo design:

"No caso das cadeiras, às várias maneiras de sentar [...] ou, mais cômodas, do tipo "meio-repouso", apropriadas para estar, conversar ou leitura [...] Em todas elas, as peças que constituem o encosto, o assento, e, em muitos casos, os braços, são soltas e independente da estrutura pròpriamente dita, podendo ser removidas com finalidade para limpeza ou substituições de das capas respectivas. Os armários, quando não incorporados à construção, desenvolvem-se mais no sentido da largura, bastante afastados do chão [...] o que concorre para tornar o ambiente por assim dizer mais asseado e espaçoso" ${ }^{11}$.

Em 1941, como forma de suprir a carência no setor - estudado por Maria Cecília Loschiavo dos Santos, em Móvel Moderno no Brasil ${ }^{12}$-, Galiano Ciampaglia aceita desenhar algumas peças para a residência de Fulvio Nanni. Acrescidas de outras, seriam reproduzidas no apartamento do próprio arquiteto, em 1942.

A questão do mobiliário na cidade de São Paulo, nos anos 40 , é trazida também por Maria Cecília França Lourenço, em Operários da Modernidade, através de um depoimento de Lina Bo Bardi ao chegar ao país, no pós-guerra: "Nessa época não tinha nada. Apenas um artesanato e alguns decoradores tipo 'Plaisir de France'" ${ }^{13}$. Ainda, em 1952, por ocasião da abertura da loja Branco \& Preto, Salvador Candia falaria sobre a situação do móvel moderno, na cidade de São Paulo:

"naquela época, ninguém fazia arquitetura de interiores em São Paulo, numa linha moderna. Existiam apenas alguns decoradores antiquados e uma ou outra incursão da arquiteta Lina Bo Bardi através do Studio d' Arte Palma" ${ }^{14}$, fundado em 1948.

O mobiliário desenhado por Galiano Ciampaglia sintetiza a preocupação com a economia, a ergonometria e a função pretendida. Confeccionado em embuia, o design pensado como arquitetura resulta da articulação de perfis com cantos vivos ou placas encaixadas e coladas, guardados alguns balanços. 
No caso da poltrona, a estrutura é definida por perfis retangulares. $\mathrm{O}$ assento de mola é encaixado na estrutura e o encosto de crina e pluma é removível, da mesma forma que as almofadas do sofá. A mesa baixa e o móvel para livros resultam da associação de placas de igual espessura.
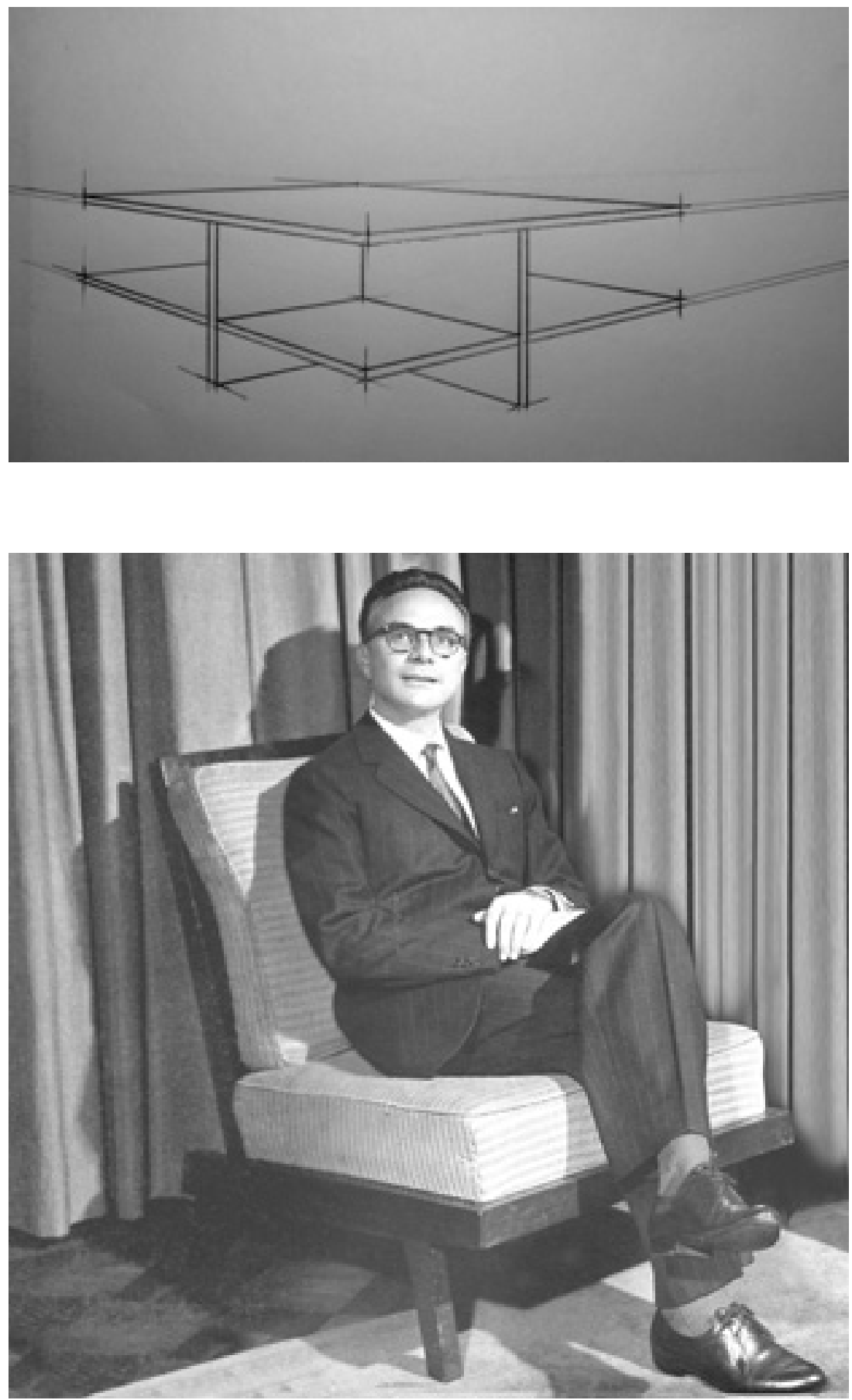

NOALTO:

MESADE CENTRO

DESIGN GALIANO CIAMPAGLIA

REDESENHO 2012

ABAIXO:

POLTRONA

DESIGN GALIANO CIAMPAGLIA

ENSAIO PEIER SCHEIER, 1962 
$\mathrm{Na}$ proposta fica claro o afeto de Galiano Ciampaglia pelas fibras naturais, seja através da madeira ou do algodão nas tramas tecidas por Klara Hartock nos tons cru, verde oliva e vermelho. Sobre a tecelã é interessante recuar a alguns dados trazidos por Ethel Leon, em IAC. Instituto de Arte Contemporânea: Escola de desenho industrial do MASP (1951-1953): primeiros estudos. Consta que como professora de tecelagem do IAC, Klara "foi apresentada a todos os alunos por Bardi como ex-aluna de Anni Albers da Bauhaus [...] $\mathrm{O}$ curioso é que ninguém, ao comentar o passado de Klara, refere-se a um depoimento dela sobre a Bauhaus" ${ }^{15}$.

O resgate do designer Galiano Ciampaglia foi possível graças a um ensaio familiar realizado por Peter Scheier ${ }^{16}$, nos anos 60 , e à memória dos usuários que viabilizou o redesenho de algumas peças, inclusive aquelas ausentes das imagens. Nesse sentido, persiste uma busca no Instituto Moreira Salles que preserva o acervo do fotógrafo.

O "cliente" Fulvio Nanni foi trazido ao estudo a partir de uma correspondência de familiares que inclui a descrição do apartamento de Galiano Ciampaglia:

"[...] a atmosfera transpirava novidade: os móveis eram leves e o sisal já forrava os espaços daquele apartamento modernista. Naquela época não sabia que a mesa, as cadeiras, os sofás, os consoles, o móvel que dividia as salas e aquela mesa de canto eram desenhos do Galiano. Vim saber disso muito mais tarde, quando comecei a freqüentar a casa do Fulvio Nanni. Pois bem, tinha móveis idênticos na casa dele. Impressionante; fiquei espantado com essa coincidência e ele explicou-me que os móveis haviam sido desenhados por um antigo colega de Mackenzie, o Galiano Ciampaglia" 17.

Bem construídos, os móveis foram executados pelos "Irmãos Pássaro" que, na década de 40, assumiram a marcenaria iniciada pelo pai, na Rua Cincinato Braga. A conexão arquiteto-marcenaria teve por intermediário o próprio Fulvio Nanni, amigo da família Pássaro ${ }^{18}$ e que anos mais tarde faria a mesma ponte com a loja Branco \& Preto, através de Plinio Croce. 


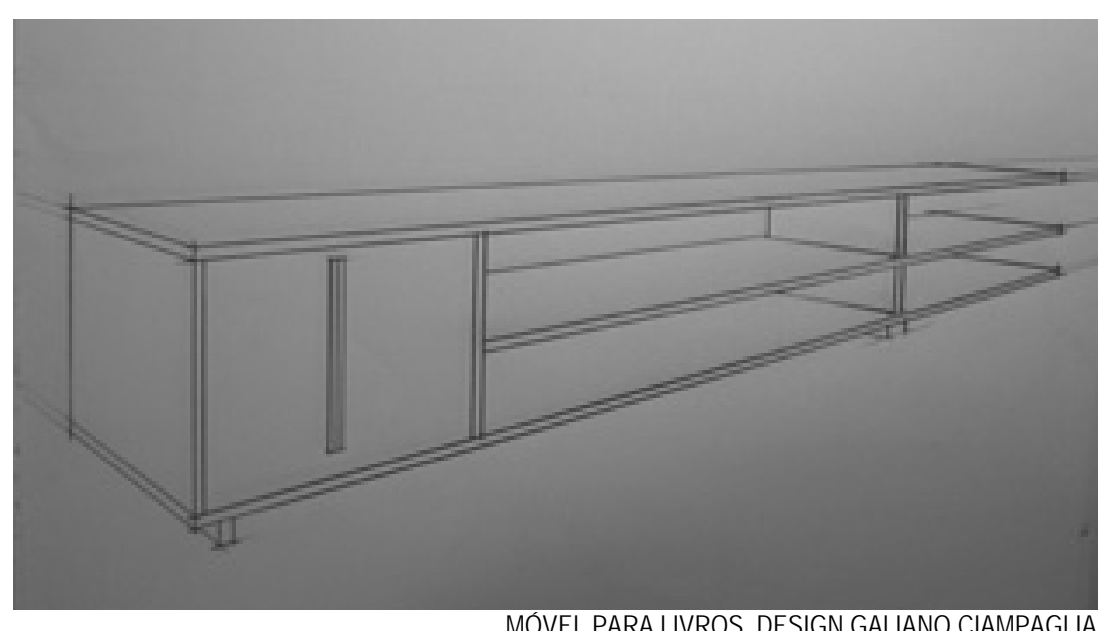

KLARA HARTOCK NO TEAR

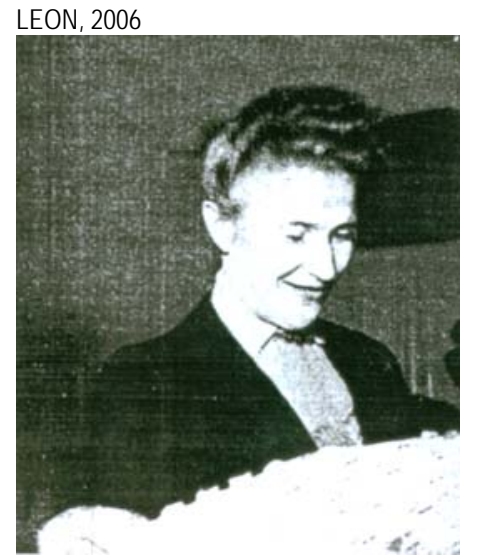

REDESENHO 2012

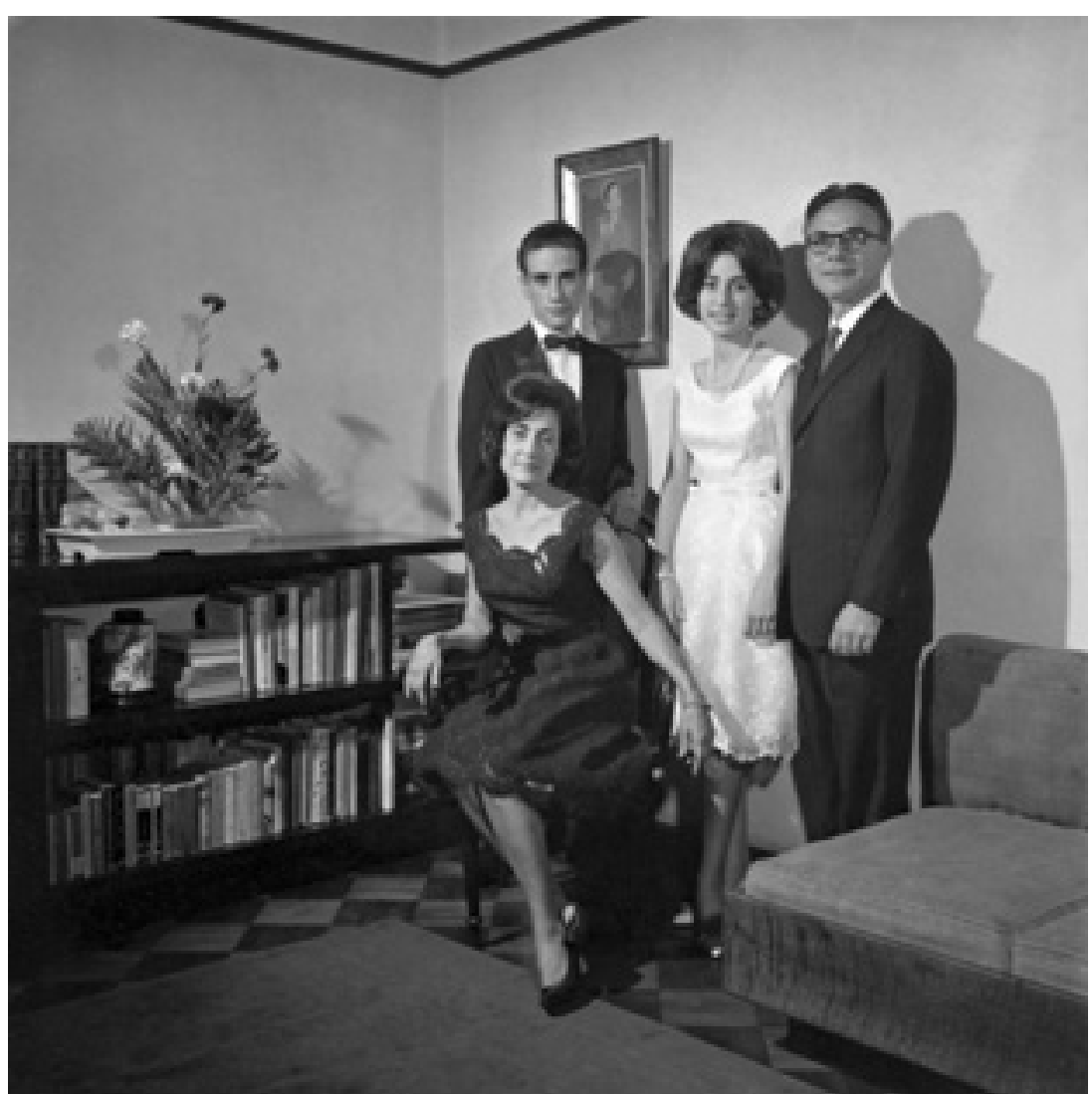

ENSAIO FAMILIAR PETER SCHEIER, 1962 
FORTE \& CIAMPAGLIA LTDA. ARQUITETOS E. E. M.

rua xavier dee toledo, 140

10. Ander-Salas 2-3 - TEL, 1 4-EEaS

SKO PAULO

CARTÃODE VISITAFORTE \& CIAMPAGLIA

ARQUIVOGC 
O escritório Forte \& Ciampaglia

Até aqui, a trajetória de Galiano Ciampaglia com Miguel Forte não recebeu melhor referência que a de Siegbert Zanettini: "[...] a minha geração sempre soube que Galiano e Miguel eram uma 'dupla'. São as gerações mais novas que desconhecem a verdadeira trajetória" 19

Formados na mesma turma de 1939, os arquitetos reencontram-se casualmente, no verão de 1941, na Praia dos Pescadores ${ }^{20}$. Alí Miguel Forte conheceu a experiência em madeira, realizada por Galiano Ciampaglia e, este por sua vez, foi apresentado a Yolanda Forte com quem se casaria em 1943. Disse Galiano que o convite de Forte, "[...] nós gostamos do Wright; vamos abrir um escritório?" ${ }^{21}$, aconteceu pouco depois durante uma das reuniões do Edifício Esther onde os arquitetos se reuniam para discutir interesses da classe.

Nascido em São Paulo, Miguel Forte (1915-2002) descende de imigrantes da província de Salerno, localizada no golfo de Nápoles, na Itália. De uma família comunicativa, desde cedo manifestou a predileção pela música e pelo piano. Depois de passar pelo Instituto Médio Dante Alighieri, transferiu-se para a Escola Americana de filosofia de aprendizagem dinâmica e participativa. Para satisfazer o pai, estabelecido como um industrial do ramo de guarda-chuvas, em 1934, ingressou na Escola de Engenharia Mackenzie, no curso de engenheiro. Logo solicitou a transferência para o curso de Belas Artes - Arquitetura onde conheceu Galiano Ciampaglia. Juntos, freqüentaram o ambiente moderno da casa de Jacob Ruchti. No quinto e sexto anos letivos, Miguel Forte estagiou no escritório de Rino Levi. Em meados de 1940, transferiu-se para o escritório de Jayme Fonseca Rodrigues. Segundo Acayaba, a formação tradicional, recebida na Escola de Engenharia Mackenzie "foi superada por um autodidatismo guiado pela intuição e sensibilidade [...] extraído dos projetos publicados em revistas estrangeiras" 22.

Todavia, a busca de Miguel Forte por outras referências se reflete, em 1947, na viagem que realiza com Jacob Ruchti, aos Estados Unidos. 
No manuscrito Diário de um jovem arquiteto. Minha viagem aos Estados Unidos em 1947, Miguel Forte adiciona à sintonia com o trabalho desenvolvido em São Paulo e ao interesse vinculado ao grupo Arquitécnica, um roteiro que alterna visitas ao Institute of Design de Chicago, dirigido por Serge Chermayeff, contatos com Paul Lester Weiner, visitas a galerias e museus, como o MoMA, quando conhece Philip Johnson e a assiste à preparação de uma exposição de design com móveis de Charles Eames e Isamo Nogushi. Sobre a produção doméstica, Miguel Forte e Jacob Ruchti visitam a casa de Richard Neutra - segundo Forte "o melhor que vi nas construções deste país" ${ }^{23}$-, além das casas de Gropius e de Breuer. No que diz respeito a Wright, os viajantes visitam obras da fase Prairie, em Chicago, Textile Block, na Califórnia, além do Taliesin West e Taliesin Green Spring, quando conhecem o arquiteto norteamericano.

O propósito da associação entre Galiano Ciampaglia e Miguel Forte, formalizada em 20 de janeiro de 1942, justificou o nome do escritório, além das cotas e as atribuições igualitárias discriminadas no contrato social. A produção focada em projetos de residências e na qualidade de sua execução foi caracterizada pela política de revezamento, lembrada por Miguel Forte ${ }^{24}$, e pela cumplicidade dos clientes majoritariamente parentes - que garantiu a fiscalização dos arquitetos do primeiro ao último detalhe, resguardado o envolvimento comercial "proprietário-empreiteiro" ${ }^{25}$. A filosofia exercida em sintonia com a visão de Bruno Zevi, para quem, "em arquitetura, como na poesia, não acontecem fases criadoras distintas [...] entre matéria e forma, pensamento e ato, autor e executor: se a separação acontece, a arquitetura está perdida ou comprometida" ${ }^{26}$, resultou em obras muito bem construídas e na incompletude dos desenhos substituídos pelas muitas decisões tomadas no canteiro.

Todavia, o discurso acadêmico não é claro quanto a essa interface exercida pelos arquitetos. Em Residências em São Paulo: 19471975, ao destacar Miguel Forte no cenário da casa paulista, a autora reforça que a "sua maior virtude estava na maneira de construir" ${ }^{27}$. Passada uma década, no estudo Branco \& Preto. Uma história do design brasileiro nos anos 50, ao escrever sobre a produção compartilhada com Galiano Ciampaglia, a mesma autora não só afasta Miguel Forte do canteiro como sugere distinção de atribuições entre os arquitetos ${ }^{28}$. 

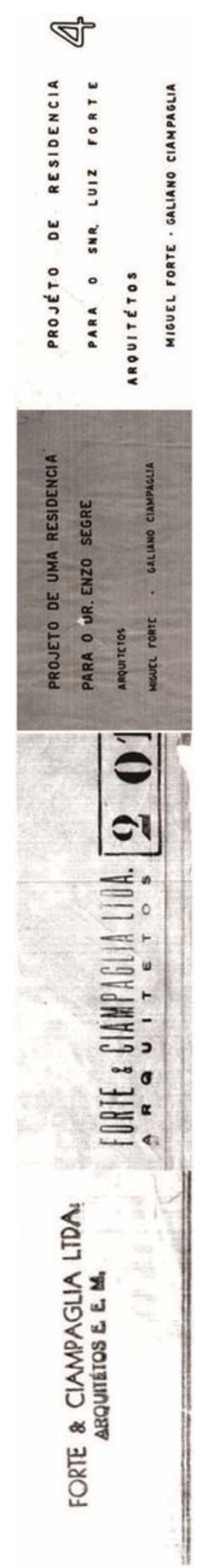

ACIMA: VARIANTES DE CARIMBOS ARQUIVOFAU-USP

AOLADO: CONTRATO SOCIAL $1^{\circ}$ OFICIAL DE REGISTROS DE TÍTULOSE DOCUMENTOSE CIVL DE PESSOA JURÍDICA
O fato é que, sobrepujando os documentos, inclusive os próprios originais ${ }^{29}$, nas biografias de Miguel Forte, publicadas a partir de 2001, o escritório já está rebatizado como "Firma de Projetos e Construções Forte \& Ciampaglia" ${ }^{30}$. E, mais. Ao confundir uma transação imobiliária, dos anos 60 , com o encerramento da sociedade, nunca formalizado, autorias compartilhadas se mesclaram àquelas independentes que se seguiram, desde meados dos anos $50^{31}$.

DR. PAULO ROBERTO DE CARVALHO RÊGO, I' OFICIAL DE REGISTRO DE TÍTULOS E DOCUMENTOS E CIVIL DE PESSOA JURIDICA da Capital do Estado de São Paulo, República Federativa do Brasil, sito à Rua XV de Novembro, 251 - CEP 01013-001 - tel. (011) 3104-8770 / Fax (011) 3101-2082

\section{CERTIFICA e dá fé, que a seguinte}

cópia reprográfica, composta de ${ }^{\star} 07^{\star}$ (-SETE-) folhas, numeradas e perfuradas, é fiel reprodução do(s) original (ais) registrado(s) nesta Serventia, no Livro "A" do REGISTRO CIVIL DE PESSOA JURIDICA, sob o(s) número(s) e data(s), ao final assinalado(s) em chancela.

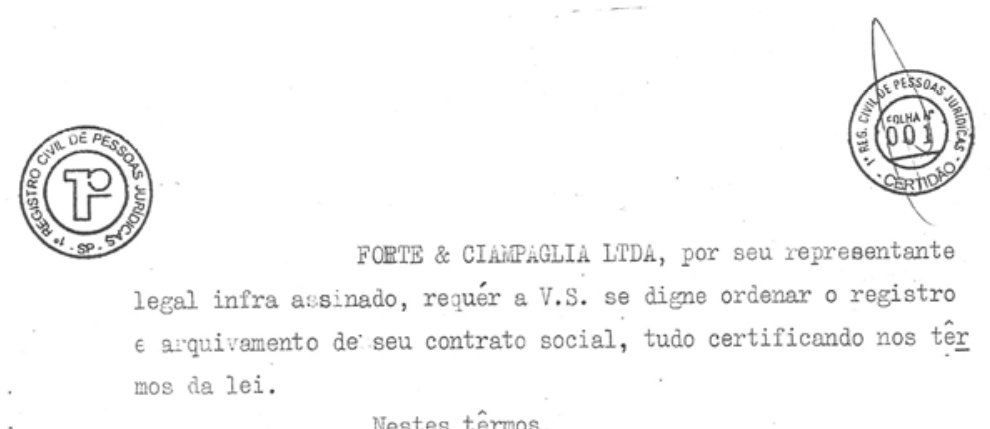

P. Deierimento
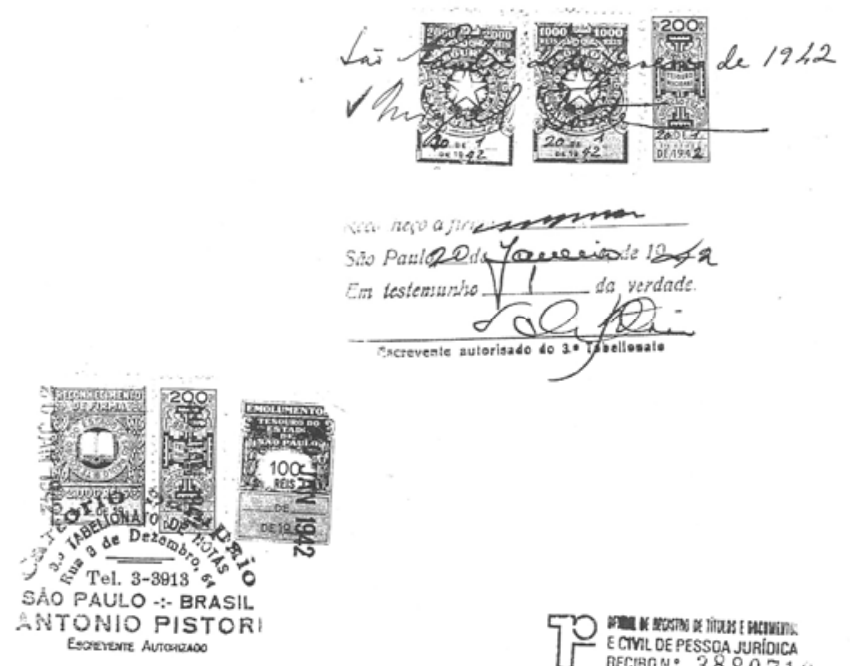

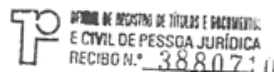

Segundo documentação, o único diferencial entre os sócios está no fato de Miguel Forte se apresentar como representante legal do escritório na abertura da sociedade. 


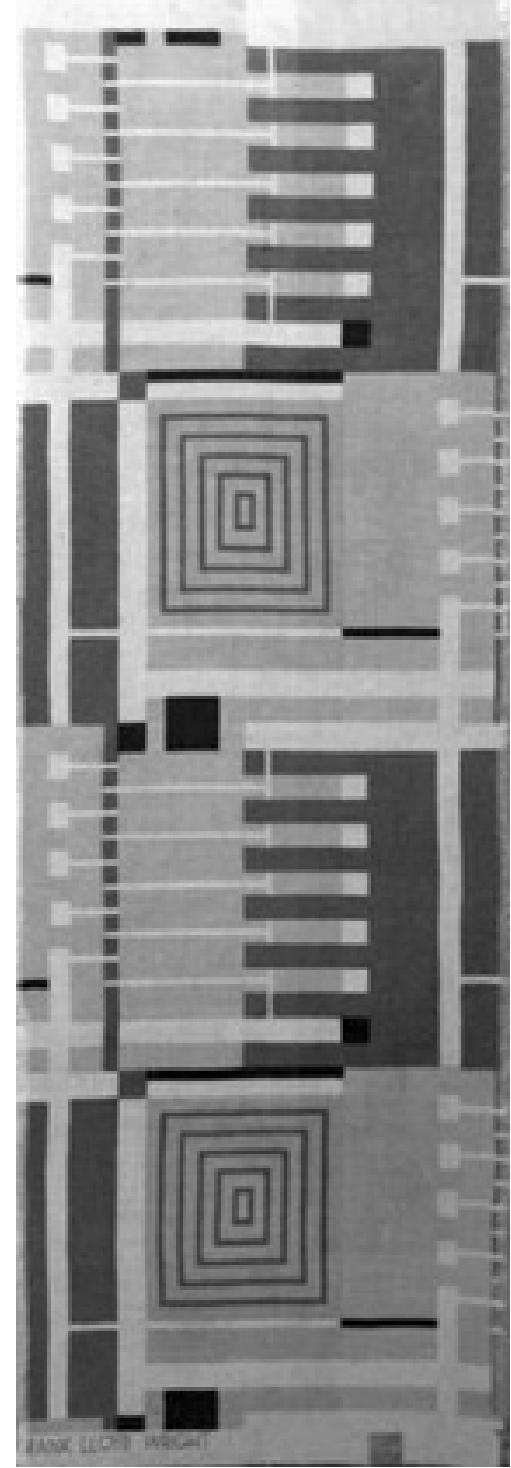

TECIDO EXPOSIÇÃOIAB-SP, 1959 ACERVOGC
As casas projetadas por Galiano Ciampaglia e Miguel Forte se alternaram nas edições da II e da IV Bienais do Museu de Arte Moderna de São Paulo, são matérias da revista Habitat e, no caso da casa Luis Forte, a obra integra a antologia de Henrique Mindlin, Modern Architecture in Brazil.

A produção foi referência para gerações de mackenzistas, dos anos 50, como revelou Pedro Paulo de Mello Saraiva a Irigoyen: "a influência norte-americana chegou à sua geração filtrada pela visão de Oswaldo Bratke, Miguel Forte e Galiano Ciampaglia" 32. Ou ainda, para o grupo de estudantes Fau-usp, dos anos 50 e 60, formado por Dacio Ottoni, Eduardo de Almeida, Henrique Pait, Ludovico Martino e Siegbert Zanettini que, "liderados por Martino" ${ }^{33}$, saíam em busca da arquitetura moderna.

A admiração comum pelos mestres modernos foi compartilhada com Galiano Ciampaglia na palestra de Richard Neutra realizada na Fau-usp, em 1959, e na exposição realizada no IAB-SP, no mesmo ano, em homenagem ao mestre norte-americano, recém falecido ${ }^{34}$. Na ocasião, Henrique Pait presenteou Galiano com um tecido desenhado pelo mestre.

HANKS, 1979, PLATE 24 / ACERVOGC
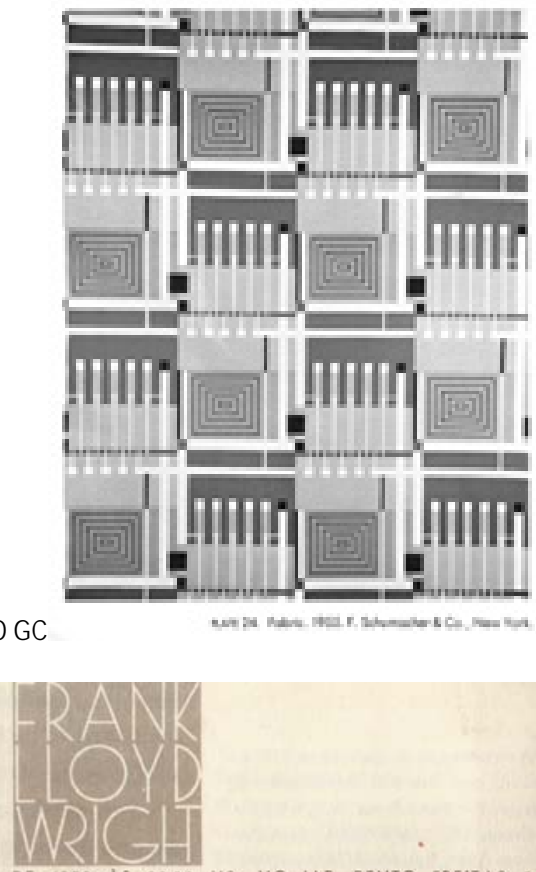

ABERTIRA DA EXPOSIÇAO FLLW, 29 DE OUTUBro DE 1959 AS 20,30 HS. NO IAB, BENTO FREITAS 306 CARTAZDA EXPOSIÇÃO FRANK LOYD WRIGHT, IAB-SP, 1959 / IRIGOYEN, 2002, P. 106 
A trajetória de Galiano Ciampaglia compartilhada com Miguel Forte transcorre em meio a um cenário estimulante. Em 1943, em reciprocidade às revistas norte-americanas que chegavam ao Brasil fazendo do american way of life o "objeto de desejo" dos paulistas, as revistas norte-americanas descobrem a arquitetura e os arquitetos brasileiros, a partir da Exposição Brazil Builds, realizada no MoMA, como prenúncio das relações culturais entre São Paulo e os Estados Unidos. No mesmo ano é criado o Departamento Paulista do Instituto de Arquitetos do Brasil. Em 1947 e 1948, são fundadas a Faculdade de Arquitetura Mackenzie e a Faculdade de Arquitetura e Urbanismo da Universidade de São Paulo, simultaneamente à criação do Museu de Arte de São Paulo e do Museu de Arte Moderna. Em 1951, a I Bienal de Artes, promovida pelo Museu de Arte Moderna de São Paulo incorpora a primeira mostra de arquitetura. Como parte dos festejos do IV Centenário de São Paulo a II Bienal (1953-54) é instalada nos Pavilhões dos Estados e das Nações, no Parque do Ibirapuera, projetado por Niemeyer e equipe. Ao lado de galerias de arte, até então inexistentes na cidade, são criadas lojas de design como o Studio de Arte Palma, em 1948, e a Branco \& Preto, em 1952.

O período coincide com a formulação de novas propostas por parte dos arquitetos contratados pela elite paulistana. Em Rino Levi. Arquitetura e cidade, os autores destacam a série de "casas introvertidas de Rino Levi", que se inicia na própria residência, em 1944. Localizada no jardim Europa, o arquiteto propõe os limites entre o interior do lote e o exterior urbano em total opacidade opondo-se à tipologia de casas com varandas abertas para jardins frontais, até então dominante e estimulada pelas normas desses loteamentos ${ }^{35}$. Oswaldo Bratke, depois de uma trajetória de "casas em estilo Tudor, missões, neocolonial, etc." ${ }^{36}$, em meados dos anos 40 , volta-se para a uma nova estética de viver, associada à funcionalidade organizacional, racionalidade construtiva e novas tecnologias.

1944. CASARINOLEV

RINOLEV

ANELL, 2001, P. 91 
A retomada da produção Forte \& Ciampaglia implica rever questões que lhe são centrais.

A primeira questão diz respeito à identificação do escritório e das autorias em conformidade com os carimbos dos originais arquivados na Fau-usp.

A segunda questão refere-se ao período compartilhado, equivocadamente vinculado a 1942 - $1965{ }^{37}$, em contraponto aos alvarás de construção e habite-se, requeridos entre 1943 e 1955. O compartilhamento é ampliado até a IV Bienal do Museu de Arte Moderna de São Paulo, realizada em 1957, quando os arquitetos expõem as últimas realizações ${ }^{38}$.

Finalmente, uma terceira questão implica ultrapassar os vínculos familiares e societários dos arquitetos e focar mais na associação de dois profissionais com referências e personalidades próprias.

Diante da afinidade de ambos, com Frank Lloyd Wright, uma leitura da obra sugere associar algumas constantes da arquitetura moderna identificadas por Zevi, como o princípio da individualidade e da assimetria, às ferramentas da gramática wrightiana assinaladas por Irigoyen na busca por conexões de Vilanova Artigas com o arquiteto norte-americano ${ }^{39}$ :

a. uma grelha básica permite inúmeras variações nas articulações das formas e na configuração dos espaços

b. o sistema axial propõe uma alternativa para a prática Beaux-Arts: eixos compositivos não coincidem com os do movimento, os quais são periféricos e determinam a disposição oculta do acesso

c. o modo de projetar de dentro para fora determina uma organização centrífuga em torno de um núcleo que, não por acaso, coincide com a lareira, símbolo do fogo doméstico

d. a utilização de um sistema estrutural no qual o balanço assume um papel destacado introduz a terceira dimensão na obra de Wright

Por se tratar de uma obra em co-autoria, não é intento estabelecer onde termina o trabalho de um arquiteto e começa o do outro mesmo porque a cumplicidade e a política de revezamento extrapolaram a prancheta compartilhada também por um desenhista ou estagiário. 
CASAS FORTE \& CIAMPAGLIA arquivo $F \& C$

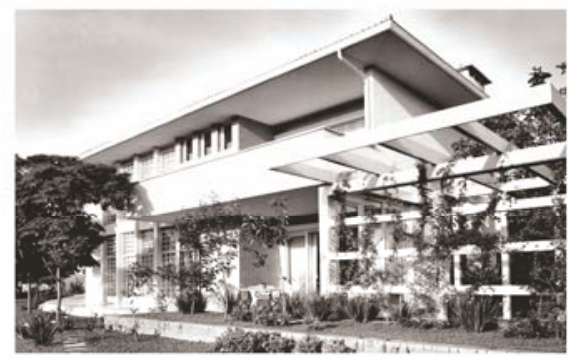

1943 (PMSP)

casa S. Fileppo 


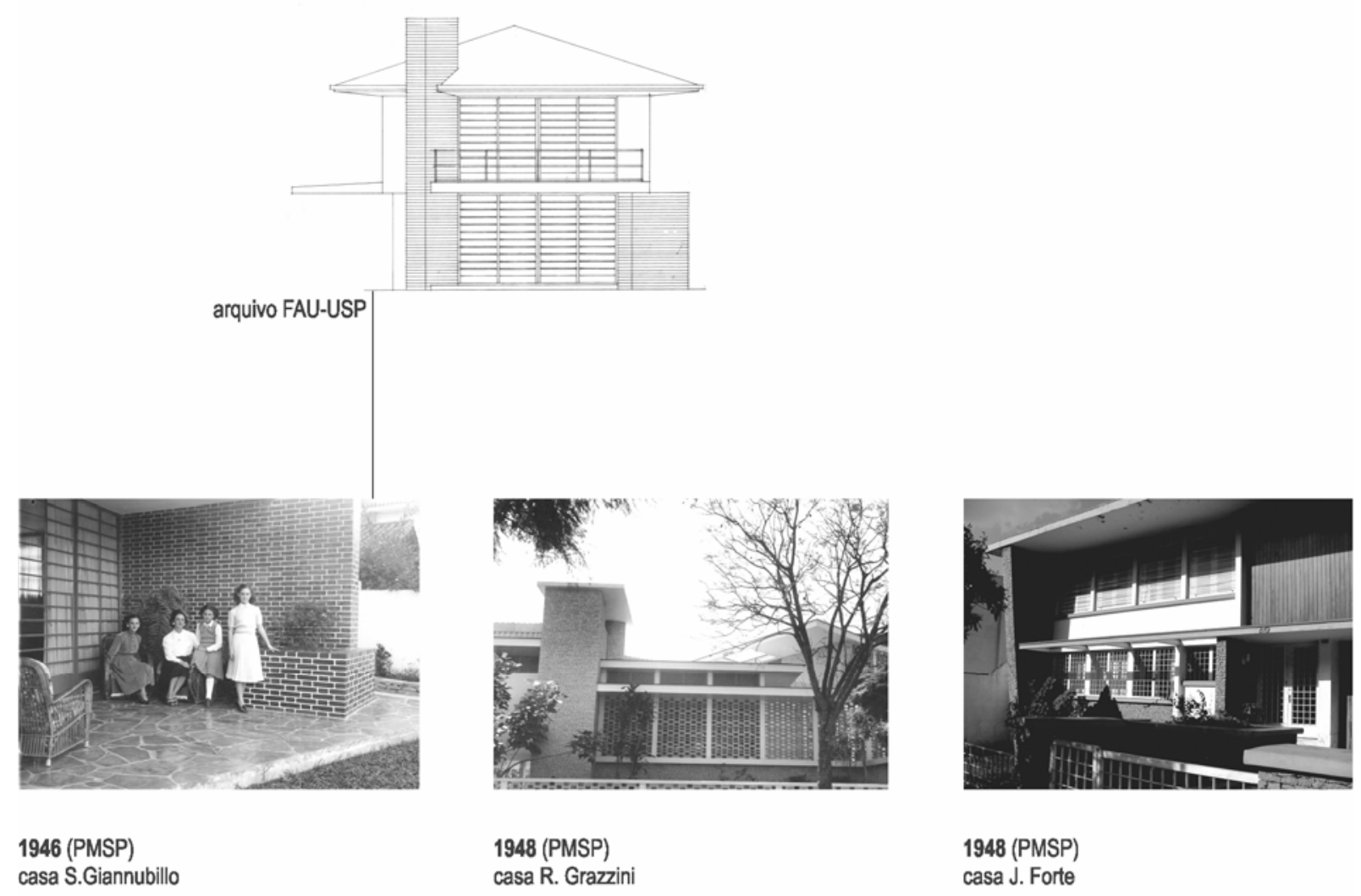




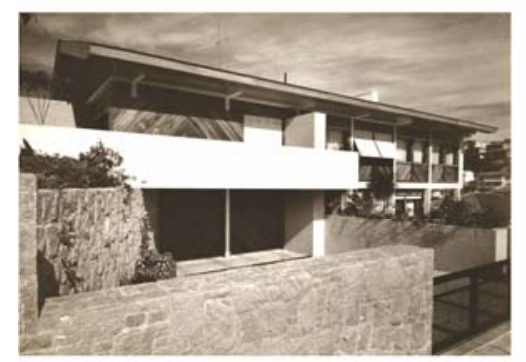

1952 (PMSP)

casa L. Forte

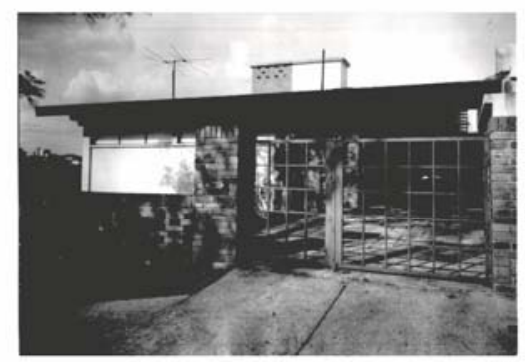

1952 (PMSP)

casa E. Segre

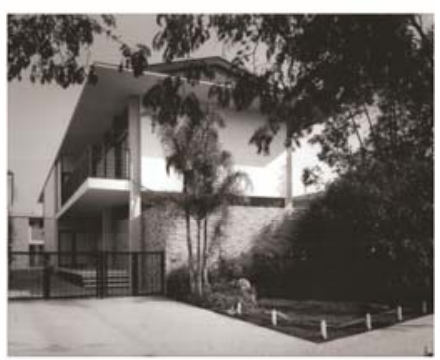

1952 (PMSP)

casa D. Cacace 
O princípio da individualidade aplica-se a toda a produção Forte \& Ciampaglia. No caso das casas Luis Forte e Domingos Cacace, projetadas e construídas quase que simultaneamente, é interessante destacar uma similaridade única no conjunto da obra.

A partir de diferentes implantações - a primeira, em aclive, e a segunda, em nível, sobre laje -, ambas as casas são caracterizadas por prismas contidos sob coberturas de duas águas. Além da aplicação da mesma modulação, materiais e detalhes, os projetos adotam o partido estrutural racionalista definido por pilastras independentes das vedações, no piso inferior. Nas plantas compactas de traçado ortogonal não se identifica a composição centrífuga de Frank Lloyd Wright, a partir da lareira, no caso adjacente aos terraços. O diferencial está na distribuição funcional da casa Luis Forte que adota a sala de jantar e a cozinha no piso dos dormitórios. No caso, o acesso frontal e central se contrapõe ao acesso periférico e ocluso da casa Domingos Cacace, voltada para o jardim. Além do ornamento integrado nas esquadrias de madeira, as casas adicionam referências wrightianas: a casa Domingos Cacace na laje-beiral, um detalhe de Frank Lloyd Wright que acentua a horizontalidade da volumetria; na casa Luis Forte, além do terraço em balanço, a influência wrightiana, também identificada pela revista Habitat ${ }^{40}$, é nítida no jogo de volumes que se prolongam até a divisa da rua. A casa Domingos Cacace é um dos exemplos da construção a cargo de construtora indicada pelo cliente.
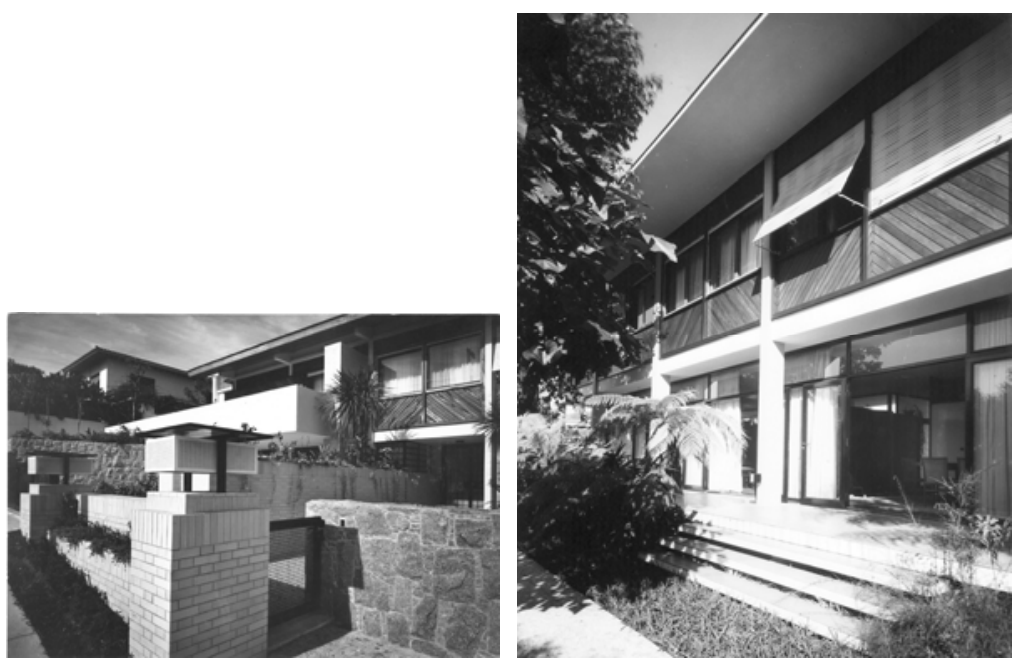
DE CIMAPARABAIXO:

PERSPECTIVA CASA L. FORTE, 1952

PERSPECTIVACASA D. CACACE, 1952 (DESENHO CHENG Y HWA) ARQUIVOF\&C
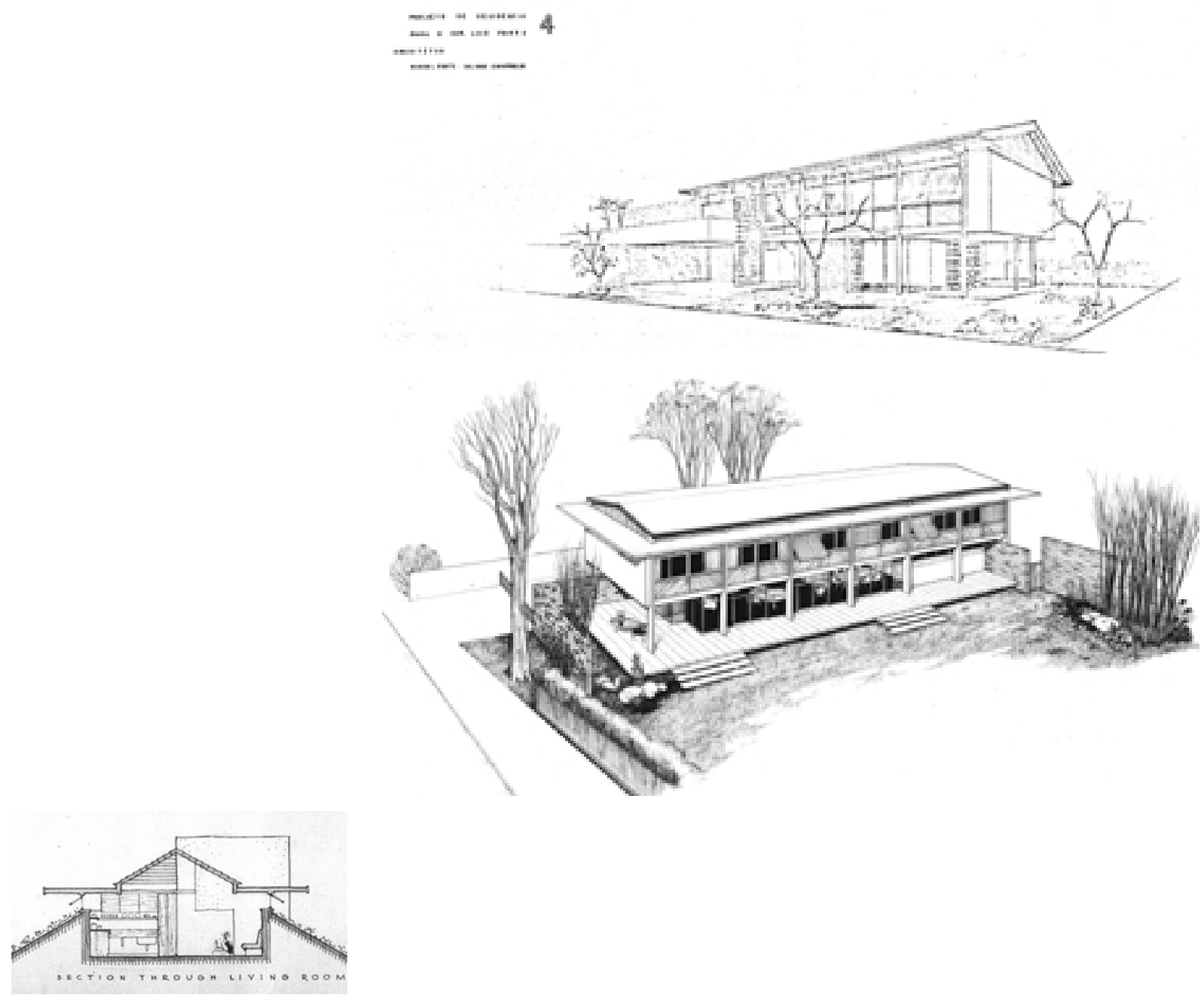

1942. THE COOPERATIVE HOMESTEADS, DEIROIT

PRANKLLOYDWRIGHT

THEARCHITECTURAL FORUM, 1948 N. 65 P. 83 ACERVOGC

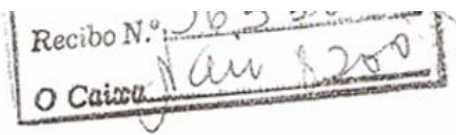

REPINADORA PAUIISTA S/A, estabelecida á Rua Formosa n2367, I8 eand., nesta Capital, desejando construir uma residencia a Rua Austria a 38,00mts da Rua Teixeira e Souza, no Jardim Europa, vem mui respeitosamente requerer a V.Excia.que se digne aprovar as plantas em 5 (cinco)vias e memoriaes em 2 (duas) vias. Outrosim aproveita para apresentar como autores So projéto a firma Forte \& Ciampaglia Itda. (arquitétos Miguel Forte e Galiano Ciampaglia) com escritorio \& Rưa Barãofga Itapetininga ne124, 12 and, sala 1201 e como firma construtora o Escritorio Técnico-Arquitetura e Cons ruções Carmine Coppola tendo como responsavel técnico construtor o arquitéto Domingos desasta com ęscritorio á Rua fuintino Bocaiuva $n^{2}$ 176, 6qandar, salas $608 / 609$.

1952.

REQUERIMENTO DE ALVARÁ DE CONSTRUÇÃO SOLICITADO PELA REFINARIA PAULISTASIA(DOMINGOS CACACE) CONSTRUÇÃO: CARMINE COPPOLA ARQUIVOPMSP 
O repertório Forte \& Ciampaglia também é caracterizado pela assimetria. Das articulações ortogonais às rotações angulares, há espaço para a adequação formal de Alvar Aalto que "fragmentou o traçado sempre que as peculiaridades do terreno ou do programa assim o exigissem" ${ }^{41}$.

A casa Serafino Fileppo é primeira residência projetada pelos arquitetos. Implantada em lote de grande visibilidade e com acesso principal pela avenida Brasil, é uma típica adequação formal ao terreno e à única solicitação do proprietário: "uma casa inundada pelo sol" ${ }^{42}$. O segmento de arco se assume como articulador dos volumes ortogonais adjacentes. A acomodação de um único telhado através das águas-furtadas denuncia a justaposição de diferentes traçados geométricos. $\mathrm{O}$ acesso ocluso e periférico mescla-se com a marquise modernista. Referências wrightianas como o terraço em balanço, a horizontalidade definida pelos grandes beirais e alguns materiais in natura, não superam a tradição acadêmica do hall central de distribuição em ambos os pavimentos. Ainda que articulada, a planta não caracteriza a composição centrífuga a partir da lareira, no caso, adjacente ao jardim. A pérgola de madeira sugere uma proposta voltada ao paisagismo e não à estrutura do conjunto.

1943. CASAS. FILEPPO IMPLANTAÇÃOE TÉRREO ARQUIVOF\&C

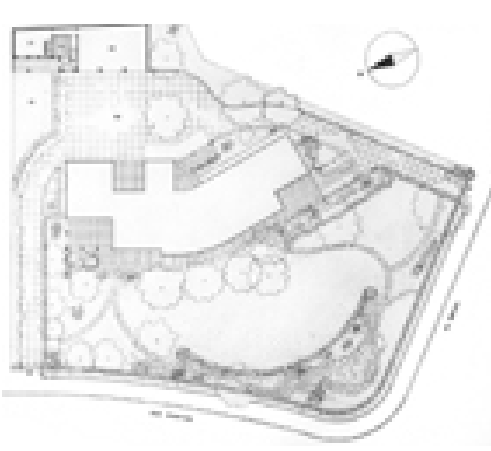

FACHADA POSTERIOR ARQUIVOF\&C

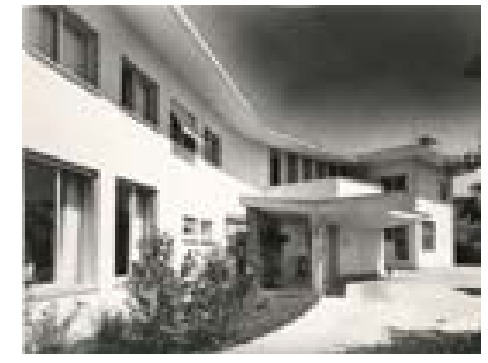

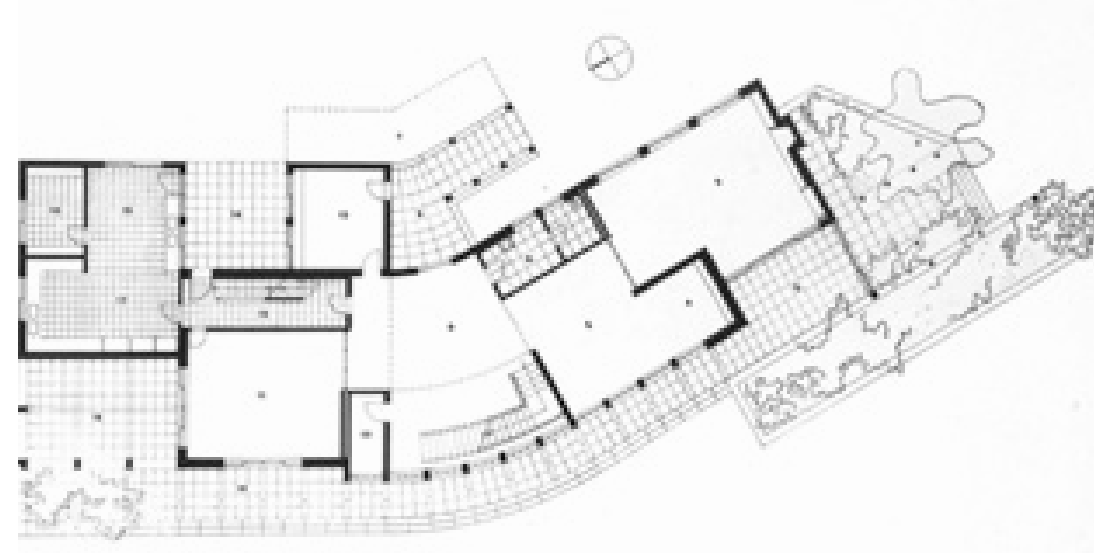

MAQUETE

ARQUIVOPMSP

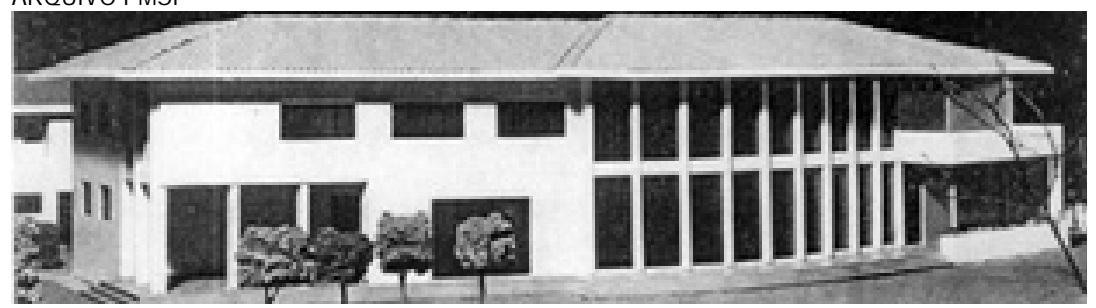




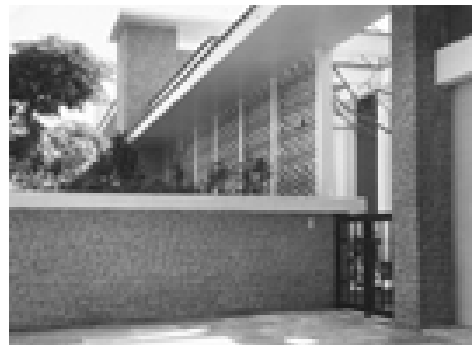

1948. CASAR. GRAZZINI ARQUIVOF\&C
A adequação formal identificada na casa Silvio Giannubillo e na casa José Forte é solução recorrente do projeto do edifício residencial da Rua Henrique Schaumann (1944) e da proposta para o concurso do edifício-sede IAB-SP (1946). Na casa S. Giannubillo, o eixo periférico determina a disposição oculta do acesso, o que não acontece na casa José Forte que, em contraponto, tem na lareira o núcleo de distribuição.
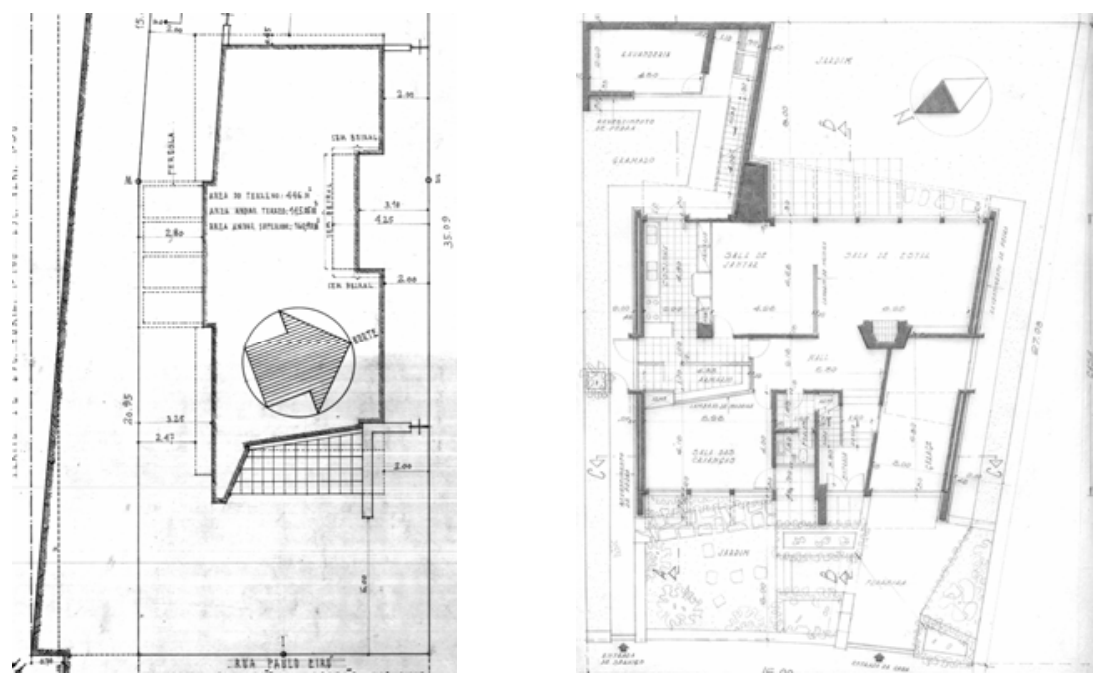

A exemplo das Usonian de Frank Lloyd Wright, a casa Renato Grazzini é definida pela nítida rotação de $60^{\circ} \mathrm{em}$ relação a um eixo. $\mathrm{Na}$ associação de corpos prismáticos, identificam-se matrizes wrightianas como estruturas salientes, o eixo compositivo não coincidente com o do movimento, o acesso ocluso pela articulação e o modo de projetar de dentro para fora. No caso, o núcleo é substituído pela sala de jantar proposta na articulação dos blocos como um polígono de oito faces. De grande sofisticação - chegando a "impressionar" ${ }^{43}$ Eduardo de Almeida, quando estudante -, é o desenho do muro e da membrana de elementos de concreto que remete ao trabalho com tijolos de Frank Lloyd Wright. O uso do material no sentido da sua natureza orgânica é analisado por Behrendt: para Frank Lloyd Wright, "o material é por natureza um amigo bem disposto e tudo depende de extrair dele, mediante um tratamento cuidadoso, o seu potencial essencial" ${ }^{44}$. 
Uma expressão brasileira é identificada nas varandas contínuas do bloco articulado. No piso superior, a seqüência de dormitórios interligados e acessados externamente por portas-balcão remete às casas de fazenda. A estrutura de pilares delgados e independentes foge ao vocabulário de Frank Lloyd Wright.

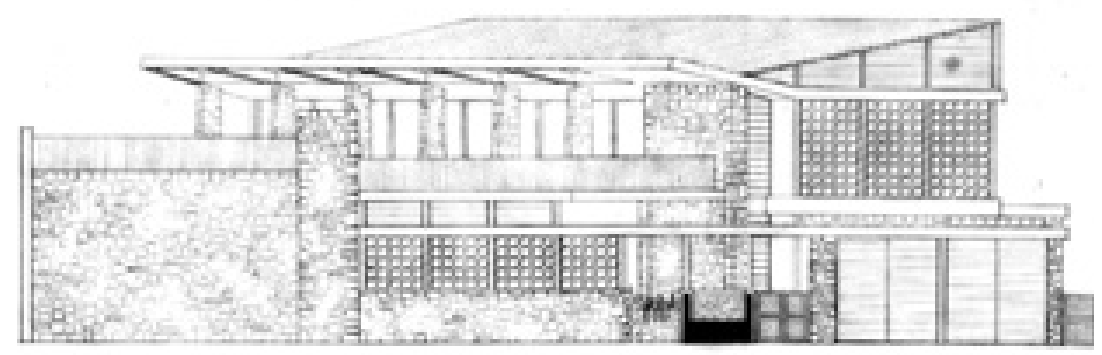

1948. CASAR. GRAZZINI ACIMA: FACHADA ARQUIVOF\&C AOLADO (E/D): TÉRREOESUPERIOR ARQUIVOFAU-USP
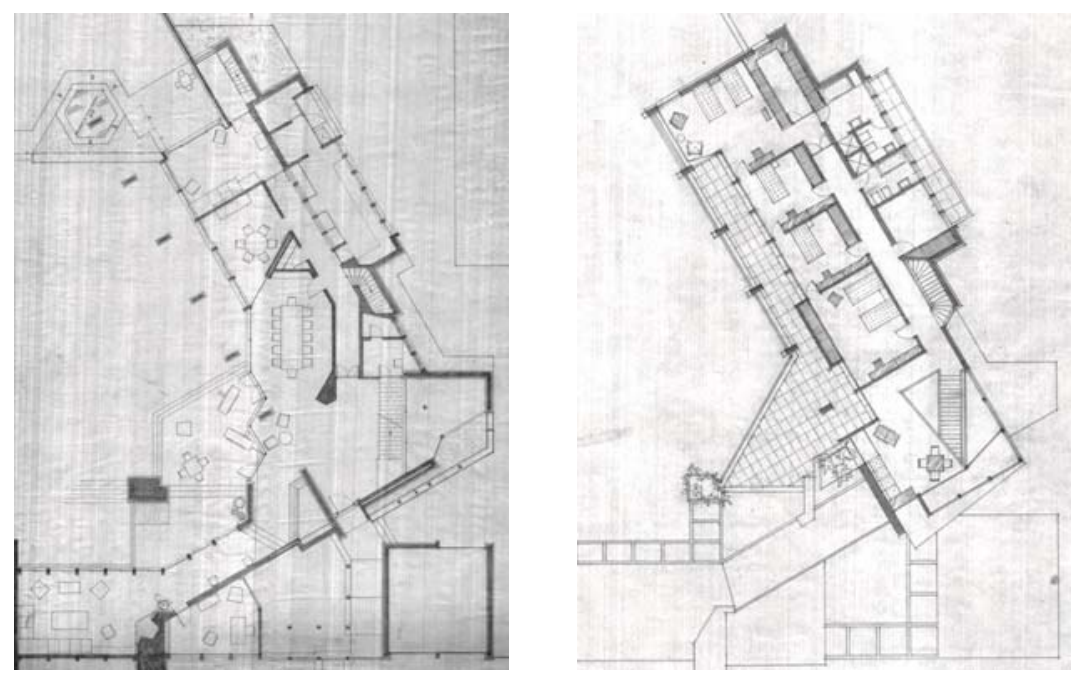

DETALHEEMTJOLOS

MALCOM MLY HOUSE, 1932

FRANKLOYDWRIGHT

WRIGHT, 1959, P. 247

ACERVOGC
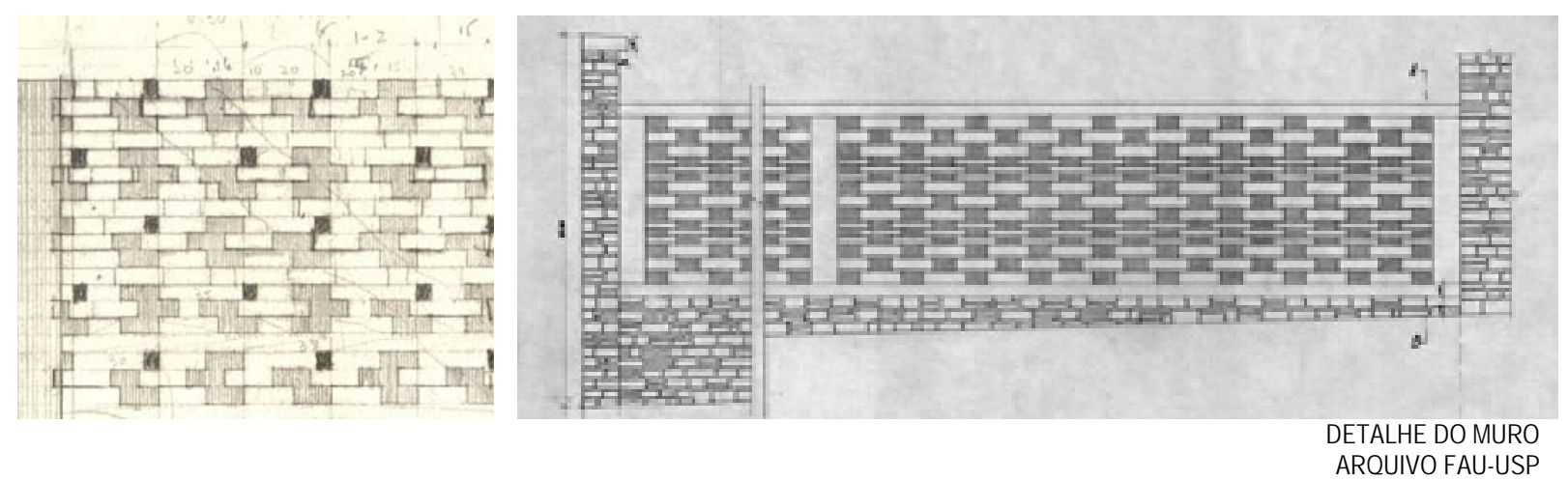


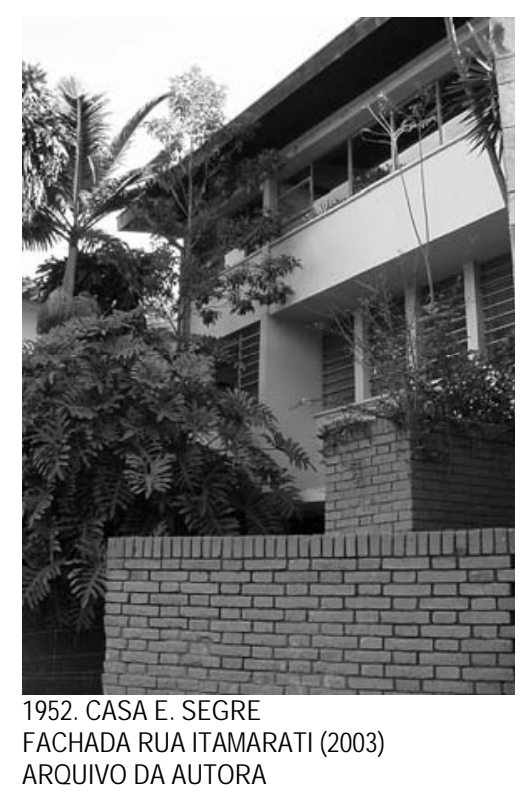

A casa Enzo Segre foi projetada para uma família composta de dois irmãos com necessidade de vida independente ${ }^{45}$.

Com programas distintos, cada unidade volta-se para uma das ruas opostas desniveladas em 12 metros. Trata-se do primeiro projeto a incorporar o despojamento de um novo estilo do habitar doméstico como o carpot e o workplace, ainda que associados a soluções convencionais em uma das unidades. Na unidade do nível superior de acesso ocluso, a lareira funciona como um núcleo da composição centrífuga. Em comum, os usuários desfrutam do pátio interno, do apartamento para hóspedes e dos serviços. A estrutura se desenvolve através de um ritmo modulado de sucessivos pórticos de concreto convertidos em apoios de diferentes lajes acomodadas à cobertura que acompanha a inclinação do lote. Uma fachada intimista se contrapõe à outra marcada pelo ritmo da fenestração e pelo prolongamento de volumetrias de tijolos até a divisa. Entre os originais identifica-se um estudo de vitrais adequado ao cliente, um industrial do ramo de vidros. A casa integra o livro Residências em São Paulo: 1945-1975. Este é um dos casos em que a construção pelo engenheiro Vicente Giordano não consta da ficha técnica da obra $^{46}$. 


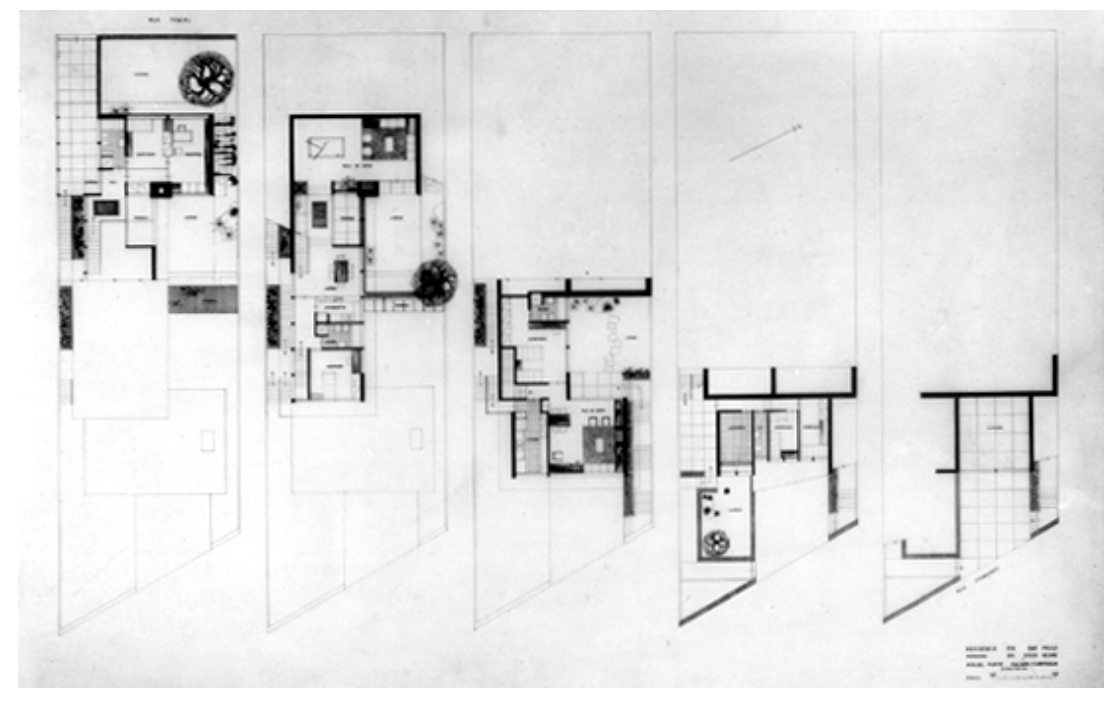

PLANTADOS PAVMENTOS

DESENHOCHENYHWA

ARQUIVOF\&C

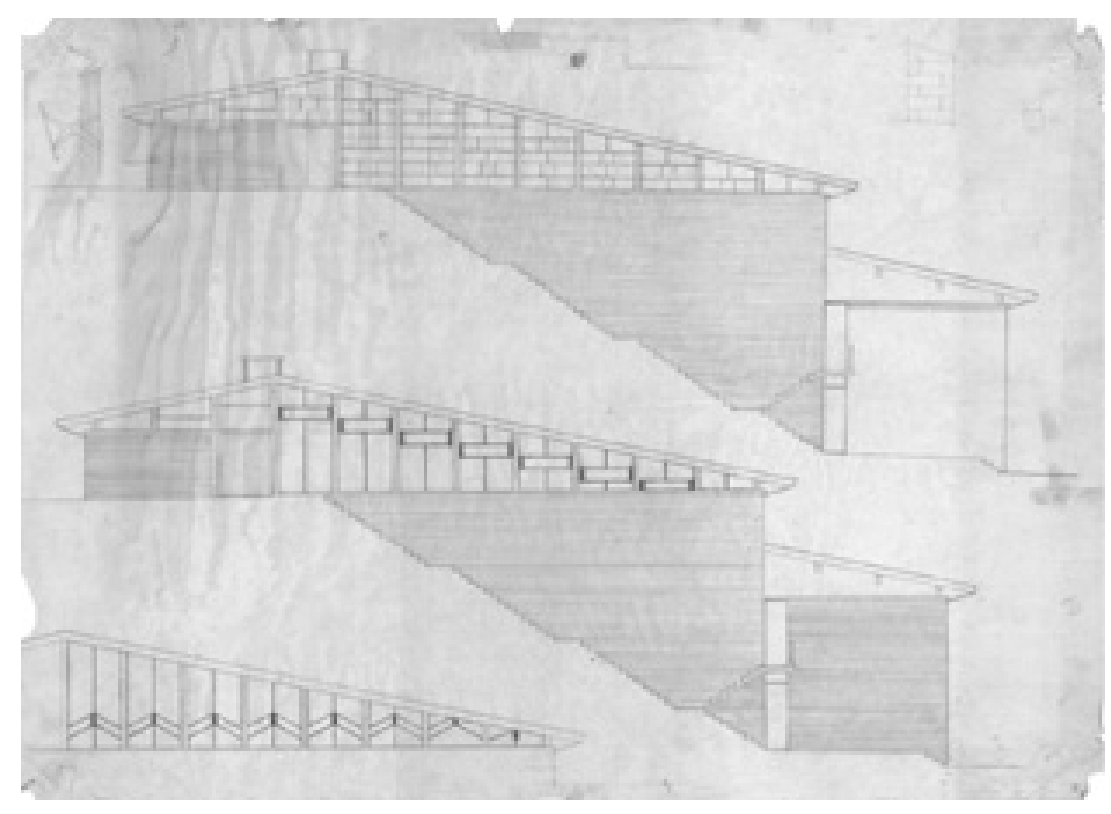

ESTUDODEVITAIS

ARQUIVOFAU-USP

Dr. Bnzo Segre, residente á R.Santa Madalena no 362, nesta Capftal, desejando construir uma residencia á Rua Traipú pegado ao ne803 ver, mui respeitosamente requerer á V.Excia. que se digne aprovar as plantas em 5 vias e memorial em 2 vias.

Outrosim aproveita para apresentar como autores do projeto a firma Forte \& Ciampaglia Itda(arq.Miguel Forte e Galiano Ciampaglia) com escritorio á R.Barão de Itapetininga ne 124,120 e como construtor responsavel o eng.civil Vincerzo Giordano com escritorio á Ladeira Porto Geral ne 106,5\%.

1952. CASAE. SEGRE REQUERIMENTO DE ALVARÁ DE CONSTRUÇÃO CONSTRUÇ̃̃O: ENG ${ }^{\circ}$ CIVL VICENTE GIORDANO 


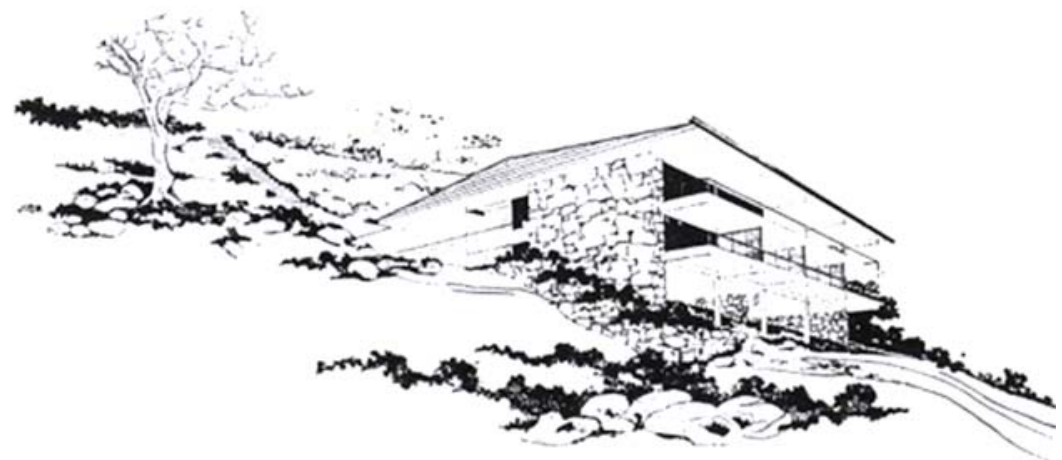

1954. CASAF. GERODEITI

GALIANO CIAMPAGLIAE MIGUEL FORTE

NÃO CONSTRUÍDA

DESENHO CHENG Y HWA

ARQUIVOF\&C 

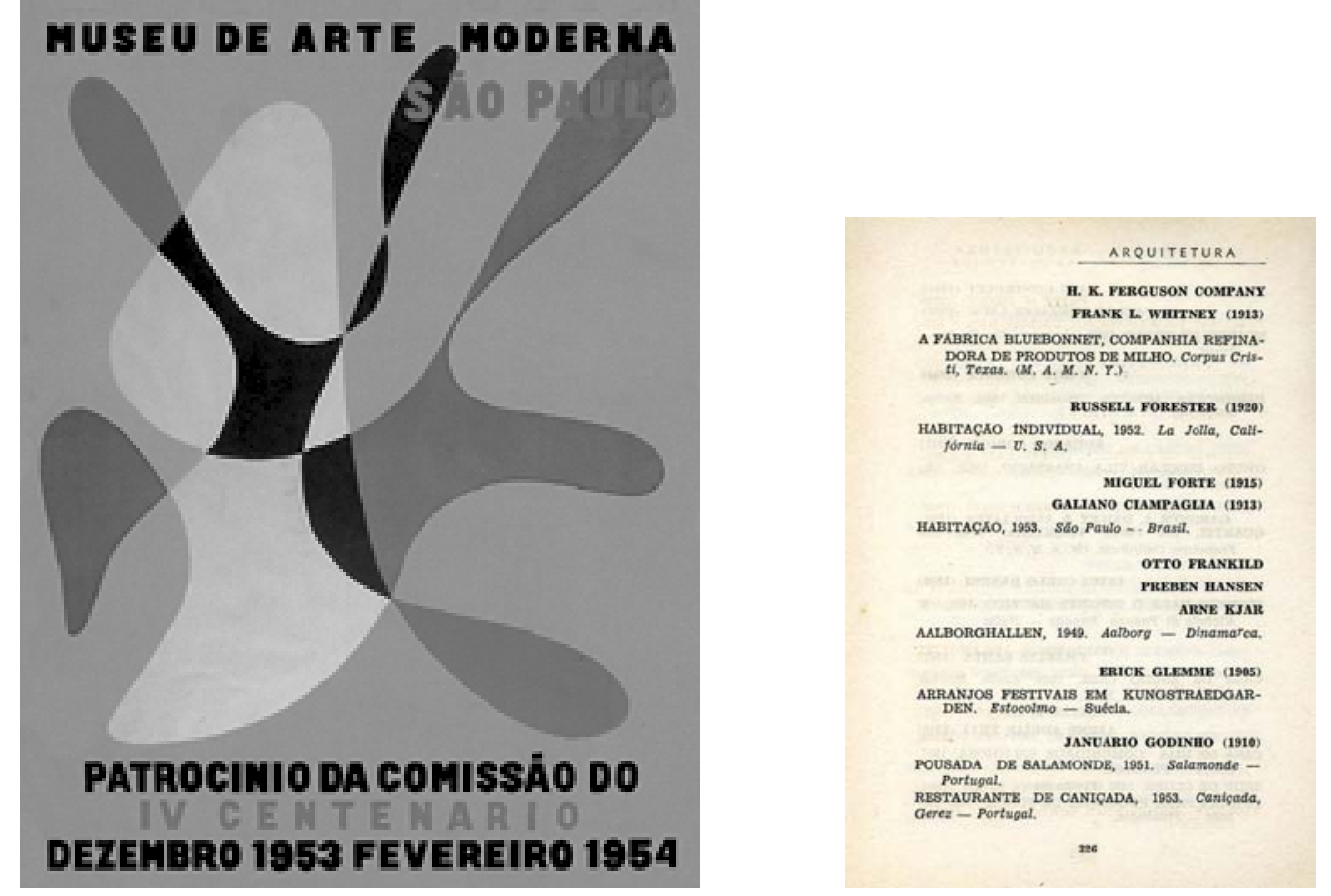

CARTAZ E CATÁLOGO DE ARQUITTIURA II BIENAL DO MUSEU DE ARTE MODERNA DE SÃOPAULO ARQUIVOWANDA SEVERO

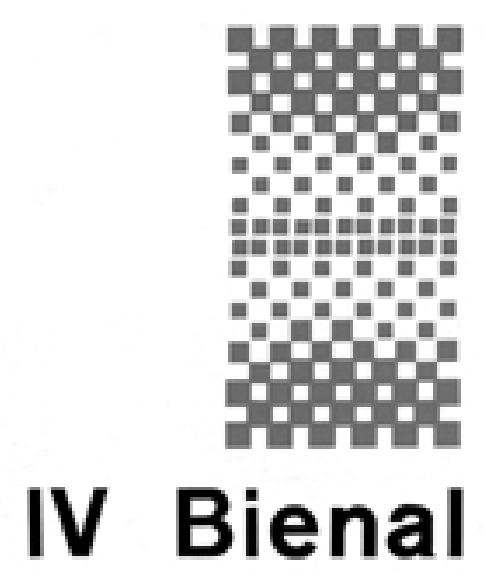

Museu de Arte Moderna Sáo Paulo

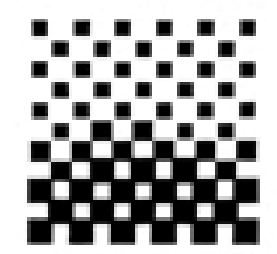

Brasill setembro-dezembro de 1957

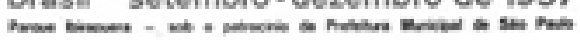

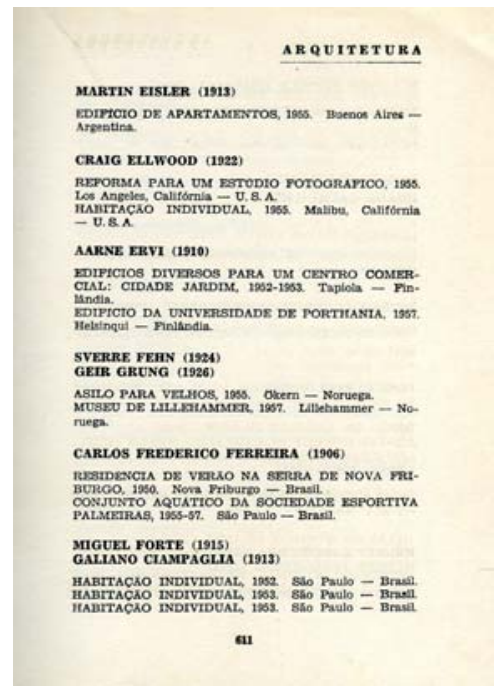

CARTAZ E CATÁLOGO DE ARQUITETURA IV BIENAL DO MUSEU DE ARTE MODERNA DE SÃO PAULO ARQUIVOWANDA SEVERO 


\section{* Bienais}

Contando com a disponibilidade dos meios de comunicação das empresas de Assis Chateaubriand, a inauguração do Museu de Arte de São Paulo, em 1947, representa vital contribuição na divulgação do projeto cultural proposto pela diversidade da formação do acervo, das exposições e das atividades de ateliê, além dos cursos ministrados, entre outros, por Jacob Ruchti, Leopoldo Haar, Flávio Motta e Oswaldo Bratke, Lina Bo e Pietro Maria Bardi ${ }^{47}$. Lina Bo e Pietro M. Bardi, curadores do museu, são responsáveis pela adaptação do espaço inaugural instalado no segundo andar dos Diários Associados.

Em via de mão dupla, o industrial Francisco "Ciccillo" Matarazzo Sobrinho ambicionava a liderança paulista no campo das artes, e Nelson Rockfeller, como presidente do Museu de Arte Moderna de Nova York, pretendia consolidá-lo como pólo de irradiação cultural na América Latina. Ao tomar conhecimento da articulação paulista entre Matarazzo, Sergio Milliet, Rino Levi, Eduardo Kneese de Mello, Carlos Pinto Alves e o adido cultural do Consulado dos Estados Unidos, C. Sprague Smith, Rockfeller doa o acervo como impulso à criação do Museu de Arte Moderna de São Paulo, em $1948{ }^{48}$. A Assembléia de fundadores, presidida por Matarazzo, é assinada em 3 de junho por intelectuais, pelo crítico Sergio Milliet, e por alguns arquitetos, entre eles, Eduardo Kneese de Mello, Galiano Ciampaglia, Jacob Ruchti, Luiz Saia, Miguel Forte, Rino Levi, Roberto Cerqueira César, Salvador Candia e Vilanova Artigas. O fato de alguns arquitetos pertencerem aos quadros da seção paulista do IAB sedimenta os vínculos entre as entidades. Para as instalações do novo museu é cogitado, entre outros espaços, o próprio edifício-sede IAB-SP, decidindo-se o conselho pelo edifício dos Diários Associados. Artigas é o responsável pelo projeto de reforma para as novas instalações abertas oficialmente em 9 de março de 1949. Respaldado pela doação generosa, Rockfeller impõe regulamentos e objetivos que incluem no Conselho da Administração da fundação expoentes paulistanos como Eduardo Kneese de Mello, Luis Saia e Rino Levi. 
A realização de grandes mostras, a exemplo da Bienal de Veneza, já estava prevista quando da criação MAM. O próprio MoMA, em 1939, por ocasião do 10 aniversário e inauguração do novo prédio projetado por Philip L. Goodwin e Edward D. Stone, havia organizado a exposição Art in our Time diferenciada das demais mostras pela pluralidade. O catálogo da exposição enuncia o propósito através do diretor, Alfred Barr:

"Art in our time é planejada especialmente para os visitantes da Feira mundial de Nova York [...] Ela difere das exposições especiais de arte moderna em outros museus de Nova York no momento da Feira pela sua inclusão de obras estrangeiras, bem como 0 americano, e por sua preocupação não só com pintura, escultura e artes gráficas, mas também com a arquitetura, mobiliário, fotografia e cinema" 49.

\section{AIRT IN OUIR TIME}

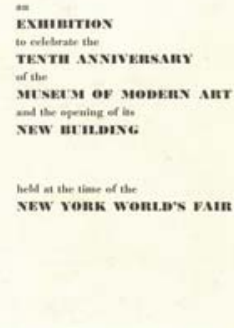

MUSEUM OF MOIERN AIET

Antecipando as mostras integradas das bienais de São Paulo, dos anos 50, projetos de Aalto, Breuer, Gropius, Mies, Lê Corbusier e Wright, são apresentados ao lado de peças de design e das salas de pintura, escultura, artes gráficas, fotografia e cinema.

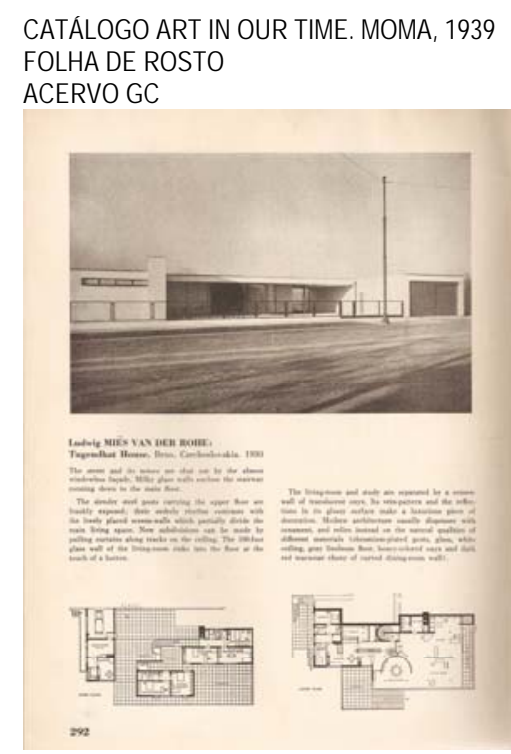

TUGENDHAT HOUSE, 1930

MIES VANDERROHE

MOMA, 1939, P. 292

ACERVOGC

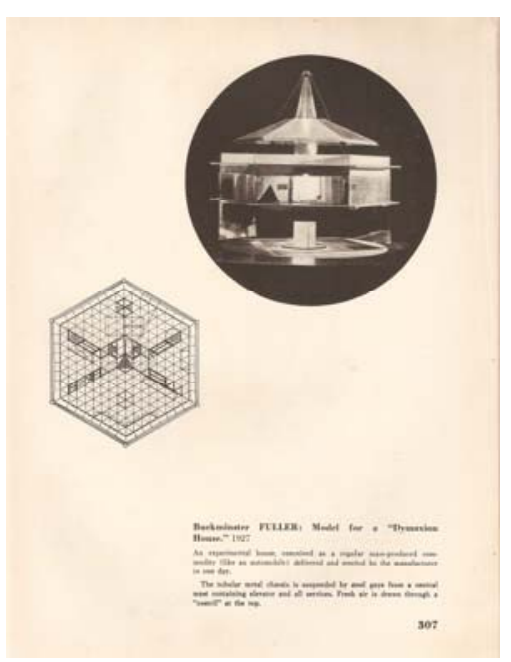

MODEL "DYMAXION HOUSE"

BUCKMINSTER FULLER

MOMA, 1939, P. 303

ACERVOGC

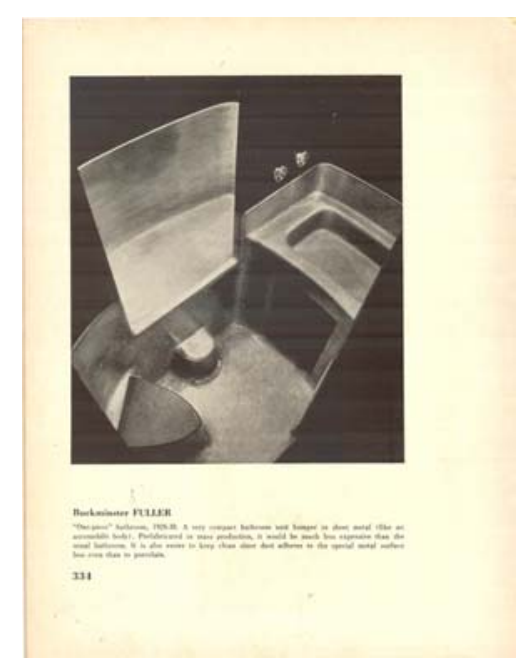

“ONE PIECE', 1926-38

BUCKMINSTER FULER

MOMA, 1939, P. 334

ACERVOGC 
O convênio entre o MoMA e o MAM, firmado em 19 de outubro de 1950, sinaliza a criação da I Bienal do Museu de Arte Moderna. A exposição é aberta em 20 de outubro de 1951, no antigo Belvedere do Trianon, na avenida Paulista. O Catálogo da mostra atribui o projeto arquitetônico da seção de arquitetura a Eduardo Kneese de Mello e Luiz Saia, e a concepção do espaço expositivo, a Jacob Ruchti. A participação de Miguel Forte é questionada por Valeria Ruchti, no estudo publicado em $2011^{50}$.

O júri esteve representado por Eduardo Kneese de Mello, Francisco Beck, Junko Sakamura, Mario Pani e Siegried Giedion. Foram homenageados, Attilio Correia Lima, Flávio de Carvalho, Gregori Warchavchick e Lucio Costa. Os prêmios principais couberam a Le Corbusier e Pier Luigi Nervi. A produção arquitetônica nacional foi premiada através de Affonso Reidy, Álvaro Vital Brazil, Helio Uchoa Cavalcanti, Henrique Mindlin, Lucio Costa, Oscar Niemeyer e Rino Levi ${ }^{51}$.

Vista por Maria Cecília França Lourenço como "o ápice de um percurso" para a institucionalização do moderno como um todo, ao destacar a exposição Internacional de Arquitetura, a I Bienal vai de encontro à ótica do movimento moderno sobre como divulgar e convencer o público sobre a nova arquitetura.

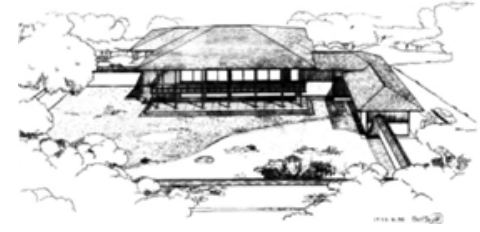

Em 1953, a exposição conhecida como a Bienal do IV Centenário da cidade de São Paulo é instalada no Parque Ibirapuera, no conjunto arquitetônico projetado por Oscar Niemeyer. Um dos pontos de interesse da mostra é atribuído à montagem do pavilhão japonês.

A arquitetura japonesa era uma forte inspiração de Frank Lloyd Wright, não apenas pelo conceito espacial, mas pela simplicidade no uso de materiais. Galiano Ciampaglia, que à época já demonstrara interesse por essa cultura, "confirmou o interesse que despertou nele a simplicidade do pavilhão. Ele acompanhou diariamente as obras durante a montagem" 52 . 
O júri da Exposição de Arquitetura era formado por Walter Gropius, José Luis Sert, Alvar Aalto, Ernesto Rogers, Oswaldo Arthur Bratke, Affonso Reidy e Lourival Gomes Machado. Gropius foi homenageado com o Prêmio São Paulo de Arquitetura. A categoria moradia individual distribuiu prêmios, entre outros, a Philip Johnson, Paul Rudolph, Craig Ellwood, Donald Bartheleme, Jorge Machado Moreira, Roberto Burle Marx e Sergio Bernardes. Galiano Ciampaglia e Miguel Forte participaram da mostra com a casa Renato Grazzini.

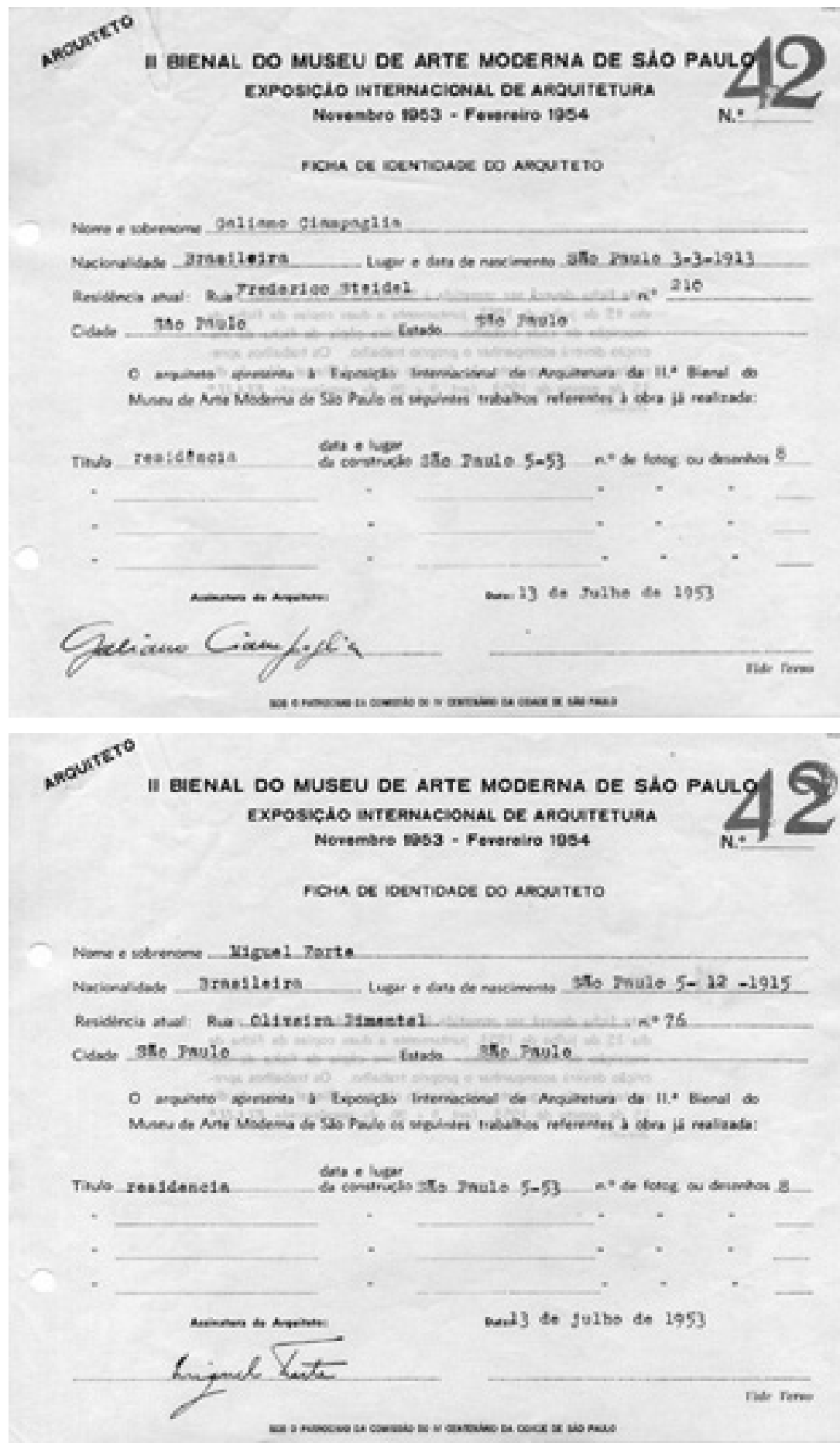


Para abrigar a IV Bienal do Museu de Arte Moderna, realizada em 1957, as instalações são transferidas para o Palácio das Indústrias. Com regulamentos assinados por Ciccillo Matarazzo, o processo de seleção é conduzido por Eduardo Kneese de Mello, Francisco Beck, Mario Henrique Glicério Torres e Plínio Croce. O Júri de premiação incorpora Jacob Ruchti, Kenzo Tange, Marcel Breuer e Philip Johnson. Na oportunidade, a sala especial de Mies van der Rohe foi vista com muito entusiasmo pela imprensa. A lista de selecionados é composta de quarenta e três arquitetos brasileiros, entre os quais, Niemeyer e Lucio Costa.

$\mathrm{Na}$ categoria moradia individual, entre as trinta e seis casas escolhidas, catorze eram do Brasil. Três unidades foram projetadas por Galiano Ciampaglia e Miguel Forte: casa Luis Forte, casa Enzo Segre e casa Domingos Cacace.

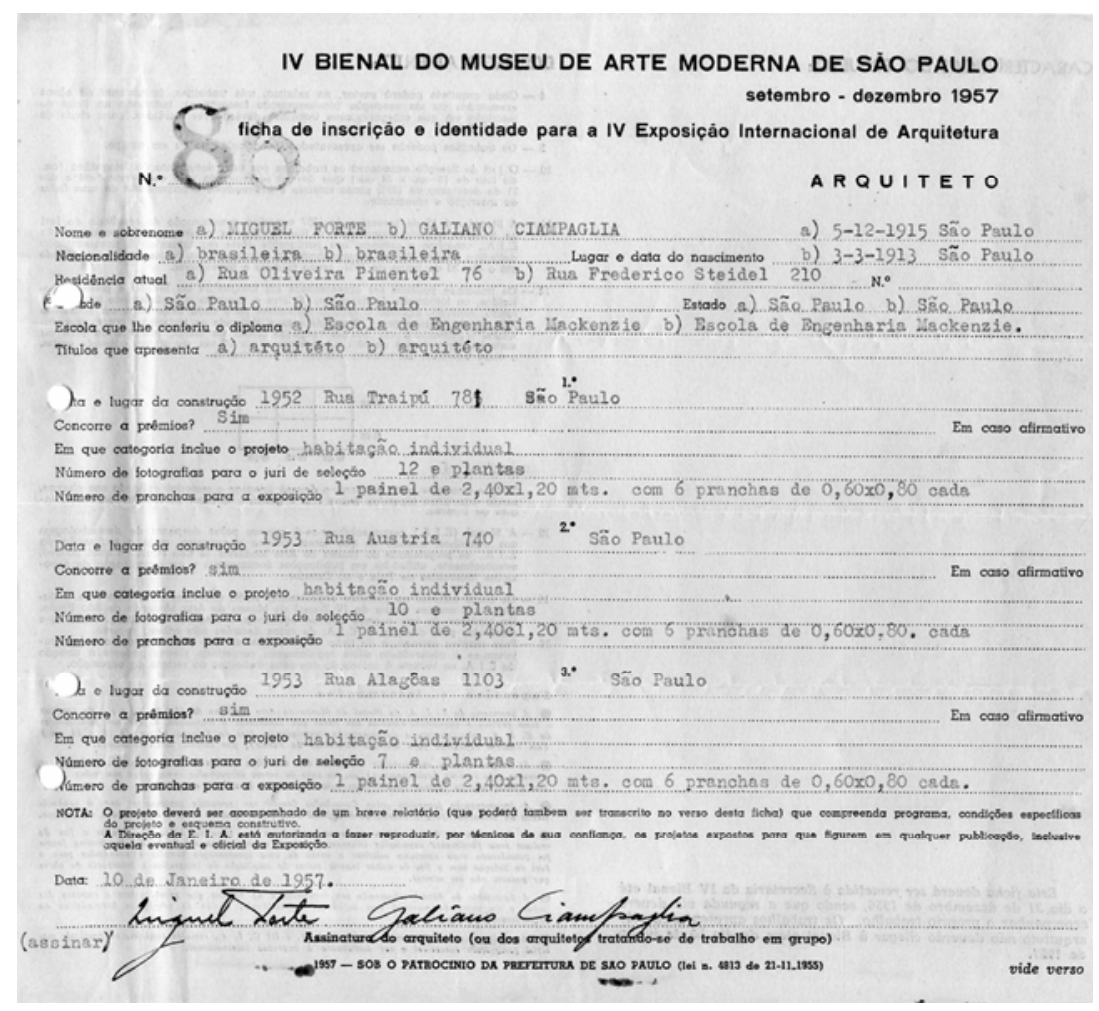



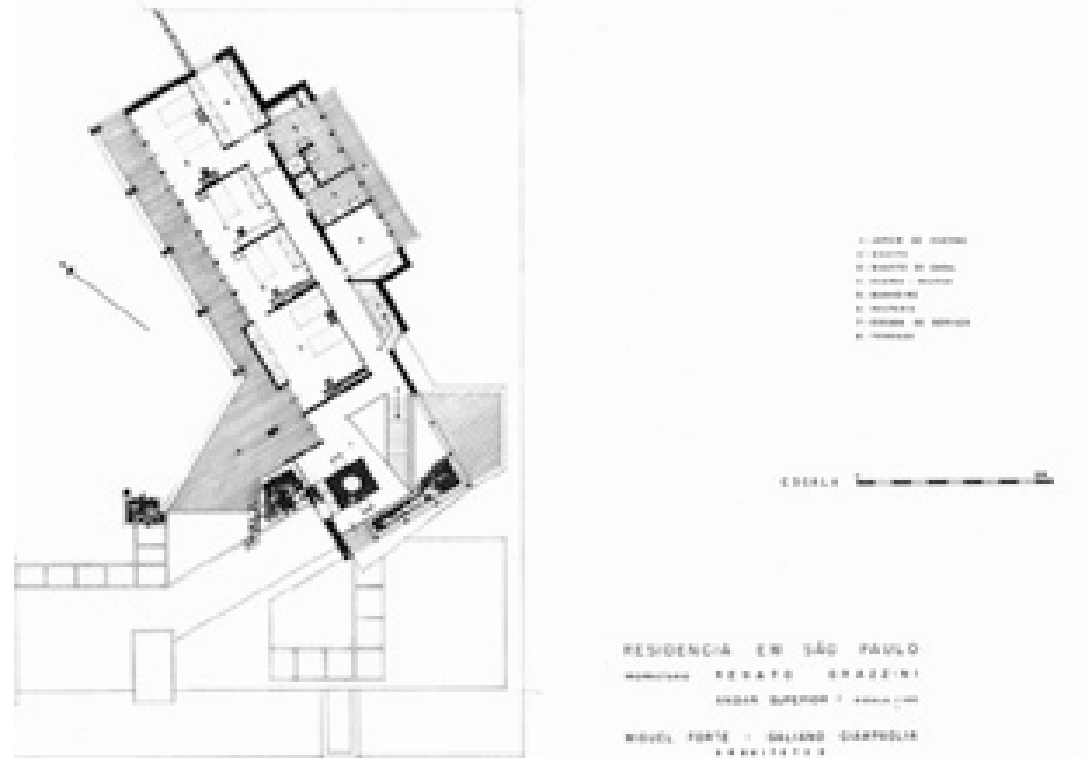

ACIMA: PAINEI CASA R. GRAZZINI (1947-48)

ARQUITETOS MIGUEL FORTEE GALIANO CIAMPAGLIA

ABAIXO: PAINEI CASAL. FORTE (1952)

ARQUITETOS MIGUEL FORTEE GALIANO CIAMPAGLIA

DESENHOS CHENG YHWA ARQUIVOF\&C

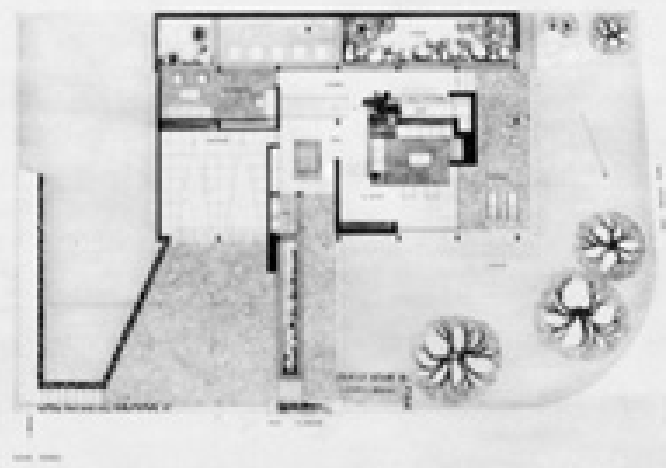



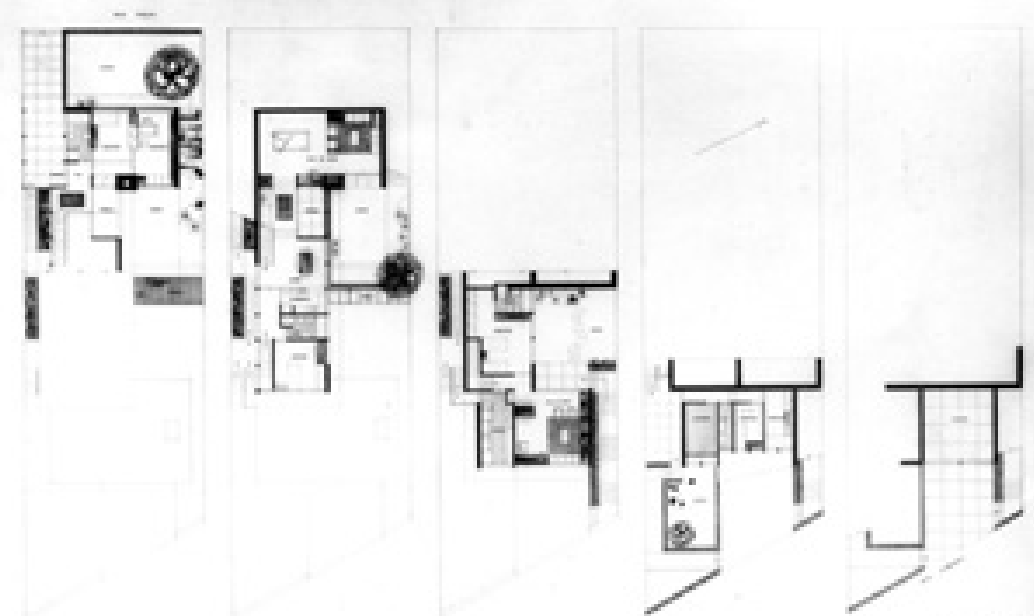

ACIMA: PAINEI CASA E SEGRE (1952)

푸골

ARQUITETOS MIGUEL FORTEE GALIANO CIAMPAGLIA

ABAIXO: PAINEI CASA D. CACACE (1952)

ARQUITETOS MIGUEL FORTE E GALIANO CIAMPAGLIA

DESENHOS CHENG YHWA ARQUIVOF\&C

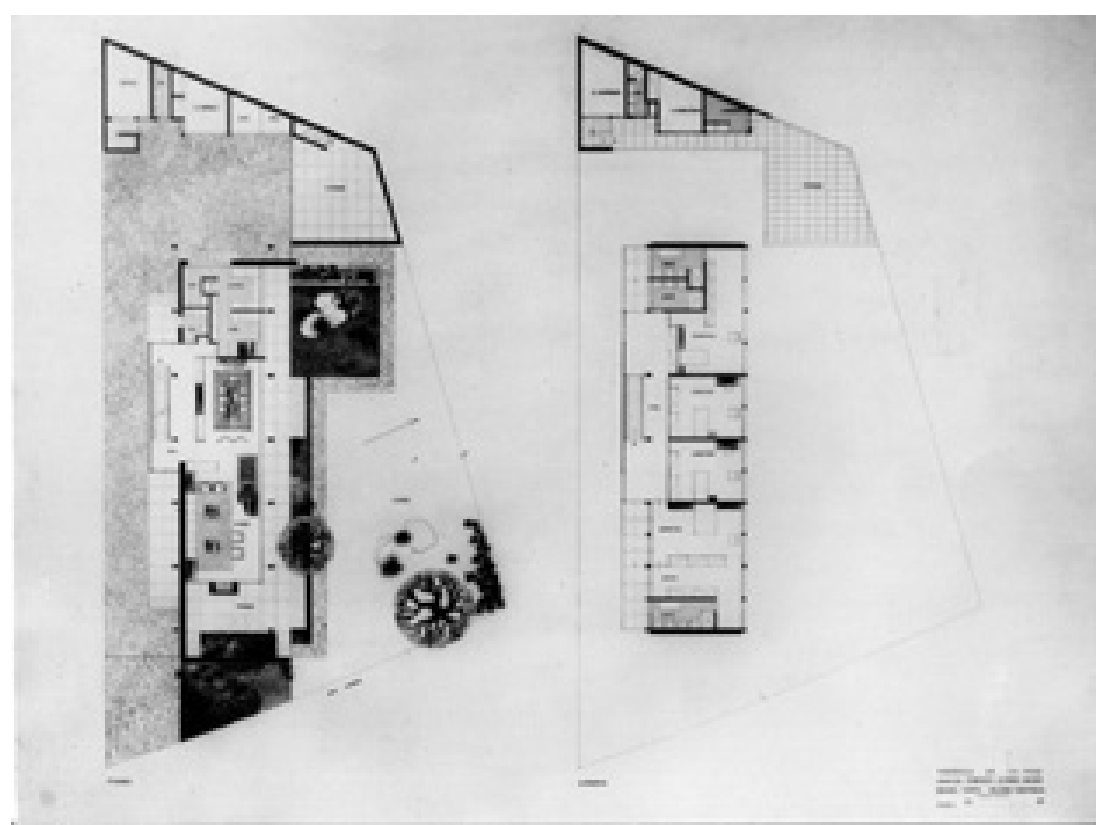




\section{* Uma pista}

No período vinculado às autorias compartilhadas, Miguel Forte se volta a outras vertentes como, em 1949, quando elabora com Jacob Ruchti o projeto expositivo da exposição de fotografias de Tomas Farkas, realizada no MAM.

Em meados de $1952^{53}$, Miguel Forte, Jacob Ruchti, Carlos Millan, Cheng Hwa, Plínio Croce e Roberto Aflalo iniciam as articulações para a abertura de uma loja de móveis. Focados nos projetos de edificações, Galiano Ciampaglia e Salvador Candia não aderem ao grupo.

A loja Branco \& Preto é inaugurada em dezembro de 1952, um mês após o requerimento de construção da casa Domingos Cacace. Segundo a autora do livro Branco \& Preto. Uma história de design brasileiro nos anos 50, além do design do mobiliário, para facilitar a comercialização dos móveis, os arquitetos do grupo Branco \& Preto elaboravam "para os clientes que desejavam comprá-los, projetos de decoração. Na maior parte das vezes faziam estudos de ambientes que não haviam projetado" 54 .

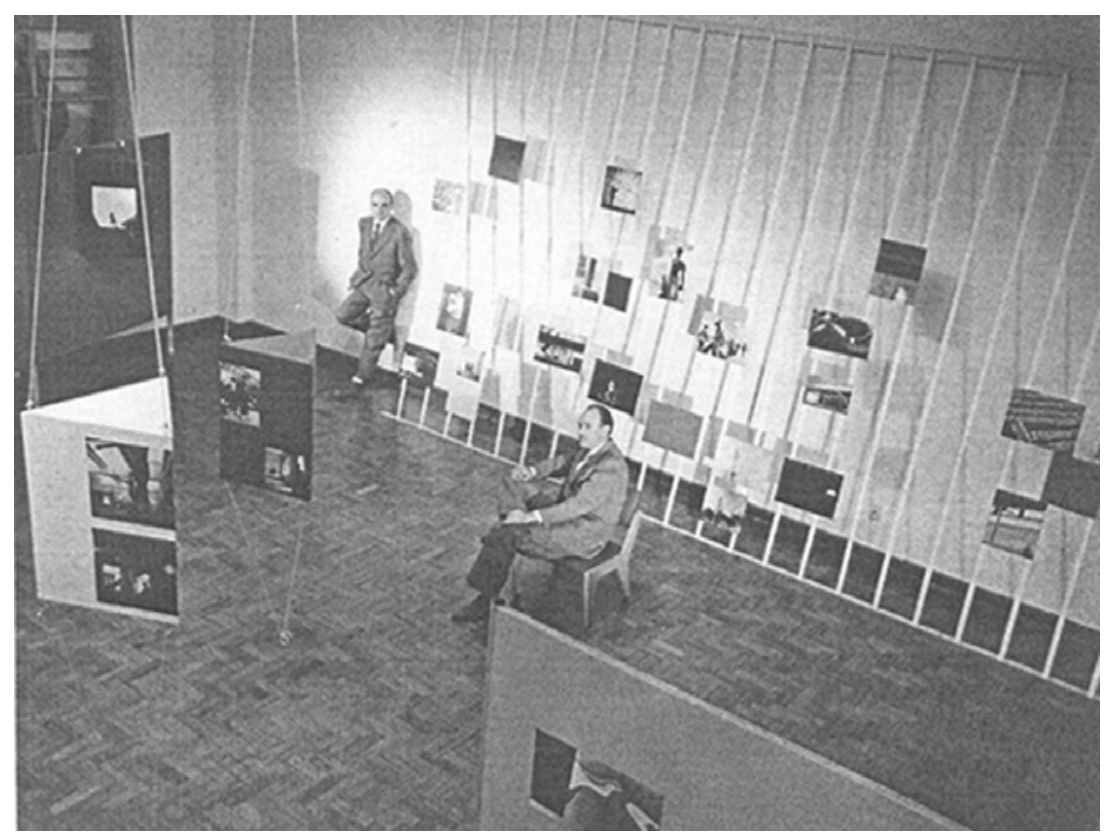


1952. CASAD. CACACE

INTERIORES BRANCO \& PRETO ARQUIVOF\&C
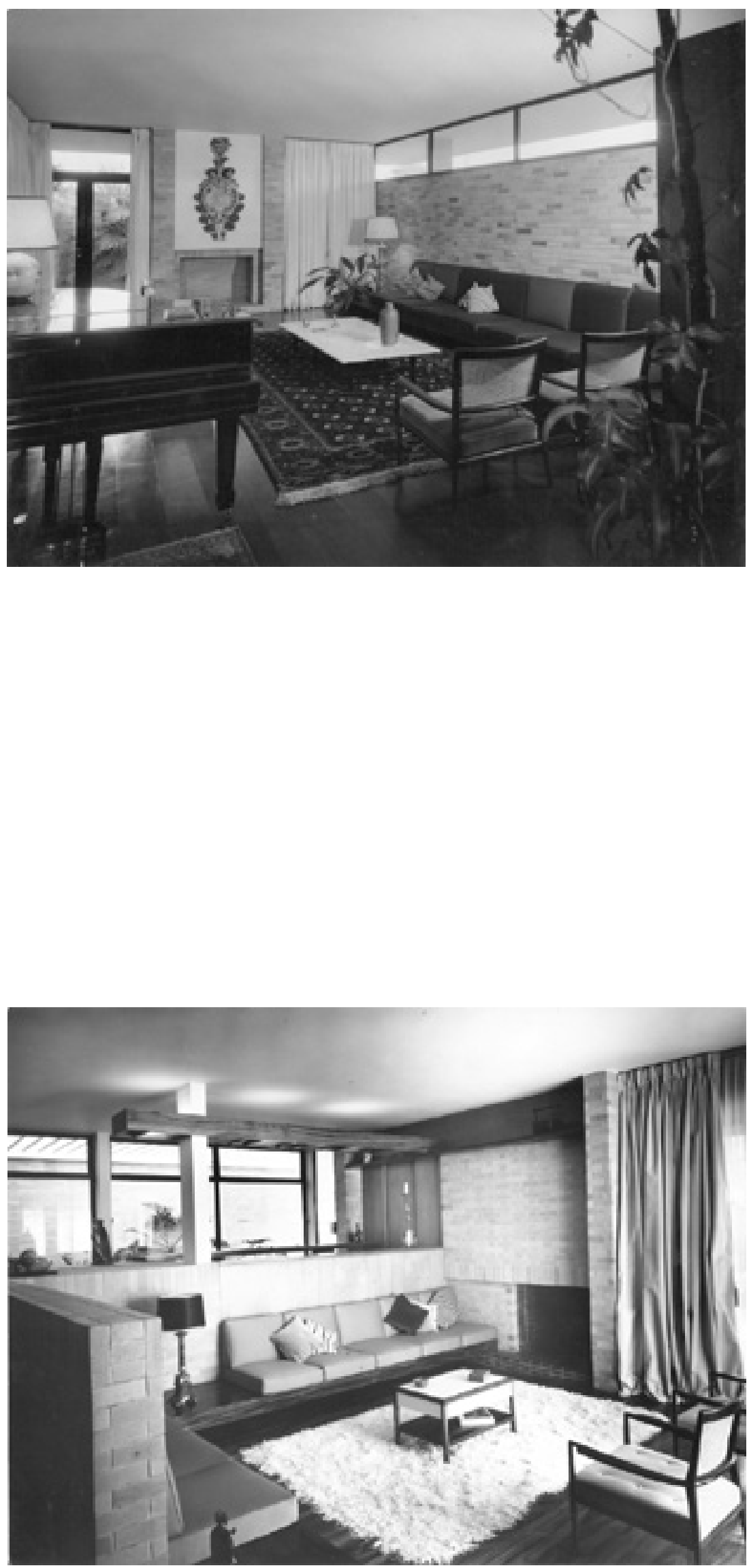
Diante de interesses distintos dos sócios, em 1954, o grupo Branco \& Preto passou a pertencer apenas a Miguel Forte, Roberto Aflalo e Carlos Millan ${ }^{55}$. A não adesão de Galiano Ciampaglia e o crescente envolvimento de Miguel Forte com a loja determinaram a trajetória autônoma dos arquitetos o que não impediu o compartilhamento do escritório por alguns anos.

A reconstrução do período compartilhado (1942-1955), em lugar daquele divulgado pela literatura acadêmica (1942-1965), explica a ausência da casa Miguel Forte, como conhecida na literatura especializada. Além de aquela autoria caber exclusivamente a Miguel Forte, a nítida releitura Prairie introduzidos, nos anos 60, não respondem à linha conceitual dos anos precedentes, adequada ao projeto original (1948). No caso, de volumetria contida sob um único telhado de quatro águas ${ }^{56}$

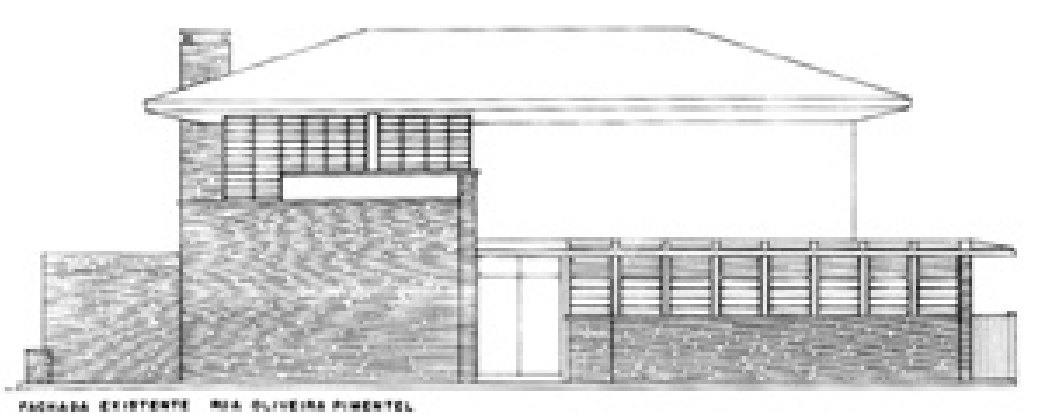

1948. CASAM. FORTE MGUEL FORTE ARQUIVOMF

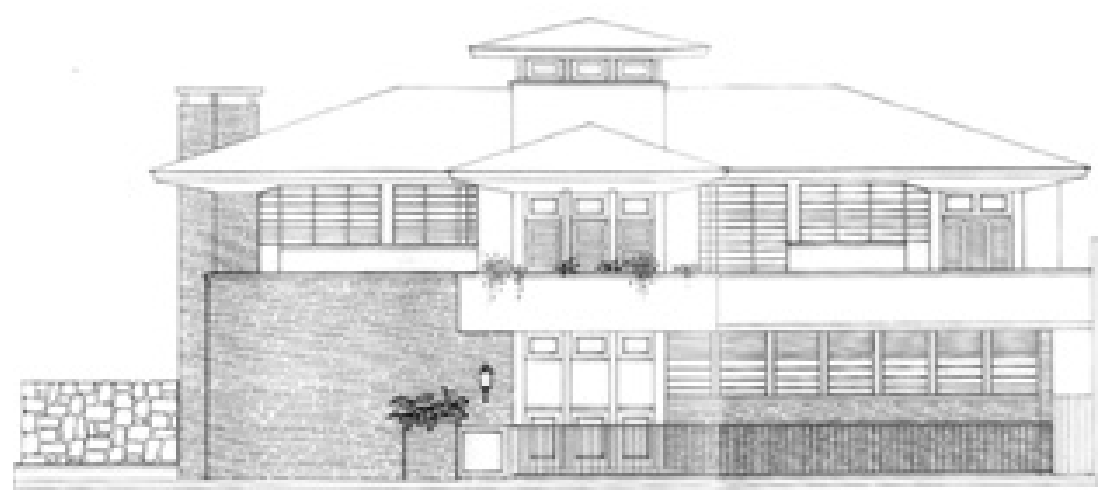

1961. CASAM. FORTE (PROJETO CORRESPONDENTE ÀS IMAGENS DIWLGADAS DESDE 1986 57) MIGUEL FORTE ARQUIVOMF 

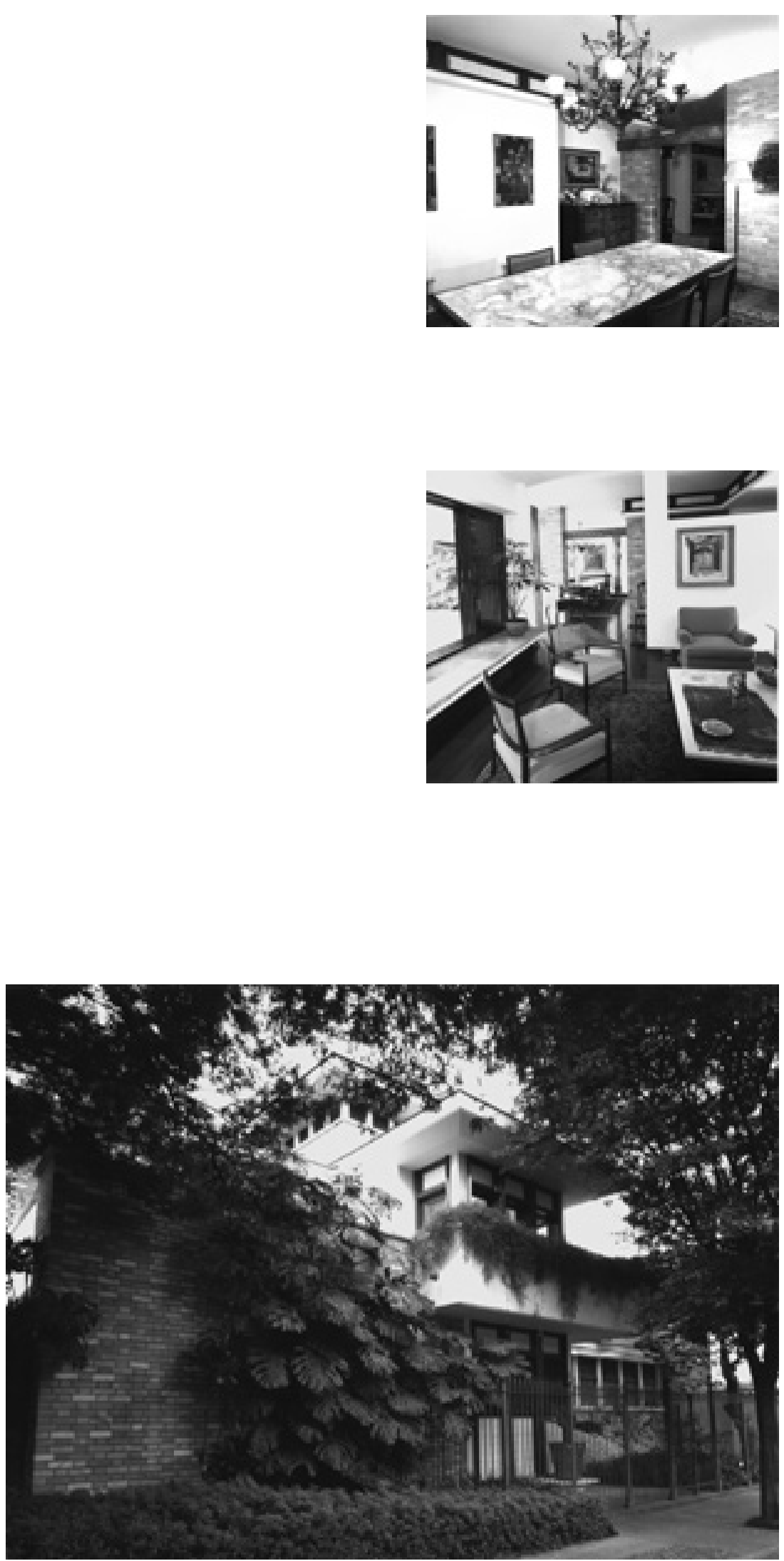

1961. CASA MIGUEL FORTE (IMAGEM DIVLLGADA DESDE 1986 E EQUIVOCADAMENIE DATADA DE 1948-50 58)

MIGUEL FORTE

INTERIORES EFACHADA

ARQUIVOMF 


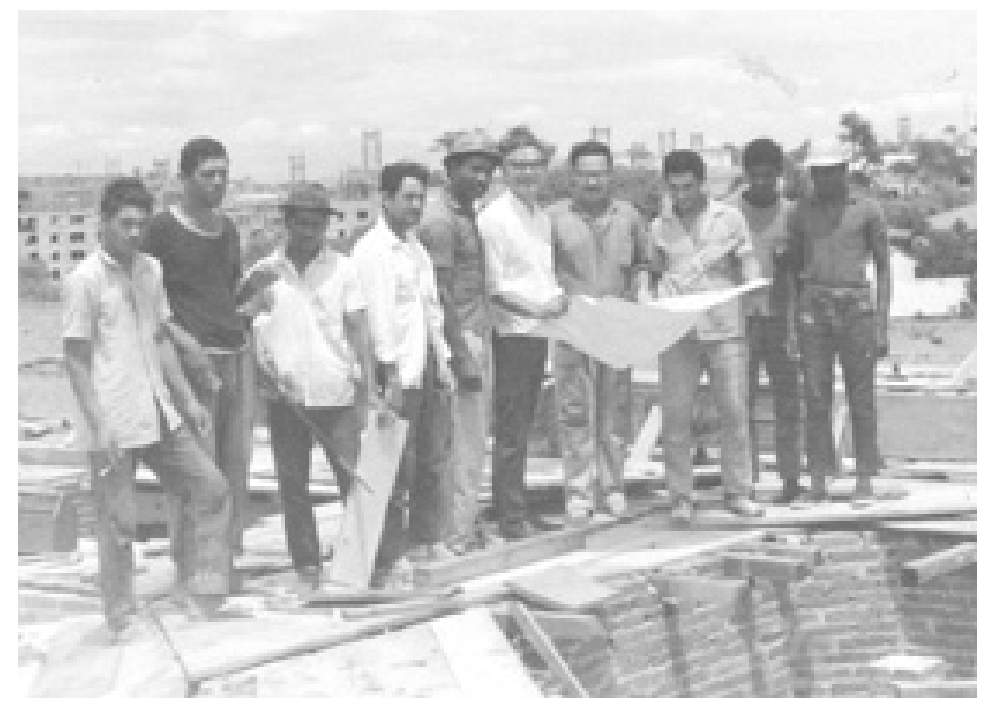




\section{Galiano Ciampaglia lui même}

Em 1958, Galiano Ciampaglia assina a casa da Rua Inglaterra (Justo Pinheiro da Fonseca).

Se a obra compartilhada com Miguel Forte foi pautada na política de revezamento da prancheta ao canteiro, as trajetórias independentes dos arquitetos podem sugerir o pensamento de um em relação ao outro, naquele período. A começar pela metodologia de trabalho.

Em contraponto à fase anterior, quando os desenhos dos arquitetos eram também compartilhados por um projetista ou estagiário, Galiano Ciampaglia optou por não ter colaboradores no escritório que dividia com Miguel Forte, na Rua Barão de Itapetinga, transferindo-se depois para o conjunto 62 do edifício-sede IAB-SP.

O desenho, do croquis ao detalhe passando pelo projeto legal, invariavelmente é de sua autoria. $\mathrm{Na}$ (des)organização frente aos padrões usuais para desenhos arquitetônicos, identifica-se a sintonia entre o ritmo dos acontecimentos e o domínio do processo controlado diretamente e com autonomia. Não há padronização de folhas ou de carimbos, sequer dos instrumentos utilizados. Não raro, uma mesma folha contempla plantas, cortes e elevações, a exemplo de Palladio como "maneira de minimizar essa fragmentação" 59.

$\mathrm{Na}$ análise sobre a linguagem gráfica na arquitetura, Fialho parte do fato de que um projeto não se explica apenas pela palavra, seja para a sua produção, seja para o entendimento do cliente. Cabe, portanto, ao arquiteto, "caminhar" com o desenho no ritmo do receptor, na maioria das vezes carente do treinamento adequado a essa compreensão. Sobre os desenhos de Carlo Scarpa, escreve Mario Frascari:

"os desenhos de Scarpa mostram a verdadeira natureza dos desenhos arquitetônicos, isto é, o fato de que são representações resultantes de construções. Eles são uma interpretação de juízos perceptivos sobrepostos ao processo real de construção física de um objeto arquitetônico [...] 0 pedaço de papel escolhido para suportar o lento processo de construção de um projeto apresenta seções verticais e horizontais simultâneas, bem como elevações do objeto projetado" 60 . 


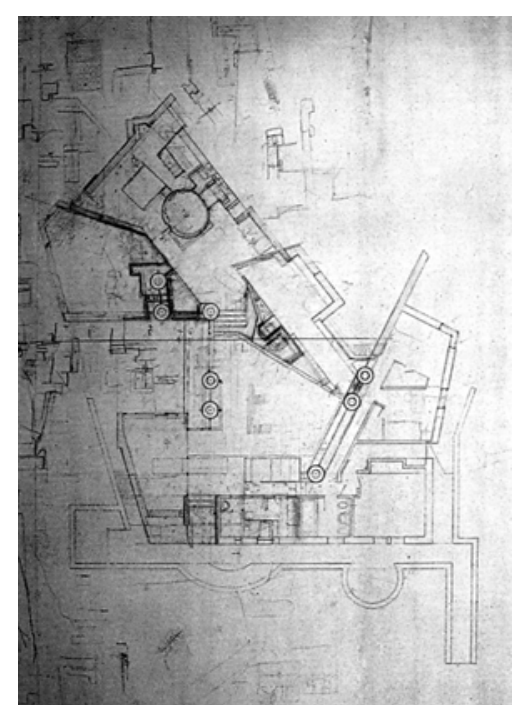

1974. VLLA OTTOLENGH

CARLOSCARPA

SCARPAEDAL CO, 1998, P. 21

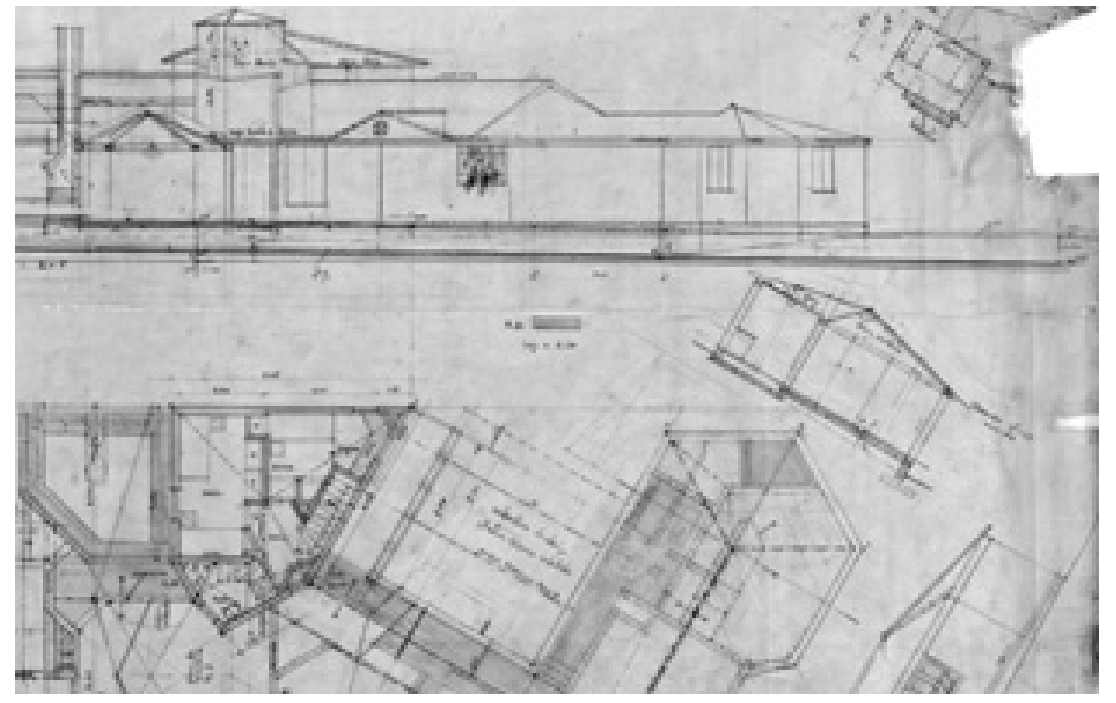

1972. CASA DOS TELHADOS

GALIANO CIAMPAGLIA

ARQUIVOGC 
O exercício projetual de Galiano Ciampaglia não se furtou aos ensinamentos de Wright:

"O que precisamos saber sobre a arquitetura orgânica não se encontra nos livros [...] É necessário aprender das árvores, flores e conchas - objetos que contêm verdades da forma seguindo função" ${ }^{61}$.

Na produção também focada na arquitetura doméstica, a qualidade de execução permaneceu garantida pela cumplicidade dos clientes em favor da fiscalização do arquiteto até o último detalhe, resguardado o envolvimento comercial entre o proprietário e o construtor ${ }^{62}$.

Do pragmatismo do pai e do discurso de Wright - "nunca mais os arquitetos de prancheta" 63 -, Galiano Ciampaglia enxergou na interface escritório-canteiro o laboratório para a sua evolução profissional: "escritório e canteiro me davam igual prazer, eles se complementam" ${ }^{64}$. A sinergia com o cliente é lembrada em depoimento:

"Galiano buscava e exigia a perfeição da execução com visitas praticamente diárias ao canteiro [...] E nas inúmeras vezes em que lá nos encontrávamos, era particularmente agradável ouvir a descrição entusiasmada do efeito desejado em cada detalhe a ser executado [...] Era um aprendizado de arquitetura [...]" 65 .
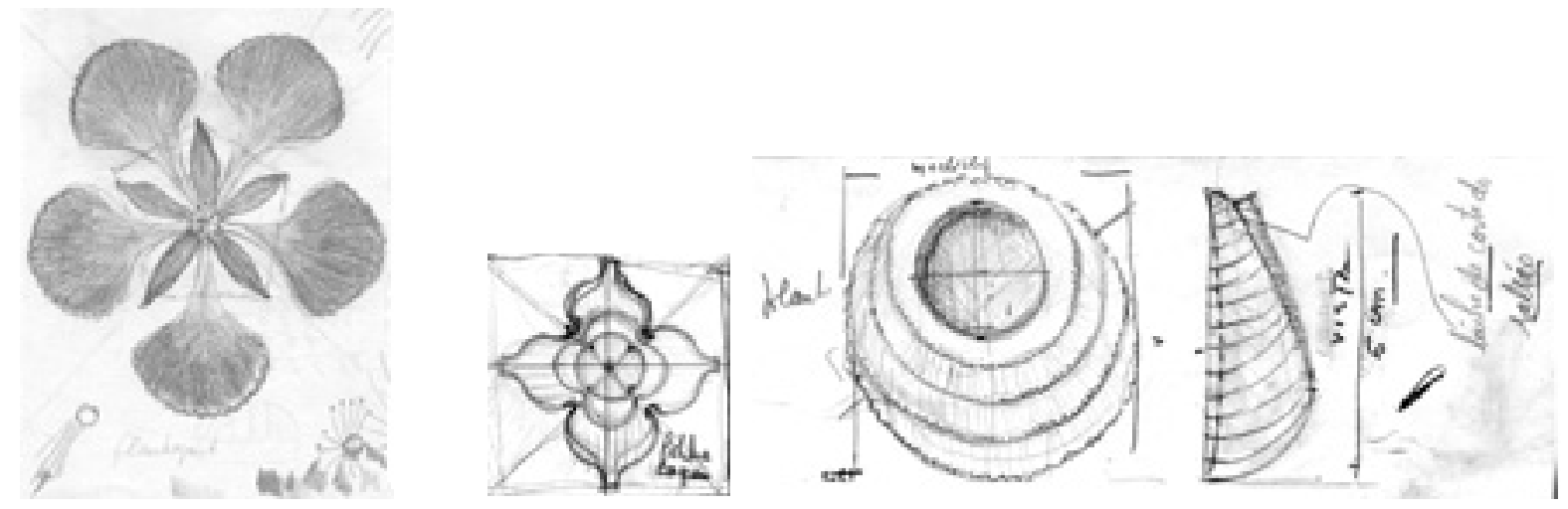
Um aspecto vinculado à personalidade de Galiano Ciampaglia está na reserva do seu trabalho nunca divulgado. Passadas quase cinco décadas sem acesso, o que hoje se configura como a sua produção residencial é um puzzle de alguns originais, desenhos devolvidos por clientes, projetos legais, imagens à época das obras e correspondências como aquelas que resgatam a memória da casa de Belo Horizonte (Paulo Augusto de Lima, 1960) ${ }^{66}$. Diante da fragmentação do material, de obras descaracterizadas pela venda do imóvel, como a casa da Península (Silvano Macchiarolli, 1962) e a casa da Rua Holanda (Dante Pellegrino, 1970), o que ora se desenha é um panorama de realizações entre 1958 e 1975 que atendem critérios como localização na capital paulista e material gráfico mínimo. Apenas um estudo não desenvolvido foi incluído pela abordagem conceitual e confirmação da data de sua realização. A casa da Rua Simpatia (Adelino Del Carlo, 1964), cuja pintura recente esconde a natureza dos materiais, conserva intacto o projeto.

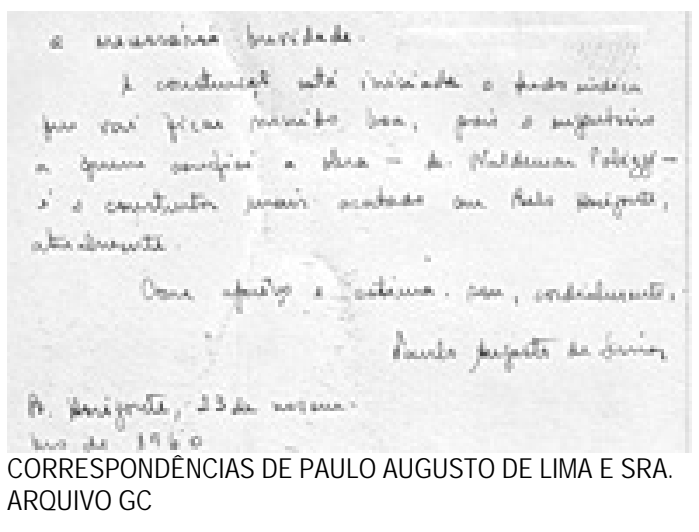

1962. CASADA PENÍNSULA, GUARUJÁ (SILVANOMACCHIAROLLI)

GALIANO CIAMPAGLIA/ IAMGEM DOS CEDIDA PELO CLIENTE (ANOS 80)
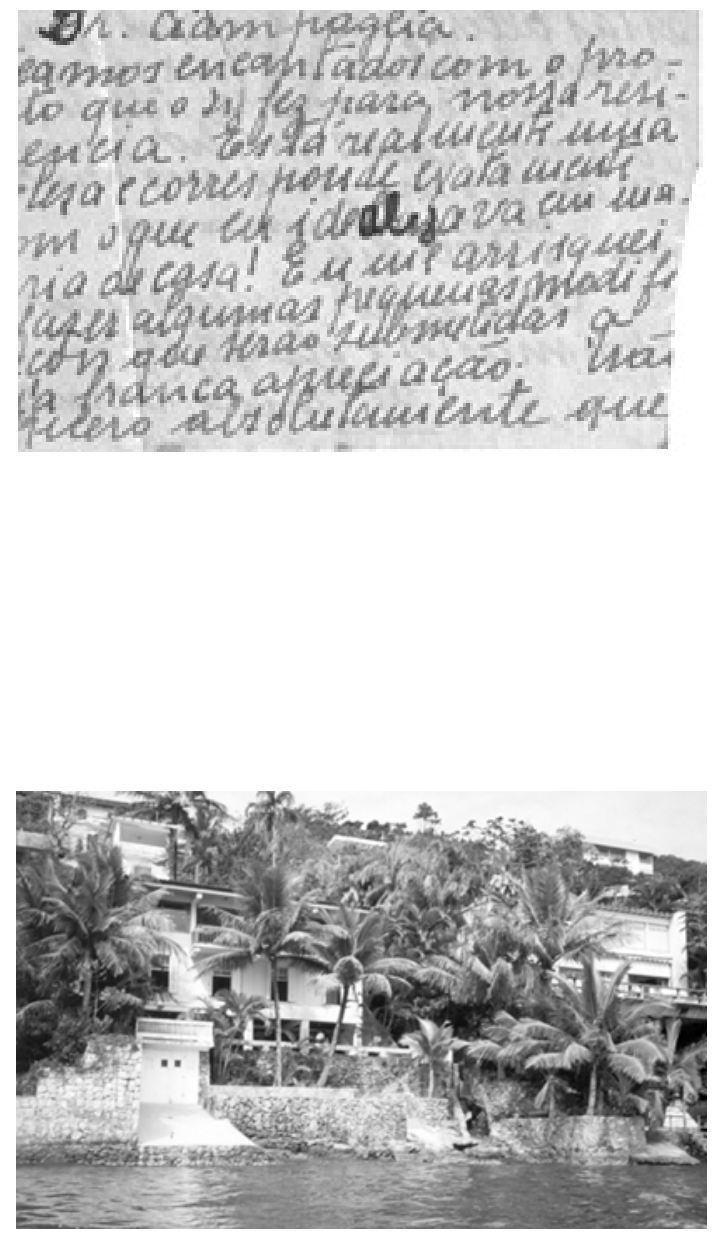

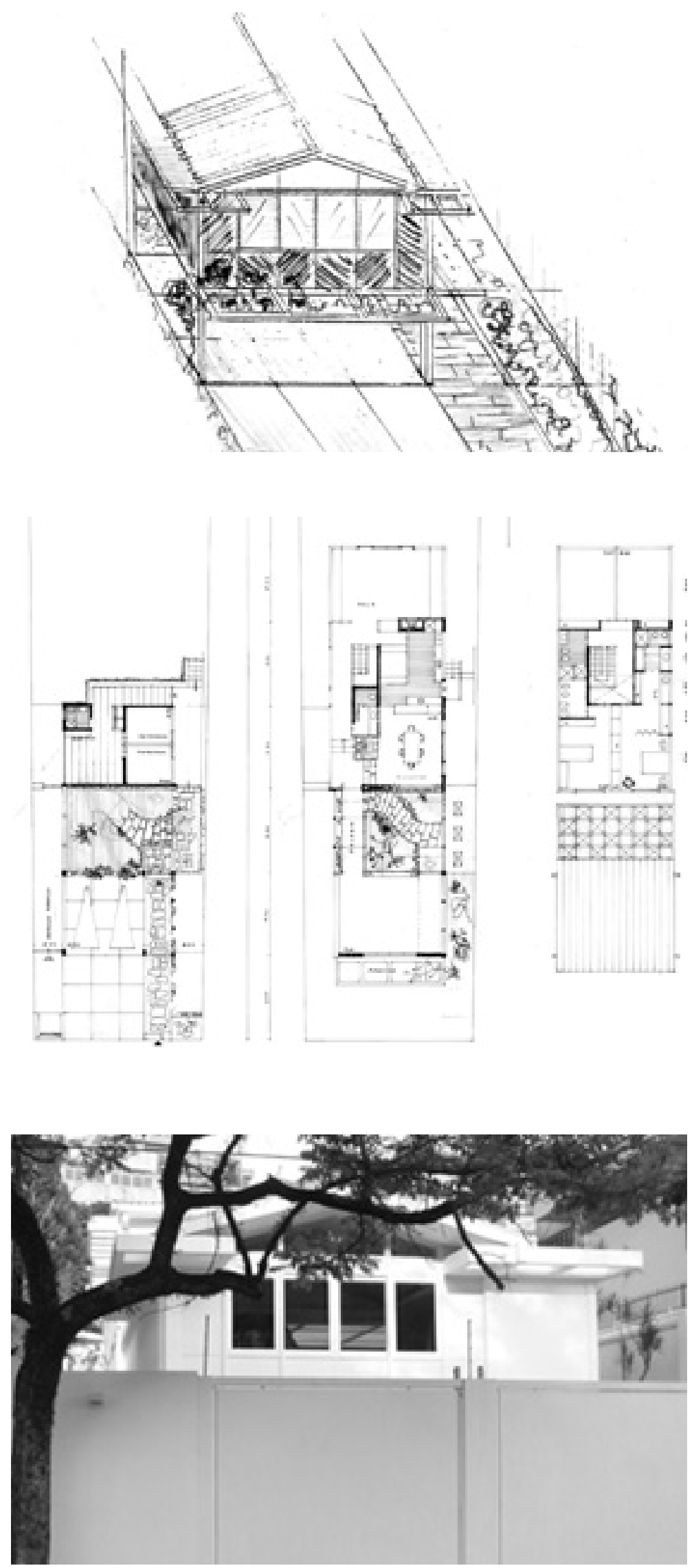

1964. CASADARUA SIMPATA

GALIANO CIAMPAGLIA

DE CIMA PARA BAIXO: CROOUIS, PLANTAS, IMAGEM PÓS PINTURA, 2010

ARQUIVOGC 


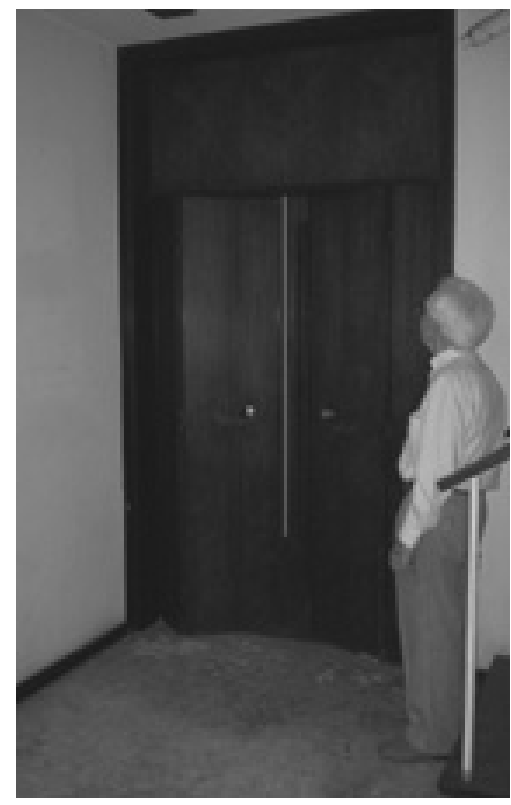

A casa da Rua Inglaterra (Justo Pinheiro da Fonseca), projetada para a família mineira de um banqueiro, uma psicanalista e escritora $^{67}$, e três filhos, define 0 autor independente. No lote triangular de esquina e em nível, a volumetria cega da Rua Bucareste contrasta com a exuberante fachada da Rua Inglaterra, a mais reservada em relação ao entorno. Galiano Ciampaglia exercita articulações entre pátios internos e a rotação de $30^{\circ}$ do bloco térreo oculto ao longo do logradouro. No caso, a garagem funciona como módulo articulador. O sistema axial de eixos compositivos não coincidentes com os de movimento resultam no acesso oculto pela Rua Inglaterra. Todavia, a planta ainda não caracteriza a composição centrífuga a partir da lareira, no caso, adjacente ao jardim. $O$ desenho guarda referências wrightianas como os grandes beirais e o telhado de pouca inclinação apoiado

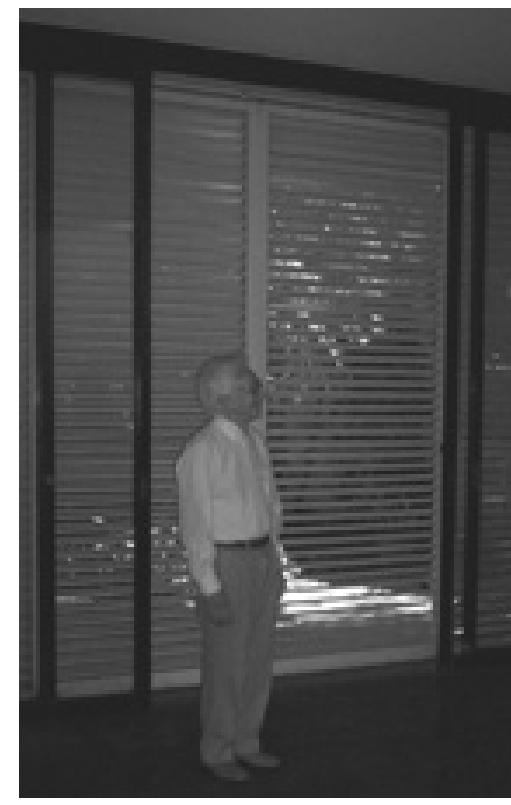
na laje-beiral experimentada na casa Domingos Cacace (Forte e Ciampaglia, 1952). A configuração agora de quatro águas reforça a horizontalidade e confere leveza ao conjunto.

A analogia com a fase anterior é sugerida também pelos materiais, pela estrutura independente das vedações no piso inferior e por alguns detalhes. Em contraponto, Galiano Ciampaglia investe nas portas de passagem articuladas e nas venezianas metálicas para controle da luz em substituição às cortinas da fase anterior.

Avaliada como "elegante" 68 por quem a conhece, a casa foi mantida intacta pelos clientes, até a sua desocupação, em 1987.

Vendida, a volumetria da rua Bucareste foi comprometida por intervenções e ampliações. O imóvel está fechado há cinco anos para comercialização. Do projeto, foi localizada uma fachada de

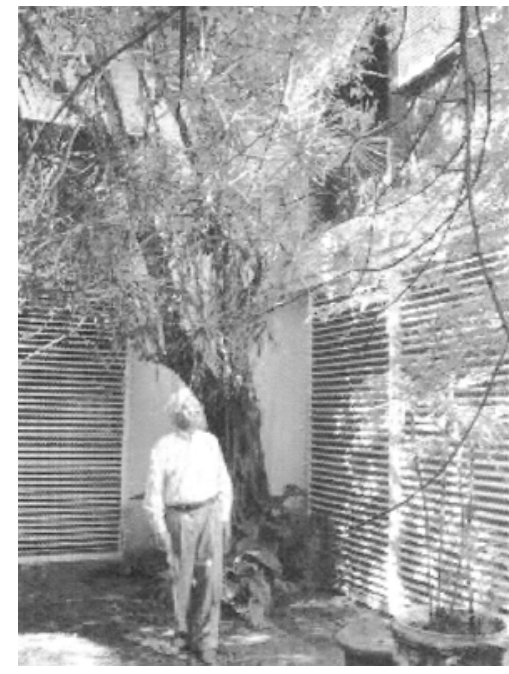
apresentação e o processo legal compatível com a obra. 


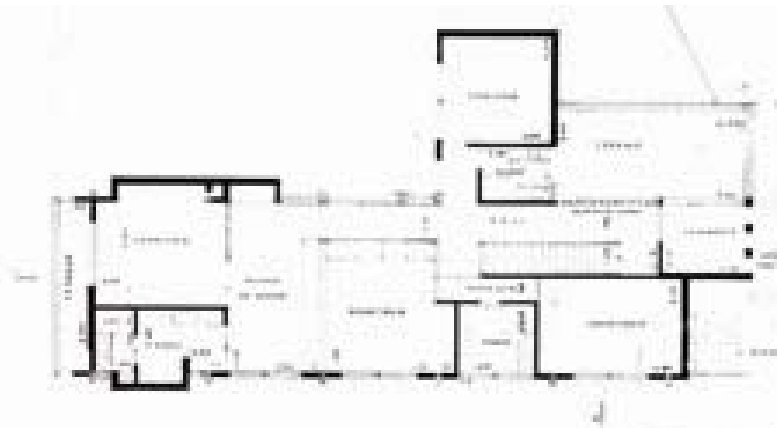

(\$)

1958. CASADA RUA INGLATERRA. GALIANO CIAMPAG IA

PLANTASDOS PAVMENTOS

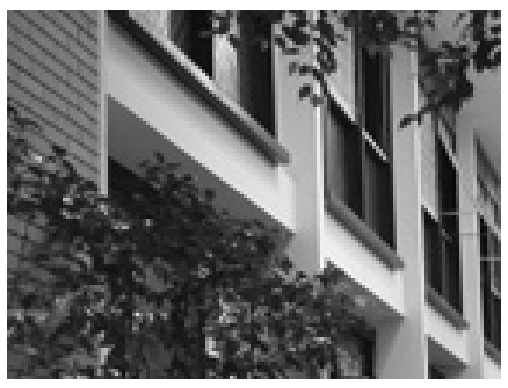
ARQUIVOGC

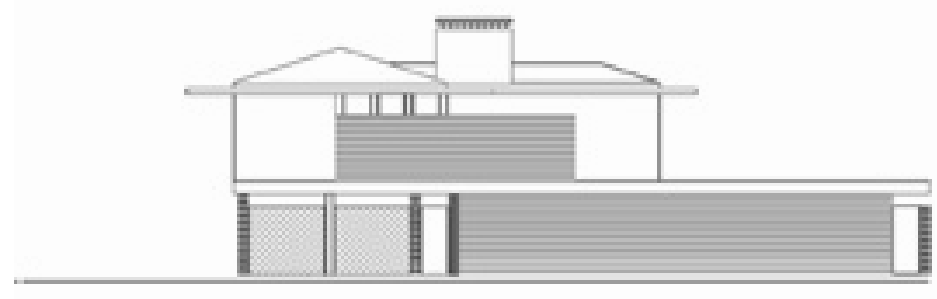

FACHADA RUA BUCARESTE. REDESENHO (FONTE PMSP). ARQUIVOGC
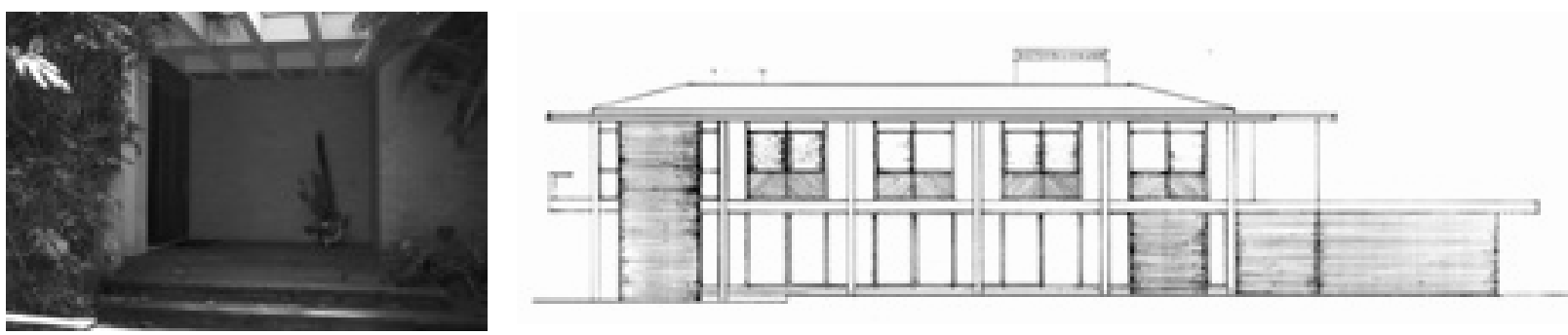

FACHADADA RUA INGLATERRA.

DE CIMA PARA BAIXO: ARQUIVOGC

DETALHE DA FACHADA E DA ENTRADA 2003, ARQUIVO GC 
De 1960, é o estudo para a casa dos Losangos (Vitor de Paula Freitas). No lote de 1600 metros quadrados, em declive, a acomodação em quatro níveis sugere uma maior afinidade com a gramática wrightiana, a começar pela grelha básica. A configuração de diferentes espaços é caracterizada pela organização centrífuga a partir do núcleo da lareira no living, ainda que um segundo elemento seja proposto no escritório do proprietário ${ }^{69}$. De modo a evitar a pontuação de pilares de concreto no terraço e no carpot, telhados poligonais de duas águas são apoiados em grelhas metálicas ${ }^{70}$, mantida a laje-beiral de concreto ao longo da edificação. Frank Lloyd Wright utilizou o aço para atingir maior balanço na Robie House, cujo proprietário trabalhava no ramo ${ }^{71}$. Um novo estilo do habitar doméstico experimentado na casa Enzo Segre (Forte e Ciampaglia, 1952), ganha nitidez. Além do carport em substituição à garagem, são eliminados os fechamentos entre a cozinha e a sala de jantar. A dinâmica do habitar orgânico como um todo é sugerido no mobiliário incorporado, nos ângulos visuais e na iluminação natural inserida na cobertura do carpot e da sala de jantar, no caso, em sofisticado detalhe.

A partir da edícula incorporada, os jardins se ampliam. No caso, o desenho não contempla o perímetro do terreno $(35.00 \times 38.00)$ e o recuo de 8 metros de fundo. Desenhado a nanquim sobre vegetal, os cortes a lápis foram esboçados para o cliente durante a apresentação do projeto ${ }^{72}$.

Como no estudo para a casa Erico Stickel (Forte, Ciampaglia e Millan, 1954), de grelha hexagonal, o projeto não foi aceito pelo cliente. 


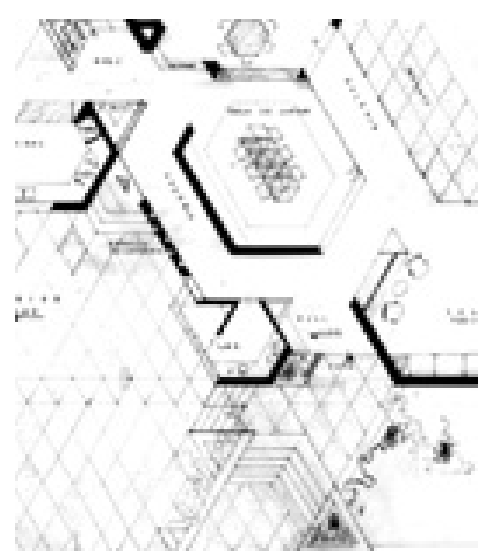

1960. CASADOS LOSANGOS

GALIANO CIAMPAGLIA NÃO CONSTRUÍDA

DE CIMAPARA BAIXO:

PISOS +1,00; +2,50

PISOS 0,00; +4,50; CORTES ARQUIVOGC

DETALHE
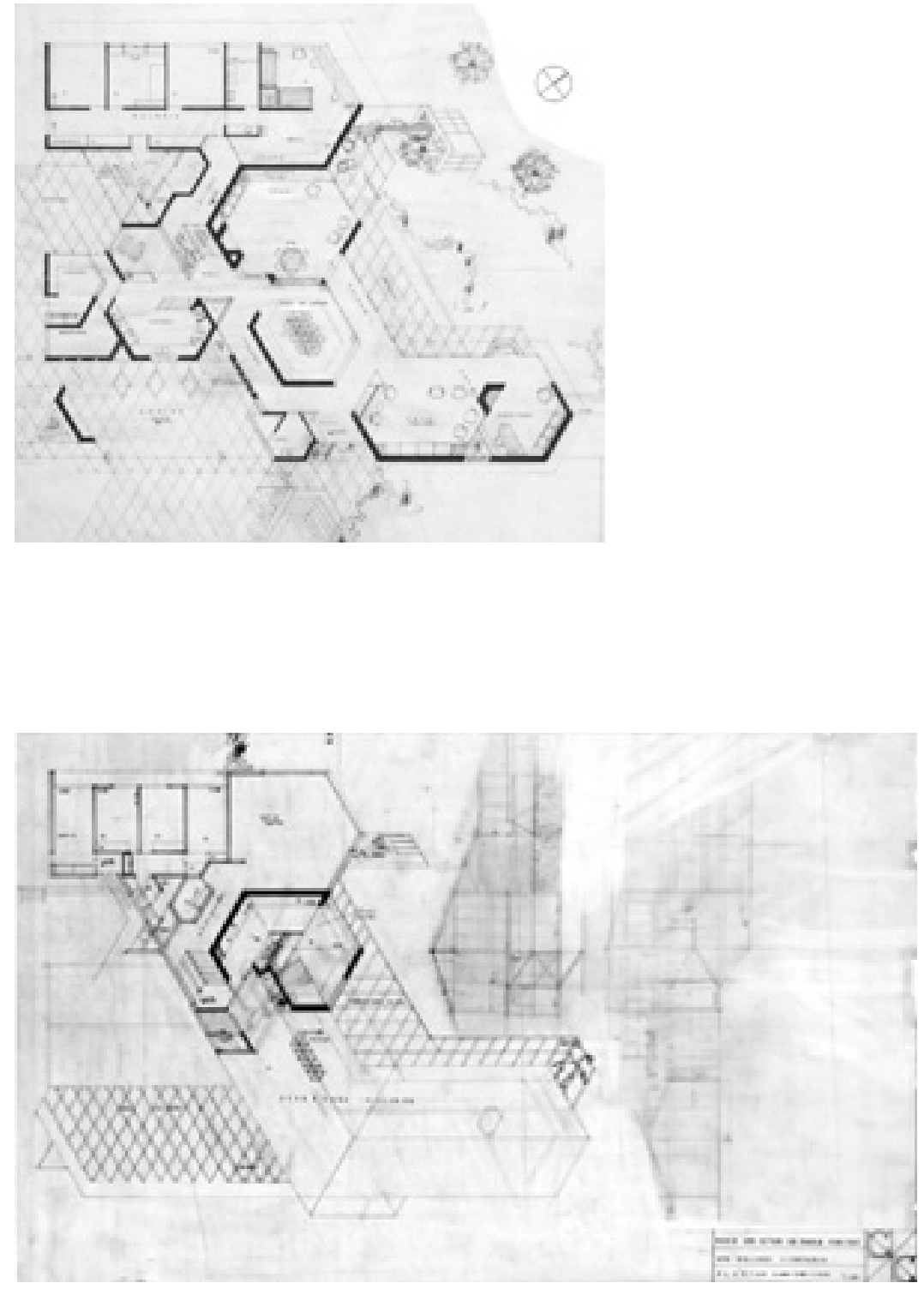
Implantada em um terreno de 2400 metros quadrados, a casa da Rua Campo Verde (Tuffy Mattar) foi projetada a partir de algumas premissas da proprietária: a ocupação de $50 \%$ do lote, um salão de festas independente e "uma casa sem corredores". De traçado ortogonal com origem no quadrado, o hall e a escada funcionam como núcleo e os pátios garantem a fluidez espacial. A rigidez do prisma é rompida pelas lajes em diferentes níveis e pelo balanço da volumetria sobre o muro que se estende até a divisa. A proposta conserva o detalhe da laje-beiral como apoio do telhado de quatro águas. Em contraponto, se liberta do ritmo estrutural, ainda presente na casa da Rua Inglaterra. Do projeto foram localizadas apenas cópias de apresentação ao cliente, compatíveis com o processo municipal. Voltada à economia e à facilidade de manutenção, o detalhamento de madeira se mescla ao de alumínio. Os proprietários permanecem no imóvel.
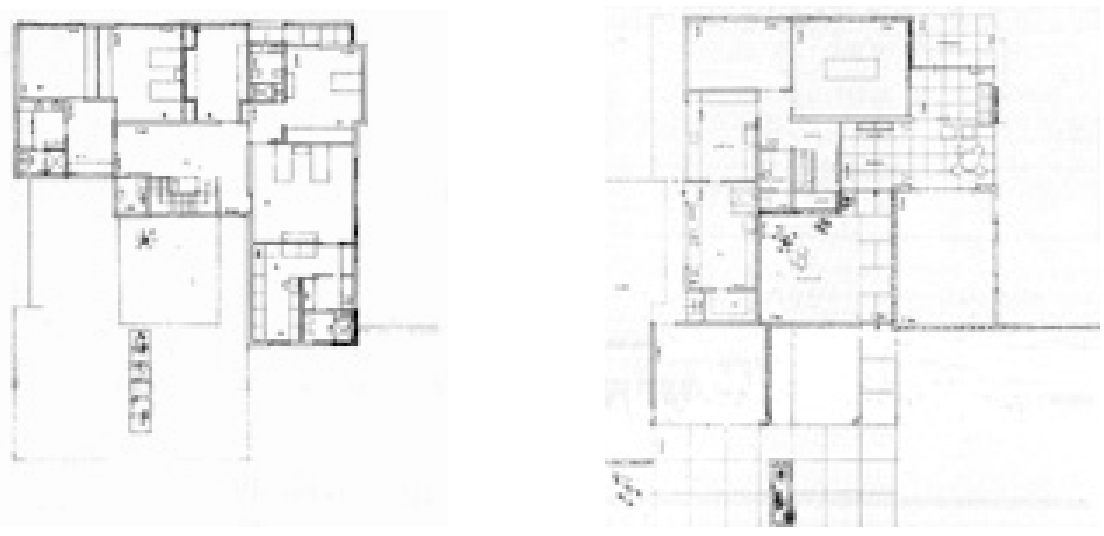

1961. CASA DARUA CAMPO VERDE GALIANO CIAMPAGLIA

(E/D): TÉRREOE SUPERIOR

ABAIXO:

PERSPECTIVA

ARQUIVOGC 
Encomendada pelo pai como presente de casamento para a filha, o "artista" - como se refere Marisa Cacace ao arquiteto - "recebeu total liberdade e uma tarefa: entregar a casa o mais breve possível" ${ }^{73}$. A casa das Esquadrias azuis, com 250 metros quadrados, sugere a releitura Usonian compatível com o estilo de vida do jovem casal ${ }^{74}$. Partido horizontal térreo e definido por articulações dos telhados e alternância de pé-direito; workspace reversível através de painéis articulados para esse fim; carport em substituição à garagem; materiais aparentes com predomínio da madeira e do tijolo; mobiliário e iluminação integrados. A gramática wrightiana é expressiva: um corpo prismático acoplado ao quadrado rotacionado; eixo compositivo não coincidente com o do movimento; acesso perimetral e ocluso; composição centrífuga a partir da lareira; ornamento integrado sugerido pela combinação de materiais e cores. No terraço, Galiano Ciampaglia associa o racionalismo de Mies van der Rohe, na estrutura metálica desvinculada dos caixilhos.

Projetada em 1961, a casa foi habitada pelos clientes sem qualquer intervenção, até a sua demolição, em 2010, para o novo desenho da alça de acesso à ponte Cidade Jardim. Em 2009, foi realizado um ensaio fotográfico com o imóvel vazio. $\mathrm{Na}$ oportunidade, algumas peças tiveram a função de sugerir a escala do ambiente.

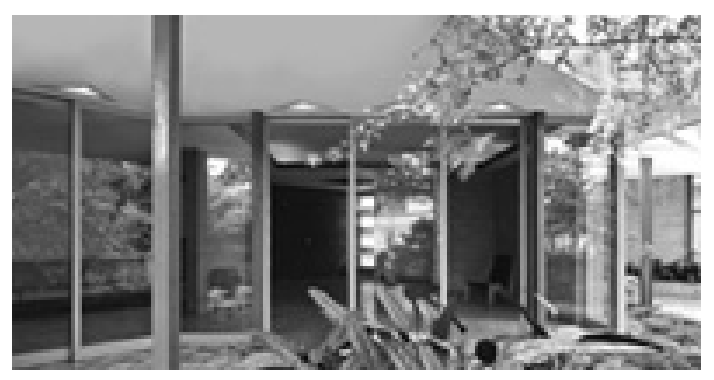

1962. CASA DAS ESQUDRAIS AZUIS 


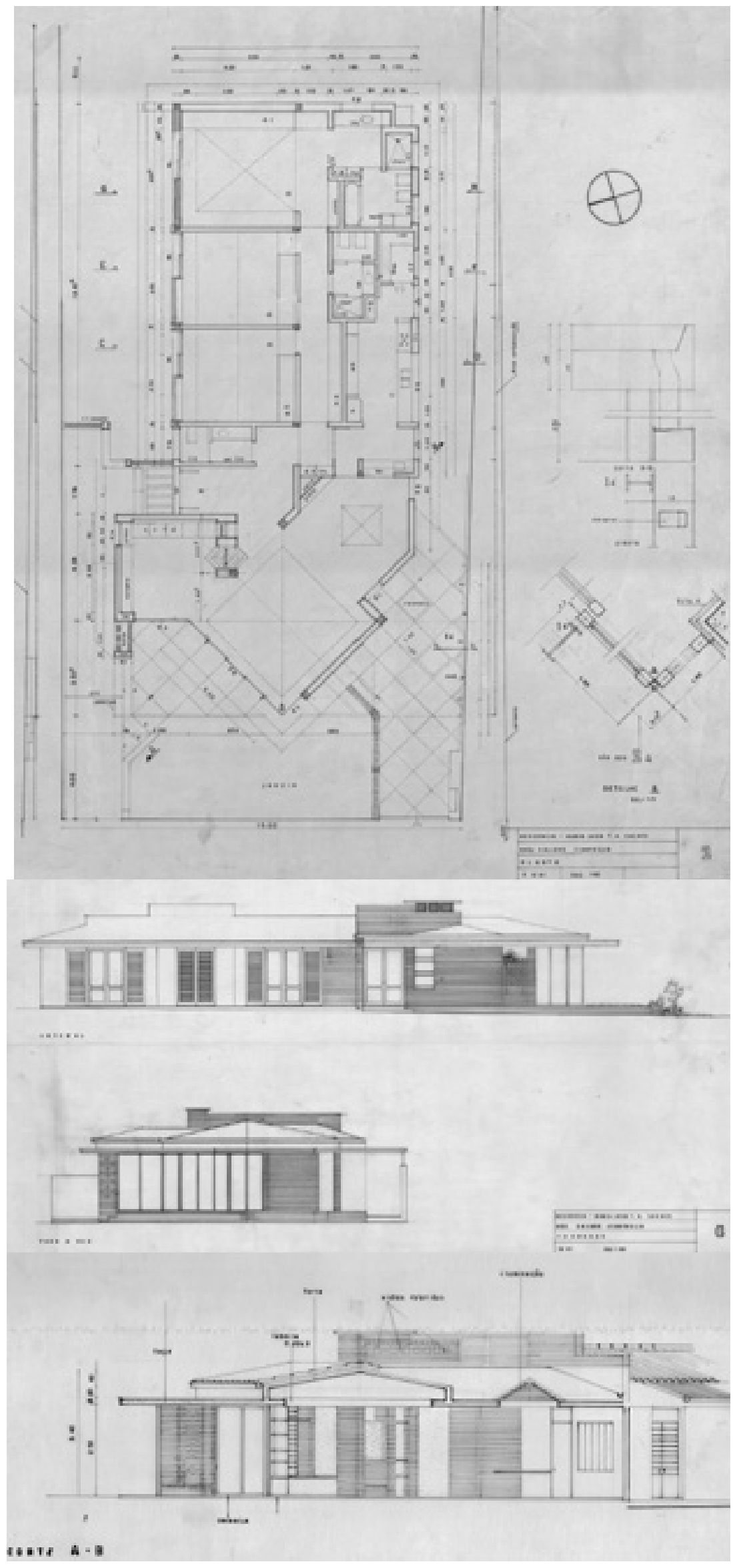

DE CIMAPARABAIXO:

PLANTA-FACHADAS - CORTE PARCIAL

ARQUIVOGC 

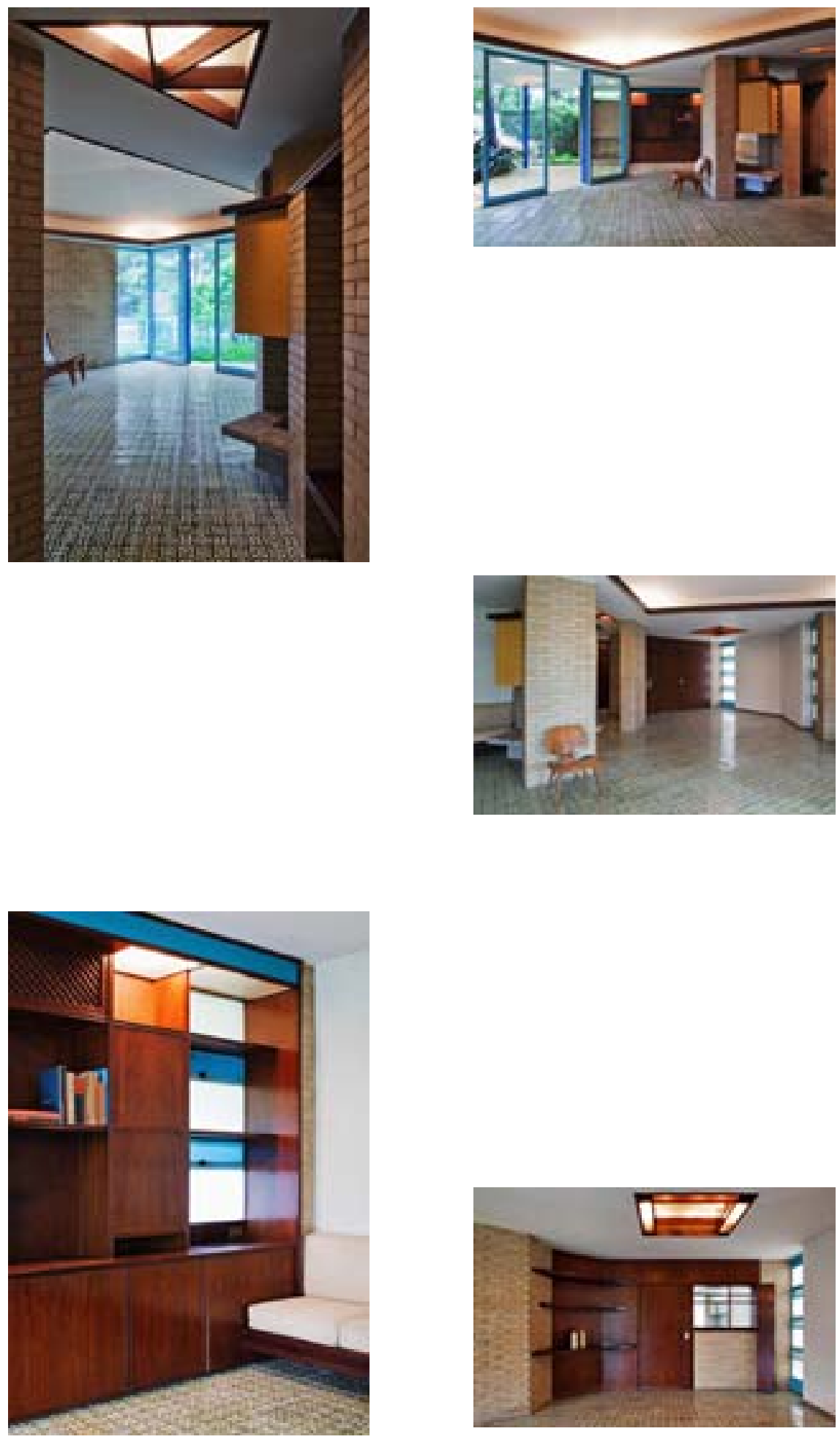

DE CIMAPARABAIXO

DIFERENTES VISTASDO ESTAR-LAREIRA-REFEÇÕES

POLTRONAASH WOOD CHARLES EAMES

ACERVOGC

POLTRONALINABARDI

ACERVOM. PAULAC. OUANG 


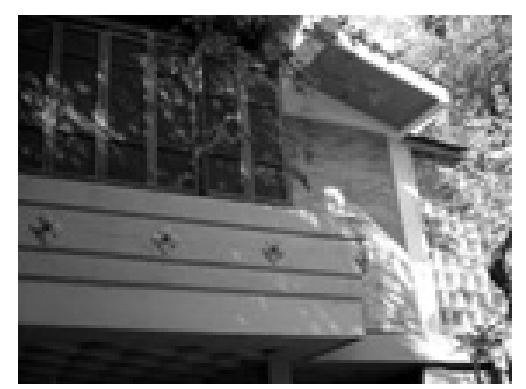

CASADOBALCÃO

GALIANO CIAMPAGLIA

COMPOSICCÃO ORIGINAL DAFACHADA

IMAGEM 2003

ARQUIVOGC

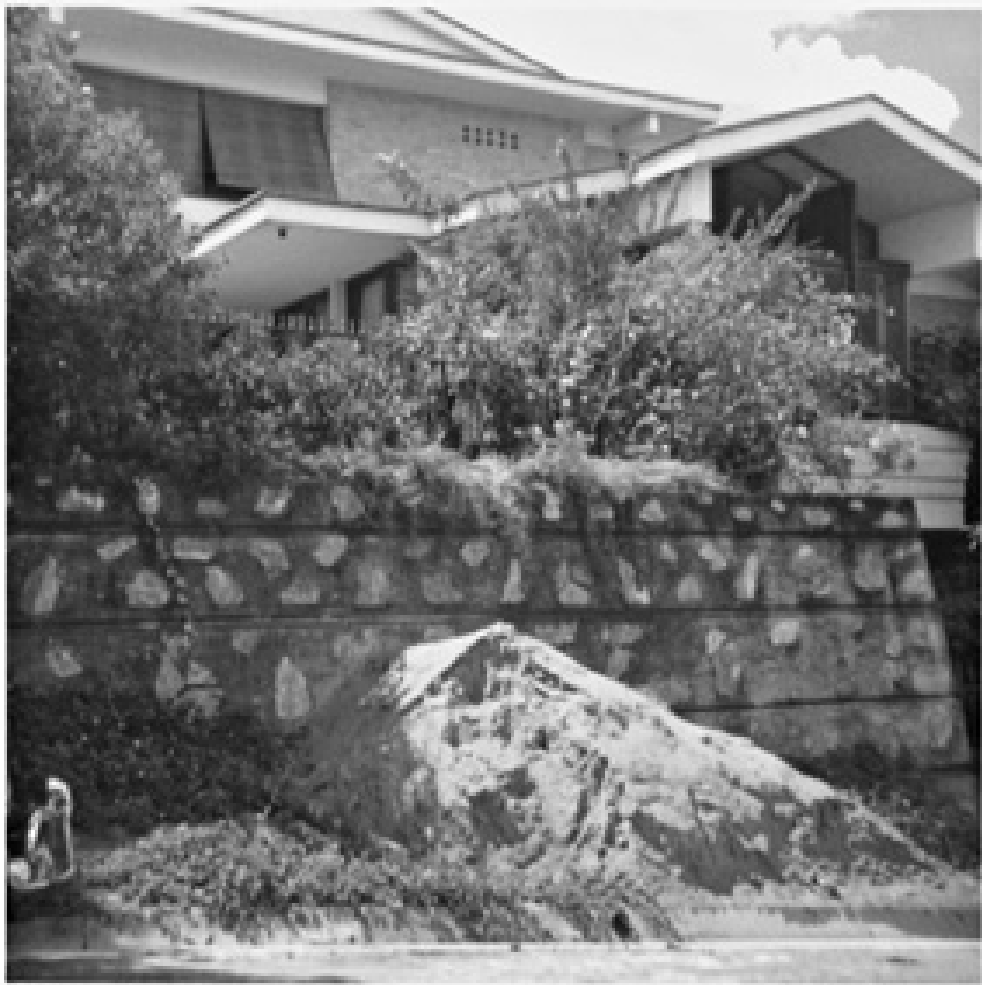

F

CASADOBALCÃO

GALIANO CIAMPAGUA

IMAGEM 1971

ARQUIVOGC 
A casa do Balcão (Adriano Beneduce) foi projetada em duas etapas (1962 e 1970). O projeto em "T" com as aberturas voltadas para norte estimularam a aquisição do lote vizinho para piscina e jardim. Implantada em aclive, resultou em volumetria escalonada em três pisos. O projeto reúne um expressivo conjunto de ferramentas da gramática wrightiana que já se confirmam como constantes na obra de Galiano Ciampaglia: corpos articulados; estruturas salientes; eixo projetual não coincidente com o do movimento; acesso perimetral e ocluso; composição centrífuga tendo a lareira como núcleo geométrico.

No exercício compositivo de materiais, além do jogo de luz e sombra, a obra encontra analogia com a visão de Behrendt, a respeito de Frank Lloyd Wright. Segundo o crítico, para o arquiteto norteamericano, "nunca existe uma justaposição de materiais casual ou sequer conflitiva: os materiais estão harmonicamente relacionados entre si e reunidos organicamente em uma união comum natural" ${ }^{75}$. O "potencial essencial" ${ }^{76}$ do material, explorado na membrana da casa Renato Grazzini (Forte e Ciampaglia, 1947-48), neste caso, atinge seu maior refinamento na galeria de acesso. A associação de painéis verticais de tijolos com planos horizontais de blocos perfurados resulta na filtragem da luz em todas as direções. Como observa Behrendt, "Wright trata a luz como se fosse um material natural de construção. A interação graduada de luz e sombra é para ele um meio artístico de expressão" ${ }^{77}$.

Em contraponto à fase compartilhada, a partir desta obra Galiano Ciampaglia investe nas lajes inclinadas e na abertura de oitões para a entrada de luz. O fato de a casa ter sido referência para os alunos de Miguel Forte, nos anos $70{ }^{78}$, e não ter passado despercebida da banca seletiva Fau-usp ${ }^{79}$, intriga o seu desconhecimento por parte da crítica especializada.

Do projeto, foi recuperado o original do projeto legal e o estudo da piscina. Vendida em 1988 para novos proprietários entusiastas do projeto, a instalação de uma biblioteca e de equipamentos de segurança agregaram ajustes e fechamentos executados em respeito ao projeto. Em 2010, foi realizado um ensaio fotográfico restrito a detalhes. Para Nelson Kohn, autor do ensaio, o impacto diante da galeria de acesso foi de "serenidade". 
1970. PISCINA E JARDIM

GALIANO CIAMPAGLIA

ARQUIVOGC

(linha de divisa inserida pela autora)

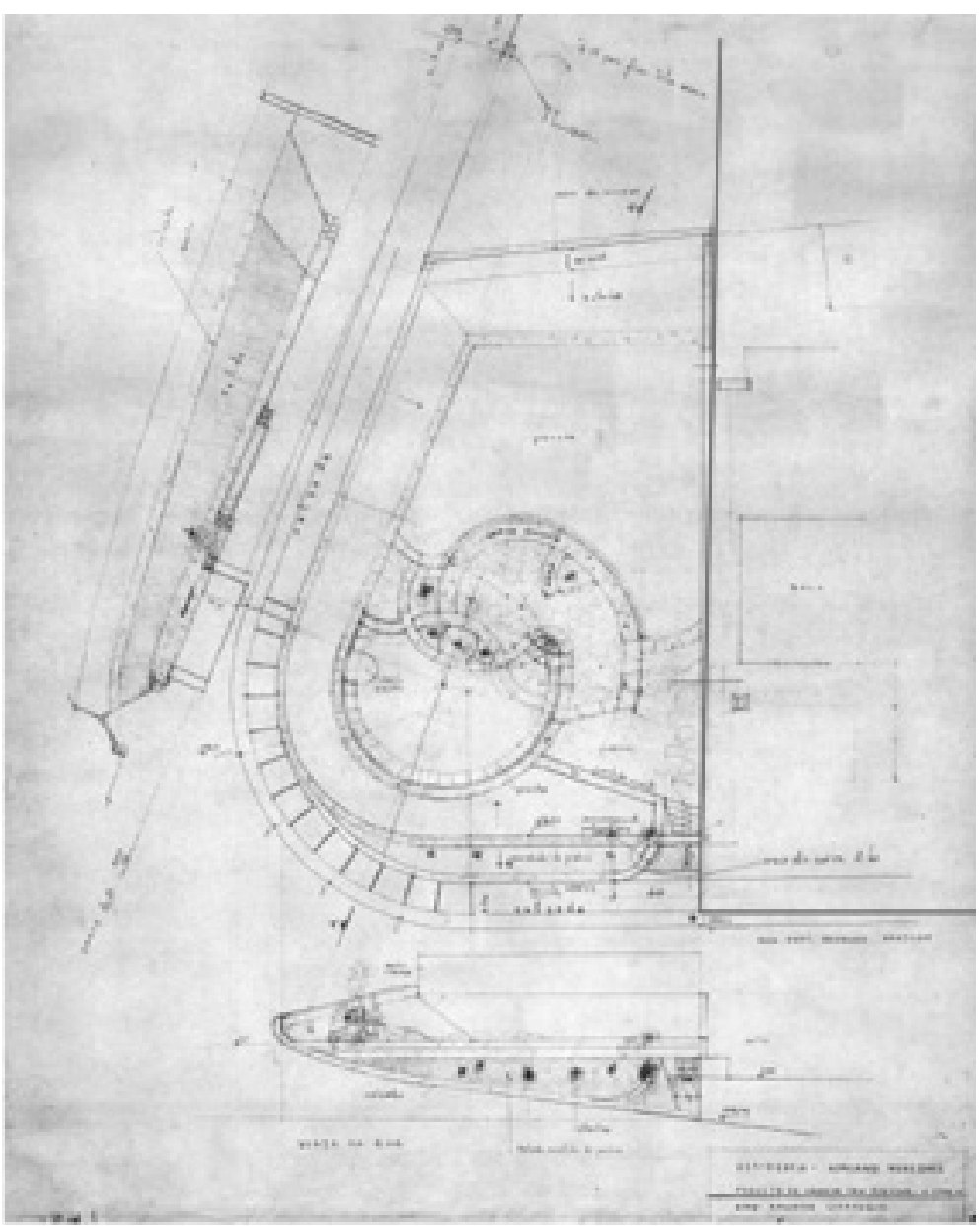

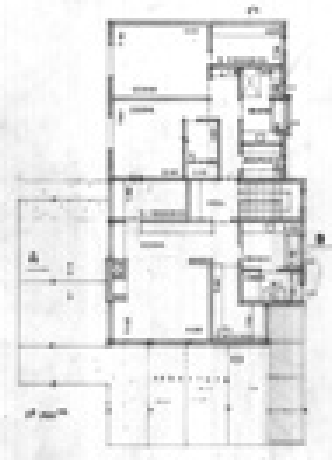
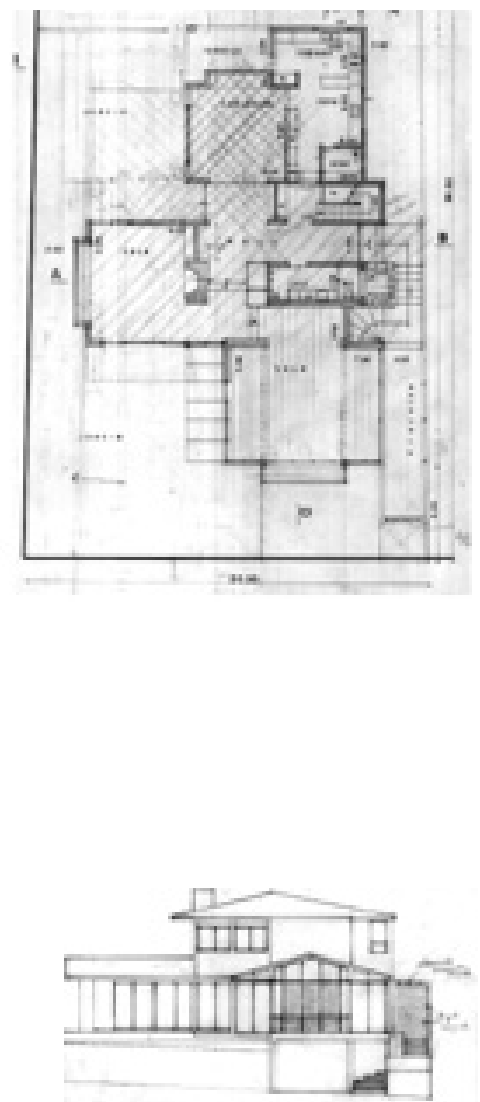

DE CIMA PARA BAIXO: PAVIMENTO SUPERIOR PAVIMENTO INTERMEDIÁRIO

FACHADA ARQUIVOGC 
1962. CASADOBALCÃO

GALIANO CIAMPAGLIA ENSAIO NELSON KOHN, 2010
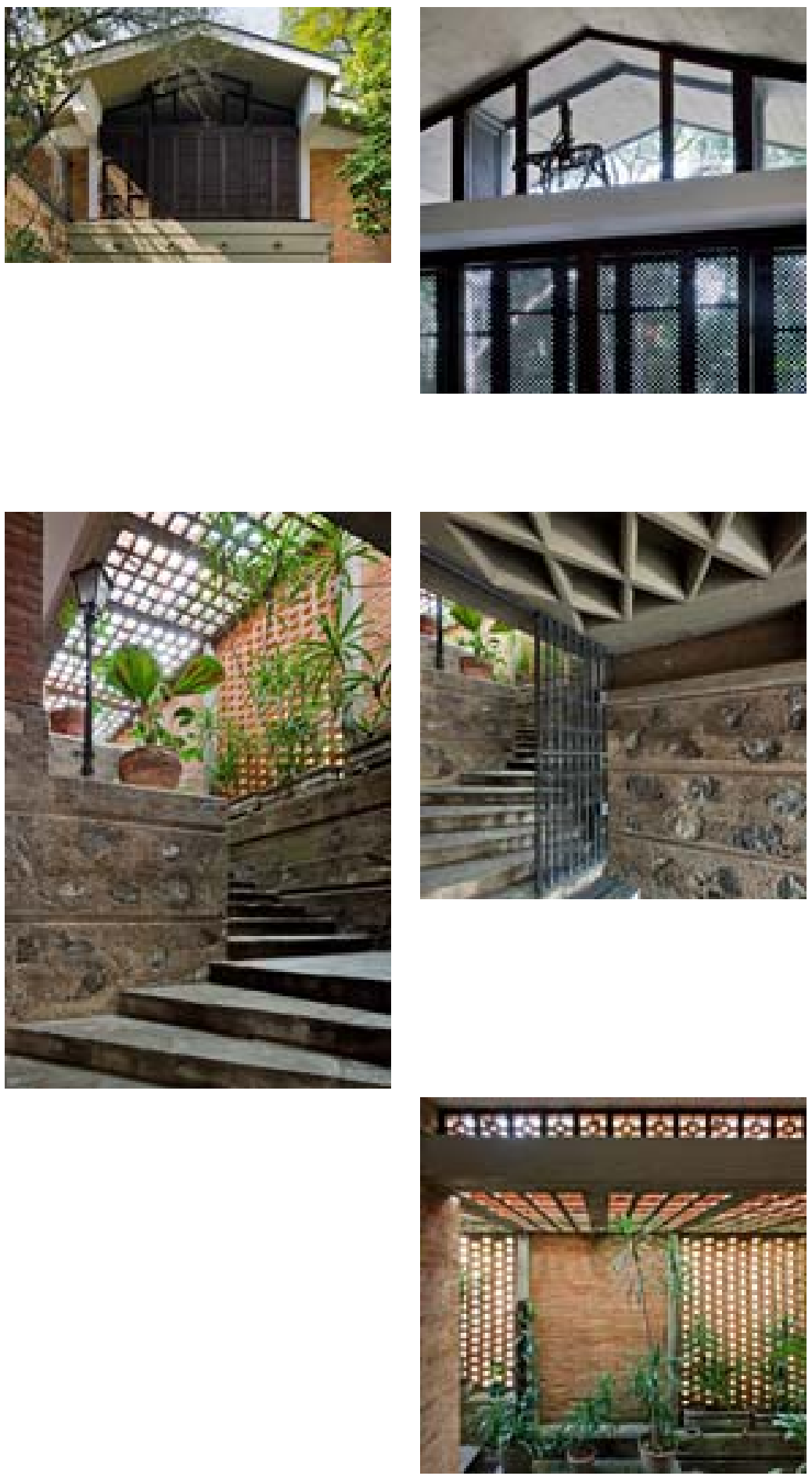

DE CIMA PARA BAIXO:

(E)

BALCÃO

GALERIA DE ACESSO

(D)

BALCÃOLIMING

DETALHE GREIHA (PORTÃOINSTALADO EM 2008)

HALL DEENTRADA 
1968. CASA DOS OCTÓGONOS

GALIANO CIAMPAGLIA

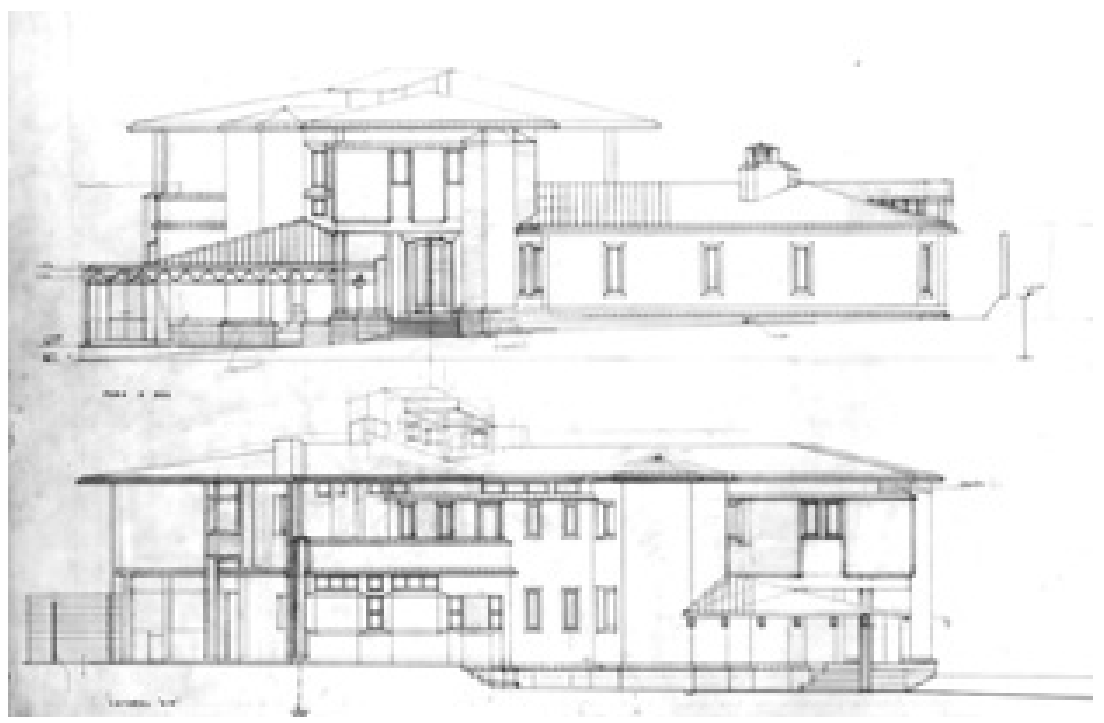

FACHADADA RUA ELATERAL ARQUIVOGC
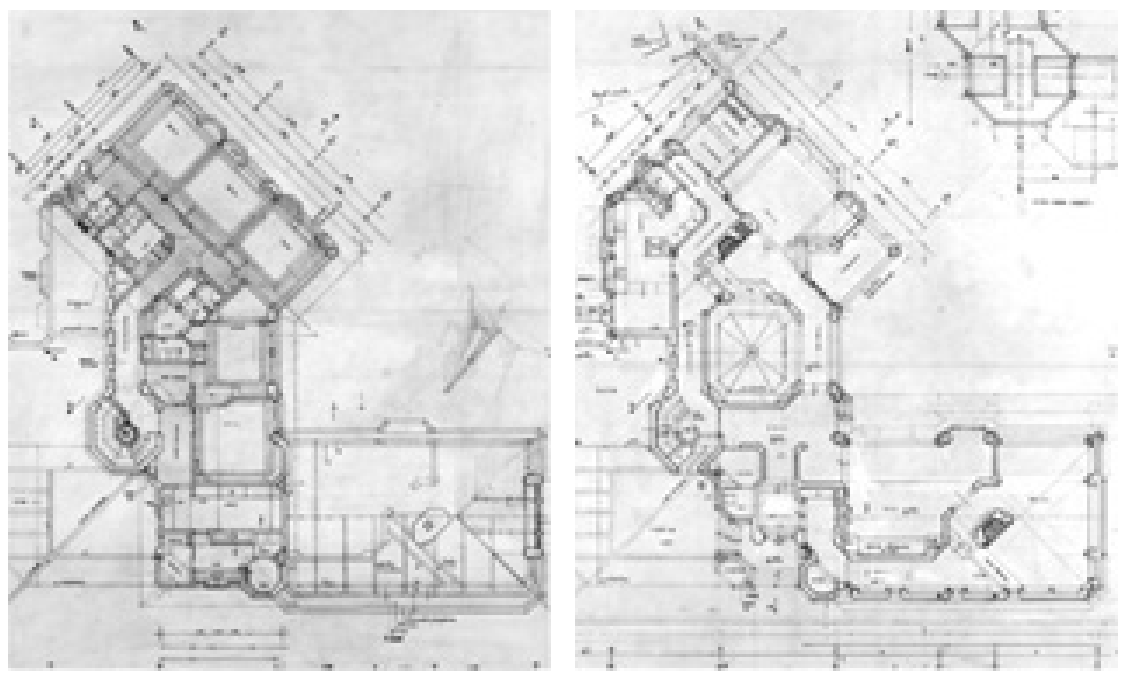

(E) TÉRREO

(D) SUPERIOR

ARQUIVOGC 

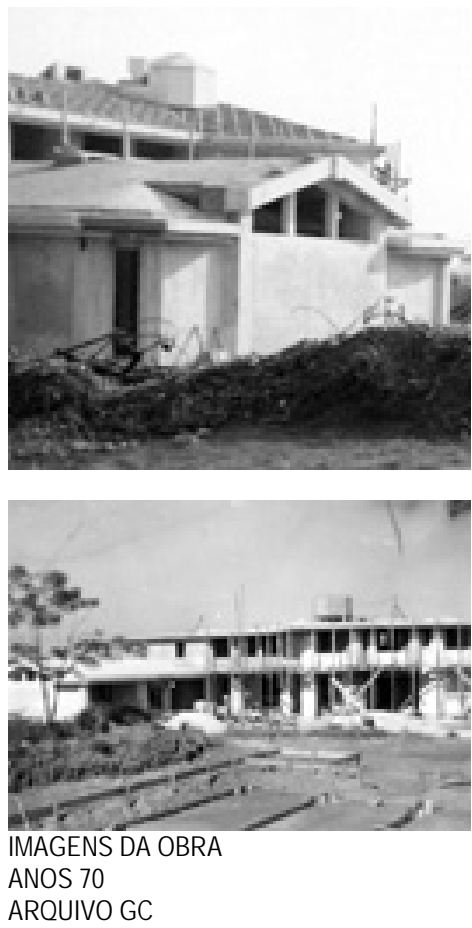

ANOS 70

ARQUIVOGC
Casa dos Octógonos (Erasmo C.Schutzer). Um casal de advogados com quatro filhos, "uma importante biblioteca" e a angulação do lote configuraram a ocasião para uma releitura de solidez da fase Prairie de Frank Lloyd Wright ${ }^{80}$. Em contraponto ao arquiteto norteamericano que não chegou a utilizar o polígono como grelha - como o faria com o hexágono-, Galiano Ciampaglia se utiliza do octógono da estrutura aos detalhes atingindo o refinamento de unidade na composição das fachadas. O complexo programa é organizado na planta em "L" articulada pelo carport de estrutura metálica. O corpo térreo abriga a biblioteca e o de dois pavimentos, o núcleo de serviços e familiar, com dormitórios no piso superior. A gramática wrightiana é identificada nos corpos articulados em todas as direções, nos eixos compositivos não coincidentes com o do movimento, no acesso perimetral e ocluso e na composição centrífuga tendo a lareira como núcleo do ambiente familiar. Como na casa dos Losangos, uma segunda lareira articula o escritóriobiblioteca. O espaço fluído e contínuo ao mesmo tempo oferece privacidade e explora diferentes ângulos de visão. Através de oitões vazados, Galiano Ciampaglia "trabalha os efeitos de luz" ${ }^{81}$ na biblioteca. O fechamento da biblioteca voltado para o jardim ilustra a "delicada relação entre o volume da construção e os detalhes" ${ }^{82}$, destacada por Behrendt, na obra de Frank Lloyd Wright. A casa é habitada pelos clientes desde 1974. A cobertura de hera nas fachadas e o recente fechamento do gradil comprometem a realização de um ensaio fotográfico. Nos anos 70 , Miguel Forte monitorou visitas de alunos do Mackenzie, à obra ${ }^{83}$.

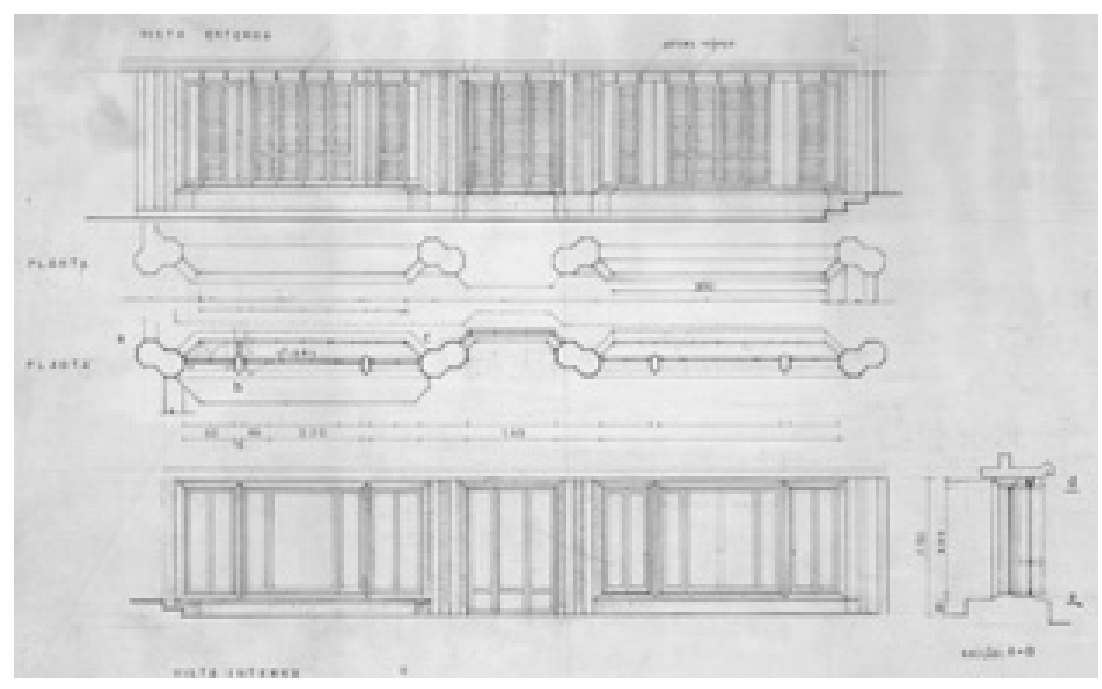


Projetada para um executivo da área financeira, uma designer e um casal de filhos, a casa dos Telhados (Gianpaolo Baglioni) é uma referência poética à Florença, cidade natal do proprietário, associada a uma nítida reflexão da tradição brasileira.

No projeto, a funcionalidade desenhada a partir de múltiplas articulações é transferida para a cobertura de diferentes telhados justapostos. O refinamento das rotações de $30^{\circ}, 45^{\circ}, 60^{\circ}$ e $135^{\circ}$ ao longo do eixo longitudinal, dissipa a configuração do lote estreito através dos diferentes vazios reservados a pátios laterais. Ferramentas da gramática wrightiana são identificadas nos eixos compositivos não coincidentes com o do movimento, no acesso perimetral e ocluso, e na composição centrífuga que tem a lareira como núcleo do ambiente familiar vazado. A um só tempo o espaço fluído e contínuo que resulta da independência tridimensional de cada ambiente oferece privacidade e explora diferentes ângulos de visão.

A predileção de Galiano Ciampaglia pelos detalhes em madeira é explorada na associação "função - ambientação" nos pendurais das plataformas propostas para reduzir o pé direito no espaço familiar e nos travamentos da sala de jantar.

A casa é habitada pelos clientes desde 1975. Recentemente, um studio foi incorporado ao piso originalmente reservado ao apartamento de funcionários. Em 2010, foi realizado um ensaio restrito a detalhes.

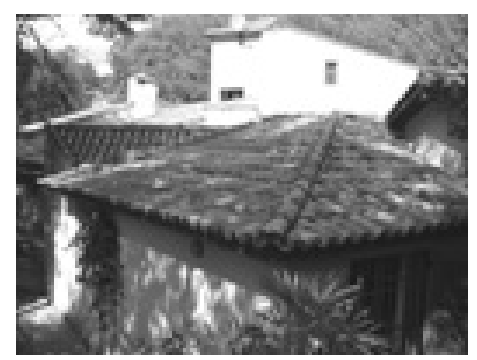

1972. CASA DOS TELHADOS. GALIANO CIAMPAGLIA VOLUMEIRIA ORIGINAL, 2003 ARQUIVOGC 

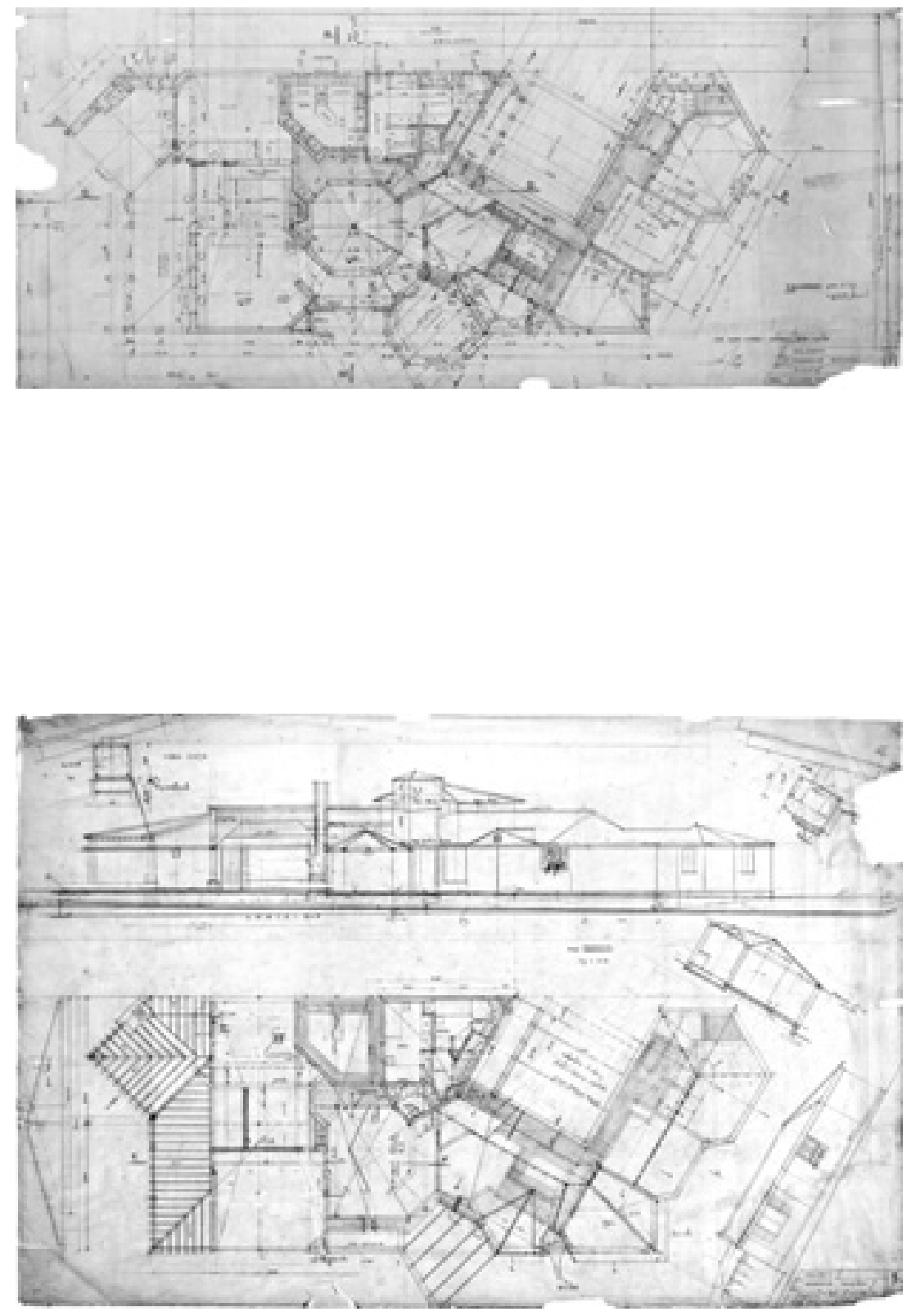

1972. CASA DOS TELHADOS GALIANO CIAMPAGLIA

DE CIMAPARABAIXO:

TÉRREO

COBERTURA

ARQUIVOGC 


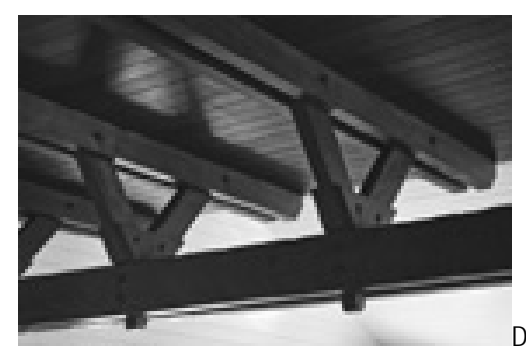

DETALHE PENDURAL (PINTURA DO FORRO APUICADA EM 2005)

1972. CASA DOS TELHADOS

GALIANO CIAMPAGLIA

ENSAIO NEISON KOHN, 2010

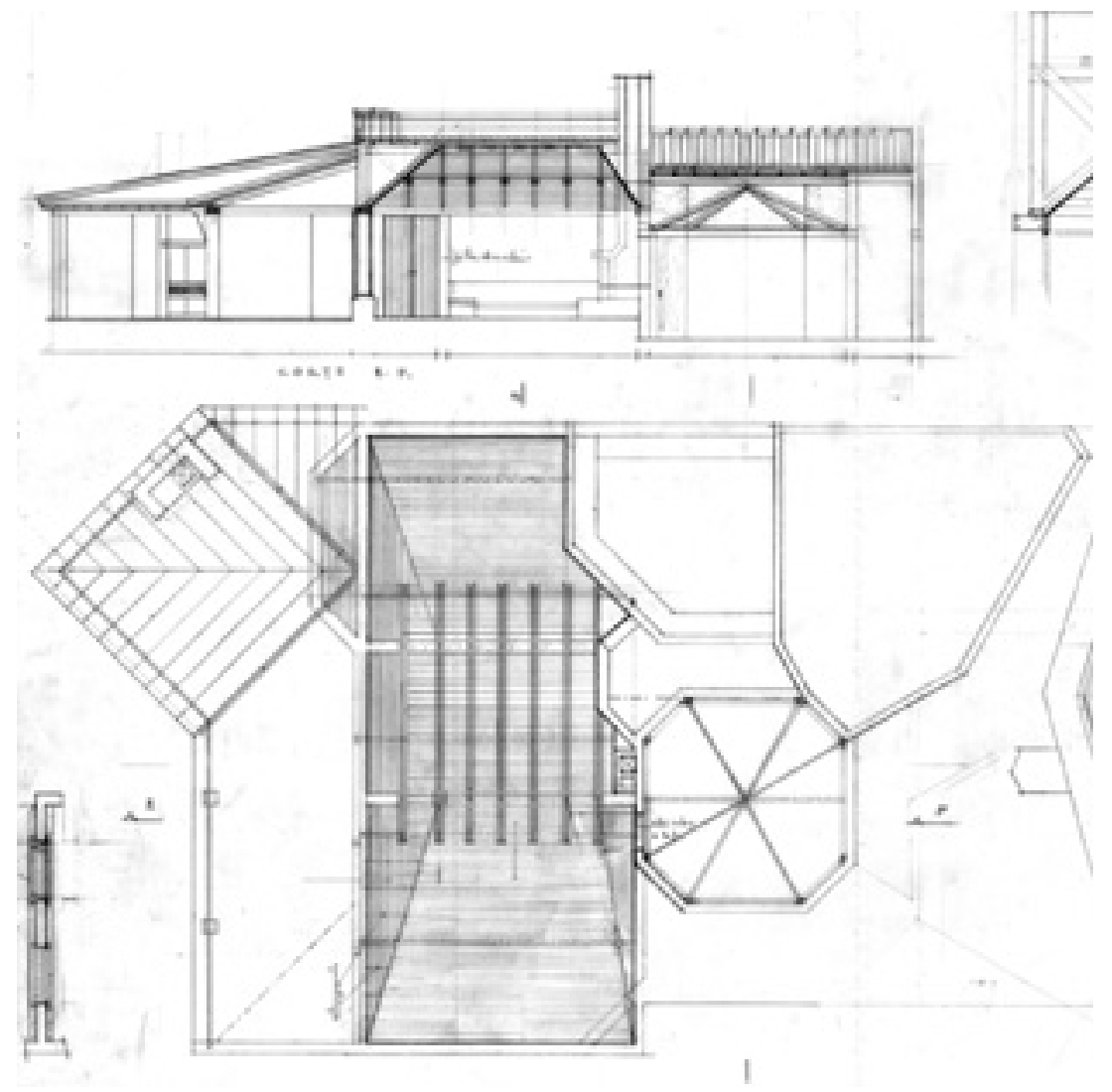

DETALHE DOS FORROSE PLATAFORMAS DE MADEIRA

ARQUIVOGC 

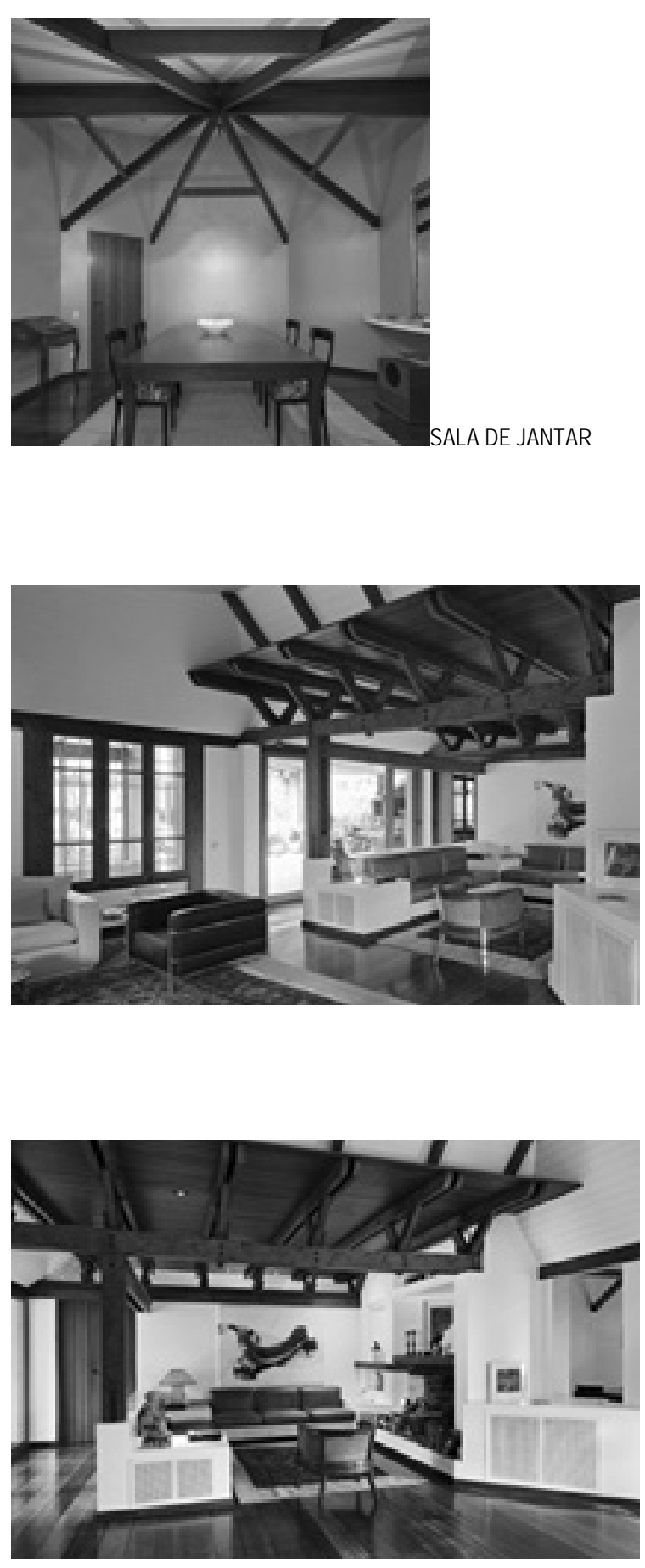

DE CIMAPARA BAIXO: ESTAR-TERRAÇO

ESTAR-JANTAR (PINTURA NO FORRO APLICADA EM 2005)

ENSAIO NELSON KOHN, 2010

ARQUIVOGC 


\section{Conexão Frank Lloyd Wright}

Uma concepção toda nova entrou na mente do arquiteto e na vida dos homens. Instintivamente a intui sozinho: quando comecei a construir a tendo fixa na mente não sabia nada de Lao-Tse que li muito mais tarde e por acaso. Um dia voltando do jardim onde estive trabalhando, me dediquei a ler um livrinho que o embaixador do Japão nos Estados Unidos me havia mandado, e lendo... lendo encontrei a idéia da arquitetura que vos expus, aquela mesma que havia em mente e a qual tenho tido fé no meu trabalho: "a realidade de uma construção não consiste nas paredes e no teto, mas no espaço compreendido entre eles e onde se vive" ${ }^{84}$ [...] Não podia esconder aquele livro e negar a evidência [...] mais tarde compreendi que no final das contas a minha idéia não derivava daquela de Lao-Tse, era qualquer coisa mais profunda que sobrevive ao mundo, um conceito eterno, universal, que permanece e permanecerá para sempre. Comecei então a pensar que deveria estar orgulhoso de ter tido a milésima intuição de Lao-Tse e de ter procurado dar-lhe uma forma tangível. Não deveria sentir-me humilhado.

Frank Lloyd Wright (conferências de Londres)

De 1937, quando propôs uma volumetria assimétrica na aldeia de pescadores, a 1972, na casa dos Telhados de múltiplas rotações, a obra de Galiano Ciampaglia como um todo, sugere o arquiteto ter transitado pela arquitetura moderna com a coerência de quem conceituou bases para o exercício da profissão e a propriedade de quem busca uma identidade própria. Da mesma forma o fizeram no período compartilhado, Galiano Ciampaglia e Miguel Forte, quando as necessárias concessões de um em relação ao outro, aflorariam nos autores independentes.

Permeadas por referências wrightianas, as casas Forte \& Ciampaglia tem origem na organização funcional. Através de critérios de transparência, os interiores se integram aos pátios e jardins como extensões do convívio social. À exceção do complexo programa da casa Enzo Segre (1952), a funcionalidade é distribuída em dois pavimentos. Todavia, a experiência do desmembramento da área de estar e da sala de jantar, em diferentes pisos, proposto na casa Luis Forte (1952) não foi eficaz se considerarmos a transferência do centro da vida familiar para onde as atividades sob o comando da matriarca ${ }^{85}$, assim o exigiam. Diante dos paradigmas domésticos, nenhuma das casas chegou a se constituir em bloco único. A garagem frontal, introduzida na casa Renato Grazzini (1948), retorna 
ao fundo do lote, na casa Domingos Cacace (1952). Da mesma forma mantiveram-se desvinculadas do corpo principal, as edículas.

Como linguagem, à exceção da casa $R$. Grazzini, articulada em $60^{\circ}$, o conjunto da obra é caracterizado por constantes, como adequações formais, volumetrias contidas sob um único telhado, beirais fartos, terraços e pérgolas, além da reprodução de experiências que haviam dado certo. A integração com a cidade oscila da exposição da casa S. Fileppo (1943) à opacidade da casa R. Grazzini (1948), para retornar à exposição da casa $L$. Forte em contraponto à oclusão da casa $D$. Cacace, ambas projetadas em 1952.

Da mesma forma, nas casas Galiano Ciampaglia, através de critérios de transparência, os interiores se integram aos pátios e jardins como extensões do convívio social. Todavia, em contraponto à fase anterior, desenha-se um repertório de volumetrias térreas alternadas por outras de um ou mais pavimentos associados e coberturas articuladas. Três exemplares são propostos em bloco único a partir da incorporação da edícula ${ }^{86}$. Não há paralelo entre duas residências. Os materiais e os detalhes são distintos e específicos, caso a caso. Mantida a origem na organização funcional, paulatinamente, as plantas se expandem em diferentes direções. São introduzidas as cores e explorados os ângulos fazendo as pessoas compreenderem o quanto é agradável o percurso que deles resulta. É uma fase onde "a união da representação com a função" ${ }^{87}$ se intensifica. Através de lajes inclinadas, a ambientação é explorada através das fontes de luz que procedem dos oitões, agora vazados. Releituras de Frank Lloyd Wright que remontam a Louis Sullivan são propostas numa chave moderna. É o caso da casa do Balcão frente à Crane Bradley House, projetada pelo Leiber Meister, em 1907.
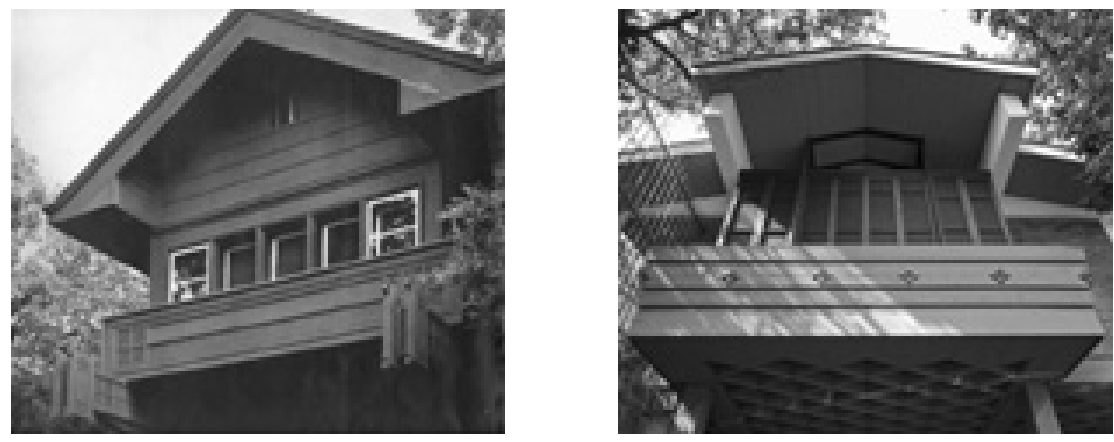
Nesse sentido, Paulo Bastos, visitante assíduo da casa das Esquadrias azuis, destaca a afinidade de Galiano Ciampaglia com Wright sem limitar-se a um "formalismo de empréstimo". Além do incentivo aos aprendizes de Taliesin sobre desenvolverem a sua identidade, a busca de uma expressão própria foi tema da passagem de Frank Lloyd Wright pela ENBA ${ }^{88}$, em 1931, através da pergunta do estudante, Ângelo Murgel, ao arquiteto norte-americano: "Copiar o modernismo estrangeiro ou procurar criar um estilo de acordo com as necessidades?".

Quando recentemente, um pesquisador avaliou na obra de Galiano Ciampaglia, "a passagem da referência wrightiana direta para uma expressão mais pessoal onde é possível perceber uma reflexão sobre a tradição brasileira" ${ }^{89}$, sugeriu a genuína assimilação dos princípios do mestre.

A questão extrapola 0 desenho. A introspecção se acentua conservando intacto o sentimento da casa como abrigo. $O$ foco nos princípios da arquitetura orgânica, segundo Wright, é identificado por Siegbert Zanettini diante da seleção de casas Galiano Ciampaglia e como visitante assíduo de uma delas: "a relação que Galiano estabelece entre o usuário, o espaço e a matéria, é nítida [...] ele parece acomodar o usuário ao espaço".

Parece fazer sentido o conjunto de correspondências e entrevistas trazido ao estudo, assim como o fato de os proprietários da casa do Balcão e da casa dos Octógonos terem presente as visitas de alunos da Faculdade de Arquitetura Mackenzie, monitoradas por Miguel Forte, nos anos 70 .

Outro fato observado ao longo do estudo, além da admiração dos clientes pelo arquiteto, foi a sinergia estabelecida ao longo do projeto e da execução da obra. Não é raro identificar no acervo de Galiano artigos ou publicações sobre Frank Lloyd Wright trazidas pelos proprietários, como também não é difícil perceber o papel de professor nessa relação.

Salvo descaracterizações decorrentes da venda de alguns imóveis, as intervenções que se fizeram necessárias respeitaram o projeto. Excepcionalmente, a casa das Esquadrias azuis, demolida em 2010 para novo traçado urbano, foi desocupada pelos clientes sem que qualquer intervenção tivesse sido introduzida, ao longo de cinco décadas. 
"Eu tinha tanta confiança no arquiteto que só disse quantos dormitórios eu precisava. $O$ resto foi tudo decidido por ele. Os detalhes, a madeira, etc. Ele fez o projeto, a piscina, o paisagismo e desenhou todos os moveis incorporados. Eu só completei com os móveis soltos. A casa foi construída durante quatro anos. Depois em 1970 foi feita a piscina no terreno ao lado. Moramos 22 anos na casa. Nunca tive qualquer queixa ou arrependimento. $A$ casa nos deu satisfação total. Em 1988, a casa foi vendida por falta de segurança na região. A beleza da casa e os detalhes eram tão importantes que quando a casa ficou pronta, o arquiteto Miguel Forte levou, por duas vezes, grupos de 8 a 10 alunos. Me lembro dele falando aos alunos que a casa era um exemplo a ser seguido".

DEPOIMENTO DE MARA BENEDUCEÀAUTORA $1^{\text {a }}$ PROPRIETÁRIA DA CASA DO BALCÃO SÃOPAULO, 26 DE MAIODE 2010

"[...] Não seria necessário salientar a especial atenção por ele dispensada à harmonia das formas. Essa preocupação revelou-se inicialmente na implantação da casa sobre o terreno irregular, resultante da união de dois lotes, no centro de uma quadra triangular [...] Como atributo inerente ao amor pela perfeição, estava sua dedicação ao controle da execução, com visitas praticamente diárias ao canteiro, para que tudo fosse feito como ele tinha imaginado. E nas inúmeras vezes em que lá nos encontrávamos, era particularmente agradável ouvir a descrição entusiasmada do efeito desejado em cada detalhe a ser executado e da sua admiração pelos arquitetos Frank Lloyd Wright e Alvar Aalto. Era um aprendizado de arquitetura [...] Outra virtude está na invejável cultura do arquiteto Galiano Ciampaglia, que sem dúvida enriquecia seu trabalho. Trabalho que era, aliás, admirado até por colegas de igual nível. Lembro-me de um dia em que o arquiteto Miguel Forte levou alunos seus, da Faculdade de Arquitetura Mackenzie, para visitar as obras de minha casa, já em fase de acabamento [...] Eu suma, pela harmonia das formas e pelo cuidado da execução, resultaram ambientes por si só agradáveis, dos quais não me canso, apesar de neles viver há mais de 35 anos".

TRECHO DA CORRESPONDÊNCIA DE ERASMO DE CAMARGO SCHUTZERÀAUTORA PROPRIETÁRIODA CASA DOS OCTÓGONOS SÃOPAULO, 6 DE JANEIRO DE 2010 
"Galiano. Um homem gentil, característica primeira do arquiteto talentoso, sensível ao belo - capaz de parar, na correria diária, na Marginal Pinheiros, para observar o por de sol. Detalhista - às vezes perdendo a cabeça com os mestres de obra e atirando o chapéu de palha ao chão - elegante. Introspectivo - suas casas voltadas e se desenvolvendo para dentro não revelando todo o potencial pelo exterior. Privilégio conhecer a pessoa, o arquiteto e morar por mais de 30 anos numa "timeless house", planejada por ele, sem jamais perder o encanto da visão dos ângulos, das descobertas de novas perspectivas, - o prazer que tem nos proporcionado por toda uma vida".

CORRESPONDÊNCIA DE ANA MARIA BAGLONI ÀAUTORA PROPRIETÁRIA DA CASA DOS TELHADOS FIRENZE, 6 DE JUNHODE 2010

"As casas projetadas pelo Galiano sempre me impressionaram. Curiosamente, externamente, não eram iguais. Internamente era um mundo de ambientes e de detalhes. Inconfundíveis. Visitei, no seu final de construção, a casa de Alto de Pinheiros, e me apaixonei. Um dia teria uma casa do Galiano...Meu terreno no Morumbi não era o mais feliz. Estreito, 20 metros de frente, profundo, 60 metros, era quase plano. Era baixo, sem vista. Os primeiros planos eram maravilhosos. A casa se desenvolvia ao longo do eixo longitudinal, num correr de planos que se elevavam, em pequenos níveis, com um sinuoso corredor envolvendo os diversos ambientes. Tudo coberto por telhados, que correspondiam aos planos internos, em um longo movimento que terminava na varanda, abrindo-se para um amplo jardim que envolvia uma piscina oval. Porém o marcante eram os interiores. Uma escultura de alvenaria e madeiras que se complementavam onde cada detalhe se insere em um conjunto de formas e ambientes. As aberturas permitiam a entrada da luz e a visão do jardim dando uma sensação de estar no jardim, dentro de casa. Viver a casa é um prazer estético. Não nos cansamos de observar as perspectivas, os detalhes, as luzes. E parte da nossa vida".

CORRESPONDÊNCIA DE GIANPAOLOBAGLIONI ÀAUTORA. PROPRIETÁRIO DA CASA DOS TELHADOS FIRENZE, 6 DE JUNHODE 2010

"O grande interesse de Ciampaglia em projetar com perfeita adequação dos usuários em suas habitações dentro dos conceitos de arquitetura humanizada explica o porquê de vários proprietários ainda viverem por décadas nas residências por ele projetadas". 
"Eu me formei em 59 na FAU e faço parte de uma turma privilegiada de colegas, entre outros, Ludovico Martino, Eduardo Almeida, Dacio Ottoni e é claro, o Henrique Pait, que cursou a Faculdade com alguns anos de acréscimo. Estar falando desse tempo é uma "saborosa recordação": os "artistas de domingo", (quando eu apresentava peças de mobiliário que faziam sucesso), as mãos sujas de grafite, a régua " $T$ ", e a indispensável Gilette, que o computador acabou. Mas, sobretudo, o entusiasmo que tínhamos naquela época quando tudo nos obrigava a nos posicionarmos: as artes, a política, a arquitetura. O que havia na FAU, era uma nítida divisão entre Wright e Le Corbusier. E a força do concreto acabou vencendo em São Paulo. Mas, entendo que as minhas raízes, e também a de muitos colegas, permanecem wrightianas, o que explica o meu entusiasmo pelas articulações e encaixes que a madeira e o aço permitem. Gostávamos também do Neutra e do Breuer. Corríamos atrás das obras modernas e entre as nossas referências, é claro, estava a casa da Rua Alagoas e também o Branco \& Preto, a mais importante loja de design da época. Em 58 eu trabalhei com o Millan e fiquei mais próximo ao grupo da Barão de Itapetininga. Analisando as imagens do conjunto da obra, mescladas com pequenos desenhos, anotações teóricas e correspondências de clientes, identifico um material muito rico e é assim que deve ser apresentado. $\mathrm{Na}$ obra como um todo, ficam claras, a exploração dos materiais, o vigor dos detalhes e a expressão de determinados elementos que se repetem, como as grelhas de iluminação e os frontões. As imagens da casa Marisa Cacace (térrea) são uma riqueza de detalhes wrightianos, sobretudo os de marcenaria, e olha que eu, como filho de marceneiro, entendo do assunto. Se, no início da carreira o Galiano conservava um desenho isótopo, embora permeado de referências wrightianas, a evolução da obra independente é nitidamente em direção ao "orgânico". A relação que ele estabelece entre a matéria, o espaço e o usuário é claramente sentida. Pessoalmente, eu só conheço a casa Baglioni. É uma casa que tem quase 40 anos e não envelhece. $\mathrm{O}$ Galiano parece acomodar o usuário ao espaço. $\mathrm{O}$ trabalho que você está desenvolvendo é muito importante e precisa ser documentado. $\mathrm{O}$ Galiano vem sendo distanciado da história não só pelo seu temperamento, mas também pela grande exposição do Forte através do Branco \& Preto e da carreira de Professor. Mas a minha geração sempre soube que Galiano e Miguel eram uma "dupla". São as gerações mais novas que desconhecem a verdadeira trajetória que você deve registrar, não apenas como uma necessária revisão histórica, mas pelo significado do trabalho que você me apresentou". 
"A residência Marisa Cacace, presente de casamento de um pai para sua filha, reflete um tempo em que uma boa obra de arquitetura era um bom presente, não só para quem iria habitá-la, mas também para a própria cidade. Térrea, a casa tinha presença propositadamente discreta e acolhedora, de modo a integrar adequadamente a fisionomia do bairro para o qual estava voltada. O projeto revela forte influência "wrightiana", tanto na rica variação dos panos de telhado, como, sobretudo, no jogo de $45^{\circ}$ dos volumes frontais, escapando de apresentar para rua monotonia de fachadas planas e criando espaços internos para as áreas de estar, livres da sensação de estarem contidas em uma caixa cúbica. Neste mesmo sentido, os forros também não são exclusivamente planos e, juntamente com detalhes especiais de iluminação, introduzem formas de pirâmides invertidas, contribuindo para a evidente intenção de projeto de não constranger os moradores e seus visitantes por espaços de rigidez cartesiana. A posição central da lareira nas áreas de estar adota, igualmente, um conceito muito caro à corrente arquitetônica derivada das idéias de Frank Lloyd Wright: a de que ela representa o foco (fogo) de aglutinação das pessoas junto a si, estando por isto, no projeto, aberta para lados opostos. Estas considerações, no entanto, não devem levar à conclusão de que esta obra de Galiano Ciampaglia limita-se a utilizar formalismo de empréstimo. Em sua concepção geral, como por exemplo, na relação espacial forte e ampla dos interiores com os jardins externos e nos detalhes refinados de acabamento no aparelho de tijolos, nos pisos, no mobiliário fixo, na caixilharia, aparece a personalidade criadora do arquiteto que, através de determinada obra, articula elementos de uma linguagem com a qual tem afinidade, sem que isso, deixe de falar por si próprio, contribuindo, como de fato ocorreu, para enriquecer o acervo de nossa arquitetura, enquanto patrimônio cultural paulista e brasileiro".

ÍNTEGRADA CORRESPONDÊNCIA DE PAULOBASTOS ÀAUTORA SOBRE A CASA DASESQUADRAIS AZUIS (GC, 1961) SAÕ PAULO, 05 DE DEZEMBRO DE 2011

"Eu desconhecia o conjunto da obra do Galiano, mas nas imagens identifico alguns aspectos: Personalidade: há uma grande liberdade na assimilação dos fundamentos de Wright, mas nunca uma cópia; Organização espacial muito bem resolvida, geralmente a partir de um núcleo, como na casa térrea (casa das Esquadrias azuis) onde a lareira define a distribuição dos ambientes; Beleza, como na galeria de acesso da casa do Balcão confeccionada em diferentes elementos vazados de cerâmica; Equilíbrio entre a riqueza dos materiais e a limpeza do traçado, como na fachada interna da casa da Rua Inglaterra. Apesar do rico movimento das articulações da madeira e do ferro no terraço superior, a fachada, como um todo, resulta extremamente limpa". 
"Antes de entrar na Faculdade (entrei somente com 21 anos) e liderados pelo Ludovico Martino, nós saíamos em busca das referências da arquitetura moderna (tínhamos alguns preconceitos em relação à arquitetura brasileira, dos quais hoje me arrependo de alguns). Foi assim que conhecemos a casa Grazzini ainda em fase final de construção. Me impressionou o trabalho com elementos vazados de concreto. Mais tarde tentamos visitá-la, mas já estava habitada. Também nessa ocasião conheci por fora, a casa do Miguel. Acompanhei também a construção da casa D. Cacace (linda). Essas obras foram referências, assim como a "Branco \& Preto" da Vieira de Carvalho. Acho interessante a influência projetual que havia entre o grupo formado por Galiano, Miguel, Candia, Jacob, Millan, Aflalo e Plínio Croce. Vejo muita similaridade com alguns projetos do Millan e do Galiano com o Miguel. Por exemplo, esta casa (Giannubillo) apresenta muita semelhança com algumas casas do Millan. Outra é a casa Fujiwara (54-Millan) com a casa Luis Forte. Tanto que eles chegaram a fazer alguns projetos juntos. Não cheguei a ter contato direto com o Miguel ou o Galiano. Encontrava o Miguel em exposições, ou no IAB. O Galiano, eu o vi por uma ou duas vezes (pode ter sido na conferência do Neutra na FAU e na exposição do Wright, no IAB, ambas em 1959). Tive mais contato com o Jacob, aliás cultíssimo. Cheguei a trabalhar com ele por dois meses. Foi ele quem me contou sobre a divertida e pitoresca noite de tempestade que ele e o Miguel passaram no Taliesin recolhendo as goteiras que caiam no quarto onde dormiram. O Galiano é um homem erudito. Certamente na biblioteca dele se encontram referências sobre o seu pensamento. Vendo o portfólio identifico alguma relação do trabalho do Galiano, por exemplo, com o trabalho dos elementos vazados da casa da Rua Henrique Martins. Essa análise é interessante. Só conheço por fora a casa da Rua Inglaterra. Muito elegante".

ENTREVSTA DE EDUARDO DE ALMEIDAÀAUTORA SÃOPAULO, 13 DE MARÇO DE 2009

"Eu vi uma casa linda e perguntei quem era o arquiteto. Procurei o Dr. Galiano e pedi uma casa igualzinha. Ele disse que era impossível porque para cada terreno se projetava uma casa. Depois de alguns dias ele apresentou o projeto. Adoramos e não precisou mudar nada. Apenas ele mostrou 02 fachadas, com ou sem portão. Escolhemos deixar tudo aberto para a praça. Nunca fizemos qualquer reforma ou modificação. A casa é perfeita. Lembro que há muitos anos meu marido chamou um pintor que pintou as pérgolas de azul. Não sei como o Dr. Galiano soube, porque ele telefonou muito bravo e disse que aquilo não era enfeite. Meu marido mandou voltar ao acabamento original e nunca mais nos atrevemos a fazer qualquer modificação. Somente após o seu falecimento, resolvemos pintar toda a casa de branco e instalar os portões."

DEPOIMENTO DE MERCEDES DEL CARLO PRESTADO ÀAUTORA PROPRIETÁRIA DA CASA DA RUA SIMPATIA SAÕ PAULO, 13 DE NOVEMBRO DE 2008 
${ }^{1}$ FALBEL, 2003, p. 51

${ }^{2}$ Entrevista de Galiano Ciampaglia ao IAB-SP, em 2003 (ANEXO 1 deste)

${ }^{3}$ SEGAWA, 2002, p. 43

${ }^{4}$ Op. cit. p. 28

5 TAUT, Bruno. Die Neue Baukunst in Europa und Amerika. Stuttgart: Julius Hoffmann, 1929

${ }^{6}$ IRIGOYEN, Op.cit. p. 27

${ }^{7}$ MOMA, 1939, p. 14

${ }^{8}$ WRIGHT, 1943, p. $489-493$

${ }^{9}$ LEMOS, 1972

${ }^{10}$ Ibidem

${ }^{11}$ COSTA, 1939, p. 161

12 LOSCHIAVO DOS SANTOS, Maria Cecília. Móvel Moderno no Brasil. São Paulo: Studio Nobel, Fapesp, Edusp, 1992

${ }^{13}$ LOURENÇO, 1995, p. 201

${ }^{14}$ ACAYABA, 1994, p. 59

${ }^{15}$ LEON, 2006, p. 97-98

${ }^{16}$ Peter Scheier (1908-1979) foi fotógrafo oficial do Masp desde 1947. O seu acervo encontra-se depositado no Instituto Moreira Salles.

${ }^{17}$ Carta de Arthur Caruso Junior encaminhada à autora em 14/10/2010

${ }^{18}$ Depoimento de Vera Pássaro à autora em 31/03/2011

${ }^{19}$ Entrevista de Siegbert Zanettini à autora em 19/03/2009

${ }^{20}$ Depoimento de Yolanda Forte Ciampaglia à autora

${ }^{21}$ Entrevista de Galiano Ciampaglia ao IAB-SP, em 2003 (ANEXO 1 deste). Por seu lado Forte daria outros detalhes, em entrevistas a Lourenço Gimenes, em 16 de maio de 1998 e 18 de junho de 1998 (CD Miguel Forte: vida e obra)

${ }^{22}$ ACAYABA, 1986, p. 18 e 21 n. 11

${ }^{23}$ FORTE, 2001, p. 173

24 "[...] eu trouxe essas plantas também para você ver como a gente trabalhava naqueles tempos, os desenhos que a gente fazia, agora é tudo feito no computador [...] nós nos revezávamos sempre, porque tudo isto que eu estou mostrando para você foi feito com meu cunhado Galiano Ciampaglia". Entrevista de Miguel Forte a Lourenço Gimenes a respeito das casas L. Forte. E. Segre e D. Cacace. 31 de junho de 1998 (CD Miguel Forte: vida e obra)

25 "O Galiano e o Miguel foram contratados para o projeto e a fiscalização da obra até os mínimos detalhes. Por isso a casa só ficou pronta em 1955. Os pagamentos, a contratação de pessoal e a compra de material era feita diretamente pelo meu pai". Depoimento de Fulvio Forte à autora em 2011.

${ }^{26}$ ZEVI, 1969, p. 129

${ }^{27}$ ACAYABA, Op.cit, p. 18

${ }^{28}$ ACAYABA, 1994, p. 33 e 43

${ }^{29}$ Os originais foram sempre disponibilizados aos pesquisadores. Em 1998, Miguel Forte chegou a liberá-los para uma pesquisa FAPESP. A autorização consta do CDMiguel Forte: vida e Obra (GIMENES, 1999).

${ }^{30}$ CAMARGO, Mônica Junqueira: In prefácio Diário de um jovem arquiteto. Minha viagem aos Estados Unidos em 1947 (FORTE, 2001, p. 16); In Arquiteto Miguel Forte (1915-2002) www. Vitruvius. Arquitextos 030; GIMENES, Lourenço. Documento Miguel Forte, AU-99, 2002, p. 85-91. 
${ }^{31}$ ACAYABA, 1986, p. 73-5; GIMENES, 2002, p. 85-91; IRIGOYEN, 2002, p.123

${ }^{32}$ IRIGOYEN, 2005 p. 108

${ }^{33}$ Entrevista de Eduardo de Almeida à autora em 13 de março de 2009

${ }^{34} \mathrm{O}$ episódio que deu origem à mostra é detalhado por Irigoyen (2002, p. 105-106)

${ }^{35}$ RINO LEVI, 2002, p. 94

${ }^{36}$ ACAYABA, 1986, p. 18

${ }^{37}$ ACAYABA, 1994; GIMENES, 2002; CAMARGO, 2002.

${ }^{38}$ Não estão incluídos os projetos não executados cuja data de realização é desconhecida

${ }^{39}$ A referência é extraída do livro Wright e Artigas. Duas viagens, 2002, p. 130

40 Três residências em São Paulo. Revista Habitat maio-junho, n. 48 p. 32, 1958

${ }^{41}$ FRAMPTON, 2000 p. 245

${ }^{42}$ Segundo depoimento de Galiano Ciampaglia à autora, essa foi a única premissa do proprietário.

${ }^{43}$ Entrevista de Eduardo de Almeida à autora em 13 de março de 2009

${ }^{44}$ BEHRENDT, 1937 p. 133

${ }^{45}$ CIAMPAGLIA, Galiano e FORTE, Miguel. Três residências em São Paulo. Habitat, n. 48, p.28-35, mai/jun 1958

${ }^{46}$ ACAYABA, Op.cit. p. 52.

${ }^{47}$ LOURENÇO, 1995, p. 314

${ }^{48}$ IRIGOYEN, Op.cit. p. 141.

${ }^{49}$ MOMA, Op.cit. p. 13

${ }^{50} \mathrm{RUCHTI}, 2011$, p. $78-80$

${ }^{51}$ EXPOSIÇÃO internacional de arquitetura. O Estado de S. Paulo, São Paulo, dez, p.13

52 IRIGOYEN, Op.cit. p. 182 n. 28.

${ }^{53}$ Depoimento de Irene Ruchti à autora em 2011

${ }^{54}$ ACAYABA, 1994, p.66

${ }^{55}$ ACAYABA, Op.cit p. 67

${ }^{56} \mathrm{O}$ contrato de constituição do escritório Forte \& Ciampaglia não foi encerrado nos cartórios competentes. O que fica claro no levantamento realizado junto à Secretaria de Gestão da Prefeitura do Município de São Paulo, é que a partir de 1958, Galiano Ciampaglia não se utiliza do nome do escritório em nenhum dos processos municipais do qual é autor dos projetos. Em contrapartida, Miguel Forte, em 1961, ainda associa o nome do escritório no processo municipal da reforma da própria residência, ainda que sem qualquer participação efetiva de Galiano Ciampaglia

${ }^{57}$ ACAYABA, 1986, p. 73-75

58 Ibidem

59 PERRONE, 1993, p. 53

${ }^{60}$ FRASCARI, in Nesbitt, 2006, p. 548.

${ }^{61}$ Anotações do arquiteto extraídas de WRIGHT, 1955, p. 260 (New York Times Magazine, october 4)

62 "Na construção de minha residência, a autuação do arquiteto Galiano Ciampaglia consistiu em elaboração do projeto, inclusive detalhes de execução e fiscalização destinada a assegurar a absoluta observância desse projeto. Não cuidou ele de contratação de pessoal empregado na obra ou de prestadores de serviços, nem de compra de materiais, o que tudo foi providenciado por mim ou por terceiros a meu serviço". E-mail de Erasmo C. Schutzer encaminhado à autora em 19 de setembro de 2011.

${ }^{63}$ WRIGHT, 1943, p. 401 
${ }^{64}$ Depoimento de Galiano Ciampaglia à autora em 2003.

${ }^{65}$ Correspondência de Erasmo C. Schutzer encaminhada à autora em 06/01/2010

${ }^{66} \mathrm{Em}$ depoimento à autora em 2008, Beatriz de Lima Braga confirmou o início da obra, em 1961. Devido à transferência da família para São Paulo, não há mais dados. Sabese apenas que a casa estava localizada no bairro Cidade Jardim.

${ }^{67}$ Em 1976, a Sra. Yone Giannetti da Fonseca foi vencedora do Premio Jabuti Poesia com o livro Rosa Dialética.

${ }^{68}$ Entrevista de Eduardo de Almeida à autora em 13 de março de 2009

${ }^{69} \mathrm{De}$ acordo com Pfeiffer, a duplicidade de lareiras é proposta por Wright, na Susan L. Dana House, em 1900. (PFEIFFER, 1993, p. 49)

${ }^{70}$ No caso do estudo para a casa Érico Stickel, inspirada na malha hexagonal da casa Hanna (1936), é nítida a estrutura pontuada de pilares ao longo das varandas.

${ }^{71}$ HOPPEN, 1993, p. 32

72 Depoimento de Galiano Ciampaglia à autora. $\mathrm{O}$ ano do estudo e o local da obra foram confirmados por uma das filhas do cliente, em 2008.

${ }^{73}$ Depoimento de Marisa Cacace à autora em 25/10/2008

${ }^{74}$ As características do habitar Prairie e Usonian são detalhadas por Ana Tagliari em Princípio, espaço e forma na arquitetura residencial. São Paulo: Annablume, 2011, p.

73-81

${ }^{75}$ BEHRENDT, 1937 p. 141

${ }^{76}$ Op.cit. p. 133

77 Op.cit. p. 132

${ }^{78}$ Entrevista de Mara Beneduce à autora em 26/05/2010

${ }^{79}$ Faziam parte da banca (2008) Prof. Dr. Hugo Segawa e Prof. Dr. Agnaldo A. C. Faria.

${ }^{80}$ TAGLIARI, 2011, p. 247, item 11, fase Prairie.

${ }^{81}$ BEHERENDT, op.cit.

82 ibidem

${ }^{83}$ Correspondência de Erasmo C. Schutzer à autora em 06/01/2010

${ }^{84}$ Wright refere-se a The Book of Tea de Okakura Kakuzo

${ }^{85}$ Depoimento de Yolanda Forte Ciampaglia à autora

${ }^{86}$ Casa dos Losangos, casa da Rua Simpatia e casa dos Telhados

${ }^{87}$ NESBITT, 2006 p. 547

${ }^{88} \mathrm{~A}$ passagem é trazida no estudo de Adriana Irigoyen, Wright e Artigas. Duas viagens, 2002, p. 30

${ }^{89}$ FUJIOKA, 2003, p. 166 
Revendo a história (à guisa de conclusão)

[...] deve-se descartar que a pesquisa histórica tenha a função de prover com conjeturas satisfatórias a falta de dados precisos sobre o lugar, o tempo e as circunstâncias em que determinada obra de arte foi executada [...] 0 próprio historiador não pode eximir-se da pesquisa direta, pois, se o seu propósito é original não pode deixar de exigir a inclusão de novos documentos ou uma interpretação diferente das já conhecidas.

Giulio Carlo Argan

Ainda que pareça pertinente atribuir o deslocamento de Galiano Ciampaglia da historiografia da arquitetura ao seu temperamento reservado ou, antagonicamente, à grande exposição de Miguel Forte como sócio do grupo Branco \& Preto e como professor do Mackenzie, por quatro décadas, eu diria que nenhum dos extremos justifica o vácuo entre o que dados básicos asseguram a ambos os arquitetos, à frente do escritório Forte \& Ciampaglia, e o que se convencionou divulgar a partir dos estudos acadêmicos.

Passar em revista aquela agenda é a ferramenta que resgata afinidades que justificam a dupla dos anos 40 e 50, a atuação conjunta dos professores, nos anos 60 e 70 , o respeito pela obra do outro e a amizade cultivada até Miguel falecer.

Estudar Galiano Ciampaglia não pretendeu limitar-se a reconduzi-lo ao lugar que the é de mérito, nos anos 40 e 50, trazer à luz a obscura Arquitécnica, ampliar o repertório arquitetônico da casa paulista ou se constituir em instrumento para novas pesquisas e interpretações. É antes de tudo uma reflexão sobre como é possível manter o foco em determinado protagonista e nas fases em parceria, se houver, ultrapassar o "espírito redutor" ${ }^{1}$ vigente em nossa cultura e somar à própria obra.

NOTA

\footnotetext{
${ }^{1}$ No caso, a autora se apropria da crítica de Maria Cecília França Lourenço, em Operários da Modernidade (1995, p. 15)
} 
Bibliografia 
Consulta a acervo público

ACAYABA, Marlene Milan. Residências em São Paulo: 1947-1975. Projeto, 1986 Branco e Preto: uma história de Design Brasileiro nos anos 50. São Paulo: Instituto Lina Bo e Pietro Maria Bardi, 1994 Dois arquitetos. Duas experiências. In Revista Projeto, 1986 ANELLI, Renato. Rino Levi. Arquitetura e Cidade. São Paulo: Romano Guerra Editora, 2001

ARGAN, Giulio Carlo. História da arte como história da cidade. São Paulo, Martins fontes, 1992.

ARQUITETURA E DESENVOLVIMENTO NACIONAL. Depoimentos de Arquitetos Paulistas. São Paulo, Editora Pini, 1979

ARTIGAS, João Vilanova. Caminhos da Arquitetura. São Paulo: Cosac \& Naify, 1999

BELLUZZO, Ana Maria de Moraes. Artesanato, arte e indústria. FAUS-USP: tese de doutorado, 1988

BENEVOLO, Leonardo. História da Arquitetura Moderna. São Paulo: Perspectiva, 2006

BROWNE, Enrique. Ler plantas e aprender arquitetura. In ProjetoDesign, p. 86-91, Julho 1996.

BRUAND, Yves. Arquitetura Contemporânea no Brasil. São Paulo: Editora Perspectiva, 2002

BRUNA, Paulo. Os primeiros arquitetos modernos. Habitação Social no Brasil 1930-1950. São Paulo: EDUSP, 2010

CAMARGO, Mônica Junqueira. Princípios de arquitetura moderna a obra de Oswaldo Bratke. São Paulo: FAU-USP: tese de doutorado, 2000___ [Prefácio] Diário de um jovem arquiteto. São Paulo: Editora Mackenzie, 2001, p. 9-21 Arquiteto Miguel Forte. www. Vitruvius, Arquitextos 030. Texto especial 158-novembro, 2002. Miguel Forte. www Docomomo.org.br/portaretratos, 2002 CIAMPAGLIA, Fernanda. Documento Galiano Ciampaglia. Revista AU-114. São Paulo: Editora Pini, 2003, p. 57-61 A primeira turma de arquitetos mackenzistas. Drops, São Paulo, 10.031, www.vitruvius.com.br/revistas/read/drops/10.01/3422

CIAMPAGLIA, Galiano e FORTE, Miguel. Três residências em São Paulo. Habitat, n. 48, p.28-35, mai/jun 1958 Casa de fim de semana. Habitat, n. 50, p.13-15, set/out 1958 
CIAMPAGLIA, Galiano, FORTE, Miguel e RUCHTI, Jacob. By, of and for Architects. Architectural Record, New York, no 2 p. 118, october 1947 House in São Paulo. The Architectural Forum, p.97, november 1947

CORONA, Eduardo e LEMOS, Carlos. Roteiro da Arquitetura Contemporânea de São Paulo. São Paulo, 1963

COSTA, Lucio. Sobre Arquitetura. Porto Alegre: Uniritter Ed., 2007 ECO, Umberto. Como se faz uma tese. São Paulo, Perspectiva, 2006 FAGGIN, Carlos Augusto Mattei. Carlos Millan: Itinerário profissional de um arquiteto paulista. FAU-USP: Tese de doutorado, 1992

FALBEL, Anat. Lucjan Korngold: a trajetória de um arquiteto imigrante. FAU-USP: tese de doutorado, 2003

FERRONI, Eduardo Rocha. Aproximações sobre a obra de Salvador Candia. FAU-USP: Dissertação de mestrado, 2008

FIALHO, Valéria Cássia dos Santos. Arquitetura, texto e imagem: a retórica da representação nos concursos de arquitetura. FAU-USP: Tese de doutorado, 2007.

FICHER, Sylvia. Os arquitetos da Poli: Ensino e profissão. São Paulo: Edusp, 2005

FLYNN, Maria Helena de Moraes Barros. Anotações para uma história dos Concursos de arquitetura no Brasil (1857-1985). Faususp: Dissertação de Mestrado, 1987 Concursos de arquitetura no Brasil (1850-2000). FAU-USP: Tese de doutorado, 2000

FORTE, Miguel. Diário de um jovem arquiteto: minha viagem aos Estados Unidos em 1947. São Paulo: Mackenzie, 2001.

FRAMPTON, Kenneth. História crítica da arquitetura moderna. São Paulo: Martins Fontes, 2000

FUJIOKA, Paulo Yassuhide. Princípios da arquitetura organicista de Frank Lloyd Wright e suas influências na arquitetura moderna paulista. Fau-usp: tese de doutorado, 2003.

GIMENES, Lourenço Urbano. Entrevistas de Miguel Forte. São Paulo, 1998 [Digitado]. Miguel Forte: vida e obra, [CD ROM], São Paulo, FAPESP, 1999 Documento Miguel Forte. AU-99. São Paulo: Pini, dez/jan. 2002 p. 85-91.

GOODWIN, Philip L. Brazil Builds: architecture new and old 16521942. New York: Museum of Modern Art, 1943.

HALL, Peter. Cidades do Amanhã: uma história intelectual do planejamento e do projeto urbanos no século XX. São Paulo: Perspectiva, 2005. 
HANSON, Norwood Russell. Observação e Interpretação. In: Filosofia da Ciência, Sidnet Morgenbesser (org), 1967

HERBST, Helio. Pelos salões das bienais, a arquitetura ausente dos manuais: expressões da arquitetura moderna brasileira expostas nas bienais paulistanas (1951-1959). FAU-USP: Tese de doutorado, 2007 HERTZBERGER, Hermann. Lições de Arquitetura. São Paulo: Martins Fontes, 1999.

HOMEM, Maria Cecília Naclério. Sobre a construção da capital do café e da Indústria (1875-1930). In Três momentos da arquitetura paulista. São Paulo, Museu Lasar Segall, 1983, p. 29-54

HOPPEN, Donald W. The seven ages of Frank Lloyd Wright: the creative process. Dover Publications, 1993

KOPP, Anatole. Quando o moderno não era um estilo e sim uma causa. São Paulo: Studio Nobel, 1990

IRIGOYEN, Adriana. Wright e Artigas. Duas viagens. São Paulo: Ateliê, Fapesp, 2002 Da Califórnia a São Paulo: referências norte-americanas na casa moderna paulista 1945-1960. FAU-USP: Tese de doutorado, 2005

LEMOS, Carlos A.C. Alvenaria Burguesa. São Paulo: Nobel, 1989- 2ª edição revisada e ampliada Arquitetura Brasileira. São Paulo: Melhoramentos, Edusp, 1979 Casa Paulista. São Paulo: Edusp, 1999 Ecletismo em São Paulo. In: Ecletismo na arquitetura brasileira. Organização Annateresa Fabris: Carlos Lemos [e] São Paulo: Nobel / USP, 1987 [depoimento] In. GIVANETTI, Bruno. Arquitetura Italiana em São Paulo. São Paulo: Raízes Artes Gráficas, 1994, p.92-93 Os três pretensos abridores de uma porta difícil. In: Três momentos da arquitetura paulista. São Paulo: Museu Lasar Segall, 1983, p. 3-8 Ramos de Azevedo e seu escritório. São Paulo: Pini, 1993 "A verdadeira origem do Movimento Moderno da arquitetura brasileira". Folha de São Paulo, São Paulo, 1972, 3 set.

LEON, Ethel. IAC. Instituto de Arte contemporânea: Escola de desenho industrial do MASP (1951-1953): primeiros estudos. FAUUSP: Dissertação de mestrado, 2006

LIRA, José Tavares Correia. Fraturas da vanguarda de Gregori Warchavchik. FAU-USP: Tese de livre-docência, 2008

LOURENÇO, Maria Cecília França. Operários da Modernidade. São Paulo: Hucitec-Edusp, 1995

LOSCHIAVO DOS SANTOS, Maria Cecília. Móvel Moderno no Brasil. São Paulo: Studio Nobel, Fapesp, Edusp, 1992 
MATERA, Sergio. Carlos Millan, um estudo sobre a produção em arquitetura. FAU-USP: Dissertação de mestrado, 2005

MENDES, Marcel. A Escola de Engenharia Mackenzie College e a questão do reconhecimento (1932-1938). São Paulo: Programa de mestrado em Educação, Arte e história da Cultura. Universidade Presbiteriana Mackenzie, 1999.

MINDLIN, Henrique. Modern Architecture in Brazil / pref. S. Giedion. New York: Reinhold Pub. Corp, 1956

MONTANER, Joseph Maria. Depois do Movimento Moderno. Arquitetura da segunda metade do século XX. Barcelona: Gustavo Gili, 2001

NESBITT, Kate (org). Uma nova agenda para a arquitetura. São Paulo: Cosac \& Naify, 2006

NEVES, Christiano Stockler das. "O Bluff Architectonico". Architectura e Construcções, vol. 2, n. 23, p.1-6, novembro, 1931

PERRONE, Rafael. O desenho como signo da arquitetura. São Paulo: FAUUSP: tese de doutorado, 1993

PIMENTA, Célio, ABASCAL, Eunice H.S. e MENDES, Marcel. Arquitetura Mackenzie. Mestres da transformação. São Paulo: Editora J.J. Carol, 2010.

REGINO, Aline Nassaralla. Eduardo Kneese de Mello: do eclético ao moderno. São Paulo: FAU-USP: tese de doutorado, 2011

REIS FILHO, Nestor Goulart. Quadro da arquitetura no Brasil. São Paulo: Perspectiva, 2006

REVISTA DE ENGENHARIA MACKENZIE. N.64. Anno XXI, maio, 1935, Architectura analytica, p. 23 N.67. Anno XXII, out, 1937, Architectura functional, p. 132-133

RIBEIRO, Patrícia Pimenta de Azevedo. Teoria e Prática. A obra do arquiteto Richard Neutra. São Paulo: FAU-USP: Tese de doutorado, 2007.

RUCHTI, Jacob Mauricio. "Construtivismo". Revista Clima. São Paulo, set. 1941, n.4, p.95-101

RUCHTI, Valéria. Jacob Ruchti: a modernidade e a arquitetura paulista (1940-1970). São Paulo: FAUUSP: dissertação de mestrado, 2011

SCARPA, Carlo e DAL CO, Francesco. Villa Ottolenghi. The Monacelli Press, New York, 1998

SEGAWA, Hugo. Arquiteturas do Brasil. São Paulo: Edusp, 2002

STOCKLER e BREIA, Maria Teresa. A transição do Ensino da arquitetura Beaux-arts para $o$ ensino da arquitetura moderna na 
Faculdade de Arquitetura Mackenzie: 1947-1965. FAU-USP: tese de doutorado, 2005

TAGLIARI, Ana. Frank Lloyd Wright. Princípio, espaço e forma na arquitetura residencial. São Paulo: Annablume, 2011 Os princípios orgânicos na obra de Frank Lloyd Wright: uma abordagem gráfica de exemplares residenciais. UNICAMP/Instituto de Artes: Dissertação de mestrado, 2008.

TOLEDO, Benedito Lima de. São Paulo: Três cidades em um século. São Paulo: Cosac \& Naify, 2004.

XAVIER, Alberto (organização). Depoimento de uma geração: Arquitetura moderna brasileira. São Paulo; Cosac \& Naify, 2003

XAVIER, Alberto; LEMOS, Carlos; CORONA, Eduardo. Arquitetura moderna paulistana. São Paulo: Pini, 1983.

ZEVI, Bruno. Frank Lloyd Wright. Obras y proyectos. Obras e projectos. Editorial Gustavo Gili, SL,2010

\section{Arquivos e Instituições consultadas}

Archivio di Stato di Campobasso con nota n. 2118/IX, 1 del marzo 2003

Arquivo Histórico "Washington Luis"

Arquivo Histório da Universidade Mackenzie

Escola de Engenharia Mackenzie

Faculdade de Arquitetura e Urbanismo Mackenzie -FAUM

Faculdade de Arquitetura e Urbanismo da Universidade de São Paulo - FAU-USP

Fundação Bienal. Arquivo Wanda Severo

Fundação de Amparo à Pesquisa do Estado de São Paulo Instituto dos Arquitetos do Brasil / Departamento São Paulo - IAB-SP Instituto Moreira Salles

Junta Comercial do Estado de São Paulo

Secretaria de Gestão da Prefeitura do Município de São Paulo 1을 Oficial de Registro de Títulos e Documentos Civil de Pessoa Jurídica

2 ㅇ Oficial de Registro de imóveis da capital

5o Oficial de Registro de imóveis da capital

7 은 Tabelião de Notas 


\section{Consulta ao acervo Galiano Ciampaglia ${ }^{1}$}

AALTO, Alvar. The Humanizing of Architectura In: The Architectural Forum, dez 1940 Architettura e arte concreta. In: Domus $\mathrm{n}$. 223/224/225/ 1947/ p. 3-15 Alcune recenti opere di Alvar Aalto.

In Casabella, n. 200, p. 5-17, 1953 University building by a master hand. In: Architectural Record, april, 1965, 169-176;

ALEXANDER, Christopher. Nuevas ideas sobre diseño urbano. Cuadernos summa-nueva vision. N. 9. Ediciones Nueva Vision SAIC, Bs. As, setiembre 1968

ARGAN, Giulio Carlo. Progetto e destino. Casa Editrice II saggiatore,1965.

ARVILL, Robert. Man and environment. Penguin Books, 1967

BACHELARD, Gaston. La poetique de l'espace. Presses Universitaires de France, Paris, 1970

BACON, Edmund N. The city as an act of will. Architectural Record, January 1967, p. 113-128

BAHRDT, Hans Paul. Lineamenti di sociologia della città. Marsílio Editori, 1966

BAUDRILLARD, Jean. Le systeme des objets. NRF, Editions Gallimard, 1968

BEHRENDT, Walter Curt. Modern Building. Its nature, Problems, and forms. New York: Harcourt, Brace and Company, 1937

BERNOULLI, Hans. La cittá e il suolo urbano. Antonio Vallardi Editore, 1951

BLAKE, Peter. The Masters Builders. Le Corbusier, Mies van der Rohe, Frank Lloyd Wright. Alfred A. Knopf. New York, 1961

BRANDI, Cesare. Struttura e architettura, Giulio Einaudi Editore, s.p.a. Torino, 1967

BROADBENT, Geoffrey. Design in Architecture. John Wiley \& Sons, London, 1973

BROOKS, Harold Allen. Writings on Wright: Selected Comment on Frank Lloyd Wright. London: The MIT Press,1985.

BROWNELL, Baker and WRIGHT, Frank Lloyd. Architecture and Modern Life. Harper \& Brothers Publishers, New York and London, 1937- 3ㄹed.

BROWNELL, Baker. The Human Community. New York. Harper \& Brothers Publishers, 1950

BRUNETTI, F. Frank Lloyd Wright. Le matrici di uma architettura organica. Teorema Edizioni. Firenze, 1974 
BURCKARDT, Jacobo. The Civilization of the renaissance Italy. The Paidon Press, Viena. Oxford University Press, New York, ?

Refexiones sobre la historia del mondo. Libreria y Editorial "El Ateneo", 1944

CANDILIS, G. JOSIC, A. WOODS, S. Reflexiones sobre planeamiento y diseño urbano. In: La ciudad viviente. Cuadernos summa-vision, Año 1, no 10, Ediciones Nueva Vision SAIC, Bs. As, 1968, p. 3-17

CARPENTER, Edmund e McLUHAN, Marshall. Revolução na comunicação. Rio de Janeiro: Zahar Editores, 1968

CASSIRER, Ernst. Antropologia Filosófica. São Paulo: Editora mestre Jou, 1972 Filosofia delle forme simboliche. Vol. 1. II Linguagio. La nuova Itália, Editrice, Firenze, 1967 Filosofia delle forme simboliche. Vol. 2. II pensiero mítico. La nuova Itália, Editrice, Firenze, 1966 Filosofia delle forme simboliche. Vol. 3 (tomo 1). Fenomenologia della conoscenza. La nuova Itália, Editrice, Firenze, 1967 Filosofia delle forme simboliche. Vol. 3 (tomo 2). Fenomenologia della conoscenza. La nuova Itália, Editrice, Firenze, 1966 Linguaggio e mito. Milano: II Saggiatore di Alberto Mondadori Editore, 1968

CHALK, Warren, COOK, Peter e outros. La ciudad viviente. In: La ciudad viviente. Cuadernos Summa-Nueva Vision, Año 1, no 10, Ediciones Nueva Vision SAIC, Bs. As, 1968, p. 18-21

CHERMAYEFF, Serge and ALEXANDER, Christopher. Community and privacy. Anchor Books Doubleday \& Company, Inc. Garden City, New York, 1965

CHERMAYEFF,S., TZONIS,A. La forma dell'ambiente collettivo. Milano: II Saggiatore di Alberto Mondadori Editore, 1972

CIAM 8. The Heart of the City. London: Lund Humphries, 1952

COOK, Peter. Architettura: azione e progetto. Edizioni Calderini,1967 COSTANTINO, Maria. Frank Lloyd Wright Design. London: Bison Books, 1995

CROCE, Benedetto. Breviario de Estética. Lisboa: Livraria clássica Editora, 1914

CROSBY, Theo. II senso della città. Studio Vista, Londra Ltd. ,1971 How to play the environment game. Arts Council of Great Britain and Penguin Books Ltd, 1973

CROWTHER, Geoffrey. Traffic in Towns. Penguin Books,1964 
DE CARLO, Giancarlo. William Morris. Buenos Aires: Ediciones Infinito, 1955

DE COULANGES, Fustel. A cidade antiga Vol. 1- Estudos sobre o culto....Grécia e Roma. Lisboa: A.M. Teixeira \& C. Filhos, Ltda, 1957; Vol. 2-Estudos sobre o culto....Grécia e Roma. Lisboa: A.M. Teixeira \& C. Filhos, Ltda, 1958

DE RUGGIERO, Guido. Sommario di storia della Filosofia. Gius. Laterza \& Figli. Bari, 1948

DI TULLIO, Mario. Scalpellini e Stucatori di Pescopenataro. Archivio di Stato di Campobasso con nota n. 2118/IX, 1 del marzo 2003, p. 74-75

DUNCAN, Hugh Dalziel. Attualità di Louis Sullivan. In: Casabella, N. 204, febraio-marzo 1954 p. 7-31

EATON, Leonard K. Louis Sullivan an Hendrik Berlage. In: Progressive Architecture, November 1956, p. 138-141, 202-204-210216-220-222-226-230-234

FAURE, Elie. History Art / Ancient Art. Garden City Publishing Co. Inc, 1937 Histoire de l'Art / L'Art antique. Paris: Le Livre de Poche, 1964; Histoire de l'Art / L'Art medieval. Paris: Le Livre de Poche, 1964; Histoire de l'Art/ L'Art moderne 2. Paris: Le Livre de Poche, $1965 \_$_L' esprit des formes 2. Paris: Le Livre de Poche, 1966; L' esprit des formes 1. Paris: Le Livre de Poche, 1966

FRANK, Edward. Pensiero Organico e Architettura Wrightiana. Dedalo Libri, Bari, 1978

GEDDES, Patrick. Cities in evolution. London: Williams \& Norgate Ltd, 1949

GEORGE, Pierre. Sociologia e Geografia. Editora Forense, Rio de Janeiro-São Paulo, 1969

GIANNOTTI, Gianni. L'Analisi ecologica. Panorama della letteratura. Editore Boringhieri s.p.a. Torino, 1966

GIBBERD, Frederick. Town Design. Reinhard Publishing Corporation, New York, 1953

GIEDION, Siegfried. Space, time and architecture. London: Humphrey Milford, 1941 Mechanization takes command. London: Oxford University Press, 1948

GOMBRICH, E.H. l'Art et son histoire 1. Paris: Le Livre de Poche, 1967; I'Art et son histoire 2. Paris: Le Livre de Poche, 1967

GRIFFINI, Enrico A. Costruzione razionale della casa. Milano: Ulrico Hoepli, 1939

GREGOTTI, Vittorio. II territorio della architettura. Feltrinelli, 1966 
GREGOTTI,V.,ROSSI, A, TAFURI, M e .....Teoria della Progetazione Architettonica. Venezia: Dedalo Libri, 1968

GUTKIND, E.A. Community and environment. A discourse on social ecology. London: Watts and Co., 1953 L'Ambiente in Espanzioni. Edizioni di Comunitá, Milano, 1955___ Our World from the air. Chatto and Windus, London, 1952

HALL, Edward T. La dimensione nascosta. Valentino Bompiani Milano, 1968

HANKS, David A. The Decorative Designs of FLLW. E.P. Dutton, N.Y., 1979

HARADA, Jiro. The Lesson of Japonese Architecture. London, The Studio Limited, 1954

HAUSER, Arnold. Storia sociale dell' arte/ I. preistoria Antichitá Medioevo. Milano: Giulio Einaudi Editore, 1955; Storia sociale dell' arte/ 2. Rinascimento Manierismo Barocco. Milano: Giulio Einaudi Editore, 1955; Storia sociale dell' arte/ 3. Rinascimento Manierismo Barocco. Milano: Giulio Einaudi Editore, 1956; Storia sociale dell' arte/ 4. Arte Moderna e contemporânea. Milano: Giulio Einaudi Editore, 1956

HEGEMANN, Werner. City Planning housing- First volume of text: Historical and Sociological. Architectural Book Publishing Co.,Inc, New York, 1936 City Planning housing- Second volume of text: Political Economy and Civic Art. Architectural Book Publishing Co., Inc, New York, 1937 City Planning housing- Volume III: A Grafic Review of civic art 1922-1937. Architectural Book Publishing Co., Inc, 1938

HEIDEGGER, Martin. Essais et conferences. Gallimard, 1954 Sobre o problema do ser - O caminho do campo. Livraria Duas Cidades, 1969

HEINZ, Thomas A. FLLW- Interiors and furniture. Academy Editions Ernst \& Sohn, 1994

HILBERSEIMER, Ludwig. In' idea di piano. Polis n. 2: quaderni di architettura e urbanística diretti da Aldo Rossi, Marsílio Editori, 1967 HITCHCOCK, Henry-Russel. In the nature of materials. New York: Duel, Sloan and Pearce, 1942

HOWARD, E- GIORDANI, Pier Luigi. L'idea della cittá giardino. Edizioni Calderini Bologan, 1962

HUSSERL, E. La crise de l'humanité européene et la philosophie. Republications Paulet. (extrait de la Revue de Metaphysique et de Morale), Avril, 1968 
ISHIMOTO, Tatsuo.The art of driftwood and dried arrangements. 1951

JENCKS, Charles. Architecture 2000. Books That Matter, New York, 1973

KAHLER, Erich. Man the measure. A new approach to history. New York: Pantheon Books, Inc., 1943

KAKUZO, Okakura. Le livre du thé. Paris: Dervy livres, 1969

KLEE, Paul. Theorie del'art moderne. Editions Gonthier.Paris, 1969

KONIG, Giovanni Klaus. Architettura e Comunicazione. Libreria Editoriale Fiorentina, 1970

KUCH, Loraine E.The Art of Japanese Gardens. New York: The John day Company, 1940

LANGER, Susanne K. Sentimento e forma. Giacomo Feltrinelli Editore. Mllano, 1965 Filosofia em nova chave. São Paulo;

Editora Perspectiva, 1971

Le CORBUSIER. L'urbanisme. Colletion de L'esprit Nouveau. Paris: Les Editions G. Crès \& Cie, 1924 _ Vers une architecture. Collection L' Esprit Nouveau- 3a edição, 1928 La Ville Radiuese. Coll. De 'L' Equipement de la civilization machiniste". Paris. L'Architecture d'Aujourd'hui, 1935 Propos d' Urbanisme. Editions Bourrelier Et Cie. Paris, 1946

LEDRUT, Raymond. Sociologie urbaine. Paris: Presses Universitaires de France, 1968

LEFEBVRE, Henri. O direto à cidade. Editora Documentos Ltda. São Paulo, 1969

LEIPZIGER, Hugo.The Architetonic City in Americas. The University of Texas Publication, № 4407, 1944

LÉVI_STRAUSS e...O método estruturalista. Rio de Janeiro: Zahar Editores, 1967

LYNCH, Kevin. L'image de la cite. Dunod Paris, 1969

MARIANO Fo, José. Acerca dos copiadores do Nordeste Brasileiro. Rio de Janeiro, 1942 Estudos da arte brasileira, Rio de Janeiro, 1942

MARÍAS, Julian. History of philosophy. Dover Publications, Inc. New York, 1967

MARITAIN, Jacques. Art et Scolastique. Paris: Louis Rouart et Fils, Editeurs, 1920 Os direitos do homem. Rio de Janeiro: Editora José Olympio, 1967 
MAYER, Albert (in consultation with Clarence Stein). Architecture as Total Community: the challenge ahead. Architectural Record, June (p. 139-146) July (p.157-162), August (p. 129-138), October (139148), December (153-156), 1964 The case for one total profession. Architectural Record, October, 1965, p. 189-194

MOMA. Art in our Time. New York: The museum of modern art, 1939 MORALES DE LOS RIOS, Adolfo. Grandjean de Montigny e a evolução da arte brasileira. Empresa A noite, Rio de Janeiro, 1941

MORRIS, William. Architettura e Socialismo. Editore Laterza, Bari, 1963

MOSSO, Leonardo. Alvar Aalto Internazionalismo e tradizione In: Casabella 415-416, 1976 p. 39

MUNFORD, Lewis. The culture of the cities. New York: Harcourt, Brace and Company, 1938 The condition of man. New York: Harcourt, Brace and Company, 1944 A conduta da vida. Editora itatiaia Limitada. Belo Horizonte, 1959 La cultura della cittá. Milano: Alfieri \& Lacroix, 1953 The City in History. New York: Harcourt, Brace \& World, Inc, 1961 La carretera y la ciudad. Emece Editores, S.A. Buenos Aires, 1966 A new Regional Plan to arrest megalopolis. In: Architectural Record, March 1965, p. 147-154 MUSCHAMP, Herbert. Man about town. Frank Lloyd Wright in New York City. The MIT Press, Massachusetts Institute of Technology , Cambridge, Massachusetts, 1983

NORBERG-SCHULZ, Christian. Intenzioni in Architettura. Paperbacks Lerici. Milano, 1967___Existence, Space \& Architecture. Praeger Publishers, New York, 1971 Meaning in western architecture. Studio Vista, New York, 1975

OSBORN, F.J. Green-Belt Cities. London: Faber and Faber Limited, 1942

PACI, Enzo. Studi di Filosofia antica e moderna. G.B. Paravai \& C, 1949

PANOFSKY, Erwin. II significato nelle arte visive. Giulio Einaudi Editore, 1962

PAWLEY, Martin. Frank Lloyd Wright: Public Buildings.Thames and Hudson, London, 1970 (rub. 73)

PFEIFFER, B. Brooks. Frank Lloyd Wright. His living Voice. The Press at California State University, Fresno, 1987 Frank Lloyd Wright.

Benedikt Taschen Verlag GmbH, 1993

PFEIFFER, B. Brooks and NORDLAND, G. Frank Lloyd Wright. In the realm of ideas. Southern Illinois University Press, 1988 
PÖETE, Marcel. Introdution a l'urbanisme. Editions Anthropos Paris, 1967

RANELLETTI, C. Applicazioni di Geometria Descrittiva. Milano: Ulrico Hoepli, 1922 _Elementi di Geometria Descrittiva. Milano: Ulrico Hoepli, 1923

READ, Herbert. A natureza criadora do humanismo. Editora Fundo de Cultura/ Brasil -Portugal, 1967 As origens da forma na arte.

Zahar Editores, Rio de Janeiro, 1967-anotações

ROSSI, Aldo. L'architettura della cittá. Marsilio Editori. Padova, 1966

ROTH, Alfred. The new architecture. Zurich: Verlag Dr. H. Girsberger, 1940 (rub 1940)

RUDOFSKY, Bernard. Architecture without Architects. Museum of Modern Art, N. Y., 1964

RUSKIN, John. The Venice Stones, 1851... La Biblia d' Amiens. Milano: valentino Bompiani \$ Co., 1946

SAMONÀ, Giuseppe. L'urbanistica e l'avvenire della città. Editori Laterza. Bari, 1967

SCOTT, Geofrey. L'architettura dell'umanesimo. 1939

SEIKE, Kiyosi. The art of Japanese Joinery. Weatherhill/ Tankosha. N.Y.-Tokyo, 1986

SERGEANT, John. Frank Lloyd Wright 's Usonian Houses. The case for Organic Architecture. Whitney Library of Design, New York, 1976__Frank Lloyd W'right's Usonian Houses. Designs for Moderate cost one-family homes. Edited by Susan Braybrooke, Susan Davis and Naomi Goldstein, USA, 1984

SERT, J. L. and Ciam. Can our cities survive? London: The Harvard University Press, 1942

SEVERINI, G. Raggionamenti sulle arte figurative. Milano: Ulrico Hoepli, 1936

SHARP, Thomas. The anatomy of the village. Penguin Books, Harmondsworth, Middlesex, 1946

SITTE, Camillo. The art of Building cities. Reinhold Publishing Corporation, New York, 1945

SMITH, Norris Kelly. FLW, a study in architectural content. PrenticeHall, Inc, New York, 1966

SPHAN. Revista do Serviço do Patrimônio Histórico e Artístico Nacional. Rio de Janeiro, MES, N. 3, 1939; no 4, 1940; no 5, 1941; no 6, 1942; n. 7, 1943

STEIN, Clarence S. Towards new towns for America. The University Press of Liverpool, 1951 
SUMMERSON, John. II linguaggio classico dell'architettura. Torino: Giulio Einaudi editore s.p.a., 1970

TAFEL, Edgar. Apprendice to Genius.Years with Frank Lloyd Wright. McGraw Hill Book Company, 1979

TAUT, Bruno. Die Neue Baukunst in Europa und Amerika. Stuttgart: Julius Hoffmann, 1929

TAYLOR, John F.A. Design and expression in visual arts. Dover Publications, New York, 1964

TOYNBEE, Arnold J. A study of History . Oxford University Press. New York, London, 1947 O desafio de nosso tempo. Zahar Editores, Rio de Janeiro, 1968 Traffic and towns. penguin books, 1963 Ciudades en marcha. Emecé Editores, S.A, Buenos Aires, 1971

TUNNARD, Christopher. Gardens in the modern Landscape. London: The architectural Press, 1938

VAGNETTI, Luigi. II Linguaggio Grafico dell'Architecto Oggi. Vitali e Ghianda, 1965

VAN DER ROHE, Mies. Mies Van der Rohe. New York: The Modern Museum of Art, 1947

VENTURI, Robert. Complexity and contradition in architecture. The Museum of Modern Art, New York, 1966

WEBER, Max. La cittá. Valentino Bompiani, Milano, 1950

WEBBER-DYCKMAN-FOLEY-GUTTENBERG-WEATON-WURSTER. Indagini sulla struttura urbana. II Saggiatore, 1968

WIRTH, Louis. El urbanismo como modo de vida. Ediciones 3 Buenos Aires, 1962

WRIGHT, Frank Lloyd. Modern Architecture. Being the Kahn Lectures. Princeton, 1931 Frank Lloyd Wright on Architecture: Selected Writings 18941940. Ed by F. Gutheim. New York: Duell, Sloan and Pearce, 1941 An Autobiography. New York: Duell, Sloan and Pearce, 1943 Architettura Organica. Muggiani Tipografo- Editore Milano, 1945 Architettura e Democrazia. Milano: Rosa e Ballo Editori, 1945 Genius and Mobocracy. New York: Duell, Sloan and Pearce, 1949 Taliesin Drawings. Wittenborn, Schultz, Inc, 1952 The Natural House. New York: Horizon Press, 1954 lo e l'architettura. Mondadori, 1955 (Libro I-II-III) An American Architecture. New York: Horizon Press, 1955 The Story of the Tower. New York: Horizon Press, 1956 
A Testament. New York: Horizon Press, 1957

The Living City. Horizon Press, N.Y, 1958

Drawings for a living architecture. The Bear Foundation inc. and

Edgar J. Kauffmann C. Foundation by Horizon Press New York, 1959

Writings and buildings. Meridien Books Inc., May, 1960

The Guggenheim Museum. S.G. Foundation and Horizon Press, New York, 1960

Architecture. Man in Possession of his earth. Doubleday \& Comapany, Inc., garden City, New York, 1962

L'avenir de l'architecture. Horizon Press, New York, 1966

La città vivente. Torino: Giulio Einaudi editore s.p.a., 1966

The Guggenheim Museum. S.G. Foundation and Horizon Press, New York, 1960

In the cause of architecture. Gutheim-Architectural Record, USA, 1975

An Autobiography. Horizon Press, N.Y., 1977

Drawings and Plans of FLW/ The early period (1893-1909). Dover

Publications, Inc, New York, 1983

WRIGHT's Studies., Vol, One. Taliesin 1911-1914. Narciso G. Menocal Editor, 1992

Details of Frank Lloyd Wright. Thames and Hudson Ltd, London, 1994

WRIGHT, Olgivanna Lloyd. Our House. Horizon Press, N.Y, 1959

The Shinning Brown , 1960 Frank Lloyd Wright, his life,his work, his words. Horizon Press, 1966

ZEVI, Bruno. Verso un' architettura orgânica. Torino: Giulio Einaudi Editore, 1945 Sapere Vedere I' architettura. Torino: Giulio Einaudi Editore, 1948 Cronache di Architettura. Editori Laterza, 1970 Architettura in Nuce. Aguilar S.A. Ediciones Madri, 1969 


\section{Periódicos e ensaios (Frank Lloyd Wright)}

1938. The Architectural Forum, January

1940. Taliesin Fellowship, vol 1. n. 1, October 1940 (Editor Frank Lloyd Wright)

1941. Taliesin Fellowship, vol 1. n. 2, February 1941 (Editor Frank Lloyd Wright).

1948. The Architectural Forum, January 1948

1949. Frank Lloyd Wright on Louis Sullivan, in Architectural Forum, August, 1949, p. 94-97;

1951. The Architectural Forum, January

1952, Jahre Lebendige Architektur

1954. Taliesin Ouest. Horizon Press Editeur,

1959. AIA MONTLY BULLETIN. Michigan Society of Architects, dec 1963. LES 9 MOTS NÉCESSAIRES "Definitions de F.L.W", IN: Architecture de Lumière, n. 11 s/data, p. 12. 1965. Forma e Colore. n. 65. Sadea Editori

1966. Drawings by Louis Sullivan. In: Architectural Record March p. 147-154

1973. Global Architecture. A.D.A. Edita, Tokyo Co. Ltd.

1977. Global Interior. A.D.A. Edita Tokyo Co. Ltd., Japan 

ANEXO 1. Entrevista de Galiano Ciampaglia formatada pelo IAB-SP por ocasião do 60 anos de fundação da Instituição. 30/06/2003.

\section{Como foi a escolha pela Arquitetura?}

Como meu pai tinha a oficina de cantaria e fazia serviços para Ramos de Azevedo, eu gostava de ver meu pai abrir as plantas com os desenhos do corte da pedra [...] $\mathrm{Na}$ escola italiana o conhecimento que eu tinha era através dos livros, das cidades da Itália, da Idade Média até a Renascença. Eu achava bonito o que representava uma cidade. Engraçado que eu passei uma grande parte de minha vida depois de arquiteto pensando em urbanismo Imagina que mais tarde eu cheguei a ter uma coleção de livros sobre urbanismo quase igual à obra do Frank Lloyd Wright.

O que o senhor achava do trabalho do seu pai?

Era muito bonito ver como se fazia o trabalho em pedra que era no primeiro momento muito grosseiro, bruto para depois chegar ao ponto onde o granito era alisado nas formas que ele deveria representar geralmente peças tridimensionais.

Como era a escola de Arquitetura?

Éramos seis alunos. O Miguel, o Igor, a Francisca, a Elma e o Soutello. O Christiano era nosso professor. Ele dava umas fotografias para a gente escolher um modelo e copiar. No primeiro trabalho eu escolhi um altar bizantino e desenhei a lápis. Mas ele queria colorido. Quando eu colori foi um desastre, porque eu nunca tinha usado aquarela e passava uma camada em cima da outra e estraguei tudo. A sorte é que a aquarela era transparente e não cobriu o desenho em baixo e ele disse: "pena porque o seu desenho estava muito bom".

A coisa mais interessante para mim foram as aulas de modelagem e de serviços de madeira, que ensinavam a fazer juntas e a serrar. Era com um professor bacana que desenhava barcos à vela. $O$ professor de modelagem era um pintor de uma certa idade, mas muito agradável e ele gostava muito de mim porque eu escolhia os modelos mais complicados para fazer. Nunca chegava ao fim, mas ele me dava boas notas. $O$ primeiro projeto que o Cristiano mandou desenhar foi uma fachada de um cinema. Depois ele venceu um concurso no Rio de Janeiro e foi embora e passou três anos fora do Mackenzie. No lugar dele ficou o professor Kosuta que dava aula de geometria descritiva. Ele ensinava perspectiva. Eu gostava muito. 
E como era o relacionamento entre os alunos?

Até o segundo ano havia certa relação entre os alunos. O Igor foi fazer estágio nessa época. Quando eu estava no segundo ano o Jacob entrou na Escola. Era muito comunicativo e gostava de falar sobre arte. Tínhamos sempre contato. Eu ia muito a casa dele. O pai dele era arquiteto e a mãe era muito culta. Na casa do Jacob eu sempre encontrava com o Miguel. Eu trocava muitas idéias com o Jacob. Foi ele que me falou a primeira vez de Wright.

O que (o senhor) achava da escola?

O curso não tinha seqüência certa, era sem ordem. Não havia um programa ou alguma aula onde se discutia alguma coisa, um projeto, nada. Nós nos formamos ou estudando pelos livros, ou nos estágios.

O que me salvou foi ter visto pela primeira vez uma revista sobre Frank Lloyd Wright de quem o Jacob já havia falado. Essa revista chegou à biblioteca da escola e mostrava todo o trabalho dele. Eu nunca pude imaginar qual o papel do arquiteto e o que ele deveria conhecer para desenvolver tudo o que eu vi. Foi até uma coisa que me impressionou, mas depois me assustou. Depois eu encontrei um livro no sebo da Benjamin Constant, com uma capa meio esquisita e eu abri e vi o nome do Frank Lloyd Wright. Lógico que eu comprei. E outra vez na livraria Francisco Alves eu comprei um livro do Corbusier sobre urbanismo, mas encostei. O do Wright foi uma dificuldade até eu pegar o sentido. Lembro que no final havia quarenta pensamentos sobre a arquitetura e sobre o que $o$ arquiteto deve ou não saber. $\mathrm{E}$ eu imaginava que conhecimento uma pessoa deveria ter para ser Arquiteto.

\section{E depois de formado?}

A minha maior preocupação logo que me formei era saber em qual escritório eu poderia pedir emprego. Um dia eu encontrei uma nossa colega do Mackenzie que trabalhava como secretária no escritório do engenheiro Francisco Matarazzo, na rua Marconi. E lá trabalhava um arquiteto polonês, Korngold. Acabei o conhecendo e trabalhei com ele até ele deixar o escritório, depois de um ano.

O que achava da cidade?

Era agradável. Eu andava sempre pela cidade. Eu me lembro que eu gostava muito de passear pelo Pacaembu e pelos Jardins. $O$ Pacaembu por causa da topografia. E os Jardins porque tinham um 
loteamento feito pelos ingleses e eu achava que era o lugar ideal para fazer casas. As casas que eu conhecia do Wright eram todas em grandes áreas verdes.

E como foi a tua participação com os outros arquitetos?

Eu encontrei o Eduardo Kneese na rua São Luis e ele me convidou para ir às reuniões de arquitetos que ele promovia no Edifício Éster. Eu participei de algumas reuniões. Um dia o Miguel me disse: "escuta, nós gostamos do Frank Lloyd Wright, vamos abrir um escritório?" E assim encontramos uma sala na rua Xavier de Toledo e começamos a trabalhar. O Jacob ia sempre ao escritório e às vezes trabalhávamos juntos.

E como foi a fundação do $I A B$ ?

Eu me senti mais seguro como arquiteto. Foi importante participar da fundação com todos os outros colegas. Depois em 54, o Candia me convidou para ser vice-presidente da chapa do Rino Levi e eu fiquei honrado porque afinal o Rino era um arquiteto muito importante. Nessa ocasião além das reuniões habituais eu participei mais. Eu também gostava muito de ir às exposições de escultura e pintura que havia. Senti muito não ter uma convivência maior com os arquitetos. 



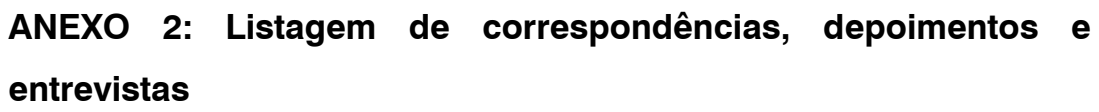

\section{Correspondência enviada ao escritório Forte \& Ciampaglia}

10/03/44 da Prefeitura do Município de São Paulo Ofício n. 12 A.C.R. / Lista de Ouro pelo projeto da S/A Domingos Forte

\section{Correspondências trocadas com Galiano Ciampaglia}

12/01/1945 de Eugene Masselink - Secretary to The Taliesin Fellowship - a Galiano Ciampaglia/ assinatura magazine Taliesin. Spring Green, Wisconsin

14/08/1947 de Eugene Masselink - Secretary to Frank Lloyd Wright - a Galiano Ciampaglia/ renovação da assinatura magazine Taliesin e inclusão no mailing de correspondente regular. Spring Green, Wisconsin

10/02/1955 De Cary Caraway - Secretary F.LL.W. Testimonial Dinner - a Galiano Ciampaglia/ convite para jantar

O0/08/1956 Convite para ser membro da The Frank Lloyd Wright Endowment Fund (mediante doação)

09/12/1956 De Cary Caraway - President The Frank Lloyd Wright Endowment Fund - a Galiano Ciampaglia/ participação do NBC-TV show "Wide, Wide World", a ser transmitido ao vivo do Taliesin West.

00/00/1960 de Sra. Paulo Augusto de Lima a Galiano Ciampaglia / casa em Belo Horizonte, MG

$23 / 11 / 1960$ de Sr. Paulo Augusto de Lima a Galiano Ciampaglia / casa em Belo Horizonte, MG

$16 / 09 / 2003$ de Galiano Ciampaglia e herdeiros de Miguel Forte à biblioteca FAU-USP At: Eliana de Azevedo Marques / doação de originais Forte \& Ciampaglia

22/09/2003 de Eliana de Azevedo Marques (FAU-USP) a Galiano Ciampaglia/ doação de originais

01/09/2008 de Galiano Ciampaglia ao Prof. Dr. Paulo J.V. Bruna/ autorização da pesquisa

29/10/2008 de Galiano Ciampaglia à Divisão de Arquivo Municipal de Processos at: Cleide de Andrade/ vistas 
em processos Forte \& Ciampaglia e Galiano Ciampaglia

$22 / 08 / 2009$ de Galiano Ciampaglia à Secretaria Municipal de Gestão de São Paulo at: Paulo Roberto Dutra / vistas em processos Forte \& Ciampaglia

15/12/2008 de Galiano Ciampaglia à Secretaria Municipal de Gestão de São Paulo at: Paulo R. Dutra / vistas em processos Forte \& Ciampaglia e Galiano Ciampaglia 07/05/2010 de Galiano Ciampaglia ao Condephaat - At: Rovena Negreiros - c.c. IAB-SP - At: Rosana Ferrari/ restauro do edifício-sede IAB-SP.

\section{Correspondências trocadas com a autora}

31/03/2003 da autora ao IAB-SP e a Revista AU/ Documento Galiano Ciampaglia

07/08/2003 da autora à FAPESP - At: Prof. Dr. José Fernando Perez / pesquisa Miguel Forte

28/08/2003 do diretor científico da FAPESP- Prof. Dr. José Fernando Perez - à autora/ pesquisa Miguel Forte

--/08/2003 de Lucio Gomes Machado à autora / texto sobre Galiano Ciampaglia: arquiteto e obra/documento $\mathrm{AU}-114$

01/10/2003 da autora a Eric Cozza e Gilberto Belleza / Documento Galiano Ciampaglia

02/06/2003 da autora a Gilberto Belleza/ entrevista Galiano Ciampaglia

06/01/2010 correspondência de Erasmo C. Schutzer à autora / casa dos Octógonos

$31 / 05 / 2010$ correspondência de Cristina Pinheiro da Fonseca à autora / casa da Rua Inglaterra

06/06/2010 correspondência de Ana Maria Baglioni à autora / casa dos Telhados

06/06/2010 correspondência de Gianpaolo Baglioni à autora / casa dos Telhados

14/10/2010 correspondência de Arthur Caruso Junior à autora /mobiliário Galiano Ciampaglia

06/12/2011 correspondência de Paulo Bastos à autora / casa das Esquadrias azuis 
Depoimentos à autora

$\begin{array}{ll}\text { Ângela Fonseca } & \text { Outubro 2008 } \\ \text { Beatriz de Lima Braga } & \text { Dezembro 2008 } \\ \text { Carlos Brandão Teixeira } & \text { Outubro 2008 } \\ \text { Carlos Eduardo Lotaif } & \text { Novembro 2008 } \\ \text { Emilio Terreri } & \text { Novembro 2009 } \\ \text { Fábio Penteado } & \text { Novembro 2008 } \\ \text { Flávio Marcondes } & \text { Março 2009 } \\ \text { Fulvio Forte } & \text { s/d 2011 } \\ \text { Irene Ruchti } & \text { s/d 2011 } \\ \text { Laércio Brandão Teixeira } & \text { Outubro 2008 } \\ \text { Mário Cacace } & \text { Outubro 2008 } \\ \text { Mercedes Del Carlo } & \text { Outubro 2008 } \\ \text { Ruth Coslovsky } & \text { Fevereiro 2012 } \\ \text { Vera Freitas } & \text { Novembro 2008 } \\ \text { Vera Pássaro } & \text { Março 2011 } \\ \text { Yolanda Forte Ciampaglia } & \text { s/d }\end{array}$

\section{Entrevista Rodopho Ortenblad Filho}

http:/ www.arcoweb.com.br/ entrevista/entrevista 119.asp

\section{Entrevistas à autora}

$\begin{array}{ll}\text { Carlos Lemos } & \text { 09/11/2010 } \\ \text { Dacio Ottoni } & 20 / 03 / 2009 \\ \text { Eduardo de Almeida } & 13 / 03 / 2009 \\ \text { Jun Okamoto } & 05 / 02 / 2009 \\ \text { Marcel Mendes } & 21 / 01 / 2011 \\ \text { Siegbert Zanettini } & 19 / 03 / 2009 \\ \text { Grazziela Macchiarolli } & 04 / 12 / 2008 \\ \text { Mara Beneduce } & 26 / 05 / 2010 \\ \text { Marisa Cacace } & 30 / 10 / 2008 \\ \text { Soraia Mattar } & 05 / 12 / 2008\end{array}$


